\title{
Meeting Notes of the High Flux Isotope Reactor Futures Group
}

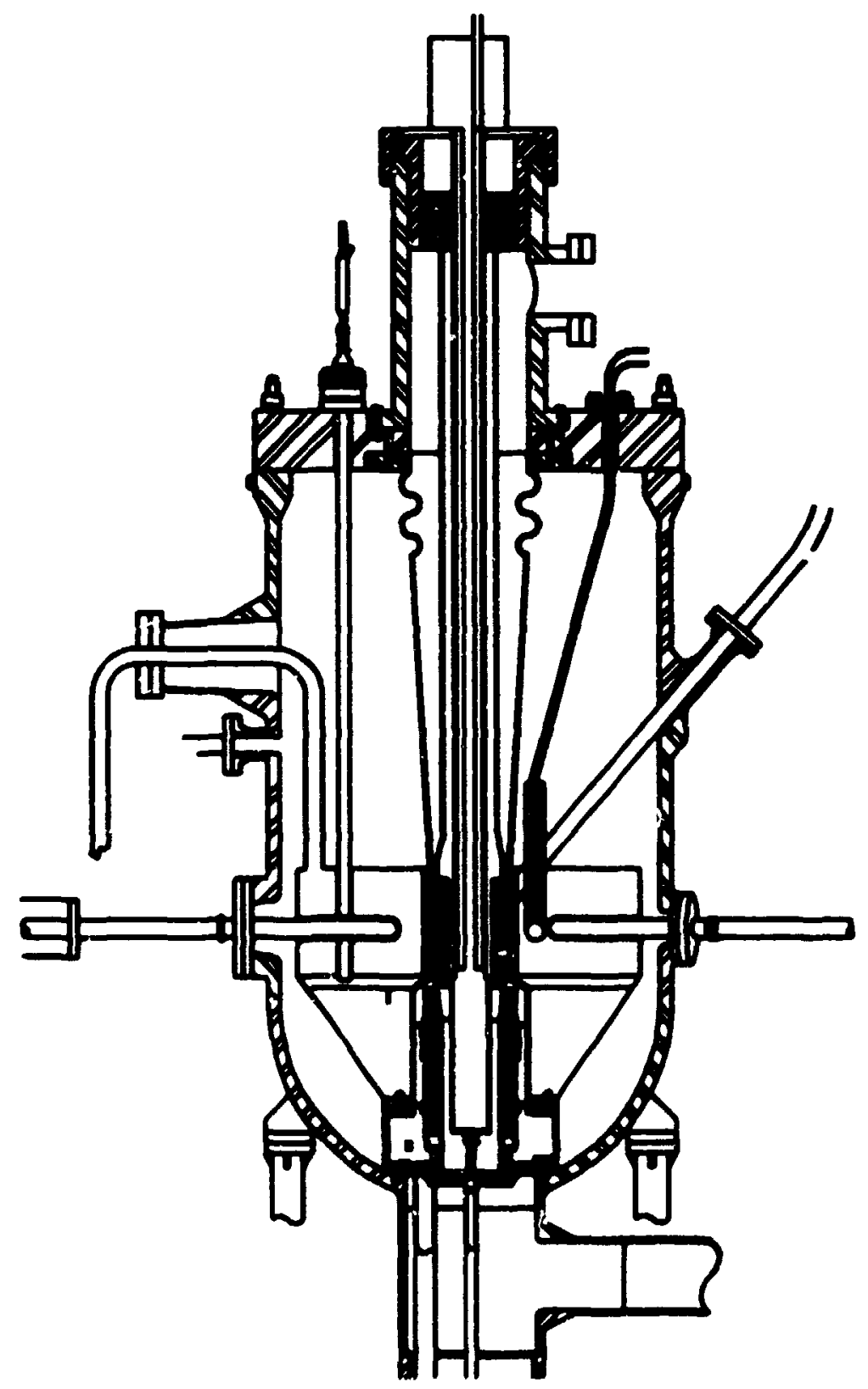


This report has been reproduces directly from tho bent aveiable copy.

Aveiabio to DOE and DOE contractors from the Oflice of Scientific end Techrical mormation. P.O. Box 62, Oak Pidoo. IN 37831; prices aveindele from (615) 576-8401, FTS 628-8401.

Aveiable to the public from the National Tectrical hformation Survice. U.S. Department of Commerce. 5285 Port Royal Rd., Springfield. VA 22161.

This report vras prepared as an eccount of work eponeored by en equicy of the United States Government. Neither the inited States Gowernment nor any soncy thereot, nor any of their employese, makes any wartanty. exprease or impliad. or escumes any hol liebility or responibility for the eccuracy, cont pleteneses, or usetuheses of any information. epperatus. product, or proceses die cloced. or represents that its ues would not intringe privatuly ounied rights. Peference herein to any spocific commerciel product, proceses, of eavirs by trade name. trademark, manulecturer, or otherwies, does not necesaarily contithte or imply its endoreement, recommendation, $\alpha$ :evoring by the United States Governonent of any epency thereot. The viowe and opinione of authors expreased herein do nof necesalarily state or reflect those of the United States Government or eny ecency thereot. 
Meeting Notes of the High Flux Isotope Reactor (HFIR) Futures Group

August 1995

compiled by

M. M. Houser

\author{
Prepared by \\ Oak Ridge National Laboratory \\ Oak Ridge. Tennessee 37831 \\ managed by \\ LOCKHEED MARTIN ENERGY SYSTEMS. INC. \\ for the \\ U.S. DEPARTMENT OF ENERGY \\ under contract DE-AC05-840R21400)
}




\section{TABLE OF CONTENTS}

INTRODUCTION Description and purpose of document

Meeting 1. March 6. 1995

Attachment 1 Agenda

Attachment 2 Charter

Attachment 3 Handouts and viewgraphs from R. M. Harrington's presentation on beryllium replacement and in-service inspection and testing

Attachment 4 Handouts and viewgraphs from G. F. Flanagan's presentation on RRD thoughts on upgrades and HFiR life extension

Auachment 5 Handouts and viewgraphs from C. D. West's presentation on HFIR reflector replacement

Auachment 6 Handouts and viewgraphs from J. B. Hayter's presentation on a HFIR cold source, guide hall upgrade, and beam upgrade

Attachment 7 Viewgraph from C. D. West on inventories of information concerning the HFIR

Meeting 2. March 13.1995

Autachment 1 Agenda

Auachmer: 2 Viewgraph from J. E. Bigelow's presentacion, "Recommended HFIR Upgrades for Improved Utilization for Radioisotope Production"

Auschment 3 Handouts and viewgraphs from M. M. Houser's presentation, "Inventory - HFIR Improvement Proposals;" also includes memo from E. C. Fox on general purpose reactor facility, meme from $C$. D. West on a cold source at the HFIR facility, sketches and a conceptual cost estimate for a cold source at the HFTR facility from T. L. Ryan, and the Executive Summary from "Study on the High Flux Isotope Reactor - Center for Neutron Research"

Attactument 4 Viewgraphshandouts of "Categorization of HFIR Upgrades"

Auachment 5 Viewgraph from K. R. Thoms, "ltems Identified by RRD Which Would Benefit Material Iradiations and Probably Isotope Production (Gleaned from George Flanagan's handout at our last meeting)"

Meeting 3. March 20. 1995

Attachmeni 1 Agenda 
Attachment ' $\ldots \ldots \ldots \ldots \ldots \ldots$ Viewgraphs from K. R. Thoms' presentation, "Improvements Made in HFIR's Material Irradiation Facilities"

Auachment 3 Viewgraphs from J. B. Hayter's presentation on "Improvements to HFIR Beam Instruments" and "Hidden Interfaces"

Attachment 4 Viewgraphs from L. Robinson's presentation, "HFIR Upgrades - Administrative liems (User Ferspective)"

Attachment 5 Handouts from C. D. West and M. M. Houser, "Categorization of HFIR Upgrades" and "Preliminary Categorization of HFIR Upgrades"

Attachment 6

Viewgraphs/handouts from C. D. West on requirements for the near-term installation of a HFIR cold source, questions, and properties of particular cryogens

Meeting 4, March 27, 1995

Auachment 1

Agenda

Autachment 2 Updated "Categorization of HFIR Upgrades"

Autachment 3 Updated "Preliminary Categorization of HFIR Upgrades" Attachment 4 Viewgraphs from C. D. West's presentation, showing drawings and sketches of the HB-4 position at the HFIR

Mecting 5. April 3.1995

Attachment I

Agenda

Auachment 2 Viewgraphs from C. D. West presentation, "Yet Another List and Categorization!"

Attachment 3 Viewgraph from C. D. West. "Additional low-cosi, no-impacton-reactor item?"

Atachment 4 Viewgraph from C. D. West, "Timing for a preliminary repor?" Altachment 5 Handout from C. D. West of another drawing of $\mathrm{HB}-4$ Attachment 6 Memo with atlachments from RRD staff, "Reconfiguration of the Southeast Quadrant of the HFIR Reactor Building to Support a HB-4 Cold Source"

Altachment 7 Updated "Preliminary Categorization of HFIR Upgrades" 
Meering6.April 10.1995

Attachment 1

Agenda

Attachment 2

Handouf from C. D. West, "Presentation to ORNL Executive Committee"

Attachment 3

Handout from M. M. Houser on changes to upgrade lists since previous meeting

Auachment 4 . Handout/fax from L. Robinson, "Enharcement of Neutron Activation Analysis Irradiation Facilities and Office Space" and "Administrative Upgrades"

Attachment 5 Viewgraph from $K$. R. Thoms concerning wording on the benefits of modifying the reactor top head

Attachment 6 Viewgraphs from $C$

D. West on "Evaluation of Minor Cost Proposals"

Attachment 7 Viewgraph from C. D. West comparing the properties oi a cold source at the HFIR versus the one at the ILL

Mecting 2.April 24.1995

Autachment 1

Agenda

Autachment 2

Handout from J. B. Hayter, program from "Workshop on ES\&H Requirements for OBES Programs"

Attachment 3 Handout from J. B. Hayter contianing public relations information from the Japan Atomic Energy Research Institute (JAERJ)

Attachment 4 Memo from C. D. West entitled "Executive Committee Meeting"

Attachment 5 Viewgraphs for G. F. Flanagan's attendance at Washington meeting

Autachment 6 Handout from K. R. Thoms, "Ideas for redesign of the reactor top head"

Atuachment 7 Fax of revised wording on upgrade list :oncerning isotope production from J. E. Bigelow

Attachment 8 Viewgraph from G. F. Flanagan's presentation of RRD upgrade idea of a $D_{2} \mathrm{O}$ tank inside the HFIR vessel

Mecting 8. Mar 8. 1995

Attachment 1 Agenda

Altachment 2 Handout from Washington meeting, "HFBR Vessel Replacement and Aging Programs" 
Attachment 3

Viewgraphs from HFIR cold source meeting, "Why Cold Neutrons?" and options for the installation of a cold source at the HFIR

Attachment 4 Handout from $C$.

C. D.

D. West, "Ret

Report of High Flux Isotope Reactor (HFIR) Futures Group--Draft Executive Summary"

Auachment 5 Handout that G. F. Flanagan had from another group of the research proposal "Center for Neutron Characterization of Engines and Energy Conversion Components"

Meeting 9. May 15, 1995

Attachment 1 Agenda

Attachment 2 Handout from J. B. Hayter of paper "Neutron optics at the Advanced Neutron Source"

Attachment 3 Viewgraphs from C. D. West, "In-house Initiatives can be Accommodated Within Existing Resources"

Attachment 4 Viewgraphs from updated upgrade lists about which C. D. West had questions or comments

Attachment 5 Handout from C. D. West, "Report of High Flux Isotope Reactor (HFIR) Futures Group (Draft Executive Summary for Discussion at Futures Group, 5-15-95)"

Meeting 10. May 22.1995

Attachment 1 Viewgraph from $\mathrm{C}$ C. D. West on national laboratories' investments in upgrades of scientific user facilities

Attachment 2 Agenda Auachment 3 Electronic mail message from K. R. Thoms concerning wording about the upgrade idea of adding a hot cell at the HFIR facility 


\section{INTRODUCTION}

The compiled meeting notes are the records of the meetings of the High Flux Isotope Reactor (HFIR) Funires Group, which took place from March 1995 through June 1995. The memoranda and attachments have been revised to avoid duplication of information, but otherwise the material is presented just as it was originally to the members of the Futures Group. 
March 13, 1995

HFIR Futures Group Meeting

Attendance

The HFIR Futures Group met on Monday, March 6, at 8:30 am. in the Blue Room of the FEDC.

Those in allendance were:

John Bigelow

Emory Collins

George Flanagan

Mike Harington

John Hayter

Michele Houser

Larry Robinson

Ken Thoms

Colin West (chair).

A proposed agenda was presented anci modified as is shown in Altachment 1. A proposed charter was presented and, after a wording change suggested by Emory Collins, was unanimously accepted by the group: the agreed-upon charter is shown in Auachment 2. Colin West remarked that in the charge given him by Mr. Van Hook be was not given a time schedule in which to complete the study of HFIR futures, but Colin felt that the group should seek to have useful results in the next few weeks. A suggestion was made to meet at least weekly and to communicate between meetings. The group agreed to meet on Mondays at 8:30 a.m. at the FEDC, and members were encouraged to send alternates if they were unable to attend a meeting.

\section{Inservice Inspection and Beryllium Changeout}

Mike Harrington, who is a member of HFIR's Reactor Operations and Review Committee (RORC) and worked with safety analysis vil the Advanced Neutron Source (ANS) project, made a presentation on inservice inspection (ISI) and beryllium changeout at. the HFIR facility. The information he presented, an ISI presentation by J. Inger (Research Reactors Division) and a 1983 Lab News article on the beryllium changeout, is tabulated in Attachment 3. A history of the HFIR was reviewed, with special attention being given to the beryllium changeout issue. The first reflector was replaced in 1975. due to an observed crack in the beryllium reflector. The HFIR facility had been fully operational since 1967 and had been running at $100 \mathrm{MW}, 92 \%$ availability. Mike informed the group that 1983 was the last time that beryllium changeout had occurred at the HFIR facility. At this time, the reflector was again replaced. ISI was also performed during the 1983 shutdown.

The HFIR facility has committed to a 10-year ISI requirement. The facility was either shut down or running at low power from 1986-1990. These facts contribute to the point that the next 
scheduled ISI shutdown for the primary coolant piping and reactor vessel is December 1997. DOE Orders 5480.30 and 5480.6 impose ASME Section XI inspection requirements, and the HFIR facility is revising its ISI program to meet these requirements.

George Flanagan made the remark that the HFIR facility is looking at the possibility of performing the next ISI in two parts. The beryllium changeout is not the driving issue tor the 1997 shutdown--the beryllium is tagged for replacement only as signs of damage are found. The Research Reactors Division (RRD) is looking at the possibility of performing ISI on those parts that do not require removal of major reactor components in 1997 (there may be new remote technologies to aid in this). The facility is considering enlisting a sub-contractor to perform ISI instead of using in-house staff (for cost and schedule reasons). This would allow them to perform the beryllium changeout up to almust 3 years later. When the beryllium is changed out. ISI can be performed on the remaining, previouslyinaccessible parts. In order for RRD to do this, they must identify the regulatory bodies that will need to be involved in making a decision to allow the separation of ISI into two stages. Also, they must decide how to address ALARA concerns if all the reactor components (sc,me of them highly activated) are not removed for the first part of ISI.

George remarked that if this could be done, it might take some pressure off of the HFIR facility in 1997. He went on to explain that DOE Order 5480.31 requires that a research reactor go through a four-layer readiness review process if it is shut down for more than 6 months. No facility has ever successfully gone through this process, and the HFIR facility has been advised by DOE headquarters to try to avoid it. There are ways to schedule work so that a facility can avoid triggering this paricular order, and the HFIR facility will attempt to do that type of efficient scheduling. George remarked that the ISI might have to be even better done in 1997 than it was in 1983, due to regularory expectations of more-advanced technology. However, this expectation may be tempered by cost considerations. RRD is currently defining what is accessible and what is non-accessible for the RORC. The facility will likely present a proposal to management in the next week or two.

George gave the group an update on some key HFIR personnel to emphasize the attention that is being given to ISI and beryllium changeout. Joe finger is currently assigned to looking at ISI issues. Mike Farrar bas been appointed "Beryllium Changeour Manager," and Jeff Schmitz is taking his place as the Operations Manager. George reiterated the fact that they would like to do only one major shutdown in 1997 for particular ISI tasks to be accomplished. A rough estimate of only $\$ 0.5 \mathrm{M}$ has been obtained for a sub-contractor to do these inspections, with most of the cost being labor cost. The new beryllium is scheduled to be machined in 1996, so any changes in the beryllium changeout schedule (from 1997) have to be addressed soon.

\section{HFIR Thoughts on Upgades.}

George did an excellent presentation for the group on the HFIR facility's thoughts on upgrades. His slides are gathered in Attachment 4. He t llked a bit about a study group that HFIR had put together to generate information about HFIR upgrades. The impact of regulatory issues on proposed upgrades was discussed. The timing of funding availability and the fact that an extended outage usually raised the visibility of a facility so that other issues were highlighted were discussed. If research reactors were to have to be reviewed by the NRC, it could substantially impact suggested changes. This would depend to a great extent on the office of the research reactors group versus the advanced reactor or commercial reactor ones within NRC with which the facility would interact. After this discussion, George presented a iist of components responsible for most of the outages at the HFIR facility (see next section). 


\section{Components Causing Unavailability}

The four largest contributors to HFIR unavailability were discussed--pressurizer pumps, offsite power disturbances, diesel generators, and instrumentation and controls (I \& C). George remarked that the power disturbances and the I \& $C$ problems usually caused the mid-cycle shutdowns. The other two contributors usually caused probiems at startup or shutdown. Work has bcen done on the power and I \& $C$ problems; coniequently, improvements have been made in these areas. $A$ joint team of I \& $C$ and RRD staff has been put logether to look at problems associated with I \& $C$. Other facilities that have made recent upgrades will be contacted so that "lessons learned" can be reviewed. The Advanced Test Reactor (ATR), which has been very satisfied with its results, and Duke Power were cspecially targeted for contact.

\section{HFIR Power Upgrade}

Some ideas that HFIR has had for a power upgrade wcre also presented. RRD is conducting a study to look at the method in which the HFIR cores are fabricated at Babcock and Wilcox (B \& W). The limit on the HFIR power level is largely due to "hot spots" in the extended "fingers of fuel" beyond the nominal edge of the fuel region, which are caused by the uncertainty of the fuel distribution in the fuel plates. Newly-available digitized scanners, purchased hy RRD and the ANS project, can scan the fuel plates more accurately than the current analog machines and thus take away much of the uncertainty. Data from plates that have been scanned with this new technology should arrive in the next few months. RRD is also looking at selecting current cores that have fuel distributions that would permit running at a higher power level.

\section{Extended Crcle Length}

George went on to present some ideas about an extended cycle length at the HFIR facility. All groups involved with the reactor want fewer shutdowns; however, a longer cycle time coupled with a longer shutdown time is not the best scenario for production of short-lived isotopes. A 32-day cycle may be possible and would give more neutrons/year. Availability and predictability are closely related at the facility.

John Bigelow remarked that he knew of a study done a few years back on plutonium-240 and longer cycle times, and George remarked that, with the new emphasis on burning up plutonium, this might be another option to consider. He asked that John B. send a copy of the study to the appropriate RRD person.

\section{Difficulties with Uranium Feed Stock}

Due to regulatory problems at the Y-12 facility, the feed stock of fully-enriched $U{ }_{3} \mathrm{O}_{8}$ is currently locked up there. George remarked that the U.S. research reactors are in danger of being shut down due to this. The HFIR facility will run out of $\mathrm{U}{ }_{3} \mathrm{O}_{8}$ by the end of the year. The reactors are currenuly trying to negotiate an agrement with a source of U-235 outside the United States in order to get feed stock to B \& W. If a particular line at $B \& W$ is down for 2 months, it has to be shut down, and it then takes another year to get it back into operation. The lockdown at $Y-12$ is a DOE issue right now, with the various offices having to negnciate a solution to the problem. 


\section{Refabricated Permanent Beryllium Hole Size}

A new arrangement of holes in the beryllium is being proposed by HFIR which would change them tn a common hole size. This study is being paid sor by the plutonium-238 users (no cost to HFIR). The hatch may is so be changed to provide verticai access to these holes. This will enhance experimenter capabilities and maximize the production capabiiity of isotopes, heightening the utility of the neutrons produced by $H^{\top} \mathrm{TR}$. This reconfiguration will cause no changes in flow characterization or regulatory authorization. This reconfiguration will also contain enhancements for operator interfaces with experiments. One of these will be "key" configurations to mark experiment turning.

\section{Improving Experiment Facilities and Capabilities - During ISLBBe Replacement Outage}

George went on to mention items that could be improved in the experimenter capabilities during the ISI/Be replacement outage. These included a permanent reflector redesign to accommodate an increased liumber and size of vertical experiment facility (VXF) sites, installing/modifying the EF (Esgineering Facility) locations, increasing the inner diameter of the main beam tubes, and modifying 'he HB-4/HB-! beam tubei to accept a future cold source. There are collimation issues on ihe main beam tube which keeps it from providing the maximum number of neutrons, and the EF sites are slant wibes which are not useful for certain types of ins'ruments (due to the facts that they are not horizontal and the beams are at lower intensity). Consideration should be given to modification of these facilities.

\section{Improving Experiment Facilities and Capabilities - Independent of ISUBe Replacement Outage}

Also in the HFIR presentation were improvements which could be made in the experiment facilities independent of the ISUBe replacement outage. These included designing a general purpose target or peripheral target position (PTP) facility, adding a second hydraulic tube, adding a cold source, adding an extemal positron facility, and pioviding "straight shot" access to VXF sites. The high cost of adding a hydraulic tube would probably prohibit this from being a current viable option.

\section{Gamma Irradiation Facility from Spent Control Cylinders and Plates in Spent Fuel Pool}

Annther no-cost option suggested by George was a large gamma-irradiation facility based on spent control cylinders and plates stored in the spent fuel pool. This type of facinity is used for the sterilization of medical equipment and can last for long periods of time.

\section{Revised Core with Light-Water Cooled, Heavy Water Reflected Design}

Colin West next made a presentation on a concept he had been working with in which the reflector vessel might be revised for a light-water cooled, heavy-water reflected design. His slides are compiled in Altachment 5. This work was based on some comparisons that the Institut Laue-Langevin (ILL) in France made during its conceptual design studies. The design described by Colin assumes that the fuel could be contained in a single element, running at 100-110 MW(th), with its sideplates extended to form the primary coolant pressure boundary tube near the core. Allowing for irradiation targets, this new HFIR design should produce flux of around 1 1/2 to 2 times that of ILL. Using the ANS forcedconvection type of design, a cold source could be placed nearer to the flux peak than the ILL one. yielding a cold neutron flux of 2 to 3 times that of ILL. The new reflector tank design would inciude features for increased scientific capability, as well as replacing the embrittled reflector currendy at the HFIR facility. 
John Hayter then made a presentation on possibilities for enhanced facilities for neutron scattering. His slides are summarized in Attachment 6. One possibility is a HFIR neutron instrumentation upgrade, which basically looks at using the available beams better. Use can be made of metailic multilayer crystals to split beams apart and divert them to various instruments. Another possibility is to make an addition to the HFIR guide hall out from beam HB-4. This would allow for more versatility of beam use. By bringing the small angle neutron scattering (SANS) facility beam straight out with a velocity selecior, its flux could be increased by a factor of 40 . This facility is currently "bent" upstairs from beam 4, which cuts the wavelength spectrum down to a very narrow region, thus losing some other advantages. The powder diffractometer would be lost to bring the SANS facility dov $\mathrm{n}$ to the lower floor. Another option is to keep the high resolution SANS as it is and to add a high intensity version underneath it. [There is an old instrument in storage at the Oak Ridge Reactor (ORR)]. Questions consequently arise as to which science should be oftimized. Ideas about enhancing the utility of insauments on the ground floor without affecting the SANS are also being considered.

John H. remarked that the HFIR is still the has thermal peutron research reactor in the world, so actions should be taken which set priorities for the type of work which would gain a lot of user attention. John $\mathrm{H}$. showed some ideas for retrofitting : cold scurce into the HB-1/HB-4 beam area and creating a cold radiography facility. The Julich cold source retrofit was shown for comparison. Issues associated with collimated heams may arise when looking at cold source options.

\section{Closing}

Colin observed that the group had been in session quite a while and that the discussion might best be resumed in one week He quickly showed a slide of "inventories" of information which is already present which might be useful (see Attachment 7). It was decided that Emory Collins would speak next time about iradiation target issues. The issue of a pos:ton source was again mentioncd. George remarked that Randy Hobbs had produced some sketches concerning this, and Colin remarked that it would be good to have him talk to the group sometime in the futur:. The group adjourned, following an excellent and productive first meeting, until March 13. 
Distribution

HFIR Futures Group (notes for record only)

J. E. Bigelow, 7930, MS-6385

E. D. Collins, 7930, MS-6385

G. F. Flanagan, 7917, MS-6398

R. M. Harrington, FEDC, MS-8218

J. B. Hayter, FEDC, MS-8218

M. M. Houser, FEDC, MS-8218

L. Robinson, 4500S, MS-6128

K. R. Thoms, 9108 , MS-8087

C. D. West, FEDC. MS-8218

For information (notes for record + attachments)

B. R. Appleton, 4500N, MS-6240

J. B. Ball, $4500 \mathrm{~N}, \mathrm{MS}-6182$

R. E. Battle, FEDC, MS-8218

H. A. Glovier, 7917, MS-6398

H. A. Mook, 7962, MS-6393

J. B. Richard, 7962, MS-6391 
ATTACHMENT 1 


\section{MODIFIED AGENDA FOR HFIR FUTURES GROUP MEETING}

Monday. March 6, 1995

8:30 a.m.

FELC, Blue room

Discussion: Agenda

- Discussion: The HFIR Futures Group Charter

- Discussion: Schedule of meetings

- Four points on the spectrum of possibilities

- what is driving the need and schedule for the in-service inspection and beryllium changeout?

- some RRD proposals

G. F. Flanagan

- a major enhancement and life C. D. West extension possibility (new pressure vessel, $\mathrm{D}_{2} \mathrm{O}$ reflector)

- additional instruments and a retrofitted cold source

R. M. Harrington

retrofited cold source

- Any other business

$$
\begin{array}{ll}
-\quad \text { Isotopes } \\
-\quad \text { Inventory } \\
* \quad & \text { Facilities } \\
* & \text { Users } \\
* & \text { Isolopes } \\
* & \text { Previous studies } \\
* & \text { Expansion space }
\end{array}
$$

E. D. Collins

C. D. West 
ATTACHMENT 2 


\section{HFIR Futures Group Charter}

- To identify and characterize the range of possibilities and necessities for keeping the HFIR operating for at least the next 15 years

- To identify and characterize the range of possibilities for enhancing the scientific and technical utility of the HFIR

- To evaluate the benefits or impacts of these possibilities on the various scientific fields that use the HFIR or its products

- To evaluate the benefits or impacts on the operation and maintenance of the HFIR facility and on the regulatory requirements

- To estimate the costs, including operating costs, and the schedules including downime, for these various possibilities

- One possible impact of proposed changes may be to stimulate increased pressure for a reduced enrichment fuel for HFIR: the performance and cost impacts of this should be evaluated 
ATTACHMENT 3 


\section{ORNL reactor resumes operation after major snutdown}

A mojor component thet helps make OAul's Migh Flux kotope Racetor the mox renful research resctor in the wortd semty war ropleced for the second time in the rewcter's 17 vears of aperation. The complex procedure for installing a now beryllium reflector necessituted a shundown of tha rasetor trom \$eptember 20 wo December 20 and

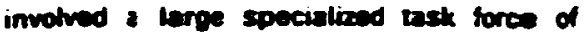
ORNL personnel.

The High Flux kotope Reactor (HFil, one of sir research rasctors $n$ OANL is a lighswater-cooted and moderated. bentliumreflected. Hux-trap-tvpe production and research reactor. Ins main purpose is to matre iestarch quantries of manmade elamments heover than plutonium and to provide irrediation facilities for various experimemers of ORNL

The berylkum reflector has the distinction of being one of the largest beryllium compone-s ever meshined.

The borvllium reflector. an eight-inch-thick cylinder that surrounds the resctor core, helps sustain the nuclear resction by reflecting the neutrons produced by the fissioning of uranium-235 back into the core to split other aroms. With a 43-inch outer diameter, it has the distinctio.s of being one of the largest beryllum components ever machined.

The first permanent beryllium reflector was replaced in 1975 after nine years of operation

a design power levet of 100 megrwatts slowng its replacement, a second changeout was otanned for 1983. Replacement becomes necessary when, as anticipated in the reactor's original design, the reflector develops cracks due to the ditfering amounts of swilling of its inner and outer portions produced by different lovels of exposure to intense neutron radiation.

The iwo inner reflector cylinders, which are removable and semipermanent, were designed to be replaced with relative ease. However, replacement of the permanent outer reflector involves removing the reszor vessel hoad aud disassembling reactor com. ponents. The process requires ine combuned efforts of operations engineers, inspection teams. numerous cratismen and reactor operations personnel.

Throe factors were responsuble for the suc. cesstul and well-timed changeour.

cur.pletion time for the work had been est. mated at 20 to 120 days; actual downtime was 91 davs. According to shite technical supervisors Luther Pugh and Gene Hicks. three factors were responsible for the suc. cessful and well.tımed changeout "There was effective plannirig and preparation betore the actual process began, individual experiıse at all levels and an excellent teamwork ati.

- Also. much of the credit should go to the

einought of the original dasigners and Laboratory personnel who provided the tech. nical and scierificic inoul," they explained.

The actual execui:ion of the work involved a composite crew of JANL Operations Division and Plant and Equipment Division oersonnel. under the direction of Rube McCord. section

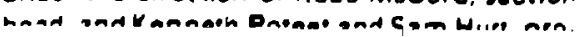

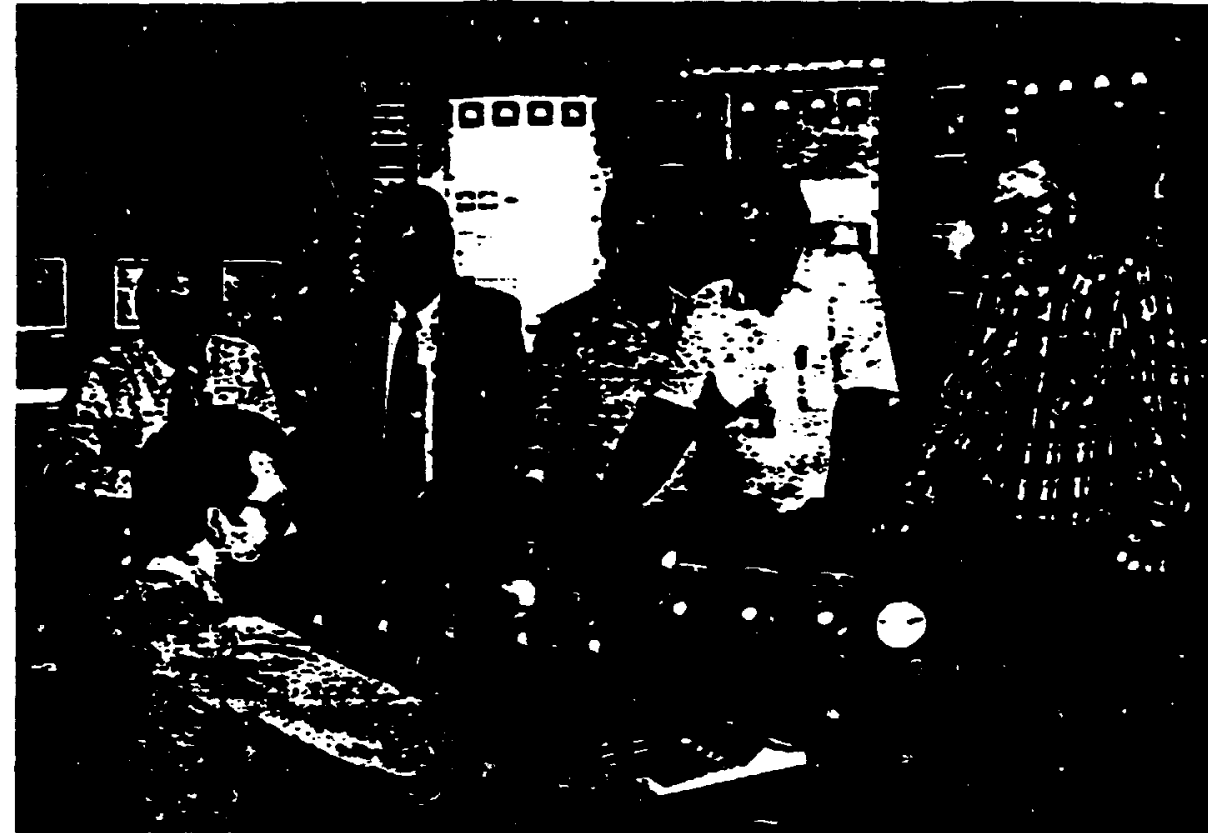

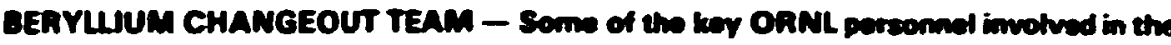

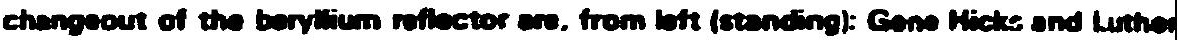

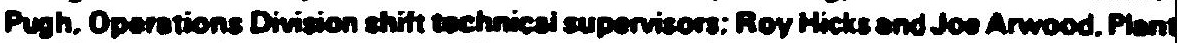
and Equipment Divition foremen: Kenmeth Belith, HFIR opesotions shift supervisor: and (seaved) Edeis Shistor, resctor controller.

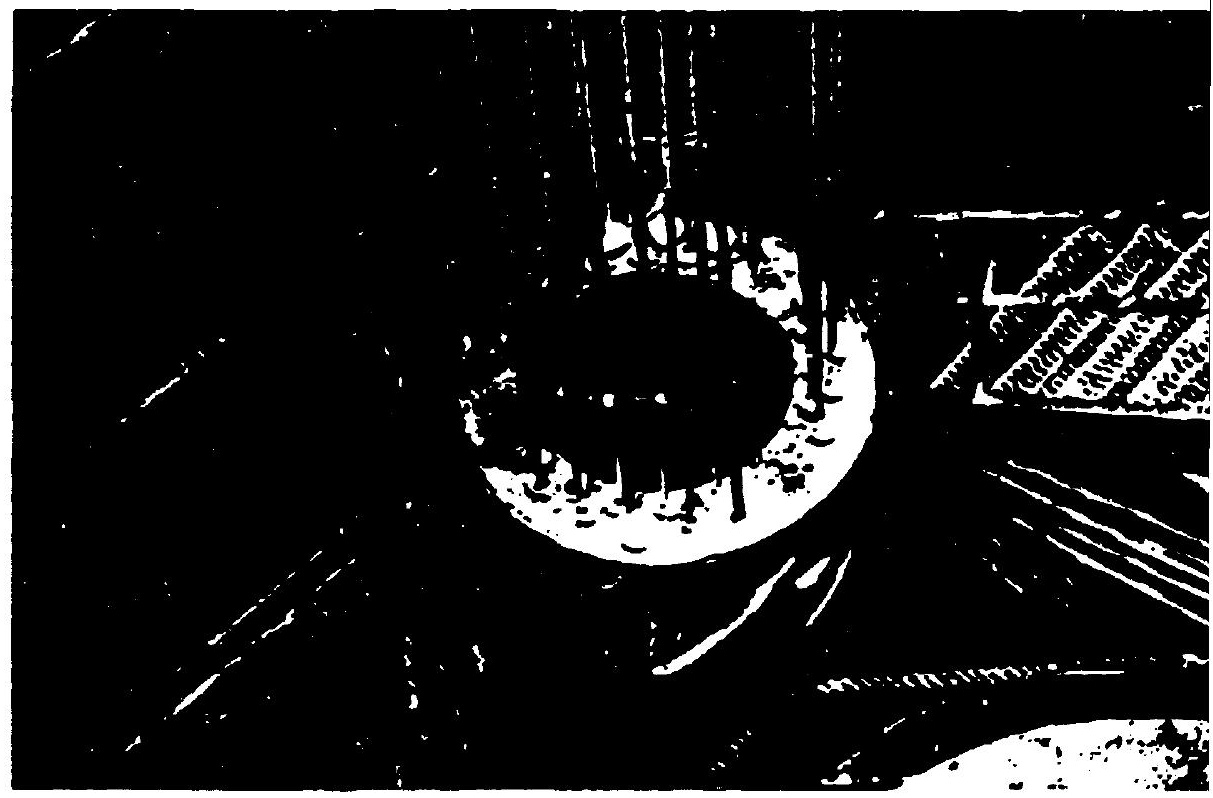

OUT WITH THE OLD - The ald beryllium reflector is removed intect. The procedure performed remotely under 10 to 30 ten of water, involves the use of 25 lifting devices attuchad to a common litting ring.

ject leaders. all of the Oparations Division. Shift supervision was performed by Plant and Equipment foremen Joe Arwood and Roy Hicks: and reactor operations supervisors Kenneth Belitz. Jerry Cotter, Charles Helton and Ted Welch.

An extensive in-service inspection of the reactor primary system and components was pertormed by the Quality Assurance and Inspection Depariment The shuldown also provided an opporiunity for reactor plani maintenance. which was coordinated by Mike Farrar

The preparations for the replacement of the Dermanent deryllium reflector included prep.

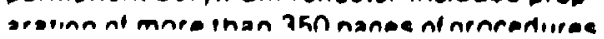

and checklists. decontamination and repai more than 130 tools used during the fi changeout. consiruction of some $163 \mathrm{n}$ special tools. supervised by Plant and Equ ment foreman Leon Ridenour; and revision more than 200 existing engineering drewir and the production of 64 new ones by $W_{a}$ Allen and John Shaw

The removal and replacement operatio were pertormed remotely. using special to under 10 to 30 teet of water The to included simple grasping and lifting insti ments as well is complex ones Both Hic and Pugh were Dart of a team that created a tested 216 specialized tools for ine fi rhanneni." 


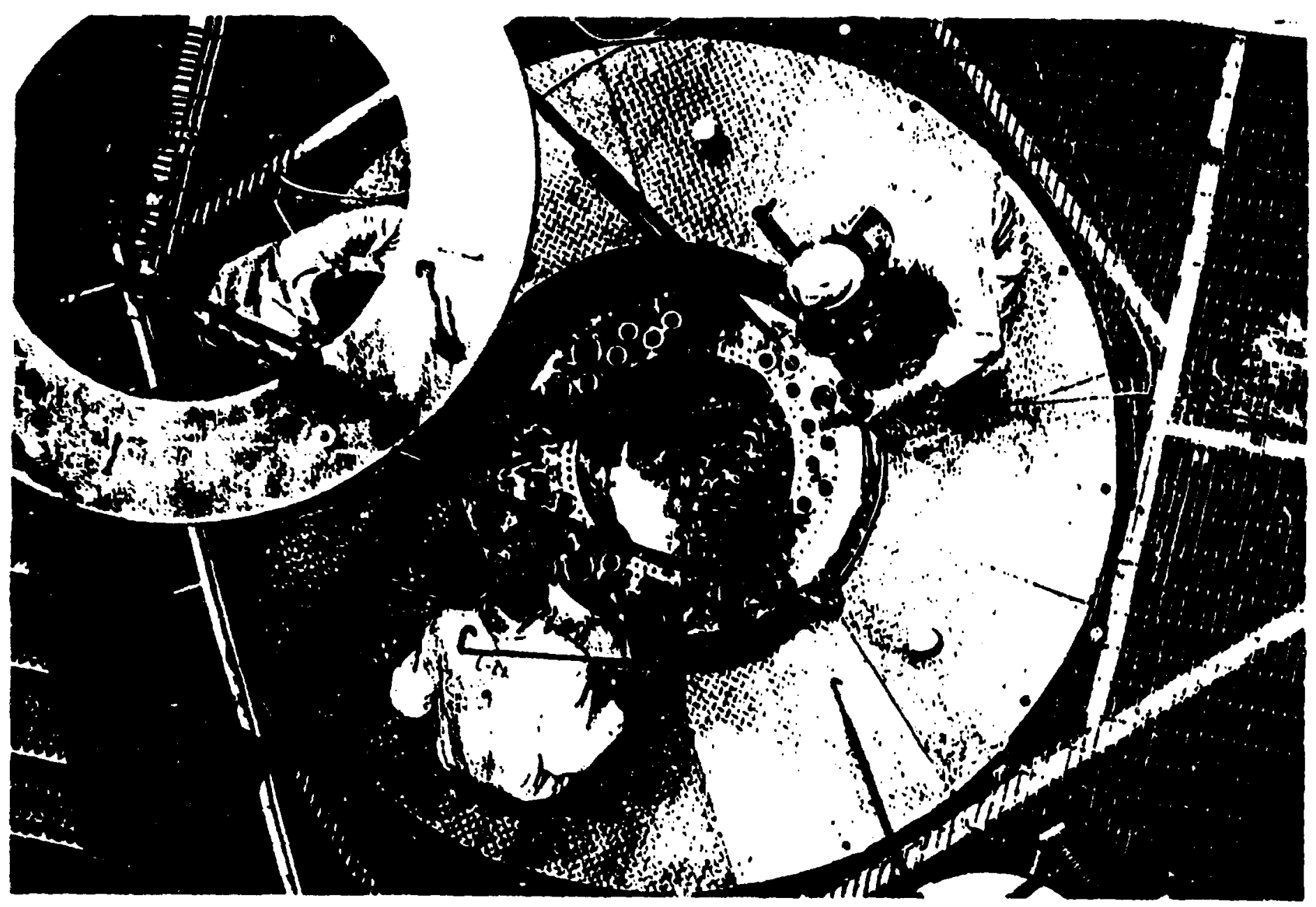

NEW REFLECTOR FOR CRNL REACTOR - A supervisor and a crow of reactor controllers prepare for the installation of the new beryllium reflector as it is lowered by a lifting ring into the vessel of ORNL's High Flux Isotope Reactor. For story and additional photos, please turn to page 5 . 


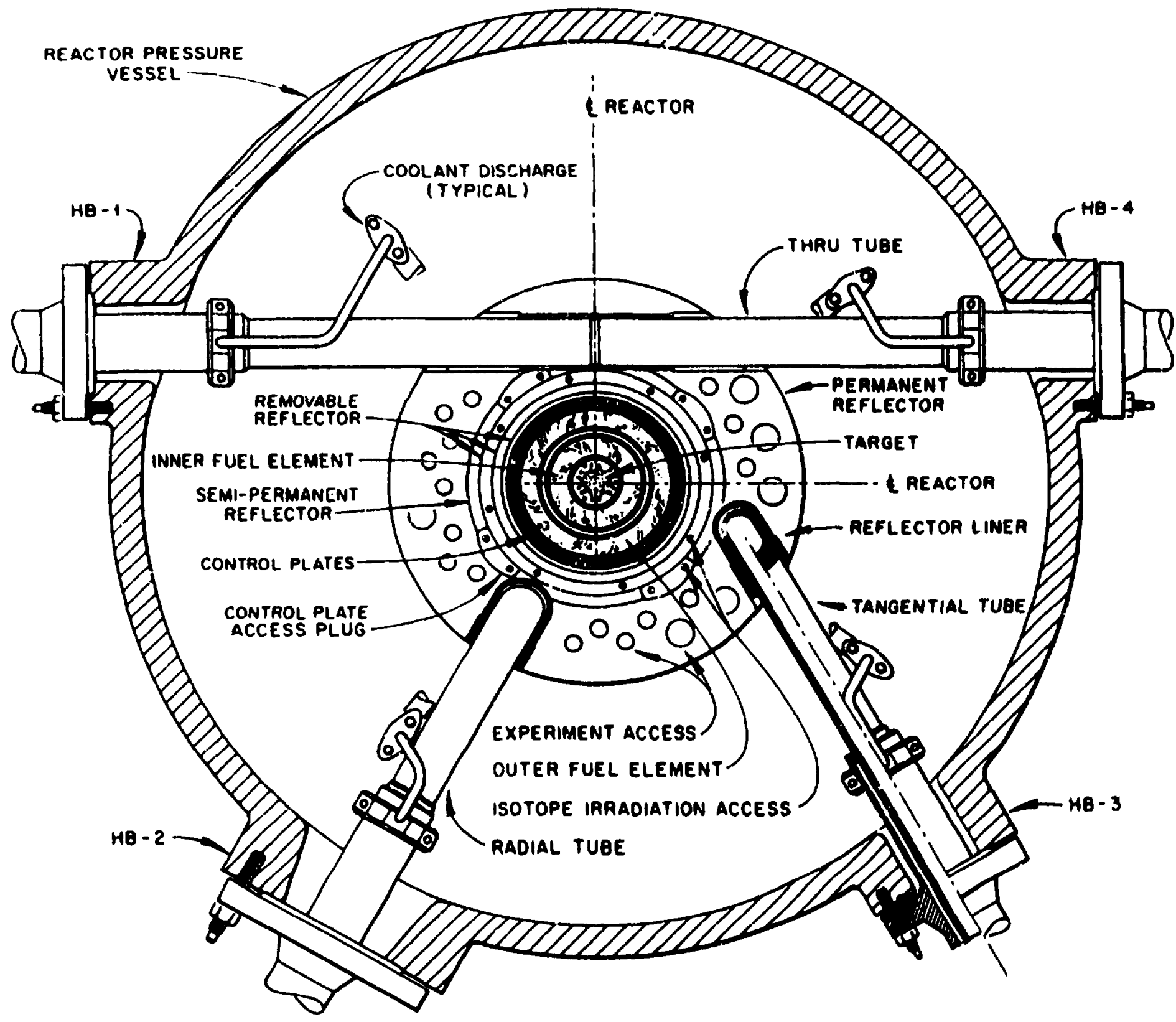




$$
\begin{array}{r}
-1 \\
8 \\
9 \\
-17
\end{array}
$$


HFIR INSERVICE INSPECTION AND TESTING

(ISI\&T)

PROGRAM

J. R. Inger, RRD ISI\&T Specialist 


\section{HFIR ISI\&T Program}

- History of HFIR ISI\&T Program

- Current HFIR ISI\&T Program

- Problems Identified

- Future Plans for HFIR ISI\&T Program 


\section{History}

- 1966 - HFIR power ascension testing began.

- 1971 - Inservice Inspections and Tests (ISI\&T) began.

- 1971 - Penetrant examination of four vessel top head studs and nuts. incipient cracking was found and all four studs and nuts were replaced.

- 1972 - UT and Penetrant examination of vessel top head studs and nuts. Some cracking was found and all A-416 SS studs were replaced with A-410 SS. UT fourteen of twenty-four bottom head studs. UT examination of thirty feet of cold leg piping.

- 1973 - UT top head nuts. Found crack-like indications and replaced all top head nuts with A-410 SS. UT examination of vessel bottom head studs and nuts. UT of top head hatch cover, ring and rim around hatch opening.

- 1974 - Baseline UT spare A-403 SS top head studs. UT examination of vessel top and bottom head studs and nuts.

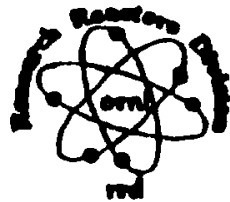




\section{History (Continued)}

- 1975 - Reflector replacement (-4FIR shutdown) - Reactor vessel examined using ASME Section XI as a guide. UT examinatior: of vessel and vessel to nozzle welds. VT cladding and internal components. UT all top head bolt hole ligaments, studs and nuts and top flange bolt hole ligaments in one quadrant. UT portion of primary coolant inlet/outlet lines of two heat exchangers.

- 1977 - UT examination all top head studs and nuts.

- 1978 - LP examination 2/3 of all primary coolant hot and cold leg and branch piping. LP piping from pressurizer pumps to tunnel wall. Pipe supports visually examined. One 10-inch and a few 3-inch supports required adjustment. UT all top head studs and nuts. Following a weld failure between heat exchanger and first let-down valve in one cell, the weld was repaired and LP and RT were performed on piping welds in all four celis between heat exchangers and first let-down valves. (Let-down piping modified with the installation of replacement heat exchangers in 1986 and 1987 to eliminate potential problems)

- 1979 - UT examination of top head studs and nuts.

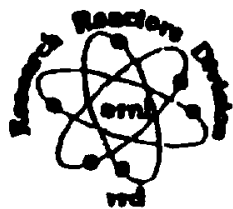




\section{History (Continued)}

- 1980 - UT examination of all top head studs and nuts. RT vessel top flange to shell weld. UT primary coolant hot and cold legs. Visual examination of vessel interior cladding.

- 198! and 1982 - UT examination of vessel top head studs and nuts.

- 1983 - Reflector replacement (HFIR shutdown) - Reactor vessel cladding and welds, internals (core support structure, etc.) and coolant piping were RT, UT, PT and VT examined, as appropriate. UT top and bottom head studs and nuts, top stud hole threads and 1-inch radially around the holes. LP top head stud holes. VT internals and ECT tubes of two heat exchangers (baffle damage and tube wall thinning were found - heat exchangers replaced in 1986 and 1987). UT internal welds of one heat exchanger. Hydrostatic test of reactor vessel and primary system. VT all primary piping supports (2-inch $U$. bolt support in each cell required nuts). VT pipe flange bolts and al representative sample of bolts, studs, nuts and component supports for each type of pump and valve. ASME Section XI used as a guide. The HFIR ISI procedure listed each item to be inspected. Inspection was performed in accordance with written procedures and included sign-offs for each completed inspection task.

- 1984 - UT examination of vessel top head studs and nuts.

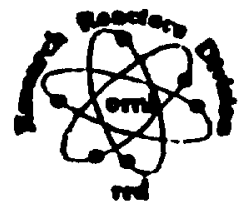




\section{History (Continued)}

- 1985 - UT examination of vessel top head studs and nuts.

- $1986-$ HFIR shut down.

- 1986 - UT examination of vessel top and bottom head studs and nuts. One top head stud had reportable indication (replaced in 1987). Receipt inspected and performed LP and RT baseline examinations of welds of two primary heat exchangers. Replaced two primary coolant heat exchangers.

- 1987 - Replaced one top head stud. UT exemination of vessel top head studs: and nuts. Receipt inspected and performed LP and RT baseline examinations: of welds of two primary heat exchangers. Replaced remaining two heat exchangers. Acoustic emission and hydrostatic test of reactor pressure vessel and high pressure primary coolant system.

- 1988 - UT examination of vessel top head studs and nuts. Technical Specifications revised to include references to Section XI ISI\&T. Standard test procedures for pumps and valves issued. Conducted pump and valve testing consistent with frequencies in Technical Specification. LP examined twenty-five percent of high pressure reactor coolant piping welds 1/2-inch s. NF'S $<$ 2-inch.

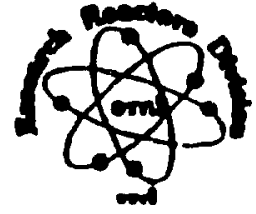


- 1989 - Conducted pump and valve testing consistent with frequencies in Technical Specification. UT examination of vessel top head studs and nuts.

- 1989 - HFIR restart and shutdown.

- 1990 - Conducted pump and valve testing consistent with frequencies in Technical Specification. UT examination of top and bottom studs and nuts. Two suspect top studs replaced.

- 1990 - HFIR restart

- 1991; - Conducted pump and valve testing consistent with frequencies in Technical Specification. UT examination of vessel top head studs and nuts.

- 1992 - UT examination of all top head studs and nuts. Conducted pump, valve, and snubber testing (one of the two snubbers failed and replaced with a spare. Test frequency temporarily increased. Conducted acoustic emission test and hydrostatic test of reactor vessel and high pressure primary coolant system.

HFIR ISI\&T Program meeting the intent of ASME XI being developed. The HFIR ISI\&T Program has been an evolutionary process in the pursuit of excellence through quality improvement.

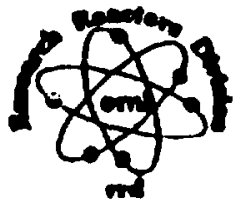




\section{HFIR 10 Year ISI Interval}

- Next periodic ISI for small bore piping is due approximately November, 1999.

(November, $1988+10+\sim 1_{(s d)} \approx$ November, 1999)

- Next periodic ISI for PCHX tubing is due approximately January, 2001 (Baseline examination was performed during shutdown. Restart ocurred January 1990. Therefore it follows, January, $1990+10+\sim 1_{(\text {sd) }} \approx$ January, 2001) 


\section{HFIR 10 Year ISI Interval}

- Last ISI's were performed October, 1983 (Primary' coolant piping, supports and reactor vessel), 1986 and 1987 (primary coolant heat exchangers tubing eddy current) and November, 1988 (Small bore piping $\leq 1$-inch, including a few 2-inch welds).

- Old and current ISI program based on ten (10) year interval. (The interval is actually driven by the permanent beryllium replacement which conveniently occurs at approximately 10 year intervals.) 


\section{HFIR 10 Year ISI Interval}

- Multiple periodic inspections not performed, except for closure head studs and nuts. Periodic tests of pumps, valves and snubbers conducted. Other inspections performed approximately once every 10 years. (Inspections are not performed at multiple periods as provided by the Code which gives more current and continuous inspection information during the passing of the interval. HFIR utilizes one inspection period which is the same as the inspection interval.)

- HFIR shutdown (sd) lasted a total of 3 years and 2 months, or 3.17 years. low power level for an additional 5 


\section{HFIR 10 Year ISI Interval}

months for training.)

- Consequently, the next periodic ISI for primary coolant piping and reactor vessel is due December, 1996. (October, $1983+10+3.17_{(s d)}=$ December, 1996) Defining the inspection interval this way is consistent with the Code (not withstanding the inspection interval is the same as the period). This will closely coincide with the next permanent beryllium replacement currently scheduled April, 1997. The Code provides an additional year with which to adjust the inspection interval to accommodate scheduled plant outages. Therefore, the inspection interval could extend to December, 1997 and still be consistent with the Code. 
ATTACHMENT 4 


\section{RRD}

Thoughts on Upgrades

at

HFIR

George Flanagan 


\section{HFIR Life Extension (25 Years)}

Plan

- Identify components and systems that will have to be replaced or upgraded (see Supplement 1)

- Identify modifications and additions to increase experiment and isotope production options versatility, availability, and to improve competitiveness (see Supplement 2).

- Establish team to justify (1) component and system replacements and upgrades and (2) modifications and additions

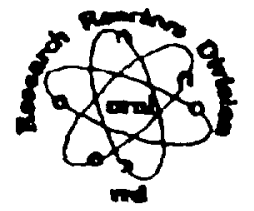




\section{HFIR Life Extension (25 Years)}

Establish team to justify (1) component and system replacements and upgrades and (2) modifications and additions

- Is the risk acceptable if changes are or are not made?

- Are operating interruptions acceptable if changes are or are not made?

- Are user revenues versus cost of changes to increase experimental capabilities positive?

- Is funding available (or will be available) to make changes to improve isotope production capabilities (DOE funding essential)?

- Is the HFIR authorization basis impacted (avoid need for new authorization)?

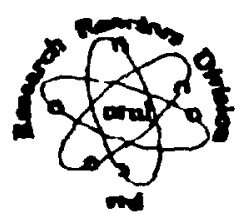




\section{HFIR Life Extension (25 Years)}

Establish team to justify (1) component and system replacements and upgrades and (2) modifications and additions (continued)

- Are user-subscription levels over subscribed/under subscribed?

- Does the change result in increase competitiveness that is cost effective?

- Is the total price tag of changes within funding and estimated user revenues levels?

- Implement changes consistent with an established prioritization system (acceptable downtime, available funding, etc.). 
- Predictability tracks availability

- Largest contributors to HFIR unavailability

- Pressurizer pumps

- Offsite power disturbances

- Diesel generators

- Instrumentation and Controls

- Programs underway to refurbish/replace older, less reliable equipment

- Implementing extensive preventive maintenance program to have better control over equipment failures which effect operation 


\section{We Have Outlined Some Initial Tasks to Initiate the Upgrade Planning}

- Identify and Prioritize problems associated with I\&C systems. Talk with HFIR staff and review drawings.

"Reliability problems

" Obsolescence problems

"Maintenance and calibration problems

- Suggest fixes to these problems. Discuss the problems with vendors and evaluate some equipment that could be used.

"Identlfy quick fixes that will have a significant Impact on availability

"Propose long-term solutions to the problems

- Scope what the HFIR would look like when the upgrades are completed.

"Develop a system architecture that addresses control, data acquisition, and business applications and allows a phased approach to upgrade

"Take advantage of the technologles and designs developed for ANS

"Outline an approach to accomplish the upgrades 


\section{We Have Outlined Some Initial Tasks to Initiate the Upgrade Planning (cont'd)}

- Summarize the experience of some other nuclear and non-nuclear systems that upgraded from old control systems to modern systems. This will include information on the sizes of systems upgraded, the approximate costs, startup and operational problems.

"Visit ATR and document the design and operational experience since upgrading.

" Talk to utilities, such as Duke Power Co., that have upgraded fossil plants to modern control systems. Document their design and operational experience.

- These tasks could be completed by mid-May and cost \$20K.

- Final product would be a presentation and a report with sketches 
We Need to Start Now if We Plan to Upgrade During Outage for Beryllium Replacement

- Form an advisory group to review HFIR I\&C upgrade needs

- Prioritize upgrades to ensure that major items get installed during Be replacement

- Prepare project schedule

- Prepare cost estimates for RRD

- RRD submit plan to DOE 


\section{HFIR POWER UPGRADE}

\section{Background}

HFIR power is limited by hot spot/ hot channel effects at the core outlet, which include the following:

1. Hot spot/hot "streak" effects based on the assumed presence of design basis fuel defects just below homogeneity scanner rejection thresholds; and

2. Fuel meat length tolerance and assembly procedures which allow a fuel tip to extend $0.5^{\mathrm{n}}$ below its neighbors (into the high thermal flux region of the lower axial refiector).

Plans

1. Using new digitized homogeneity scanner, modify acceptance criteria to reduce allowable defects at bottom end of fuel, allowing larger defects in noncritical areas of the plate, if necessary to maintain acceptable yield.

2. Modify fuel plate cropping procedure so that when welded into side plates, the fuel meat misalignment at bottom end will be decreased to around 0.25 inch with greater misalignment at the (noncritical) top end.

3. These changes should allow $100 \mathrm{MW}$ operation at the current pressure, using traditional HFIR thermal/hydraulic criteria (no incipient boiling).

Status

1. Modified acceptance algorithm to decrease hot spot factors under development; will be able to start production of "Mark II" cores this year.

2. Digitized homogeneity scanner now in use for HFIR fuel, and data from 468 plates has just been received at $R R D$ for evaluation of algorithms.

3. Based on limited digitized homogeneity data received earlier, $100 \mathrm{MW}$ should be achievable without impacting manufacturing yield.

4. Work has started to upgrade power level of existing fuel inventory, based in part on modified thermal hydraulic safety limit criteria. 


\section{EXTENDED CYCLE LENGTH}

\section{Background}

The HFIR cycle length may be increased incrementally by manufacturing cores near one end of the tolerance band (high fuel loading, thin plates) and by minimizing the reactivity impact of experiments occupying the target and removable beryllium regions. Further improvements would require a change in the nominal core design which involves higher density fuel and burnable absorber loadings and would impact lifetime power history, shutdown margin, control requirements, fuel burnup, and corrosion and mechanical effects on the fuel plates. $\mathrm{U}_{3} \mathrm{O}_{8}-\mathrm{Al}$ miniplates of higher loading were irradiated in the 1970's in support of of a "12 kg core" design study and performed satisfactorily, hence there are believed to be no technical obstacles to extending the cycle length. $A$ A preliminary long-lived core study was initiated in 1992 , to use either $\mathrm{U}_{3} \mathrm{Si}_{2}$ or $\mathrm{U}_{3} \mathrm{O}_{8}$ fuel, but little progress was made due to sther competing work.

\section{Plans}

1. Verify the capability to calculate the HFIR power distribution for the current design core by comparison with critical experiment measurements.

2. Design a core for a modest life extension (e.g. 5 days) based on the calculational model, and manufacture an experimental core. Irradiate in HFIR with flux mapping at BOC and EOC (using thin aluminum foil holders). Verify calculational model, and make further loading and BP increases as desired.

\section{Status}

1. Early HFIR critical experiment data have been reviewed, puzzling results evaluated, and an MCNP model created to compare with measurements. To date, agreement is good at internal points but not so good at the (critical) ends and comers of the fuel plates.

2. Foil and flux wire holder design has been completed for the outer fuel element; overhead clearances for handling have been identified for inner element and design is nearly complete. 


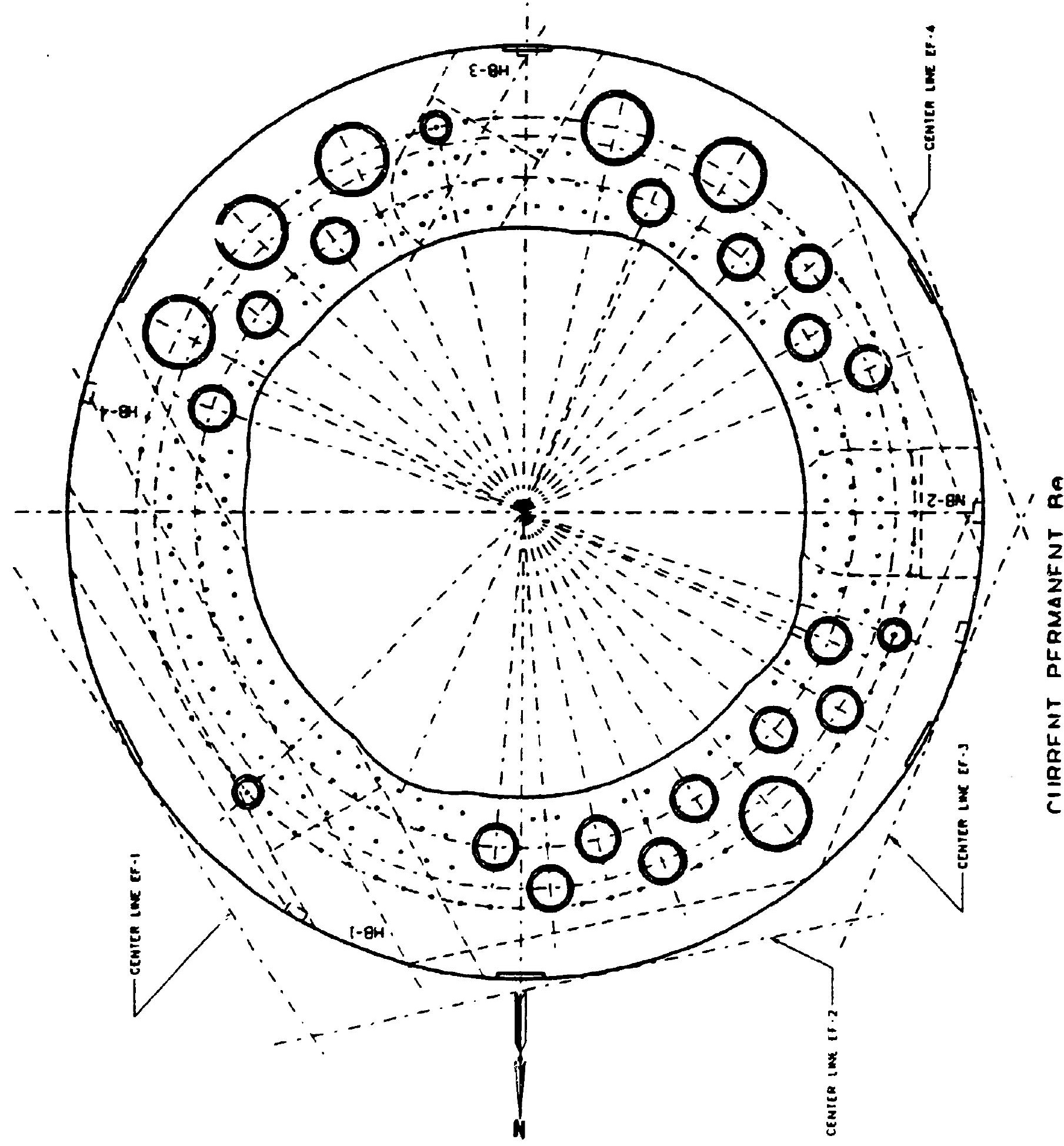




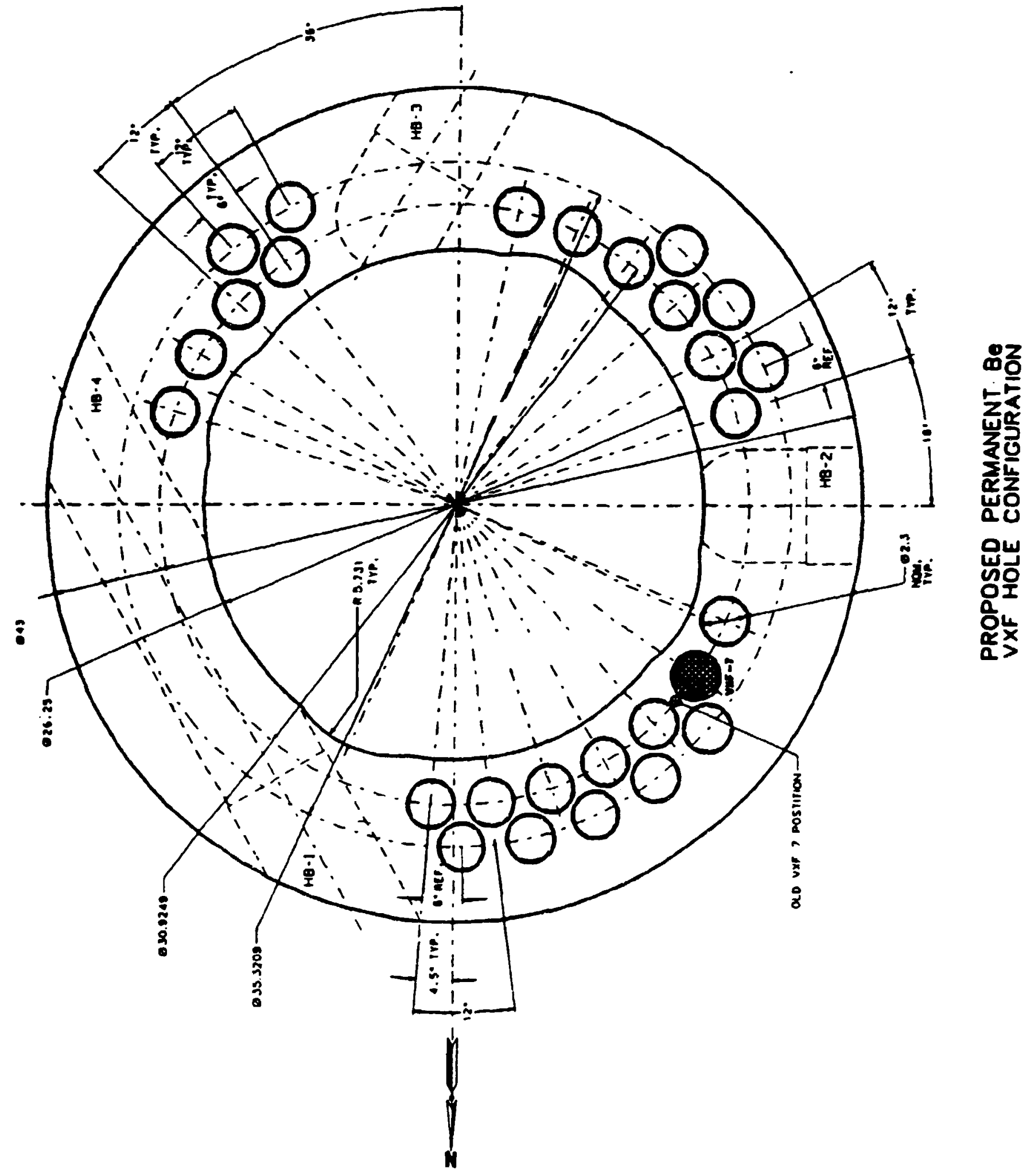




\section{IMPROVING EXPERIMENT FACILITIES AND CAPABILITIES}

\section{A. BEST PERFORMED DURING ISIBB REPLACEMENT OUTAGE}

- Permanent Reflector Redesign to Accommodate Increased Number and Size of VXF sites

Benefits Isotope Production, Materials Testing , N.A.A.

- Install / Modify EF facilities

Possible location for future cold source or materials testing experiments

- Increase size (I.D..) of main beam tubes / modify shape

Increase neutrons available for neutron scattering

Potential for Focusing of Beam at Monochromator

- Modify HB4/HB1 beam tube to accept tuture cold source. 


\section{IMPROVING EXPERIMENT FACILITIES AND CAPABILITIES}

B. INDEPENDENT OF ISI/BE REPLACEMENT OUTAGE

- Design general purpose target or PTP facility capable of irradiating standard HT rabbits

Benefits Isotope Production, Nuclear Medicine R\&D and Materials Testing Eliminates current HT oversubscription , low cost

- Add second HT

Benefits Isotope Production, Nuclear Medicine R\&D and Materials Testing High Cost - Probably not justified at this time

- Cold Source

New Capability - basic materials research

Some facets may be best done during ISI/Be replacement outage

- Positron Facility

New capability - basic materials research - potential world class facility

Facility does not need to be located in HFIR bldg.

- Provide Straight Shot Access to VXF Sites

Benefits Materials Testing

Possible Benefit to Mo-99 


\section{Develop Large Gamma-Irradiation Facility using Spent Control Cylinders and Plates}

- Large diameter (18-inch), high gamma flux $\left(10^{6} \mathrm{R} / \mathrm{h}\right.$ field) possible

- Can fill void available in commercial gamma-irradiation capability for large items (equipment qualification)

- Similar work has been done here before irradiating gems in spent core target region

- Removes some cylinders and plates from waste stream 


\section{HFIR LIFE EXTENSION (25 YEARS)}

Research Reactors Division

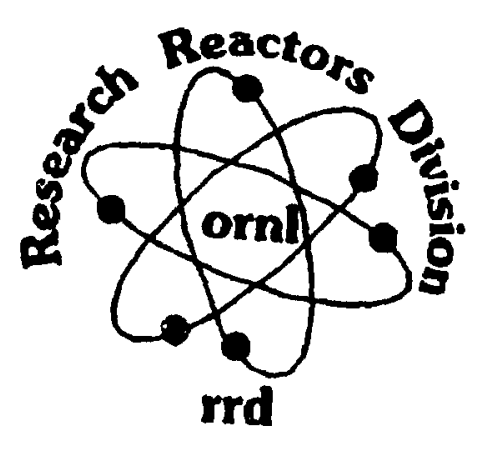




\section{HFIR Life Extension (25 Years)}

\section{Introduction}

- HFIR manages current facility aging and affects HFIR life extension through implementation of the followir:g programs:

- Inservice inspection and testing program using ASME $X I$ as a guide

- Technical specification surveillance testing program

- Numerous other surveillance, testing, sampling, monitoring, evaluation activities, and water chemistry control

- System upgrade program-accelerator/reactor improvement modifications (ARIMS) funding

- Reactor core component scheduled replacement program

- Ten-year long range plan

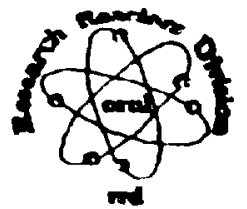




\section{HFIR Life Extension (25 Years)}

Introduction (continued)

- Major component replacement and upgrades accomplished

- All primary coolant pumps rebuilt

- All primary coolant heat exchangers replaced sith ASME III, $\mathrm{N}$-stamped components

- All batteries replaced and seismically-qualified racks installed

- Numerous others in progress 


\section{HFIR Life Extension (25 Years)}

\section{Introduction (continued)}

- HFIR's life can be extended for another 25 years while at the same time improving its isotope production and research/experiment facilities. Current facility aging programs must be continued. However, additional components and systems will have to be replaced or upgraded to affect a 25-year life extension. Modifications and additions are necessary to increase experiment and isotope production options, versatility, availability, and to improve competitiveness. A team would be established to evaluate all suggestions (modifications, new construction, etc.) using a decisionmaking process whose product is justification for the implementation of the suggestion.

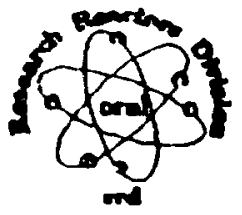




\section{HFIR Life Extension (25 Years)}

Plan

- Identify components and systems that will have to be replaced or upgraded (see Supplement 1)

- Identify modifications and additions to increase experiment and isotope production options versatility, availability, and to improve competitiveness (see Supplement 2).

- Establish team to justify (1) component and system replacements and upgrades and (2) modifications and additions 


\section{HFIR Life Extension (25 Years)}

Establish team to justify (1) component and system replacements and upgrades and (2) modifications and additions

- Is the risk acceptable if changes are or are not made?

- Are operating interruptions acceptable if changes are or are not made?

- Are user revenues versus cost of changes to increase experimental capabilities positive?

- Is funding available (or will be available) to make changes to improve isotope production capabilities (DOE funding essential)?

- Is the HFIR authorization basis impacted (avoid need for new authorization)?

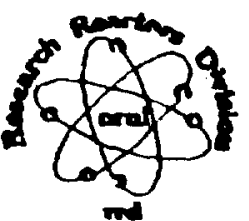




\section{HFIR Life Extension (25 Years)}

Establish team to justify (1) component and system replacements and upgrades and (2) modifications and additions (continued)

- Are user-subscription levels over subscribed/under subscribed?

- Does the change result in increase competitiveness that is cost effective?

- Is the total price tag of changes within funding and estimated user revenues levels?

- Implement changes consistent with an established prioritization system (acceptable downtime, available funding, etc.). 


\section{HFIR LIFE EXTENSION (25 YEARS)}

Supplement 1

Research Reactors Division 


\section{HFIR Life Extension (25 Years)}

Identify components and systems that will have to be replaced or upgraded

- 25 yєars operating experience/maintenance history

- Inservice inspection and testing experience

- Facility integrity reviews 


\section{HFIR Life Extension (25 Years)}

25 years operating experience/maintenance history

- Reactor vessel (embrittlement)

- Evaluate gamma flux contribution to vessel wall embrittlement

- Evaluate installation of vessel wall shielding (reduce wall embrittlement rate)

- Evaluate extending vessel life until 2015

- Evaluate annealing reactor vessel

- Evaluate replacing reactor vessel (HFIR was designed for possible replacement of all components)

- Horizontal beam tubes (corrosion, seal leak).

- Replace horizontal beam tubes

- Evaluate design to improve resistance to corrosion and primary coolant sealing mechanisms

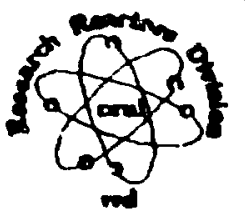




\section{HFIR Life Extension (25 Years)}

25 years operating experience/maintenance history (continued)

- Pressurizer pumps (frequent maintenance problems)

- Replace with lower head pumps (pumps will be nonsafety-related with system modification); replacement is scheduled for first half of 1995.

- Secondary coolant pipe (isolated corrosion identified)

- Upgrade cathodic protection system (some pipe not protected)

- Implement wall thickness measurement program (being developed)

- Evaluate need to replace all pipe

- Cooling towers (general deterioration)

- Evaluate need to perform additional upgrades beyond those currently underway (one cell per year is being refurbished; one has been done).

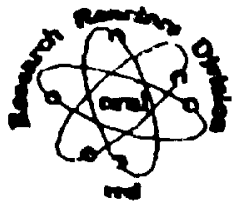




\section{HFIR Life Extension (25 Years)}

25 years operating experience/maintenance history (continued)

- Diesel generator (frequent maintenance problems)

- Replace (replacement has begun)

- Motor control centers

- Evaluate upgrade versus replacement

- Normal/emergency power system

- Evaluate need to perform additional upgrades beyond those currently underway

- Remove devices, etc., that should not be on the system and place elsewhere.

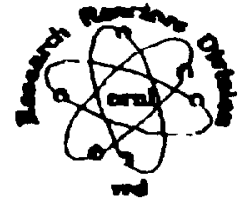




\section{HFIR Life Extension (25 Years)}

25 years operating experience/maintenance history (continued)

- Instrumentation, upgrade, or replace (frequent maintenance problems).

- Identify obsolete instruments (current effort)

- Replace ion chambers (current effort)

- Replace primary coolant RTDs (current effort)

- Others

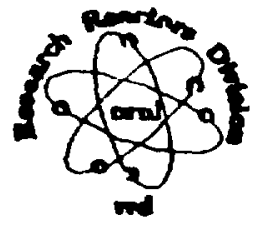




\section{HFIR Life Extension (25 Years)}

25 years operating experience/maintenance history (continued)

- Manufacture new control plates (evaluate upgrading existing plates with more durable rollers, brackets, etc.).

- Numerous items identified in ARIMS funded list

- Establish spare parts list and procure spare parts to support 25 years extended operation

- Major components (primary coolant pumps, pressurizer pumps, critical instrumentation and electrical components, etc.).

- Auxiliary and support components (radiation monitoring equipment, pool cleanup equipment, etc.).

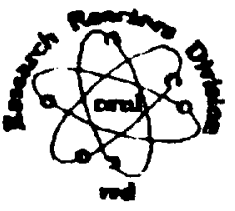




\section{HFIR Life Extension (25 Years)}

25 years operating experience/maintenance hislory (continued)

- Replace or upgrade components and/or systems identified by system or general areas follows:

- Secondary system

- Replace underground secondary piping, tower header, and tower risers.

- Clean and refurbish the secondary pump flumes

- Replace corrosion inhibitor tank with a "diked tank"

- Consider a "tertiary loop" to contain primary heat exchanger tube leaks. This would allow remediation of pond \#1.

- Replace FCV-377 and FCV-377A and the vessel inlet temperature control system with electronic controls (currently pneumatic)

- Provide a "total secondary system" flow meter

- Provide redundant secondary (or tertiary) radiation monitors 


\section{HFIR Life Extension (25 Years)}

25 years operating experience/maintenance history (continued)

- Yard utilities and piping

- Insitu form all buried process waste drain (PWD) piping (currently vitrified clay pipe)

- Refurbish the PWD deep sump; replace eductors and level indication.

- Reroute (replace) underground electrical conduit to cooling tower (it currently ruris under the Tower Chemical Addition Building; corrosion of at least one of these conduits has been identified).

- Replace transformers

- Clean and reline the underground storage tanks (pool and primary)

- Remediate the LLLW tank and piping (after FFA); remove caustic tank (after FFA).

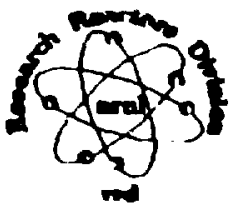




\section{HFIR Life Extension (25 Years)}

25 years operating experience/maintenance history (continued)

- Fan shed/stack

- Build above-ground SBHE filter house per current standards

- Improve testing methods for SBHE filters

- Refurbish all fans

- Move fan controls to a locked building (improve security)

- Upgrade/simplify HFIR gaseous waste radiation monitors (duct); remove all dependence on stack monitors (common to HFIR and REDC).

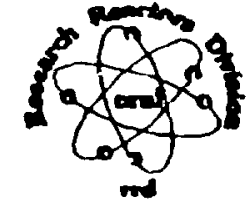




\section{HFIR Life Extension (25 Years)}

25 years operating experience/maintenance history (continued)

- Third floor

- Upgrade control room lighting

- Upgrade safety channels (currently in progress)

- Replace annunciator banks with new "reflash-type" annunciators

- Replace all control room strip charts with new instruments

- Evaluate all instruments for obsolescence; evaluate the availability of spares or spare parts; replace with new instruments as applicable.

- Provide fire alarm panel in control room (currently in progress)

- Upgrade wide-range counting channels

- Upgrade servo channels

- Upgrade/replace intercom system

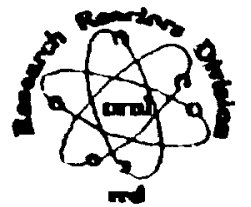




\section{HFIR Life Extension (25 Years)}

25 years operating experience/maintenance history (continued)

- Second fluor/reacter bay

- Replace instrument battery chargers (currently in progress)

- Provide badge reader/PCM-1B for east building exit

- Provide men and women rest rooms

- Replace/upgrade reactor bay recirculating and fresh air intake air conditioning units

- Upgrade decon facility

- Upgrade/enlarge ingress/egress area (airlock)

- Upgrade tool storage facility (long tools)

- Build a hot cell over the old critical pool, including transfer door and elevator.

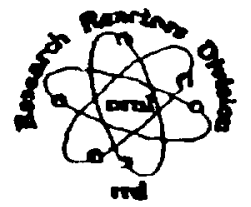




\section{HFIR Life Extension (25 Years)}

25 years operating experience/maintenance history (continued)

- Second floor/reactor bay (continued)

- The hot cell will take the control plate work area-a new control plate refurbishment area will be needed. Upgrade tooling for control plate work. (Fuel storage will be a problem.)

- Solve the fuel storage problem (dry storage, reprocessing, or another pool storage facility) in the 7900 area.

- Improve reactor bay lighting; improve light bulb change method.

- Provide solid waste segregation and packing area/equipment

- Replace pool dam seals

- Evaluate reactor spare parts needs and procure spare parts

- Move mockup/spare stack/alignment facility to a new (radiologically clean) building in the 7900 area

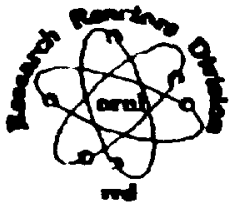




\section{HFIR Life Extension (25 Years)}

25 yeais operating experience/maintenance history (continued)

- First floor

- Refurbish HVAC room (chiller, AC-15, FN-1).

- Replace chilled water pumps (add air dryer)

- Replace pool bypass filter with back-washable filter (FFA?)

- Replace pool heat exchangers (possibly with plate heat exchanger; the current design has pool water or shell side; it is a hot-particle trap).

- Replace/improve backflow preventers

- Replace heat exchanger cell coolers

- Replace pony motors

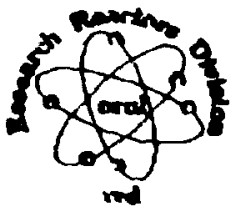




\section{HFIR Life Extension (25 Years)}

25 years operating experience/maintenance history (continued)

- First floor (continued)

- Replace letdown block valves

- Evaluate primary pump motors

- Install parallel-pump seal filters (RFM issued)

- Replace all air-handling units in the experiment room 


\section{HFIR Life Extension (25 Years)}

25 years operating experienceimaintenance history (continued)

- Ground floor

- Rebuild/redesign the steam distribution header

- Replace C-1B air compressor with screw-type (in progress)

- Replace the instrument air dryers

- Remove the caustic day tank, pump, and piping (after FFA).

- Downsize the nitric day tank; remove regeneration, filter cleaning piping.

- Upgrade the primary sample sink with a glove box or automatic system

- Replace demineralizer tanks (backwashable design)

- Procure spare pool coolant and cleanup pumps

Procure spare piping cleanup pumps

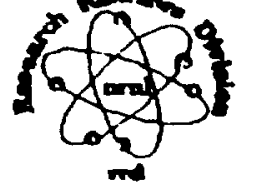




\section{HFIR Life Extension (25 Years)}

25 years operating experience/maintenance history (continued)

- Ground floci (continued)

- Pressurizer pumps (on the way)

- Provide a shielded cell for counting instruments in the control room

- Refurbish the dresser couplings (primary pipes-pool)

- Replace wiring in pipe tunnel, demineralizer cell, heat exchanger cells, deaerator cells.

- Upgrade $\mathrm{pH}$ monitoring and control instruments

- Upgrade low-low flow meters

- Increase shielded area at beam room transmitter rack

- Provide constant helium purge of beam tubes

- Replace all beam room air handling units

Replace battery room supply and exhaust fans

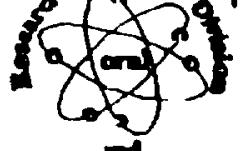




\section{HFIR Life Extension (25 Years)}

25 years operating experience/maintenance history (continued)

- Subpile room

- Procure spare drive rods and components (seal housings, etc.).

- Procure spare fission chamber drives and components

- Replace bottom vessel/head pool seal

- Electrical building

- Diesel generator upgrade (in progress)

- Switchgear upgrade (in progress)

- Construct new seismically-qualified building 


\section{HFIR Life Extension (25 Years)}

25 years operating experience/maintenance history (continued)

- Miscellaneous

- Upgrade all process instrumentation (readouts in engineering units that do not require manual conversion)

- Provide calibration tops with quick disconnects on all dp cells (in progress)

- Upgrade all CAMs and monitrons

- Replace all diaphragm valves with all valves

- Build a maintenance building with a full stack mockup alignment facility and a high bay shop

- In-building office space (e.g., add two floors over water wings to enhance conduct of operations, I\&C shop area, HP shop area, document storage, and supply storage).

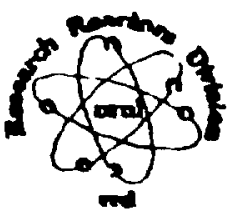




\section{HFIR Life Extension (25 Years)}

25 years operating experience/maintenance history (continued)

- Miscellaneous (continued)

- Expand and upgrade control room. Computerize control room displays and system status indications (upgrade system monitoring information).

- Suild new trainer simulator

- Upgrade or install new hot water injection system heat exchanger (evaluate elimination of heat exchanger)

- Replace trailers with permanent office building(s) 


\section{HFIR Life Extension (25 Years)}

25 years operating experience/maintenance history (continued)

- Reactor/experiment improvements

- $\mathrm{D}_{2} \mathrm{O}$ reflector tank to replace beryllium

- SANS on level with reactor centerline; provide a facility $\geq 30$ meters.

- Instruments at engineering facilities (spectrometers, etc.). 


\section{HFIR Life Extension (25 Years)}

Inservice inspection and testing program

- Primary containment valves (replace those known to leak)

- Reactor vessel top and bottom head closure studs and nuts (already replaced)

- Primary coolant heat exchangers (already replaced)

- Review inservice inspection and testing results and predict needs for other upgrades or replacements

- Perform periodic inservice inspection and testing

- Conduct UT examination on primary coolant piping for the purpose of identifying the presence of any interganular stress corrosion cracking (IGSCC)

- Evaluate changes to improve accessibility for the performance of inservice inspections on reactor vessel, primary coolant piping in pool, etc. (certain welds are inaccessible).

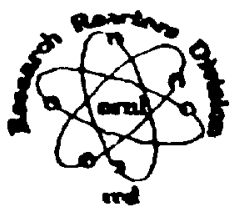




\section{HFIR Life Extension (25 Years)}

Facility Integrity reviews

- Build new (standby hot exhaust) SBHE facilities to withstand potential seismic events (current facility not seismically qualified)

- Replace obsolete equipment in fan shed

- Build new exhaust system filter plenums (filters no longer available)

- Evaluate the integrity of underground air duct/conduits ind replace if necessary

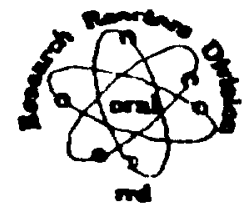


HFIR LIFE EXTENSION (25 YEARS)

Supplement 2

Research Reactors Division 


\section{HFIR Life Extension (25 Years)}

Identify modifications and additions to increase experiment and isotope production options, versatility, availability, and to improve competitiveness

- Use same reactor vessel. (Modify top head for additional penetrations.)

- Evaluate reactor core modification options to produce ${ }^{238} \mathrm{Pu}$ for U.S. Space Program. (Modify reflector or place irradiation facilities outside of reflector and provide head penetrations for straight access to the irradiation locations.)

- Evaluate the feasibility for long-term spent fuel storage (assume Savannah River closure)

- Evaluate the use of silicide fuel elements to improve fuel cycle length and increase operating efficiency. (Denser load, more ${ }^{235} \mathrm{U}$ in same volume.)

- Install second hydraulic rabbit tube. (The present hydraulic tube is oversubscribed.)

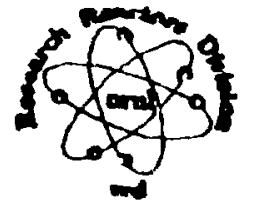




\section{HFIR Life Extension (25 Years)}

Identify modifications and additions to increase experiment and isotope production options, versatility, availability, and to improve competitiveness (continued)

- Increase heat flux capabilities of the hydraulic rabbit by approximately five times that currently avaiiable

- Evaluate methods to reduce gamma heating rates. (Improve irradiation facility versatility.)

- Increase pneumatic tube capacity to permit irradiation of multiple samples $(50 \mathrm{cc})$ at the same time. (The present tubes are sometimes oversubscribed, but the facilities are not competitive because only $1 \mathrm{cc}$ of sample at a time can be irradiated.) (Add third tube? Increase size of an existing tube?)

- Install cold source in core to provide a new realm of low energy neutronic physics not currently available at HFIR (this was originally the primary purpose for ANS)

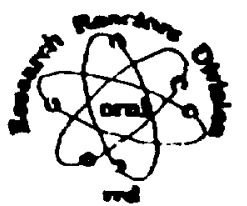




\section{HFIR Life Extension (25 Years)}

Identify modifications and additions to increase experiment and isotope production options, versatility, availability, and to improve competitiveness (continued)

- Install additional spectrometers to increase the potential utilization of the horizontal beam tubes (HB-2 beam can be bent up to the experiment room and $\mathrm{HB}-4$ beams can be extended into an add-on building. Engineering facility EF-2 spectrometers can be placed in the experiment room.)

- Evaluate changes/methods to increase production task loading efficiencies

- Improve access to and efficiency of present material irradiation facilities by making penetrations in reactor vessel top head lineup vertically with the reflector irradiation facility positions

- Demonstrate the technical and efficient merits for increasing the operating power to $100 \mathrm{MW}$. (Improves overall efficiency and competitiveness of HFIR isotope production and materials research faccilities).

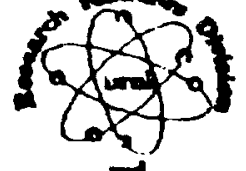




\section{HFIR Life Extension (25 Years)}

Identify modifications and additions to increase experiment and isotope production options, versatility, availability, and to improve competitiveness (continued)

- Replace spectrometers, collectors, laboratory instrumentation, etc., with state-of-the-art instruments to improve effectiveness and efficiency.

- Install positron source to improve research versatility. (Some design has already been done for HFIR. Proof of principle has already been demonstrated.)

- Install hot source in reactor core

- Run all pneumatic tubes to one shielded loading location to improve efficiency and accommodate increasingly stringent ALARA guidelines and concerns.

- Upgrade laboratory instrumentation (e.g., delayed neutron cooling) with state-of-the-art equipment to more effectively serve the International Atomic Energy Agency (IAEA) and other potential customers for total fissile material determinations.

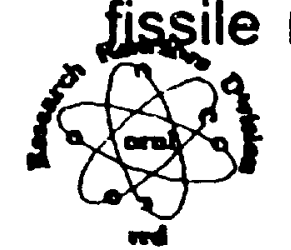




\section{HFIR Life Extension (25 Years)}

Identify modifications and additions to increase experiment and isotope production options, versatility, availability, and to improve competitiveness (continued)

- Evaluate the advantages of changing the HFIR core to a materials testing core

- Build a hot cell at HFIR for users to dismantle experiment capsules to alleviate transportation problems. (A transfer conduit would be provided from the pool to the hot cell.)

- Return the transuranium transfer tube to service that runs underground from the HFIR pool to REDC

- Evaluate feasibility for using control plates to periodically increase/decrease poison in the target region to increase target irradiation versatility

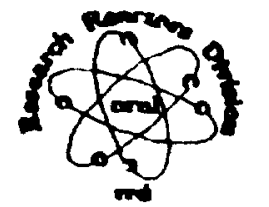




\section{HFIR Life Extension (25 Years)}

Identify modifications and additions to increase experiment and isotope production options, versatility, availability, and to improve competitiveness (continued)

- Replacement of reactor vessel required

- increase the number of beam tubes (beam tubes are currently oversubscribed and this would increase revenue)

- Evaluate the total impact on the vessel and core designs

- Determine the number of beam tubes the facility could support

- Evaluate the use of a stainless steel vessel replacement 
ATTACHMENT 5 


\title{
A MAJOR ENHANCEMENT AND LIFE EXTENSION POSSIBILITY
}

\author{
presented to the \\ HFIR Futures Group
}

by

C. D. West

March 6, 1995 


\section{MAIN CHARACTERISTICS OF SOME LIGHT - AND HEAVY-WATER CORES STUDIED BY THE ILL PROJECT}

$\mathrm{D}_{2} \mathrm{O}$ Core $\quad \mathrm{H}_{2} \mathrm{O}$ Core

Volume, L

46.6

34.76

Rendement BOC, $10^{13 /} \mathrm{cm}^{2} \mathrm{~s}$

2.75

2.65

MW

Total power, MW

54.55

56.6

$F_{u,} F_{r d}$

2.09

2.12

Maximum heat flux, $\mathrm{W} / \mathrm{cm}^{2}$

407

577.5

Maximum fuel surface

140

177 temperature $\mathrm{BOC},{ }^{\circ} \mathrm{C}$

Reactivity, pcm

24,400

23,800

Worth of control rod, pem

11,400

10,400 


\section{ADVANTAGES OF LIGHT-WATER COOLING (mainly operational)}

- Fuel element could be subcritical in every location except inside the reflector (and with the lower core volume adopted to regain some of the lost rendement, a single element would probably be practical, at least with HEU fuel)

- Simpler refueling and, with appropriate design, no need to transfer the element(s) from heavy to light water

- same (in principle) refueling process as HFIR, directly into the light-water pool 


\section{SKETCHES}

- The following sketches show how a light-water cooled/heavy-water reflected concept might be realized

- To give the principle some reality, I have assumed that the HFIR cooling system, etc. would be used, with minimal changes, i.e., that we might use this approach to upgrade HFIR

- $\quad$ Starting point was the ILL design case, with $35 \mathrm{~L}$ volume in a single element, running at $100-110 \mathrm{MW}(\mathrm{th})$

- power density would be lower than even the ANS three-element baseline core

- fuel sideplate extended to form CPBT (like ILL)

- In the sketches, I assumed upflow, three central control rods, secondary shutdown rods in reflector tank, and that a separate reflector cooling circuit would be installed (HFIR and ILL reflectors and primary coolant are all one circuit)

- Because of the separate reflector cooling circuit, the fission power could be slightly $(5 \%-10 \%)$ higher than HFIR 


\section{PERFORMANCE (1)}

- Assuming the core is similar to the ILL lightwater core, and the power is $100-110 \mathrm{MW}$, the peak thermal flux in the reflector would be about $21 / 2$ times ILL

- allowing space (i.e., a bigger central hole) and perturbations for production and irradiation targets, the flux should be $11 / 2-2$ times ILL

- Also, with the ANS forced-convection design, the cold source could be placed nearer to the peak flux than the ILL's natural-convectioncooled system

- the cold neutron flux should be $2-3$ times ILL

- the new reflector tank design would include a thimble for the cold source and guides and perhaps extra thermal beam tubes or guides 


\section{PERFORMANCE (2)}

- The changes include a new reflector vessel, which could be made from a material (e.g., $\mathrm{Al}$ 6063) chosen from structural and ALARA considerations

- this would replace the component that is now the life-limiting one for HFIR

- ILL and Petten have both replaced their reactor vessels recently: we know it is do-able 


\section{Date: January 26, 1995 \\ To: \\ B. R. Appleton \\ c: \\ J. E. Cleaves, J. B. Hayter

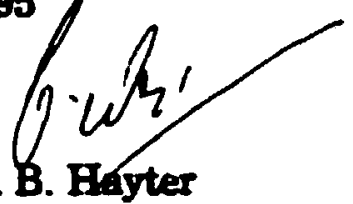 \\ From: $\quad$ C. D. West, FEDC, MS-8218 (4-0370) - RC \\ Subject: $\quad$ HFIR Upgrade Propoeal}

The continued scientific support for the Adranced Neutron Source (ANS) testifies to the importance of neutron scattering and to the extent that the United States' facilities for this economically important work have fallen behind other countries. If no new steady state high flur machine is to be built, we should consider what can be done to improve, in a cost effective way, our existing machines. Naturally, as construction of the ANS seemed to fall more and more in doubt, I began to wonder what could be done to enhance the nation's highest flux existing reactor, the High Flux Isotope Reactor (HFIR), to provide a nationally needed user capability and to keep Cak Ridge National Laboratory at the forefront of this field. My conclusions are that we could make some low cost, low risk changes to HFIR that would bring us a worldbeating capability in some carefully chosen areas.

The proposal, based on the recent euccessful replacement at the Institut Laue Langevin (ILL) of the reflector vessel assembly and all its internal components, would best be carried out before 1997 when the HFIR's beryllium reflector has to be replaced. The project would replace the embrittled steel pressure vessel of the HFIR, and the beryllium reflector within it, with a cylindrical tank of heavy water. The new rellector, fabricated from low activation material, would give our reactor a further 15 to 20 years of life, would allow us to operate at a full $100 \mathrm{MW}$ again, and would produce a higher neutron flur for beam work tiun IIL. The existing HFIR light water primary cooling system would be retained.

Taking advantage of the fact that we could plan in advance for the project, instead of having to respond to an unanticipated component failure as the IIL had to do, the work could be completed in about 2 1/2 to 3 years. During some of that time, the reactor would be shut down. Some of the normal operating budget of the HFIR over that period would partially pay for the upgrade, 80 that the marginal cost would be only about $\$ 40 \mathrm{M}-50 \mathrm{M}$.

As you know, John -Jayter has suggested, completely independently, that the HFIR through-tube be divided into two tubes viewing a vertical cold source between them. Neutron guides along the axis of the through tube would bring out cold neutron beams through the existing shielding penetrations. This idea would work with either the new beryllium reflector due to be installed in 1997, or with the upgradec rellector system 
B. R. Afpleton

Page 2

January 26, 1995

referred to above. John points out that by carefully choosing the instruments on the guides from his propoeed cold source, the laboratory could acquire the best capability in the world - better than IIL - in some important fiolds. I suggest that a cold source and new cold neutron instruments be convidersd as an excellent and extremely cost effective upgrade, whether or not the new improved reflector project is accepted.

These seem to me to be important ideas that could give the laboratory a nationully important user facility. If you agree to the importance, I think we should discuss them very soon with appropriate members of laboratory management, including Jack Richard of course, so that ORNL can try to reach a unanimous position that we can present to the administration and Congress. I would appreciate your guidance on this and your help in arranging it.

CDW.lfir

Attachment

1. HFIR Reflector Replacement 


\section{HFIR RGFLECTOR RGPLACEMENT}

The Institut Lave Langevin (ILL) has just completed the replacement of their reactor's aluminum reflector veaeal and all its internal components, giving their facility another 20 years of bife. The replacement was carried out in response to cracts discovered in a plate supporting the flow straighteners in the cooling water path from the core outlet. It took them about one year to decide upon complete replacement as their coures of action, after which it took only $21 / 2$ years to remove the old aystem and to reglace it with a new one. The wort was dose almoet entirely by the regular operations, maintenance, end technical staff of the Institut, and the whole project ( $\$ 63 \mathrm{M}$ ) was funded out of their normal operating budget, although some research staff reductions were needed to accommodate this.

The High Flux Isotope Reactor (HFIR) reflector is scheduled for replacement in. 1997, when radiation damage will have brought the "permanent beryllium" component to the end of its useful life. The HFIR has, since 1989, bren operating at a reduced power level of only $85 \mathrm{MW}$, instead of $100 \mathrm{MW}$, because radiation damage to its ateel pressure vessel or reflector tank necessitated a reduction in operating pressure.

Now that ILL has demonstrated the feasibility of such an operation, I propose that instead of putting in a new beryllium piece, the entire reflector vessel assembly and its internals be replaced. Furthermore, I propose that design changes to enhance the facility's capabilities as a neutron beam source be incorporated. In particular, the beryllium reflector components should be replaced by a tank of heavy water, the core (which would still be cooled by the present HFIR light-water primary cooling system) would be lengthened sligbtly, but decreased in diameter, to make it more similar to beam reactors such as ILL. Consideration could be given to placing the control elements in the central hole of the core, where they would have much less impact on the thermal neutron flux reaching the beam tubes. The incention would be to complete this wort for minimal cost beyond the normal operating expenses of the facility, as was done by the ILL. 
Heavy water could be uhipped to an exicting heavy water detritiation and upgrade plant in (for example, Canada), ultbough a mare effictive plan for the Department of Enerzy would be to inctall a detritiation plant close by. The plant (estimated to coet \$71M, including contingency, based on the Advanced Neutron Source conceptual desion estimnteo) would be uned to extract tritium from existing U.S. stocks of contaminated beavy water as well as from the beavy water irradiated in the new HIRR reflector.

The table below gives estimater of the cost of the reflector replacement/enhancement project only. the experimental oystems upgrade and cold cource project deacribed in the next paragraph are not included in it.

\begin{tabular}{|c|c|c|c|c|c|c|c|c|}
\hline \multicolumn{9}{|c|}{ NEW REFLECTOR VESSE AND ASSEMELY FOR MFIR } \\
\hline \multirow[b]{2}{*}{ lemen } & \multicolumn{3}{|c|}{ Fr $19928 \mathrm{sm}$} & \multicolumn{4}{|c|}{ Rened Yars sM } & \\
\hline & $\begin{array}{l}\text { Rowen } \\
\text { Estumate }\end{array}$ & Incertinity & Toter & $\overline{F Y} 1898$ & FY 1997 & Frises & TOTAL & \\
\hline $\begin{array}{l}\text { Vessed and Cortuol Rods } \\
\text { (nnoudes installation labor) }\end{array}$ & 21.3 & sosh & 32.0 & 5.6 & 20.7 & 11.7 & 380 & $\begin{array}{l}\text { Based on ANS studies and he } \\
\text { experience }\end{array}$ \\
\hline Safety and OA & 10.0 & $25 \%$ & 12.5 & 5.7 & 5.9 & 3.' & 14.7 & Baced on HFTR Reatert ectivites \\
\hline $\begin{array}{l}\text { Neutronucs and Thermal } \\
\text { Hyoraukc Anabyses and } \\
\text { Tests }\end{array}$ & 6.3 & 25* & 7.9 & 3.6 & 3.7 & 1.0 & 9.3 & Baced on ANS experience \\
\hline $\begin{array}{l}\text { Proyect Management } \\
\text { and Consturction Suppon }\end{array}$ & 5.0 & sow & 7.5 & 2.8 & 3.0 & 3.1 & 8.9 & $\begin{array}{l}\text { Besed on the ANS Projicd } \\
\text { Olitice expenencs }\end{array}$ \\
\hline Retiector Cooling System & 4.0 & 25\% & 5.0 & 0.9 & 3.2 & 1.8 & 5.9 & Besed on ANS COR \\
\hline Lhtrues & 0.8 & $25 \%$ & 1.0 & 0.2 & 0.6 & 0.4 & 12 & Bened on AMS COR \\
\hline TOTAL PROJECT COST & 9.8 & $38 \%$ & 13.5 & 18.7 & 37.2 & $\mathbf{2 2 . 0}$ & $\boldsymbol{n} . \boldsymbol{2}$ & \\
\hline
\end{tabular}


At the anme time, funding would be requedted for a project to install additional beam tubes, a cold neutron source, and additional neutron scattering instruments; J. B. Hagter hes proposed a way of inctalling a vertical cold source asecmbly that would have minimal impect on the reactor system. In fact, his approech would be applicable to either the present beryllium reflector desien or to the heavy-water refler sor described here. The new reflector assembly would give the HFIR a bigher flux of thermal neutrons than ILL. Combined with the cald source project, we would have auch (2 or 3 times) higher flux of cold noutrons than IIL, although there would be only a small fraction of the beam lines and instrument atations. The experiment systems upgrade project shoula inclode design and contruction of four or fire modern cold noutron instruments and experimental stations, including facilities for industrial application of cold neutrons to materials analysis and radiography, that would take advantage of the high flux to be the best of their kind in the world. This project has not yet been costed.

Attachment: "A New Preasure Vessel and Much Better Neutron Beam Capabilities for HFIR" 
January 25, 1995

A New Preseure Vesed and Much Better Neutron Beam Capabilities for HFIR

\section{Backeround}

The United States is ten-ta-twenty years behind Europe, and perhaps five-toten years behind Japan, in capabilities for neutron beam research. Such research is scientifically important (evidenced by the number of Nobel prizes awarded for related wath) and eccomomically important, evidenced by industrial interest and involvement in obtaining data on the atructure and properties of new materials and structures in this way.

A proposal to provide the country with a world-beating neutron research facility (the Advanced Neution Source (ANS)) has been on the table aince the mid-ighties and has received consistent and almost universal support from many scientific communities, and from rome industrial companies. It has not received strong support from the Department of Energy, and the schedule for the ANS has slipped one year per year for the past five or sir years. Such delays, and the increasing cost of doing business, have raised the estimated cost despite some cost reductions achieved by the project through value engineering.

The High Flur Isotope Reactor (HFIP), which first went critical in 1965, was designed ap a flux trap reactor, optimized for the production of transuranium isotopes with a power of $100 \mathrm{MW}$. At a late stage of the design, a few (four) beam tubes were included. Despite the higher power of HFIR, compared with the Institut Lave Langevin (IIL); beam reactor in France (100 MW vs 57 MW), the peak flux in the reflector is about the same for the two reactors, because the one was optimized as a beam reactor and the other was DJt. Furthermore, the beryllium reflector gystem in the HFIR produces a Alrx peak that. is closer to the fuel element, and of a smaller diameter, than the heavy water reflector in the IIL. There is less volume of high thermal flun, and in practice the HFIR beam tubes had to be placed in a position of lower Aur (compared to the peak) within the beryllium than the IIL beam tubes in their large heavy water tank.

Finaily, an unanticipatedly high rate of embrittlement of the HFIR pressure vessel led to a need to reduce operating pressure, and therefore power level, several years ago. The remaining useful tife of the pressure vessel is uncertain. The present operating power is $85 \mathrm{MW}$.

Following a mechanical failure of some flow streightening grids in the ILL reactor a few years ago, the Institut decided to replace their reflector tank (Luore or less equivalent to replacing the HFIR pressure vessel) and all of its internals. That work was completed in late 1994, und the ILL reactor went critical again in January 1995 . with an estimated further lifetime of at least 15 
years. Other reactors (including the HFR at Petten, aripinally of a design closely similar to the Oak Bidge Research Beactor, bat aubsequently modified and improved) have also rapleced their outer tanks. The Japanese replaced the entire reactor bloct of the JRR-3, with scene modifications and enhancements that greatly improved their neutron beam capabilities. Such replacement projects are well understood by now and are an e.copted part of research reactor operations.

\section{Replaning the HIIR Pressure Veasel}

Replacing the BFIR pressure vessel with a new one would, for a modest cost and with low technical risk, provide a 10-to-20 year kife extension, giving U.S. scientists and industry access to a first class RSDD user facility into the second decade of the next century. Given the erowing ecientific and economic importance of neutron beam tochniques and the fact that the HFIR has not needed to operate its transuranic capabilities at full capacity in recent years, the cow reflector vessel and internals should be modified to provide enhanced beam capabilities as long as the isotope production still meets the current needs.

Other changes to the HFIR system would be minimized (assuming that a minimum cost project would gain more support than the top-of-the-line approach that led the user communities to apecify their very advanced performance requirements for the ANS). Here is 8 tentative list:

Primary coolant

Power level

Pool
Same as HFIR, light water

Same as HFIR, $100 \mathrm{MW}-110 \mathrm{MW}$

Use existing HFIR pool: the new reflector vessel would be similar in size to the present one

\section{Comparison to ANS}

Refueling is easier than in ANS heavy water system, but thermal neutron Aux is $-40 \%$ lower for similar cores

Can use most of the existing cooling system. but power and therefore Aur would be only about $1 / 3$ of the $300 \mathrm{MW}$ ANS

The smaller space in and around the reflector would mean many fewer beam tubes and guides 


\section{Comparison to ANS}

Pumpe and heat exchangers
Use existing HIFIR components
Use of existing components will fix the power level at $-100 \mathrm{MW}$. The ANS oystem is derigned o provide the power level needed to meet the users' performance requiraments

Some changes, involving low technical riak, would modernize the reflector tank and systems; provide research and, perhaps operational advantages; and enhance the neutron beam capabilities by charging the balance between the flur/spectrum characteristics in the rallector region and in the in-core positions. Here is a tentative and partial list:

Reflector tank

Reflector material

Pressure boundary

Materials
Separate the reflector region from the primary coolant so that operating pressures and materials can be chosen independently for these two systems

Use heavy water instead of beryllium to give a larger volume of high flux; and to avoid the necessity for frequent replacement of complex, expensive, radioactive beryllium components. Also, the heavy water reflector permits more fleribility in adding or changing in-reflector components as research needs might require (e.g., it would be easier to include a cold source)

Provide for routine replacement of irradiated pressure boundaries (e.g., to avoid further embrittlement surprises!)

Use low activation materials, as far as possible, as the ILL reactor does, in order to meet ALARA principles

\section{Description - Reflector Yessel}

The new reflector tank would be similar in external dimensions to the old, embritt'od one, but would have a vertical chimney running through its center. The chimney would be removable, in case it needed to be changed out becauge of radiation damage or for other reasons (e.g., for inspection). It would be a very simple component, ideally a straight sylinder with flanges or other attachmentsealing mechanisms at each end (Fig. 1). 


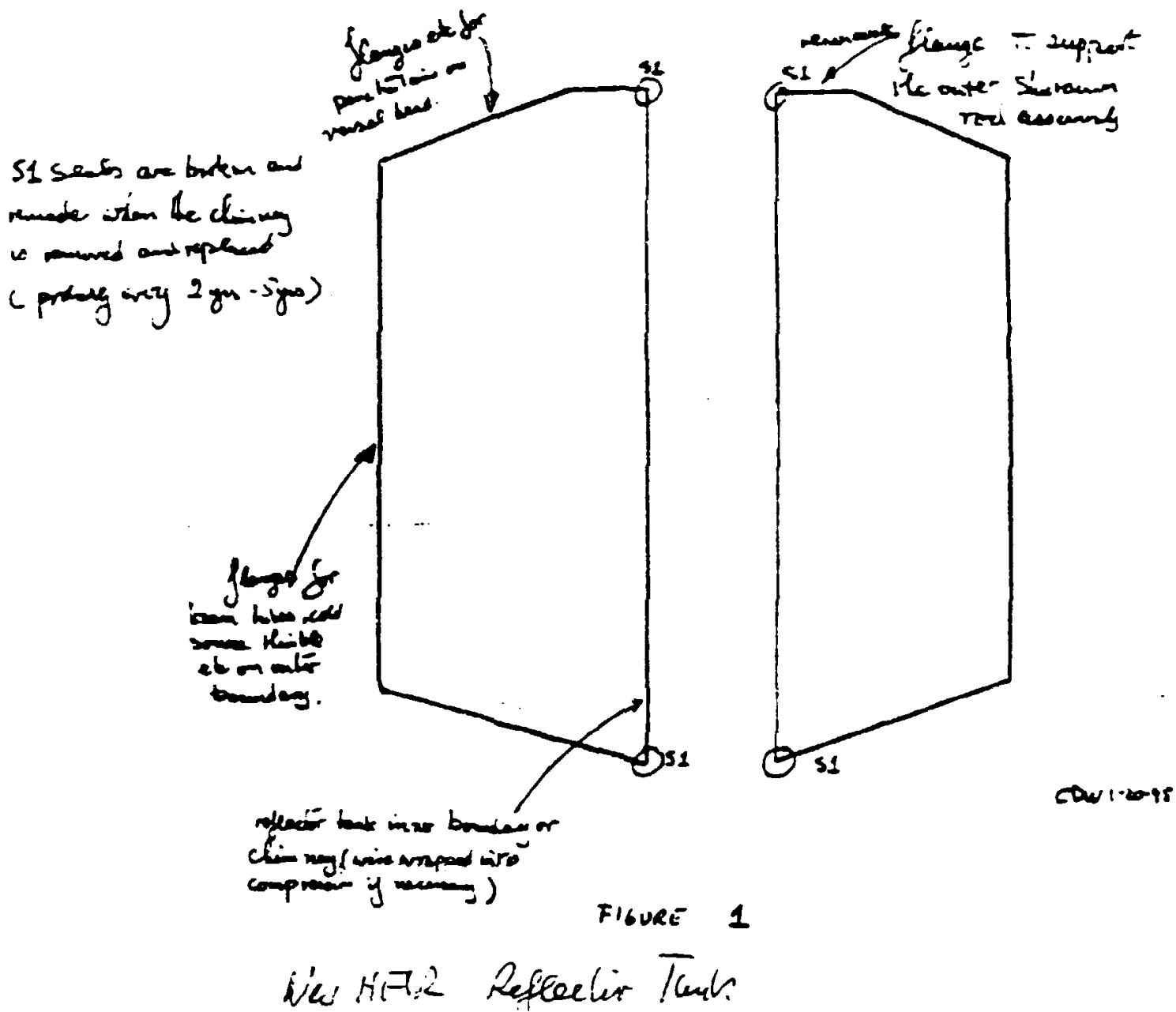

Figure 1 shows the principle, but omits the in-tank components (beam tubes, cold source, rabbit tubes, irradiation thimbles, reactor instrumentation) and the reflector heavy water cooling and treatment systems, and the outer reactor shutdown rods.

The tank would run at a low pressure (probably similar to the hydrostatic pressure in the ourrounding pool) and, unlike the ANS reflector vessel, it does not provide structural support for any of the reactor core components. It could therefore be made from materials chosen for low activation, such as the $A$ 6063 or titanium alloys that are already included in some sections of the ASME corde.

The vessel would be fixed to the pool with its chimney above a (light water) primary coolant inlet manifold and the inner control rod drives (the reactor control system will probably be similar to the ANS design, with the primary control and shutdown rods inside the core, where they have minimum effect on the beam tube flux, instead of outside the core (like HFIR) where they have minimum effect on the in-core irradiation flux). There is a set of outer rods, inside the reflector tank and anchored to its top, that provide a secondary shutdown capability. 
As will be seen, the chimney forms a guard tube around the section of the primary coolant boundary in the region of the core (the "core pressure boundary tube"). For this reason, conaideration will be given to wrapping the chimney with multiple layers of tensioned wires, probebly of aluminum, 80 that it is always in compreasion and therefore not rubject to flav growth. It will be replaced an a schedule appropriate to rndiation demage rates or other forms of deterioration, and could be subject to inspections at more frequent intervals than the echeduled replacements.

\section{Beactor Cone and Core Bressure Boundary Tube}

During very early studies for the ILL reactor, comparisons of different core designs with different coolants were made. The best core design was judged to be a compact annular core with a central hole. The comparisons of light and heavy-water coolant in cores optimized for the same flur revealed that a higher power density was needed with light water (the table below is taken from material presented by ane of the original IIL designers, Dr. Herbert Reutler, to the ANS Lecture Series on Research Reactor Degign Methods and Benchmarts in October 1989).

Table 2.5 Main characteristics of both cores

\begin{tabular}{|c|c|c|}
\hline & $\mathrm{D}_{2} \mathrm{O}$ Core & $\mathrm{H}_{2} \mathrm{O}$ Core \\
\hline Volume, L & 46.6 & 34.76 \\
\hline Rendement BOC, $10^{1 \mathrm{~s} / \mathrm{cm}^{2} \mathrm{~g} \mathrm{MW}}$ & 2.75 & 2.65 \\
\hline Total Power, MW & 54.55 & 56.6 \\
\hline$F_{a x} \cdot F_{\text {nd }}$ & 2.09 & 2.12 \\
\hline Maximum Heat Flux, W/cm² & 407 & 577.5 \\
\hline Marimum Fuel Surface Temperature BOC, & 140 & 177 \\
\hline Reactivity, pcm & 24,400 & 23,800 \\
\hline Worth of Control Rod, pcm & 11,400 & 10,400 \\
\hline
\end{tabular}

The rendements of the two cores are almost the same, but the $\mathrm{H}_{2} \mathrm{O}$ one has to run at a power density of $56.6 / 34.76=1.63 \mathrm{MW} / \mathrm{L}$ whereas the $\mathrm{D}_{2} \mathrm{O}$-cooled core runs at only $54.55 / 46.6=1.17 \mathrm{MW} /$.

If the $\mathrm{D}_{2} \mathrm{O}$ core volume were reduced to give a power density of $1.63 \mathrm{MW} / \mathrm{L}$, its rendement would increase by a factor of 1.2 to 1.3. This is consistent with the 
ANS studies that ahowed a 30\%-10\% higher flux with heavy- water cooling than with light water.

Nevertheless, if wa are to consider simply replacing the HFIR pressnre vessel, we must retsin light-water cooling of the core; otherwise, extensive modifications of the primary cooling circuit would aloo be needed. Note that there are significant, very significant, operationsl advantages to using lightwater coolant, al thoueh the world's best beam reactors have generally placed more importance on research performance than operational convenience.

In the HFIR, the aame coaling circuit removes heat from the core and from the reflector components. In the new reflector tank, these two functions must be separated because the core is light water and the reflector vessel contains heavy water. Therefore, the full capacity of the HFIR primary cooling loops can be applied to fuel and core component coaling, a cecond amaller ( $-6 \mathrm{MW}$ ) system will have to be provided for the reflector vesed components and heavy water. This means that the core can be operated at a slightly higher power (5\%-10\% higher) with the same pumps, heat erchangers, cooling towers, etc.

As a starting point for the core dimensions, let us take the IIL design case referred to above, with $35 \mathrm{~L}$ volume. This volume, which could be accommodated in a single annular fuel element, would correspond to increase in power density over HFIR of about $50 \%$, and a decrease in power density compared with the ANS baseline two-element core design of about $30 \%$. It is lower even than the power density in the present baseline ANS three-element core design, which has very large afety margins [the fuel plate surface temperature is below the coolant boiling point for all anticipated events, even when all uncertainties and tolerances are taken into account].

The single element has ils side plate extended to form a shirt, below the element, that will connect to the primary coolant inlet i.e., the skirt formed by the extension of the sideplate below the fuel plates is the core pressure boundary tube. Subject to detailed design studies, the sideplate may be extended upwards as well, or a separate upper CPBT may be joined to the sideplate (the former offers advantages e.g., no leakage). See figure 2.

For the rest of this discussion, it is assumed that reactor control is by means of an in-core system of three abeorber rods, moving together for control but independently scrammed. There reult be a secondary shutdown system in the reflector tank. This is the system used in the ANS design. However, in the HFIR modification project safety, cost, and performance trado-off studies would be used to compare control by moveable absorber and control by movcable beryllium reflector rod or rods, as is done in the FRM-II reactor design 


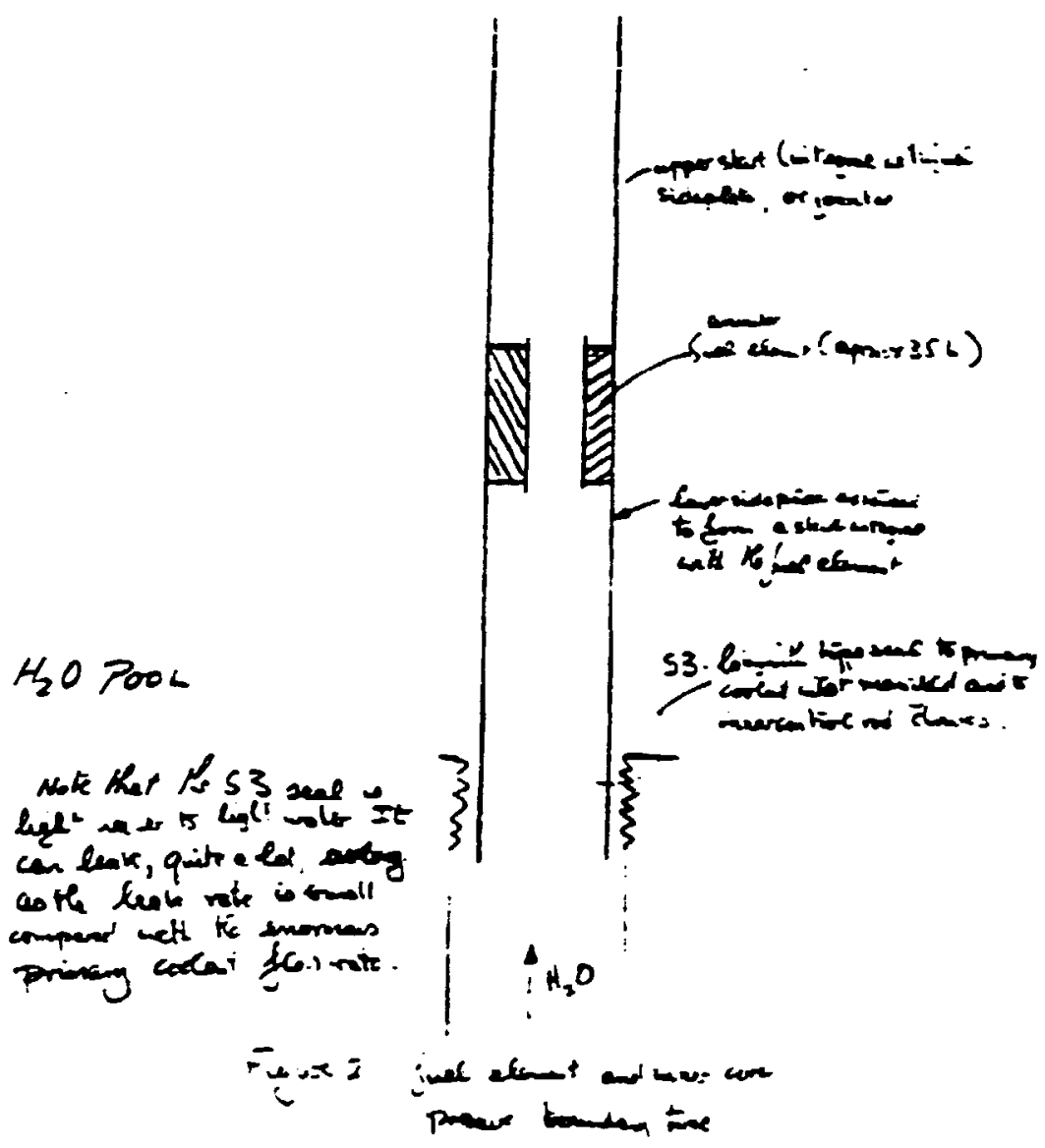

The IIL light-water cooled core calculation was for an element whose fueled dimensions were $170 \mathrm{~mm}$ ID, $290 \mathrm{~mm}$ OD, and $800 \mathrm{~mm}$ high. Such dimensions would probably not provide enough epace for the three independent scram rods of the ANS design, much less for some in-core irradiation facilities as well. As a starting point for optimization calculations, I propose the II. study-cure volume $(34.8 \mathrm{~L})$ with approvimately the inside and outaide dimensions of the ANS two-element baseline design upper core, which we tnow has space for these items). The fueled reginn would have a height of about $450 \mathrm{~mm}$. Smaller radii would be better, if practical, and ahould be investigated.

\section{Assembly}

The final assembly consists of placing the nep reflector tank in position. First fueling, like subsequent refueling, is performed by sliding the entire inner CPBT/fuel element component down the chimney and plugging it into the core inlet manifold - this operation is carried out under light water, like the present GFIR operations. Presumably the element will be suberitical unless it is in place inside the reflector.

\section{CPBT Annulus}

The next question concerns the CPBT annulus i.e., the space between the fuel element slirt and the chimney. If assembled simply as described above, this space would be filled with light water, which has many advantages. Of course, the rater could be force-convected through the annulus if calculations sh ow that single-sided cooling of the CPBT and the chimney are not feasible. 
However, light water is a strong abeorber of neutrons as well as a good moderator. The annular layer of lieht water would probably reduce the reflector neutron flur subetantially (calculations are needed to confirm this, but it was certainly a problem for the ADCL denign of the new Karean reactor, which had a thin layer of hipht water between the core and reflector region). Furthermore, the light-water annulus would probably have a positive void coefficient, which is underimable for soffoty reasons.

If single-sided cooling of the walls is poecible the gap could, in principle, be a gas-filled void, but auch a solution would require considerable analysis. A riskfree technical baseline would be to put manifolds at the top and bottom of the annulus, with heavy water circulated through it. At refueling time, the reactor would be shut down, the heavy water would be blown from the annulus system, and the system dried (to conserve heavy water). Then it would be refilled with light water, after which the top of the primary coolant boundary at the reflector is remored, and the CPBT/fuel-element assembly withdrawn upwards, and stored in the light-water pool. After refueling and sealing the system, the annulus system would be blown free of light water and dried, then refilled with beavy water prior to atart up.

A secondary benefit is that monitoring pressure and flow in the annulus system would reveal any significant leaks or breaks in the CPBT or its guard tube, the chimney.

A major leak or break in the CPBT near the core would be mitigated by the flow resistance offered to leakage by the narrow annulus.

Detailed design is needed of the lower end attachments of the CPBT to determine where the transition from aluminum to steel components should be made.

Figure 3 (next page) shows a sketch of the complete assembly.

C. D. West, 1-25-95 
54

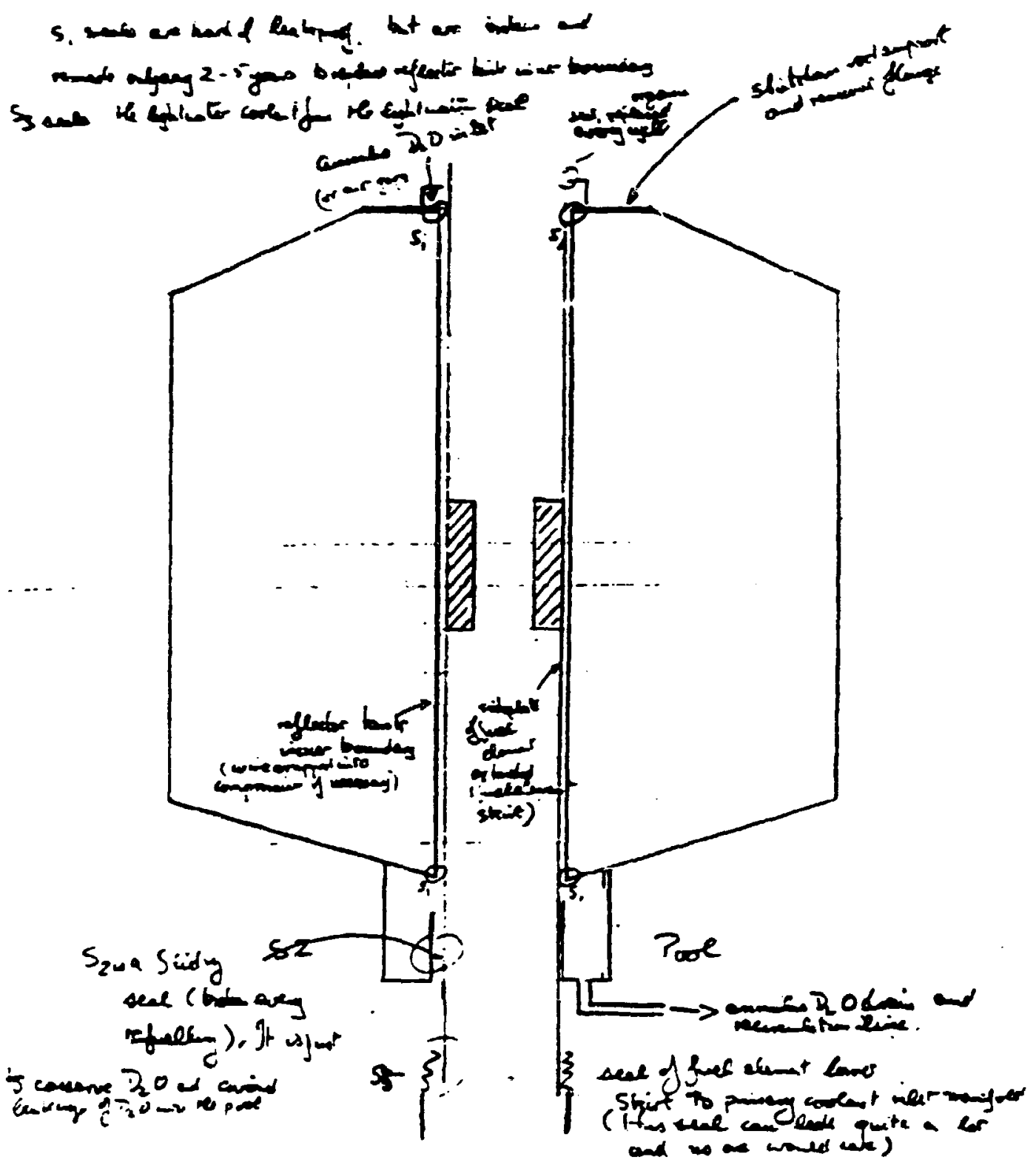

con 1.14 .15

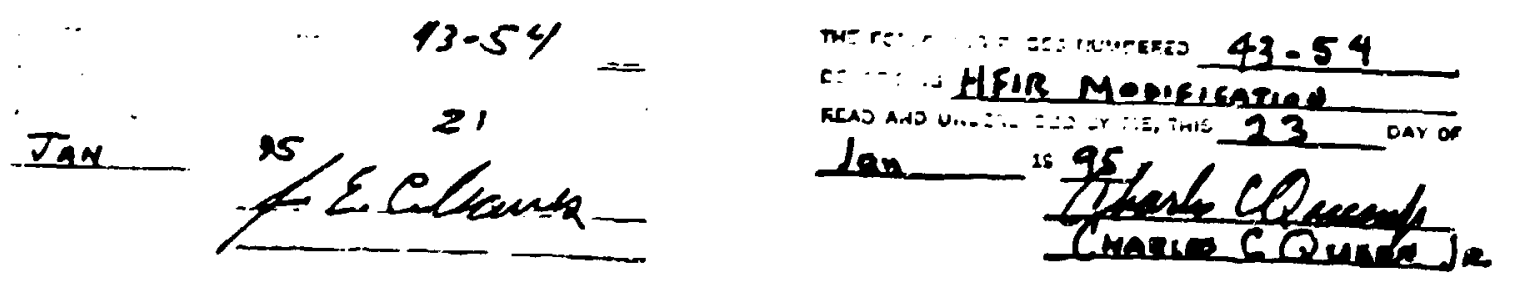


ATTACHMENT 6 


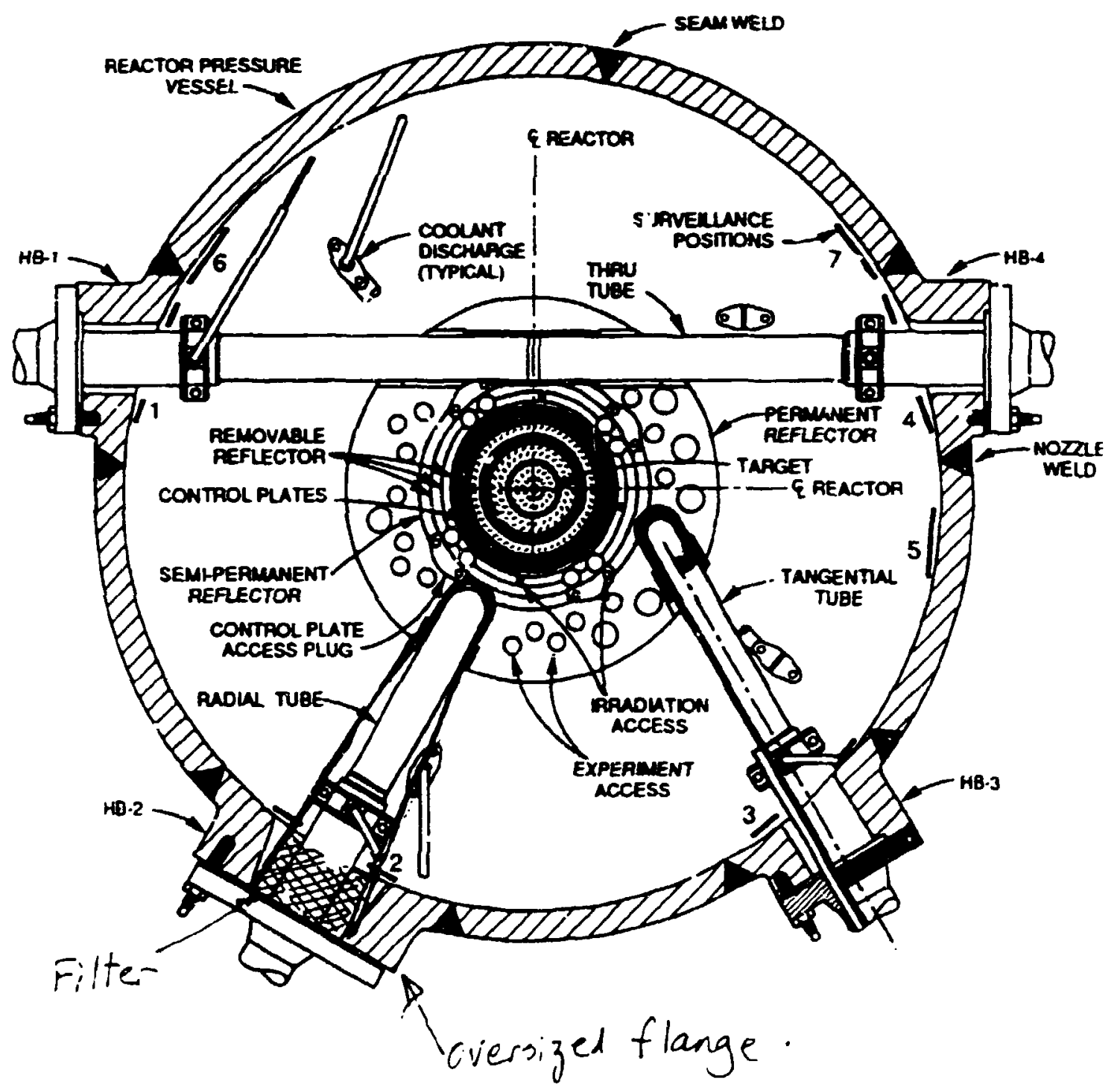




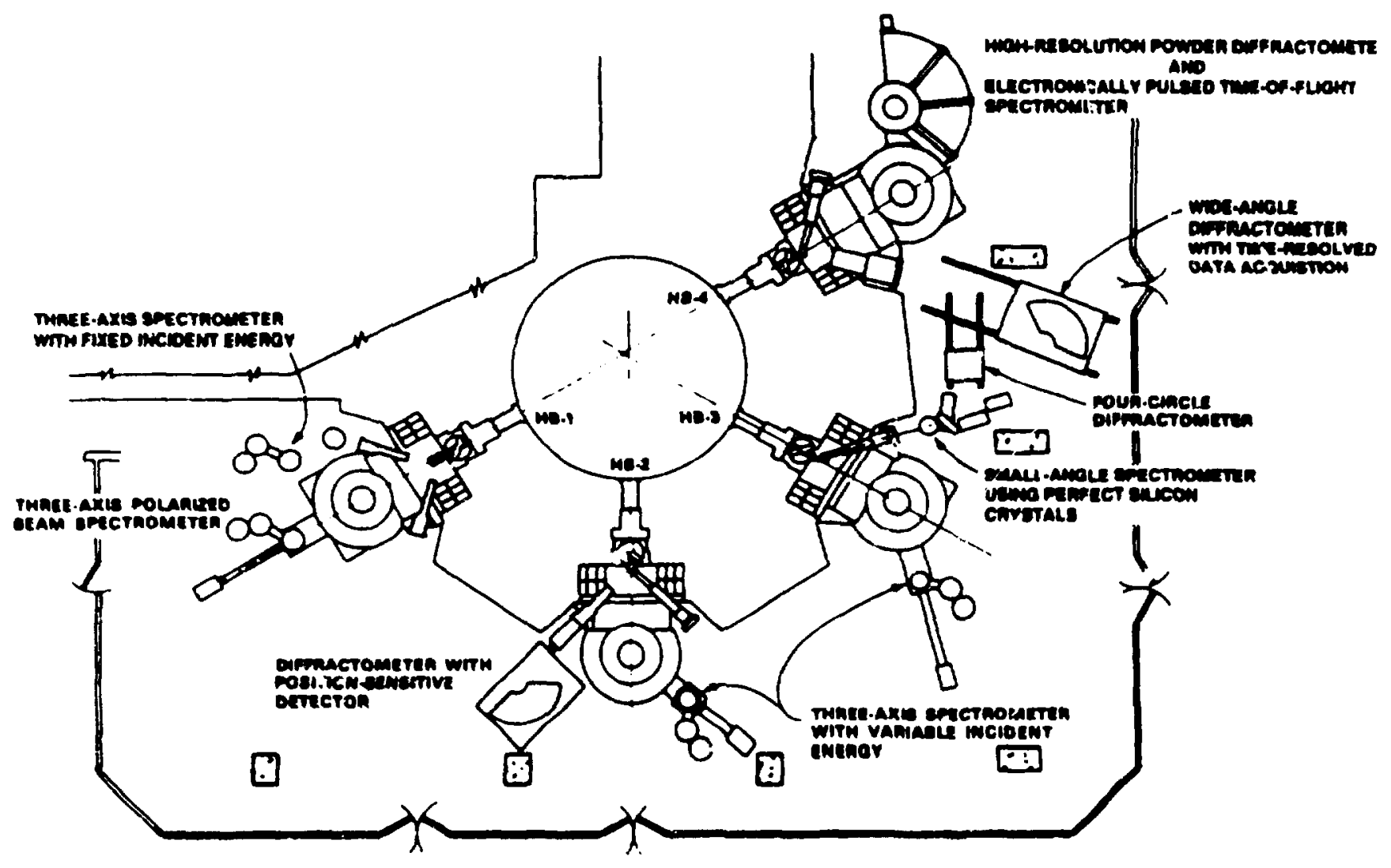

Fig. 16. Layout of the noutron scattering facillthes. 


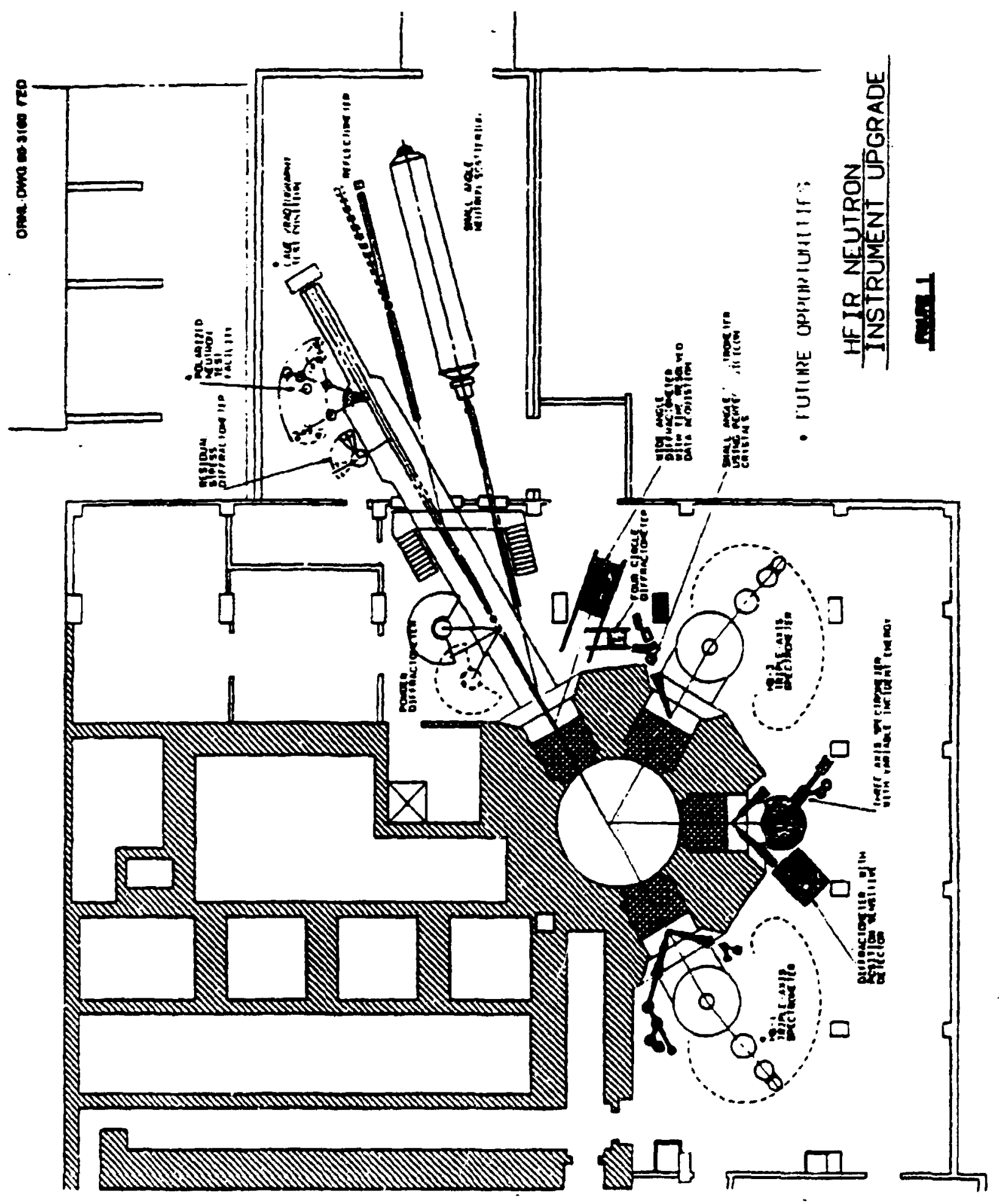




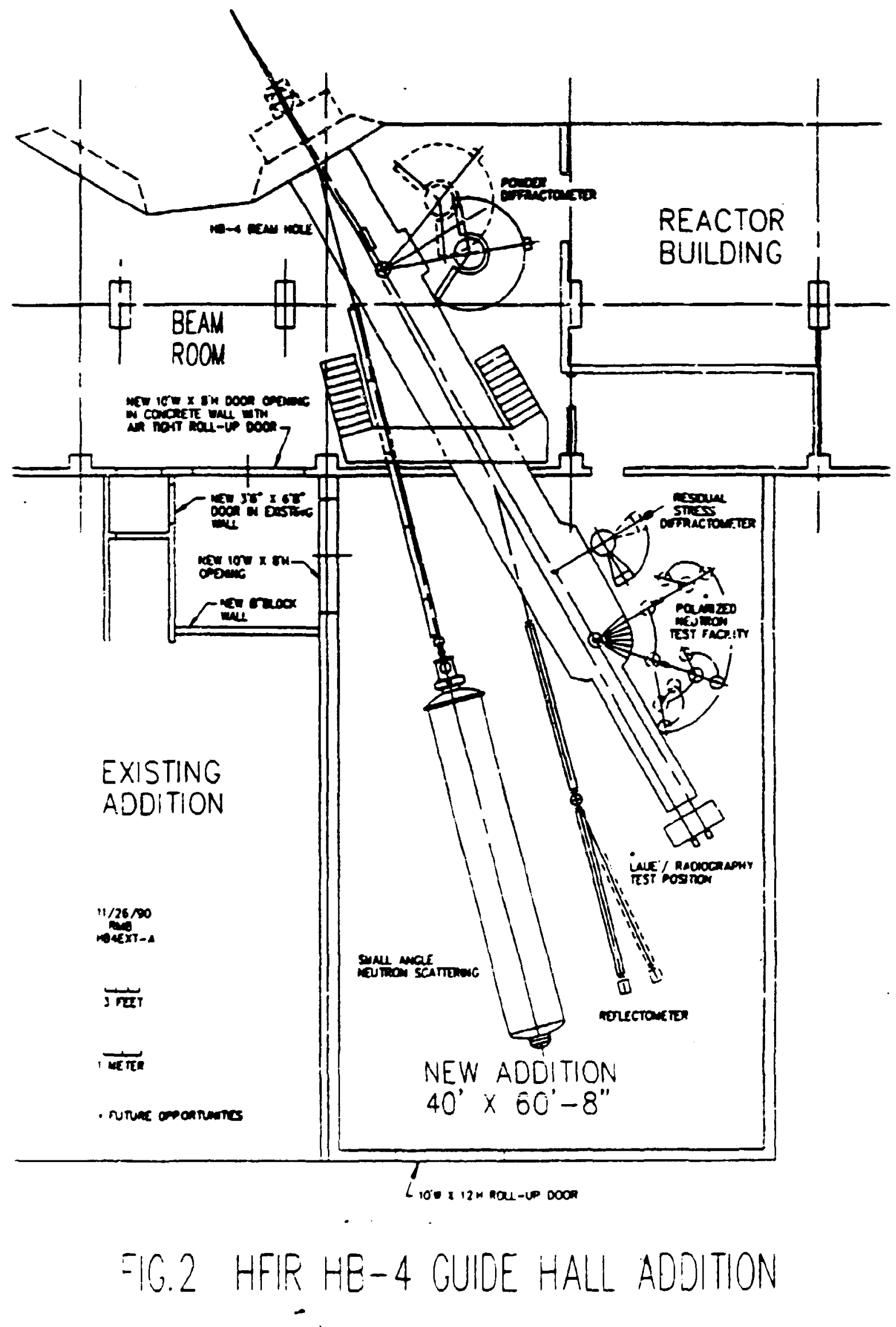




\section{Short Term}

$\square$ HFIR is still the best thermal ne!ıtron research reactor in the world. We should set priorities for beam use in areas we can make a "splash."

$\square$ That doesn't mean we push "applied science" but take every opportunity to publicize any. easily understandable application of our science.

$\square$ Safer engineering and cheaper medicine are always newsworthy.

$\square$ We are best at pinpoint residual stress. There are unexplored virgin areas here. e.g:

Thin-walled friction welds (ceramic and metal );

Medical devices: crutches, avoiding struss corrosion in artificia! joints. Only has to be done once and for all, to prove, or disprove the design. No suggestion that hip joints might be made radioactive... 


\section{Cold Source Ground Rules}

$\square$ Need a molecuiar moderator like $\mathrm{H}_{2}$ or $\mathrm{D}_{2}$.

$\square$ Cold flux gain (typically 10-20) varies as $1 / T^{2}$

$\square \mathrm{D}_{2}$ cross-section is much less than that of $\mathrm{H}_{2}$, so $\mathrm{D}_{2}$ is used if you want a big source (cf: ILL).

$\square$ Low inventory is now a bigger driver than physics, so $\mathrm{H}_{2}$ is now preferred.

$\square$ Sources since ILL (and by same designers) just use an optimal thickness of $\mathrm{H}_{2}(50 \mathrm{~mm})$ spread over the desired viewing area (e.g: Julich ).

$\square$ Saclay also reduces inventory by viewing a small source from both sides.

$\square$ The difficulty with a retrofit is often to get enough instruments to view the source to make it worthwhile. 


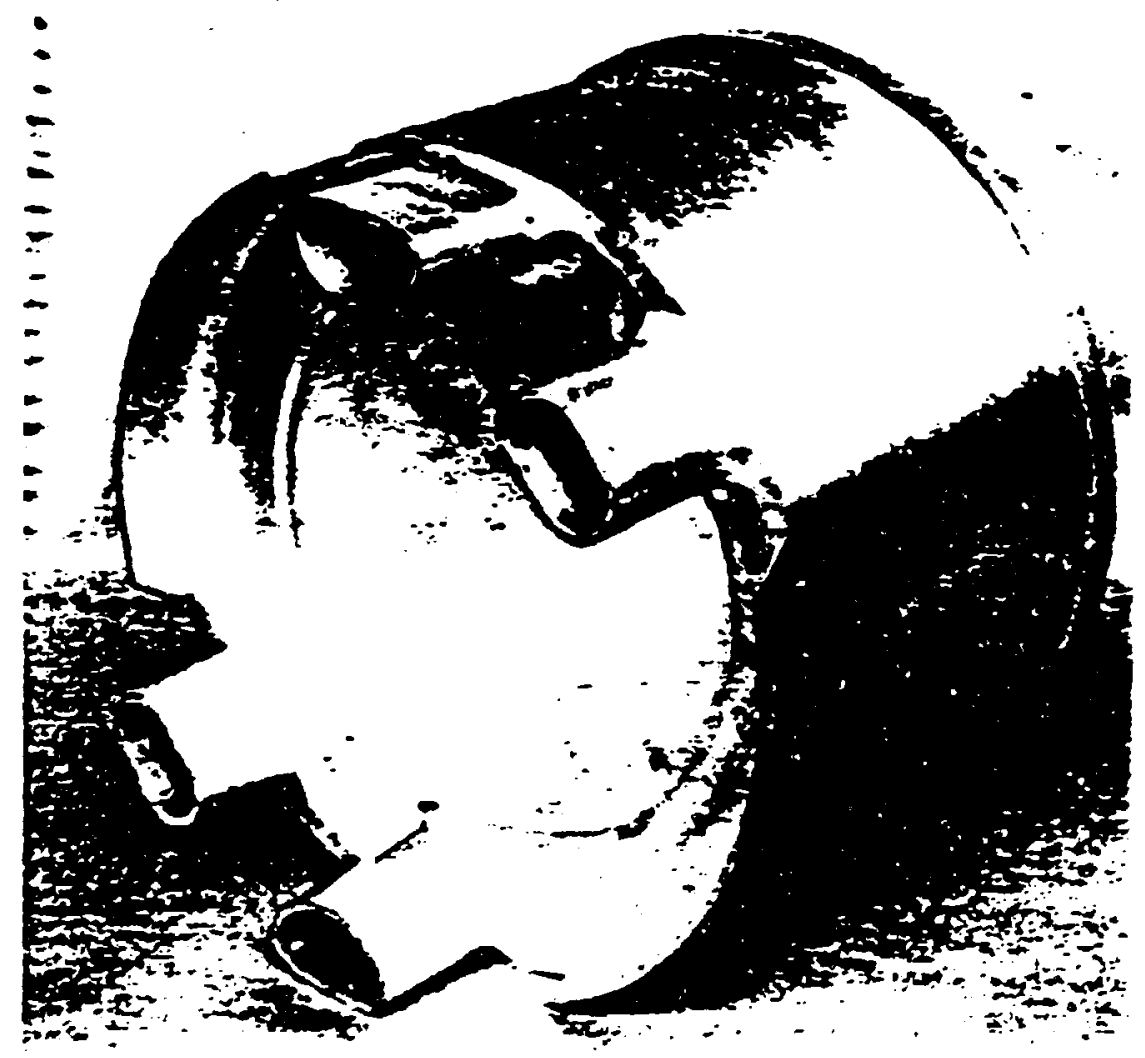

Bild 14

Moderatortopf der Kalten Neutronenquelle (TD-EV) 

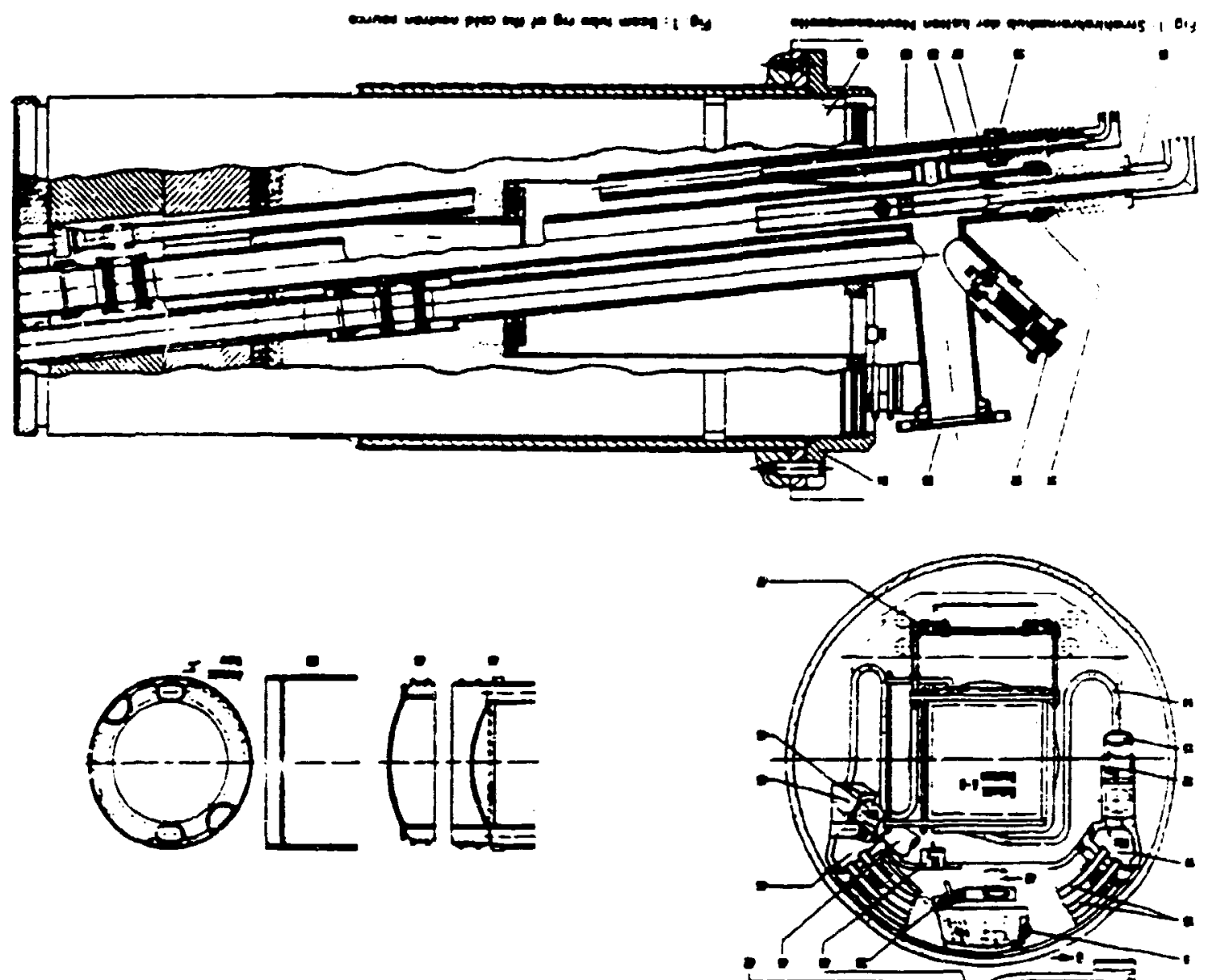

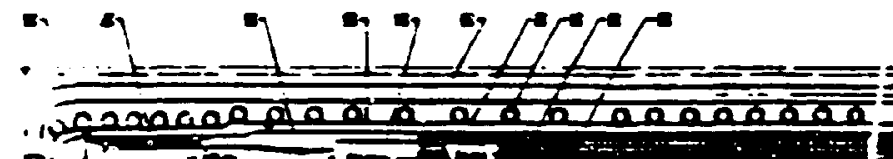
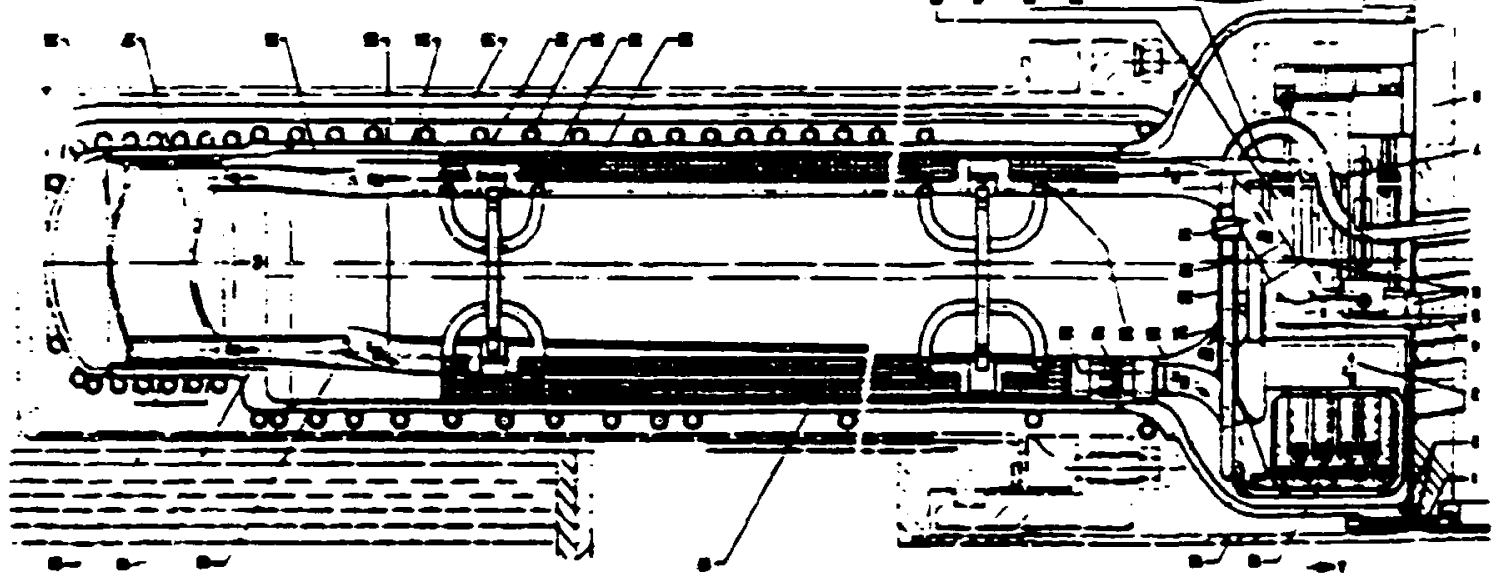


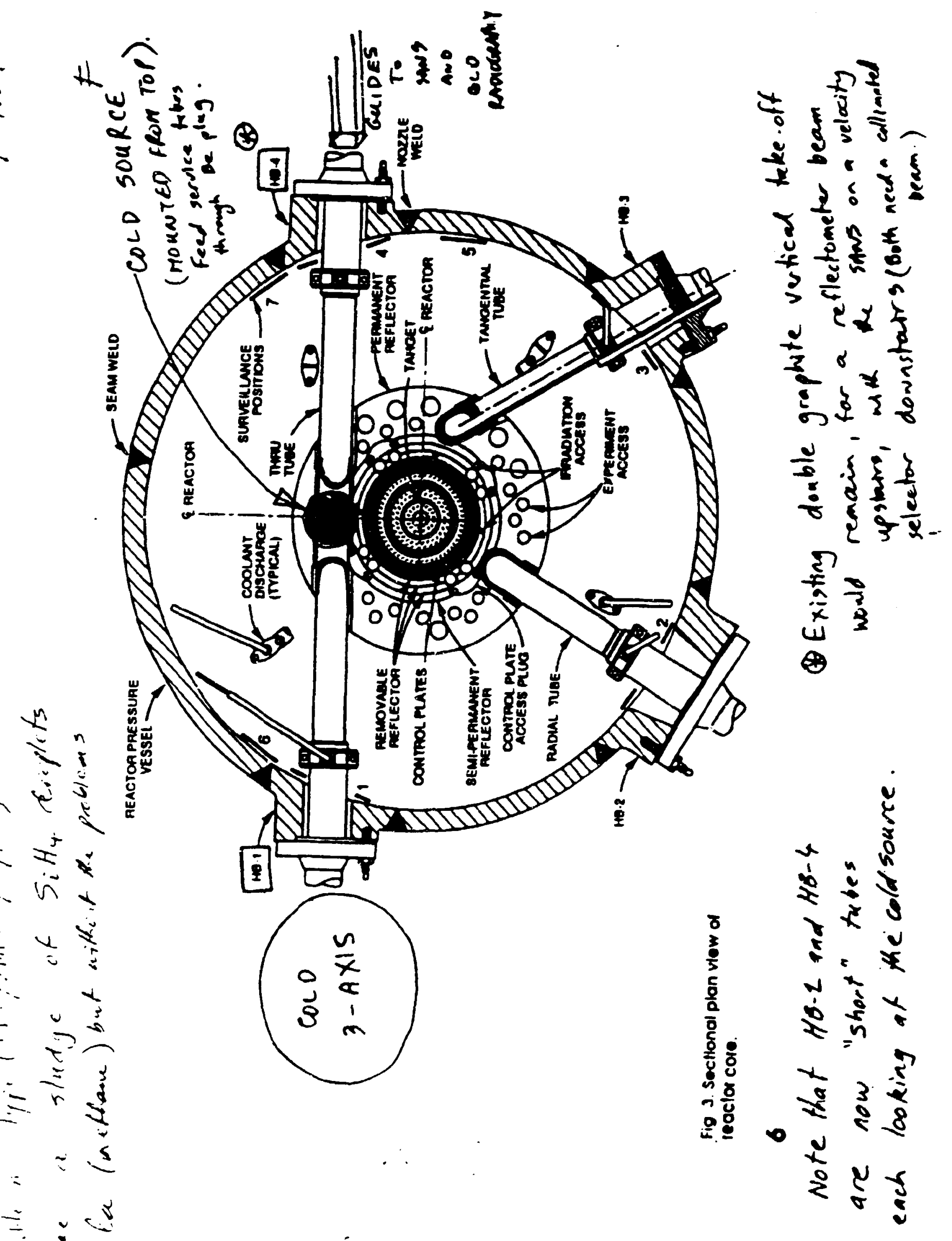


ATTACHMENT 7 


\section{INVENTORIES}

- What non-beam facilities are available at HFIR, and what use are they getting (average since restart?)

- George Flanagan?

- What beams and instruments are available, and what use (e.g., in-house vs outside users) is being made of them?

— John Hayter/Micheie Houser?

- What isotopes are being produced, who else can make them, and who uses them?

- Emery Collins?

- What proposals have been made previously for changes/upgrades?

- Colin West/Michele Houser?

- Other 
March 21, 1995

HFIR Futures Group Meeting

Attendance

The HFIR Futures Group held its second meeting at 8:30 a.m. on Monday, March 13, 1995, in the Blue Room cf the FEDC. Those in attendance were:

\author{
John Bigelow \\ Emory Collins \\ George Flanagan \\ Mike Harrington \\ John Hayter \\ Michele Houser \\ Lamy Robinson \\ Ken Thoms \\ Colin West (chair).
}

\title{
Opening
}

The meeting began with a review of the March 6 meeting minutes and was conducted according to tr. agenda shown in Attachment 1. In the discussion beginning the meeting, John Hayter remarked that the Germans had found advantages in placing a cold source in a beam tube since the reactor did not have to be taken down in order to install it. Colin West remarked that the installation of a cold source may be the highest priority of seutron beam users and ORNL management. Ken Thoms and John Bigelow had attended a meeting about the proposed changes to the beryllium reflector at the HFIR. They remarked that no beam users were at that particular meeting, but there werp irnadiation facility and isotope production users in attendance. They were asked about the schedule for the design changes to the beryllium, since the beryllium is being machined in 1996. John B. estimated that by the end of May, the group should have a good idea of the main requirements for the new beryllium. The drawings will be ready by the end of fiscal year 1995 . John $\mathrm{H}$. commented that the Icw number of staff in the scattering group precluded user representation at many meetings; however, the neutron scattering group can prioritize staff assignments in order to be able to attend important meetings. This may need to be done with respect in the beryllium study group meetings. In the course of the meeting, Colin handed out an amended version of the charter, as agreed upon in the first meeting (sec Altachment 2 of the minutes of the March 6 meeting).

Isotope production - hydraulic rabbits

John Bigelow then made a presentation on isotope production needs for the HFIR upgrade (see Aitachment 2). He suggesied that the number of hydraulic rabbits in the target island he increased as much as possible; one prossibility is to design a rabbit systen that can be exchanged, as needed, for one of the instrumented irradiation capsules. The current rabbits are not capable of withstanding a 
significant heat flux, so it is desirable to modify the new ones so that they could withstand higit rluxes. Sohn B. remarked that the facilities he described were "virtual," i.e., they have the capabulity to be installed in the future, as needed.

Isotope production - PTP, RB, and VXF facilities

Another item suggested by John B. was to provide convenient access to capsules in the peripheral target position (PTP) facilities. The PTP was originally used for neutron damage studies and can be used if the spectrum needs to be ch.siged for a particular isotope (i.e., the flux is ton high in the regular target island). Rabbits cannot be used in the ITP facilities due to the bardware. Also, some of the removable oeryllium $(\mathrm{RB})$ positions could be reconfigured to be accessible by hydraulic rabbit facilities. These lines could perhaps be interchangeable with the lines and capsules used for materials testing irradiations. Another desirabie improvement would be to make the access holes to the vertical experiment facility (VXF) a "straight shot" so that some type of on-line insertion and removal system cijuld be used. This would require the re-design of both the beryllium and the top flange but would make the processes independent of repctor operation. George Flanagan talked about this re-design in conjunction with plutonium production last week, but John B. added that it would alse aid in the production of molybdenum-99. The on-line system visualized would be similar to one used at the Oak Ridge Reactor (ORR). John H. remarked that the flux in the engineering facility (EF) tubes was almost the ORR peak thermal flux, which was also good for production of molybdenum-99. A longer core life could aggravate the problem of removing isotopes unless they could be inserted or removed during reactor operation.

\section{Isntope production - hydraulic transpont}

John B. also suggesied that the restoration of the HFIR-REDC hydraulic transport facility would be helpful. This 4-minute transit time would be a significant improvement over the 3-day time which can happen without it. The existing line was terminated when a leak occurred in the secondary 'ine at the HFIR. When this line was dug out of the ground for repair, it created the need for the HFIR-REDC transport line to be re-routed underground. Problems need to be resolved over which party has responsibility for the design and cost of the new transpon line.

Isotope production - hat cell

The last item presented by John B. was a hot cell conveniently located for the disassembly of rabbits. There was a committee 10-15 years ago to study this issue, but a dedicated hot cell was not obtained. If one were located near the pool, analogous to the one at the ORR, capsules could be readily disassembled. Gecrge remarked that if HFIR had to go to dry storage of its spent fuel elements, they would also require a hot cell. They have been looking at putting one over the critical pool (not currently in use), which would give direct access to the fuel elements. If the hot cell is big enough to can a fuel lement, it would be big enough to strip off irradiation targets or capsules. George said that manufacturers even have a portable hot cell which could be cantilevered over the pool. He went on to give the pertinent characteristics of the critical pool:

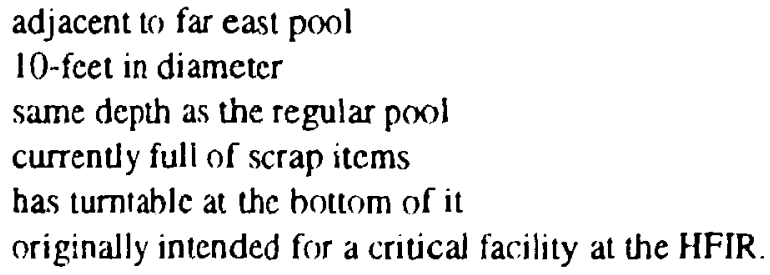


The hot cell item was in the "HFIR Life Extension" part of George's presentation last week (see Attachment 4 of March 6 meeting minutes). The idea of using the hot cell in Building 3525 has been debated in previous discussions, and it might be an option for additional consideration. That building would require some upgrade, and operating costs would need to be considered. Colin West mentioned that we could make that a part of the group's chaner.

\section{Inventory of HFIR improvement proposals}

Next, Michele Houser presented a list of past improvement proposals for the HFIR facility and handed out a few of these proposals. The information is compiled in Attachment 3. Additional studies were identified by the group. John H. remarked that a HFIR improvement proposal was made in 1975 at a Gatlinburg scientific workshop. The cold source study in the EF-2 facility was a follow-up to an instrument upgrad a called POSEIDON. The "Guide Hall Study" listed in the attachment was an accompaniment to an instrument upgrade proposal made in 1992.

John $H$. suggested we get an inventory of what has already been done. Larry, Ken, and John $H$. agreed to compile a list of what they know has been done to HIFIR's experiment facilities. It was remarked that another report exists for the HFIR-II upgrade--two studies were done around the same time period. Michele said she would get this other report. John B. said that he had not been able to find a copy of the study done on substituting plutonium for uranium-235 in the reactor fuel vet. Other group members suggested checking with Dick Cheverton to see if he could help them locate the report.

\section{Categonization of HFIR upgrades - Must do to continue operation}

Colin next did a presentation on the categorization of proposals mentioned last week. That information is summarized in Attachment 4. While discussing the "must do" items, George remarked that he had more information than he did last week on several items. The situation with the B \& W feedstock may be nore serious than thought originally. It turns out that a source of U-235 outside the United States can supply only the metal form of uranium, not the $U{ }_{3} \mathrm{O}_{8}$ form. The metal would be suitable for Advanced Test Reactor (ATR) fuel, but no HFIR fuel. HFIR is currently re-writing its white paper on beryllium replacer.zent and inservice inspection (ISI). George said that the facility presented its ideas to the DOE site office and headquarters last week, and they were better received than expected. The financial realities of the beryllium replacement and ISI are being realized. The decision about whether to do the phasing or not must be approved by ORNL management and then go up the managerial chain, eventually to DOE Headquarters. The downtime goes from 6 months to $21 / 2$ months, and the cost goes from $\$ 10 \mathrm{M}$ to $\$ 1 \mathrm{M}$ in 1997 . The machining of the beryllium is already in the HFIR operating budget $(\$ 700 \mathrm{~K})$, so the facility is going to go on with that in this next fiscal year. (The beryllium is already on-site, but it does not have the holes drilled in it yet. $A$ decision needs to be made about the hole placement soon.] The beryllium replacement will necessitate a 6-month shutdown in 1999. The proposal for the phasing has not officially been made yet. It is in the budget, which goes through the FWP process, but the approvals required for this change also go through a programmatic office. The 1997 budget submittals are due in early summer. Problems could ensue if there is only $\$ 1 M$ in the budget for a $\$ 10 \mathrm{M}$ change.

\section{Catcgorization of HFIR Upgrades - Facility or instrument improvements}

The next category that Colin presented had to do with facility or instrument improvements that would not affect the reacto: much. John $H$. asked that the benefits of the third item in this category, guide hall 
(building extension), be modified to "More space for more cold neutron instruments." He also remarked that placing a cold source in a slant tube is not good for neutron scattering research. so the wording in item 5 of this category was changed to "Cold ss urce in an existing (e.g., beam tube) facility." The benefit for this item was changed to "Would lugment ORNL's reputation as a credible national facility for major areas of neutron research." John 1 . also remarked that neutron activation users would also see this as a high priority, so these users $w$ re added to the notes for this item. A major point mentioned was that HFIR is th only significant reactor withous a cold source. If one is placed in a beam tube, it could be used instantly, and the reactor would not have to be shut down for a long period to install it .

\section{Categorization of HFIR Upgrades - Operational and fuel fabrication changes}

Colin went on to the next topic on his table--operational and fuel fabrication changes. George told us that he has authorized Cheverton and Rothrock to pursue the possibility of using HFIR's existing cores at Y-12 at the full $100 \mathrm{MW}$ power level. The cost for the analysis for this is not very high, but re-doing the safety documentation for the higher power level could be expensive. John $\mathrm{H}$. said that the greatest gains for neutron scattering work could be made by obtaining better instruments and that a $10 \%$ increase in power would not be that substantial for that type of work. However, he did say it was important to restore HFIR to running at its full capability. It was remarked that running at $100 \mathrm{MW}$ would aid materials irradiation and isotope production. There was some discussion about the definition of "low cost," operating cost impacts, and issues concerning fuel enrichment before Colin went on to the next topic.

\section{Categorization of HFIR Upgrades - Enhancements requiring some changes to the reactor}

The next category dealt with enhancements which might necessitate changes to the reactor. In discussing the items, it was remarked that changing the VXF holes does not require a new hatch, although a new hatch with "straight shot" access could be more convenient. There is a significant difference in cost between changing the hatch and changing the vessel--the vessel change is much more expensive. George then went on to tell the group that HFIR's vessel may not really be life-limiting. New studies have shown that it may be able to last until 2010, and with careful consideration, extended significantly beyond that. That led to the consideration of the next category and wording changes.

\section{Categorization of HFIR Upgrades - Major performance enhancemenulife extension}

The last grouping of suggestions involved more substantial changes to the reactor. George suggested that the wording be changed concerning the benefits of replacing the steel reflector tank. The wording about the current tank being life-limiting will be changed. In discussing the culd source, the issue of having conical beam tubes came up, and having 6-inch beam tubes which became smaller near the core was seen as a helpful enhancement. Conversation followed conceming putting in more beami tubes if the vessel were replaced. It was remarked that the small angle neutron scattering (SANS) facility showed that beams could be configured differently. George remarked that the north side of the reactor building was the only inaccessible side.

Larry Robinson proposed adding an "Administrative Changes" category, which would make reactor use more appealing to users. He gave as an example his experience with training and orientation at the National Institute of Standards and Technology (NIST) facility. Colin asked him to come up with an initial list of proposed administrative improvements for next meeting. 
Some discussion then followed about how to categorize the upgrade suggestions with regards to scheduling, funding, impacts, and benefits. The method of presenting information to Mr. Van Hook was also debated, with the idea that funure dialogues would help to structure it John $\mathbf{H}$. added that since HFIR is the best research reactor for thermal neutron scattering in the world, we do not want the addition of a cold neutron capability to impact its thermal neutron capability. Upgrades at other facilicies such as HFBR and NIST were discussed, and an additional item was proposed for the "Facility or instrument improvements" category--new, modern instruments. These new instruments could improve performance on existing beams. A modified list will be presented at the March 20 meeting.

\section{Closing}

Colin asked if anyone had anything to add, and Ken had a one-page listing of items listed by RRD (after reviewing George's slides from last week) which would also benefit material irradiations and isotope production. Ken's slide is shown in Attachment 5 . His presentation reinforced the import of several of the items in George's talk last week. It was stated that the mockup would have to be cleaned to be moved. Questions arose over the new information about the vessel's life, and George said that the new calculations had been peer-reviewed by outside analysts. Michele asked George about the life of the cooling towers, as it had been mentioned to her as an area of concern by a person in Central Engineering Services. George said that the HFIR had been doing a gradual upgrade of the cooling towers over a 4-year period--they should be sufficiently upgraded by that time. Legionnaires' disease is not a concern in the refurbished cooling towers. George remarked that the Davis-Bacon Act complicated things for their upgrade of the cooling towers: since construction work has to be contracted out through MK Ferguson, the cost is a factor of 7 greater than that originally estimated. Martin Marietta cannot go to contractors directly to get the work done due to this law. The meeting adjourned at the conclusion of this discussion.

\section{ACTION ITEMS}

Larry Robinson, Ken Thoms, and John Hayter will prepare a list of improvements already made in the HFIR facility's experiment systems.

Larry Robinson will present possible actions in the category "Administrative Changes" which would be helpful to the HFIR users. 


\section{Distribution}

HFIR Futures Group (notes for record only)

J. E. Bigelow, 7930, MS-6385

E. D. Collins, 7930, MS-6385

G. F. Flanagan, 7917 , MS-6398

R. M. Harrington, FEDC, MS-8218

J. B. Hayter, FEDC, MS-8218

M. M. Houser, FEDC, MS-82 i8

L. Robinson, 4500S, MS-6128

K. R. Thoms, 9108 . MS-8087

C. D. West, FEDC, MS-8218

For information (notes for record + attachments)

B. R. Appleton, 4500 N, MS- 6240

J. B. Ball, $4500 \mathrm{~N}$, MS-6182

R. E. Battle, FEDC, MS- 8218

H. A. Glovier, 7917, MS-6398

H. A. Mook, 7962, MS-6393

J. P. Moore, 4508, MS-6080

J. B. Richard, 7962,, MS-6391 
ATTACHMENT 1 


\section{AGENDA FOR \\ HFIR FUTURES GROUP MEETING}

Monday, March 13, 1995

$8: 30$ a.m.

FEDC, Blue room

- Discussion: Changes or corrections to $3 / 6 / 95$ meeting notes for the record

- Presentation: Isotopes (item cartied over from

E. D. Collins/J. E. Bigelow previous meeting)

- Inventory of previous proposals for HFIR upgrades

M. M. Houser

- Categorization of proposals reported at the $3 / 6 / 95$

C. D. West meeting

- Any other business 
ATTACHMENT 2 


\section{RECOMMENDED HFIR UPGRADES FOR IMPROVED UTILIZATION FOR RADIOISOTOPE PRODUCTION}

1. Increase number of hydraulic rabbits in the target island as much as possible. Hopefully 3, maybe 6

Note 1. All rabbit facilities should be modified to permit high heat fluxes - at least $1 \mathrm{MW} / \mathrm{m}^{2}$, preferably 2 .

Note 2. All facilities described herein are "virtual." That is, we would like to have the capability of installing such facilities at such time as there is a demand for them.

2. Provide convenient access to capsules in the PTP positions

3. Make several of the RB positions accessible by hydraulic rabbit facilities. These perhaps should be interchangeable with materials testing instrumentation and service lines

4. Make 6-8 VFX holes "straight through" to allow either rabbits or some other online insertion and removal system, such as Hobbs described as used on the ORR

5. Restoration of the HFIR-REDC hydraulic transport facility to move rabbits quickly to Bldg. 7920

6. Some readily available hot cell sufficient to disassemble rabbits to make the inner ampoules more easily transported 
ATTACHMENT 3 


\title{
Inventory - HFIR Improvement Proposals
}

\author{
M. M. Houser
}

HFIR Futures Group

March 13, 1995 


\section{Inventory - HFIR Improvement Proposals}

- Memorandum from E. C. Fox concerning a general purpose research reactor [1989]

- Informal study of installation of a cold source in EF-2 [1988]

- HFIR-CNR Study [1994-5]

- Report of the Materials Irradiation Facilities Improvements Committee, ORNL/TM-9709 [1985]

- Feasibility Study for the High Flux Isotope Reactor-II, XOE-247 [1984]

- Conceptual Design of a High Intensity Positron Source for the Advanced Neutron Source, ORNL/ANS/INT-56 (Appendix deals with the HFIR facility) [1994] 


\section{Inventory - HFIR Improvement Proposals (cont.)}

- Final Report of the HFIR Irradiation Facilities Improvement Project, ORNL/TM-10505 [1987]

- Guide Hall Extension Study

- Memorandum and sketches from C. D. West concerning a $\mathrm{D}_{2} \mathrm{O}$ reflector [1995]

- HFIR Life Extension (25 Years) [1994]

- Thoughts on HFIR Upgrades [1994] 
January 18,1989

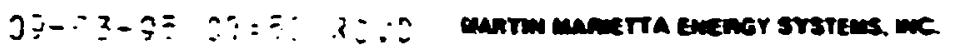

F. R. Mynatt

Thoughts on New Research Reactor

After our telephone conversation. I have discussed the proposition of a new general purpose reactor with several people here at ORWL Colin West, Trent Prima, Ken Thons, Howard Kerr, and Dnn Trauger and $J$ in Gunick of OxAU. Here are sone thoughts that have cone fron these discussions. We can see three principal uses of a new general purpose reactor:

\section{- Materials Testing \\ - Training anc Education \\ () Medical Isotope Production}

The basic assumption, on which the coments are based, is that nuclear power will make a strong comeback within the next decade and that new fuels and aterials will be developed in support of reactor improvenents and new designs. Materials testing is an area in which the Iaboratory has always been strong and should be a leader for the foreseeable future. With the shutdown of the oak Ridge Research Reactor and the uncertain future for the Bulk Shielding Reactor and its ultimate shutdown in a few years, the facilities for irradiation of materials at oRNL are limited. Without the BSR, for instance, there will be no facilities at ORNL for irxadiation of large specimens, and, in fact, the facilities in the 0.S. to perform these irradiations will be linited to a couple of university reactors (Buffalo and Virginia) that have substandard facilities. It is clear that fuel and material irradiation damage testing will continue in the foreseeable future and should becone more important as new reactor concepts are developed. Questions about the integrity of comercia: and production reactor pressure vessels underscore the importance of accurately understanding the consequences of irradiation damage. If we are aggressive, we should have a good chance of retaining our leadership in this area, and this rakes a strong argument to build a new genera? purpose reactor facility at ORHL.

Also, there will be a growing need ror nuclear training and education. The consensus is that existing university facilities are inadequate to meet present and certainly future nuclear educational needs. This view is shared by the National Research Council's Comittee on Research Reactors (Ref 1). Over the past 20 years the number of university reactors has declined from 76 to 40 and further reductions are expected. "The cowittee found that the existing population of university research reactors does not idequately fulfill the national interest with respect to the use of neutrons in the development of high technology. The effects of these deficiencies would be reduicd by better access to major national facilities, but opportunities for such access are now 
F. R. Mynatt

Page 2

January 18, 1989

inadequate." Universities have recently seen and will continue to see tighter standards for security and safety. Many will find it difficult to meet these increased demands on staff and funding and will probably abandon their training reactors. ORNL has a rich history of providing nuclear training to the nation naking a permanent mark with the oak Ridge Schoo: of Reactor Technology. Once again it appears we have the opportunity to obtain the leadership role as the Nation's nuclear training center.

The third area is one of nedical isotope production, which could be accommodated in a general purpose reactor. On the face of it. the ANS seens to be a better facility for isotope production and removing that requirement from the NS doesn't buy much.

One problem with the use of a reactor for both materials testing and training is that each usage requires a conpletely different operating strategy. Materials testing would usually require extended periods of full power operation, while a training reactor is usually most interesting during transients. One alternative is to add a facility, such as the Pool Critical Assenbly, that would be compatible with the Materials Test Reactor and use common support facilities, but operate independently.

A couple of years ago the Materials Irradiation Improvement Comittee suggested using the HFIR as a site for the next general purpose test reactor. Much of the existing equipment could be used for such a purpose, including the upgraded HFIR cooling systen, building, pool, control room, office space, etc. The cooling system should have many years of useful 1 ife and that alone would be a significant cost savings. A core configuration such as that used in the ORF or BSR could be used, although low enriched fuel should probably be considered. The reactor could be 100 un(t) without any modifications to the existing cooling system. One drawback to using the HFIR might be confinement/containnent concerns which should be evaluated. The reactor should accommodate large test specimens, and spectral tailoring should be a prime consideration in the design. A pool critical assenbly could also be included and used for training.

This seems like a good beginning but perhaps we should think broader - to a nuclear center of excellence (The Oak Ridge center for Reactor Technology) that includes the ANs, a general purpose reactor facility and more. The nuclear center would combine waining with materials testing and provide all of the suitable support facilities. In addition to the training reactor, a simulator, cafable of mimicking the operation of a nuclear plant, including support and safety systems, should be considered as part of the package. It was pointed out by $\mathrm{Jim}$ Gumnick that ORWL is not well equipped to provide for university training. There are no convenient facilities for university students to live or eat and 
F. R. Hynatt

Page 3

January 18,1989

transportation is difficult. This is also a problen that the NNS nust face. The nev reactor facilities should be integrated into one conplex that has access to dormitories, food service, and transportation to the airport. There are a number of questions ve need to address before we should proceed with this initiative. We should convene a group of potential users to better define the scope of the facility. I would reconnend a representative from ETD, RRD, MCC, Chen Tech, HESR, EPCK, and SS divisions, as well as representatives from the IRC, ANS, Fusion and Reactor prograns. Hopefully, this group could better define the potential need and progran support. In addition, Jin Gunick has offered to convene a group of their nember universities to garner their support and advice.

In sumary, we think the proposition of building a new general purpose reactor facllity is exciting and realistic. orvl should once again take the lead in nuclear technology development and this type of an initiative would direct us toward that goal. The Iaboratory has unique capabilities and facilities that we can identify and should jlace us in atrong position to be considered for such a role. The Engineering Technology Division would like to be involved in any aspect of this initiative that you think is appropriate. If I can be of any further assistance, please do not hesifate to call on ne or any of our staff.

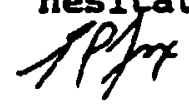

E. C. Fox, 9201-3, MS-8063, Y-12 (4-0358)

ECF:job

cc: H. T. Kerr

R. T. Primn

K. R. Thoms

D. B. Trauger

C. D. West

Ref. 1. University Research Reactors in the United states-their Bole and Value, Prepared by the Comittee on University Research Reactors, Energy Engineering Board, Comission on Engineering and Technical Systems, National Research Council, National Academy Press, Washington, DC, 1988. 
March 25, 1988

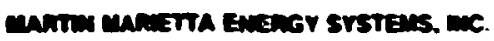

R. H. Moon

Installetion of a Cold Neutron Source at HFIR

As you know, John hayter. Blll Montgonery and Ted Ryan have been preparing a cost estinate for converting the EF-2 facility at HFIR Into a neutron source for scattering work; in particular they have been studying the possibility of installing a cold neutron source.

The results of their work are very interesting and, I think, important. An outline design for installing a moderacor (for example, polyethylena) in the EF-2, with mininue changes to the reactor and no changes to the reactor pressure boundary has been prepared. This installation could be Phase I of the proposed project and would provide a very useful extra beam line for scattering. Phase II vould install equipnent to cool the noderator to liquid nitrogen teaperature, vith a consequential gain in cold neutron flux. Phase III vould add a helium refrigerator using the nitrogen systew for precooling. allowing the aoderator to be operated at approximately $4 \mathrm{~K}$ with a further gain in cold neutron flux. The cost estimates are shown belov: note that these are "unofficial" - that is, they vere prepared by Ted Ryan, on the basis of experience and manufacturer's quotes and not by the professional estimators of Martin Marletta Energy systems Engineering; an official cost estimate vould cost $-\$ 4,000$ to prepare.

Phase I Moderator block and access tube $\$ 150,000$ design, fabrication and installation (incl. Sot contingency)

Phase II riquid nitrogen systed plus Installation ( 10 s contingency)

$\$ 178,000$

Phase III Heliun system plus installation (12. contingency)

$\$ 576,000$

Attachwent I gives a me detalled breakdown. Atcachment 2 1s Ted Ryan's study. Please let we know if there is anything further I can do to help you pursue this opportunity to provide a cold neutron source at ORNL.

C. D. West, FEDC $(4-0370)$

$$
\begin{aligned}
& \text { ¿ } 49 . \\
& \text { FEDC }(4-0370)
\end{aligned}
$$

$C D W: k f r$

$$
\begin{aligned}
& \therefore \text { ar 19i8 }
\end{aligned}
$$

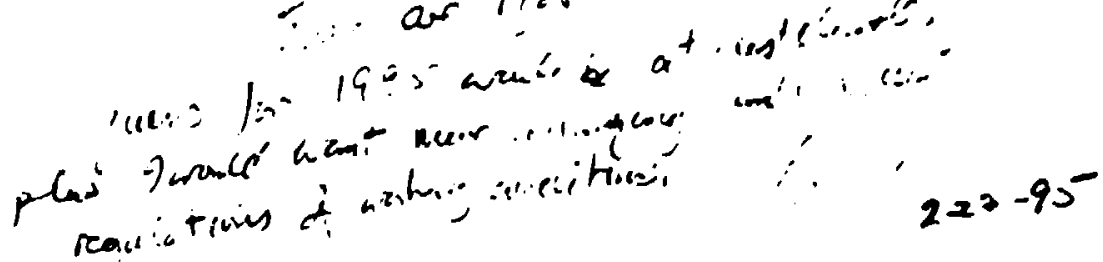


R. M. Moon

Page 2

March 25, 1988

Atrachuents

1. Cost Estinates

2. Meno, T. L. Ryan to C. D. Dest and B. H. Montgonery, dated March 21, 1988

cc/att: B. R. Appleton

J. B. Hayter

B. H. Montgonery

F. R. Kynate

T. L. Ryan

H. E. Tramell

F. U. Young, Jr.

A. Zucker 


\section{Atcachment 1 - Cost Estinates}

Phase I - roon ceaperature moderator

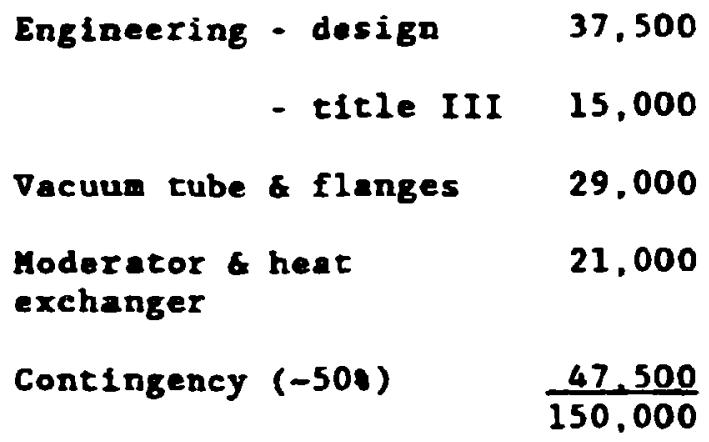

Phase II - liquid nitrogen

Installation drawings

10,000 cemperature moderator

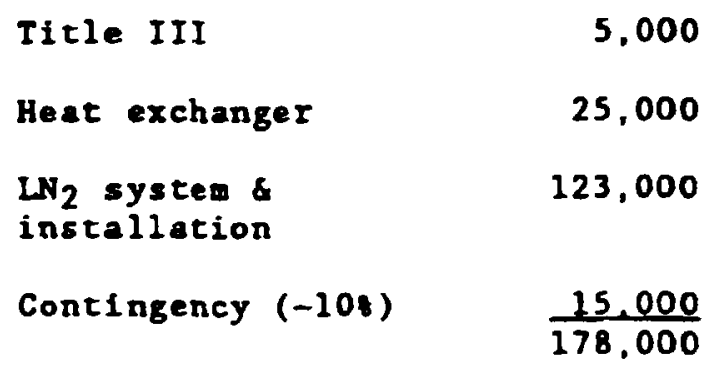

Phase III - liquid helium tenperazure moderazor

$\begin{array}{lr}\text { Installation drawings } & 20,000 \\ \text { Title III } & 5,000 \\ \text { Heliun refrigeration } & 348,500 \\ \text { systen } & \\ \text { Installation } & 153,000 \\ \text { Contingency }(-108) & \frac{49.500}{576,000}\end{array}$

\section{Sumnary}

Phase I $\$ 150,000$

Phase II $\$ 178,000$

Phase III $\$ 576,000$ 
Karch 21, 1988

C. D. West

B. H. Hantgonery

Cost Istimate for FipIR old source

Attached are viengraphs and a conceptanal cost estimate for the hFIR oold source. As you will note, nost of the cost is associated with the helium refrigerator. The cost shom is for a roch Yodel 1630 unit. A Model 1430 with the maximm rumber of compressions would work and cost $\$ 35,000$ less, but I an recommending the larger unit because it provides for uprating its capacity frem 133 watts to 218 watts. This provides growth potential at modest cost $(\$ 86,000$ today) if needed for a future cold source with a higher thermal load.

Ted L. Ryan, Brag. 9204-1, MS 15, 4-1502

TIR: Idg

c: K. K. Chipley

M. L. Goins

J. K. Jones

Attachments 


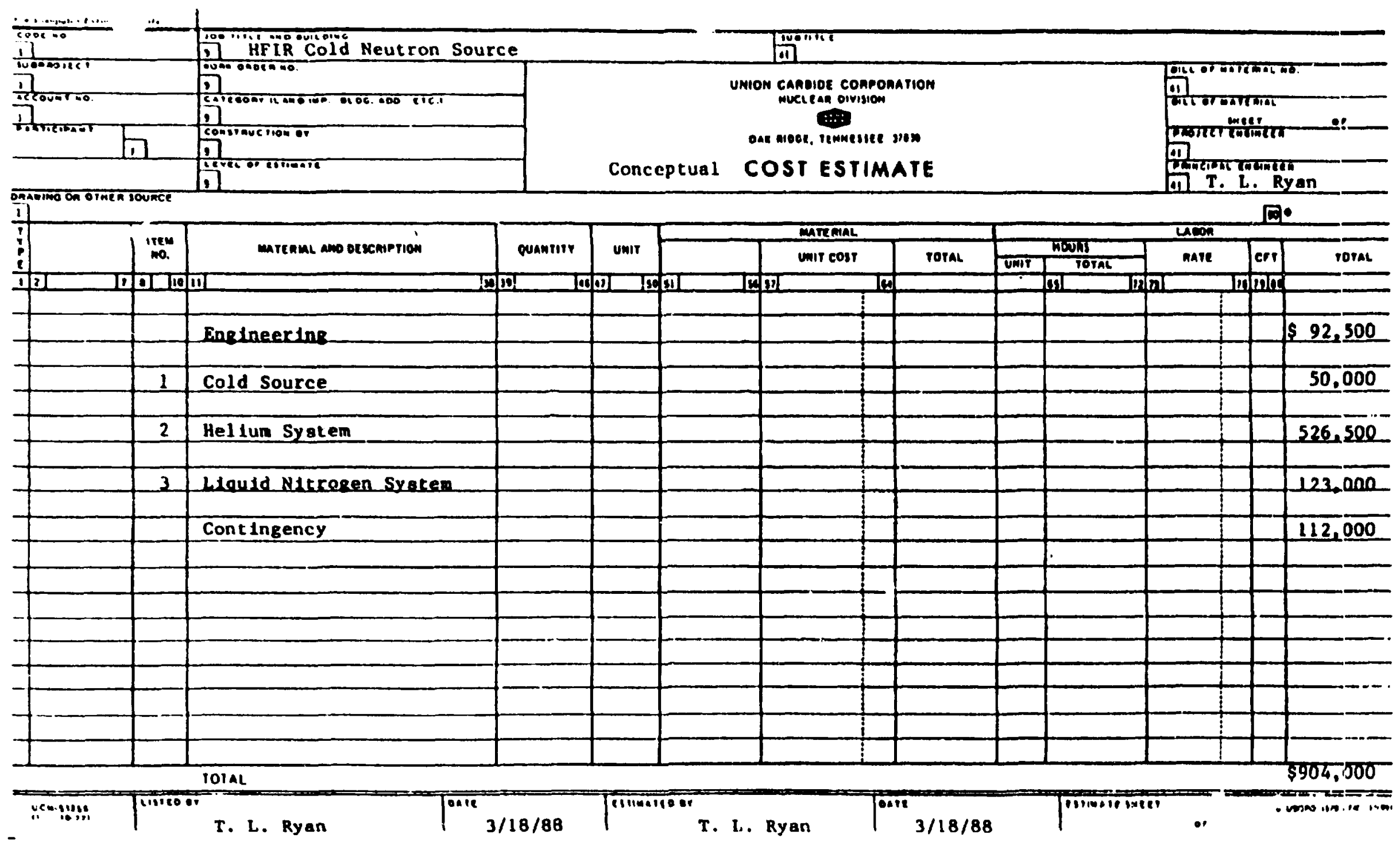




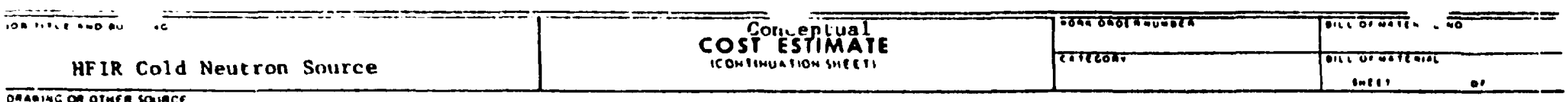

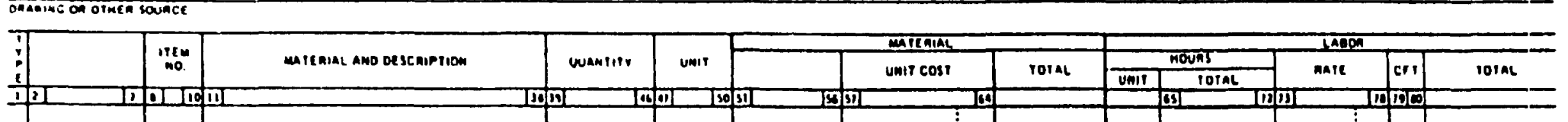

\begin{tabular}{|c|c|c|c|c|c|c|c|c|c|c|c|c|}
\hline $42 \quad 1$ & DI] & III & ODI & DIII 150 & 可 & प्य & & 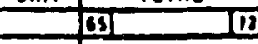 & ain & & ग्ण & \\
\hline & & & & & & & & & & & & \\
\hline & 1 & Cold Source & & & & & & & & & & \\
\hline & & & & & & & & & & & & \\
\hline & & Vacuum Tube Flanges & 1 & Ler. & & $\$ 10.000$ & 510.000 & 500 & 38 & 00 & & $\$ 29.0012$ \\
\hline & & & & & & & & & & & & \\
\hline & & Moderator Heat Exchange & ef & each & & 2,000 & 2,000 & 500 & 38 & 00 & & $21,001)$ \\
\hline & & & & & & i & & & & 1 & & \\
\hline & & & & & & 1 & & & & & & \\
\hline & & & & & & i & & & & & & \\
\hline & & & & & & & & & & & & \\
\hline & & & & & & & & & & & & \\
\hline & & & & & & & & & & & & \\
\hline & & & & & & & & & & & & \\
\hline & & & & & & & & & & & & \\
\hline & & & & & & & & & & & & \\
\hline & & & & & & & & & & & & \\
\hline & & & & & & & & & & & & \\
\hline & & & & & & & & & & & & \\
\hline & & & & & & & & & & & & \\
\hline & & & & & & & & & & & & \\
\hline & & & & & & & & & & & & \\
\hline & & & & & & & & & & & & \\
\hline & — & & & & & 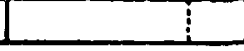 & & & & & & \\
\hline
\end{tabular}

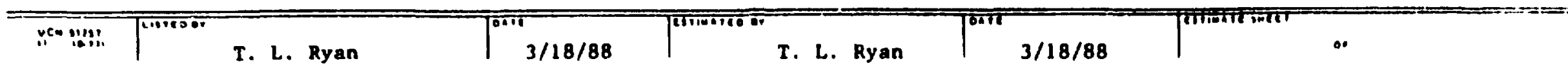




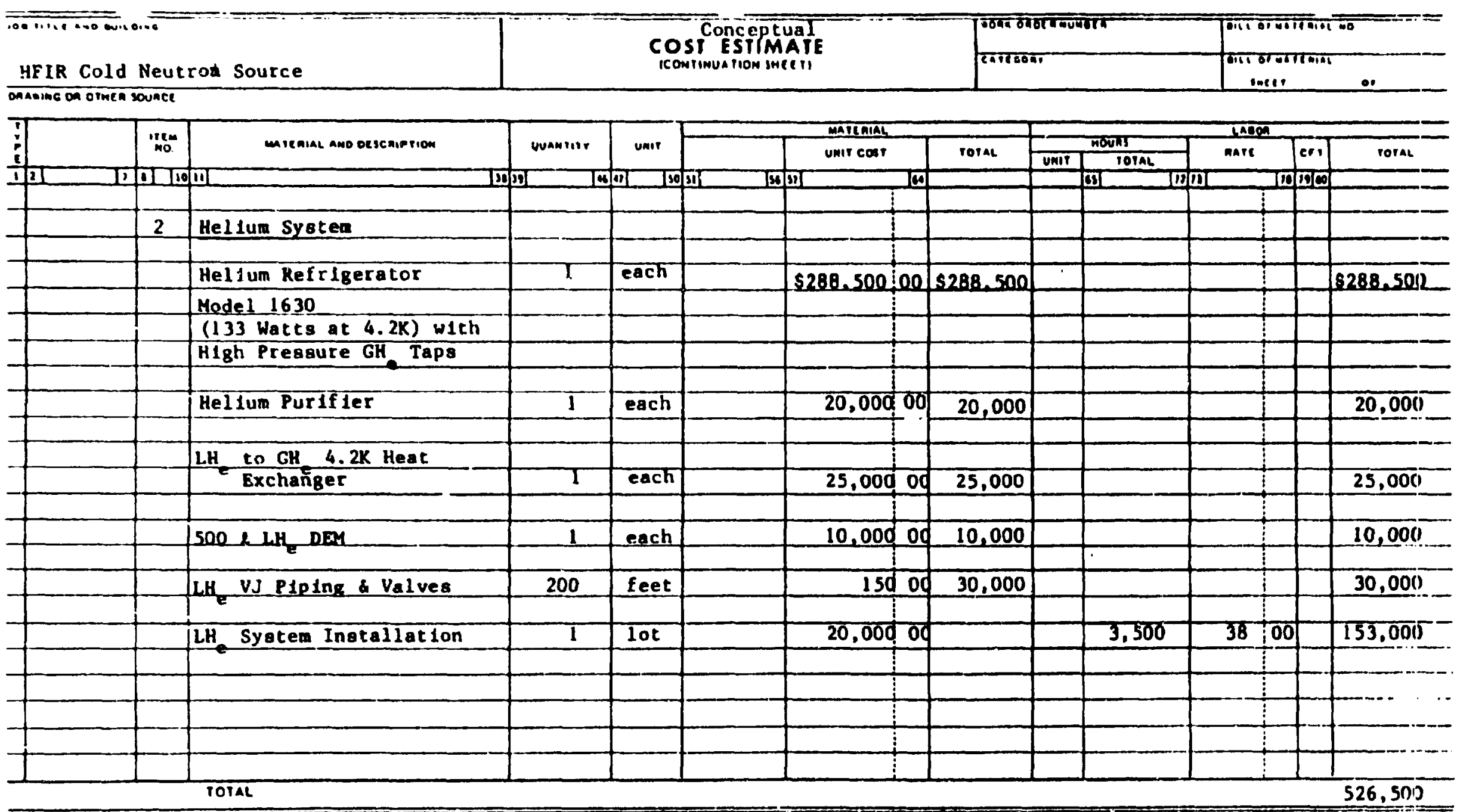

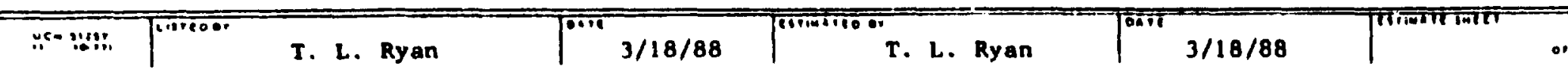




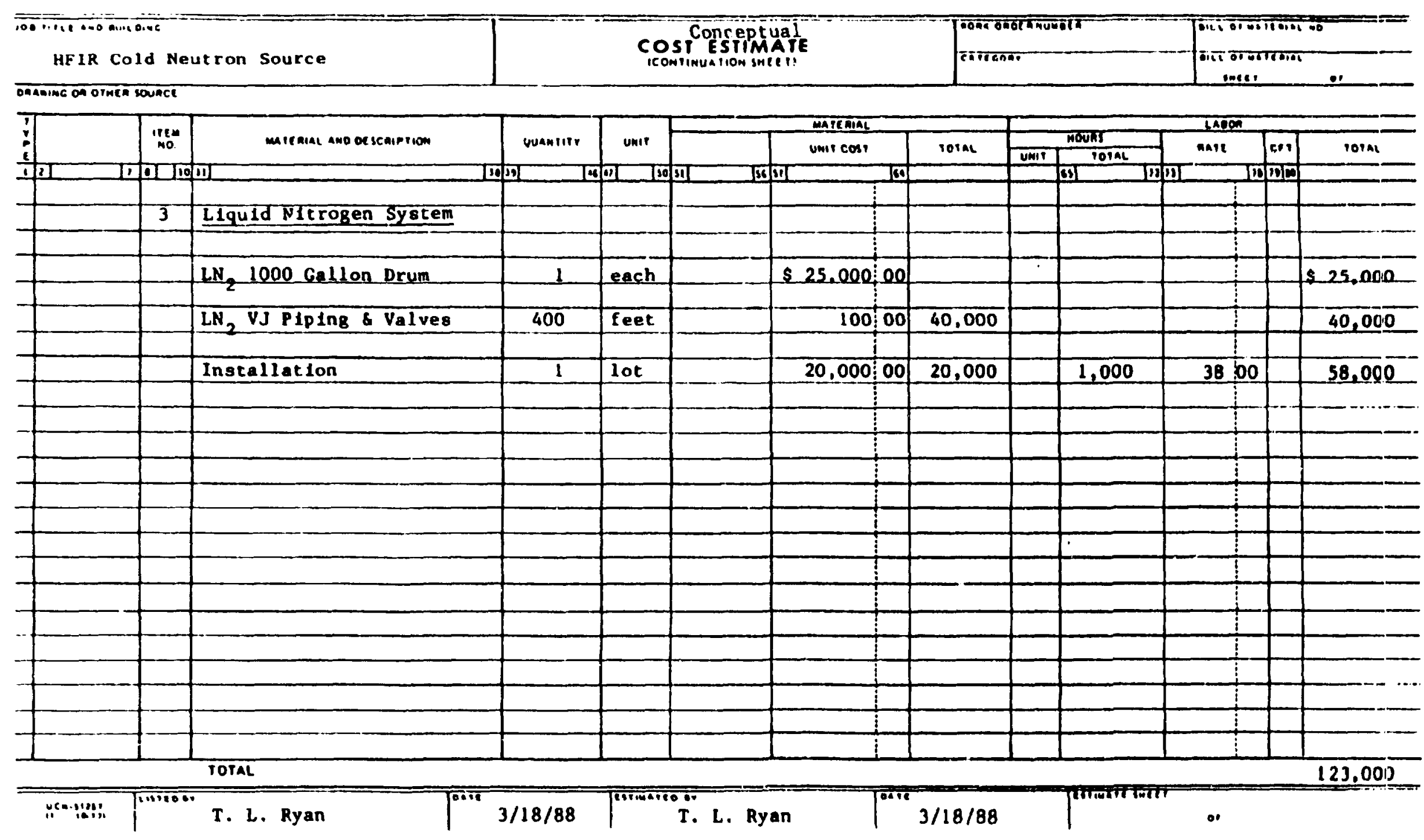




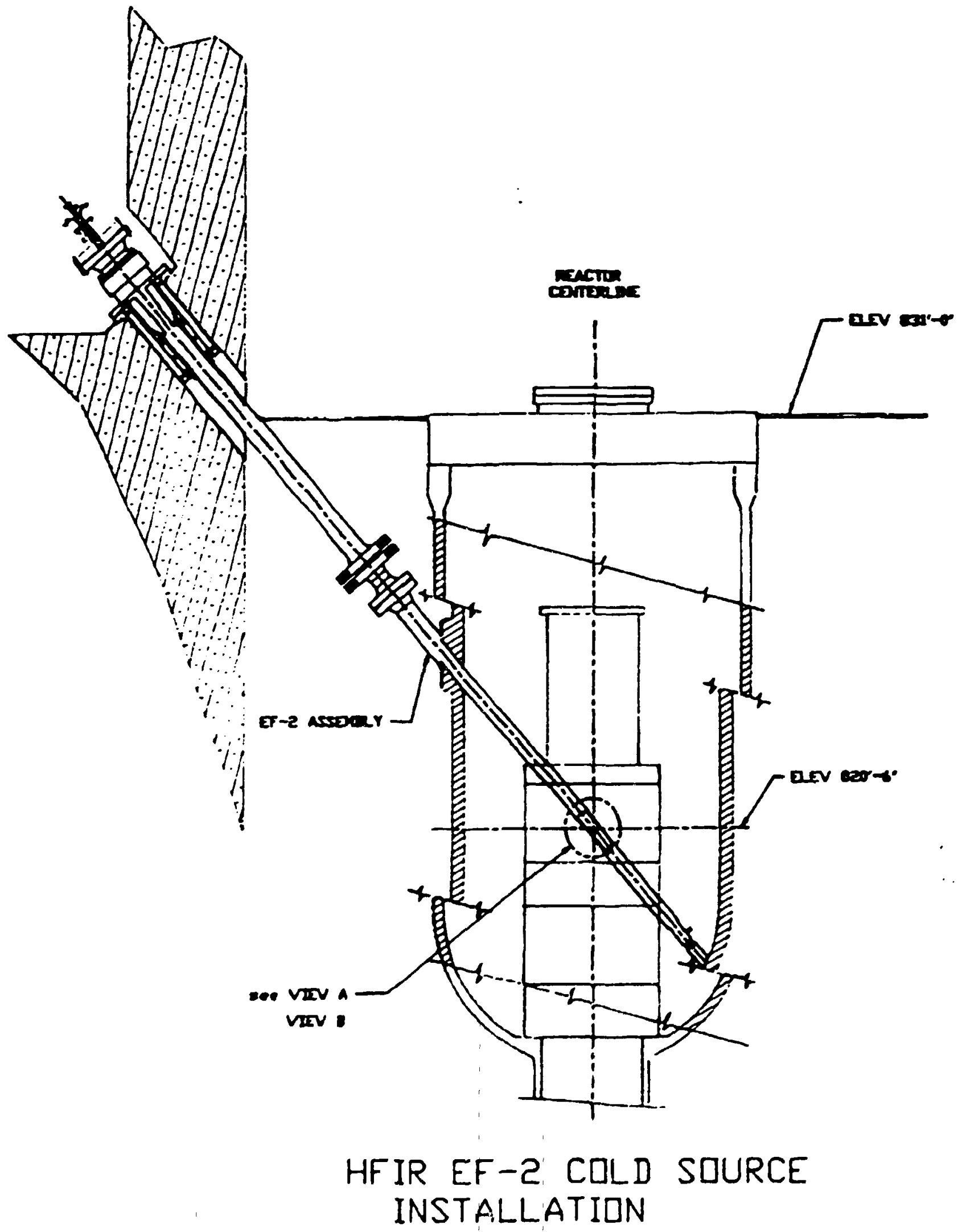




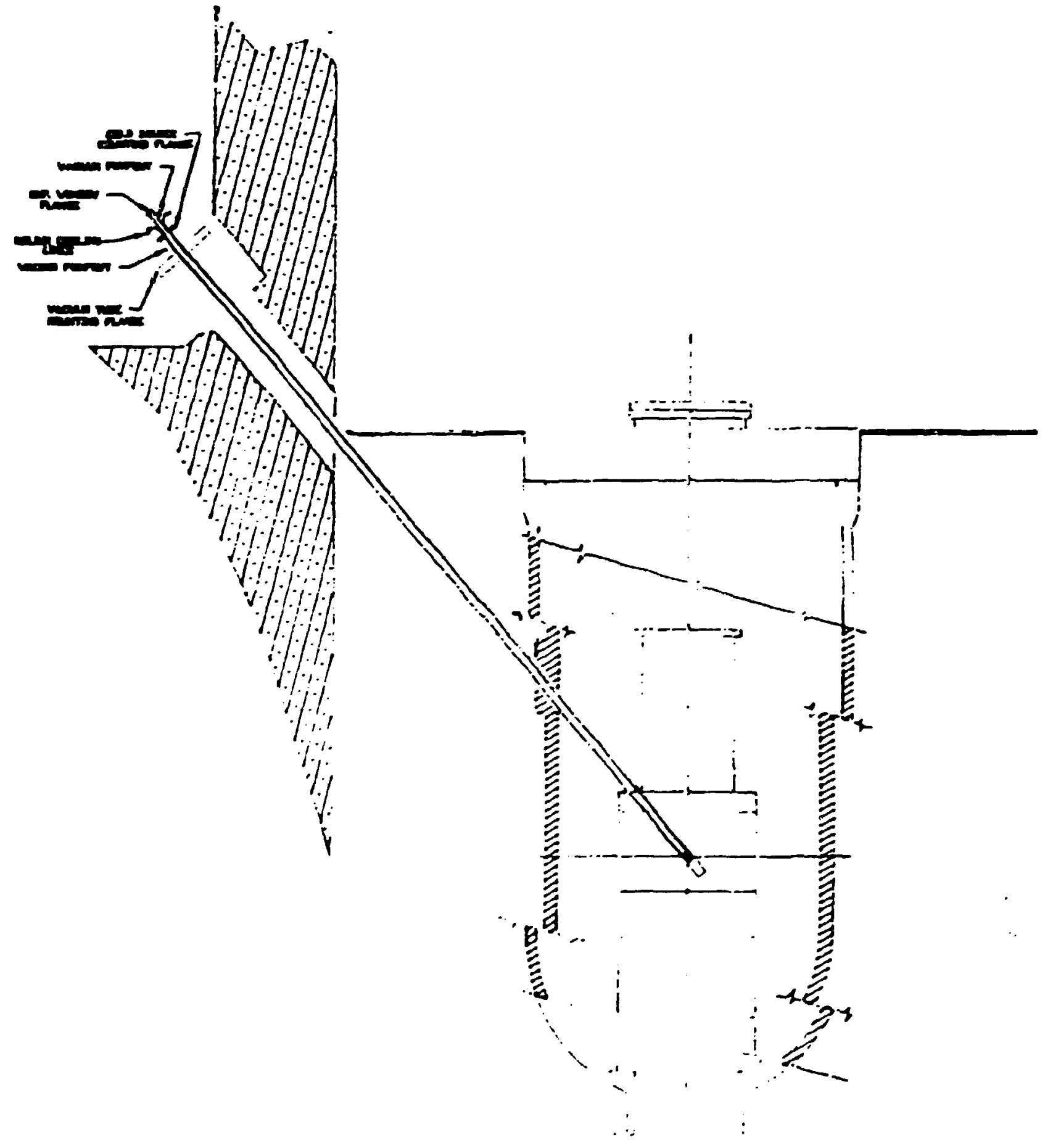

HFIR EF-2 COLD SQURCE NEW HARDWARE 


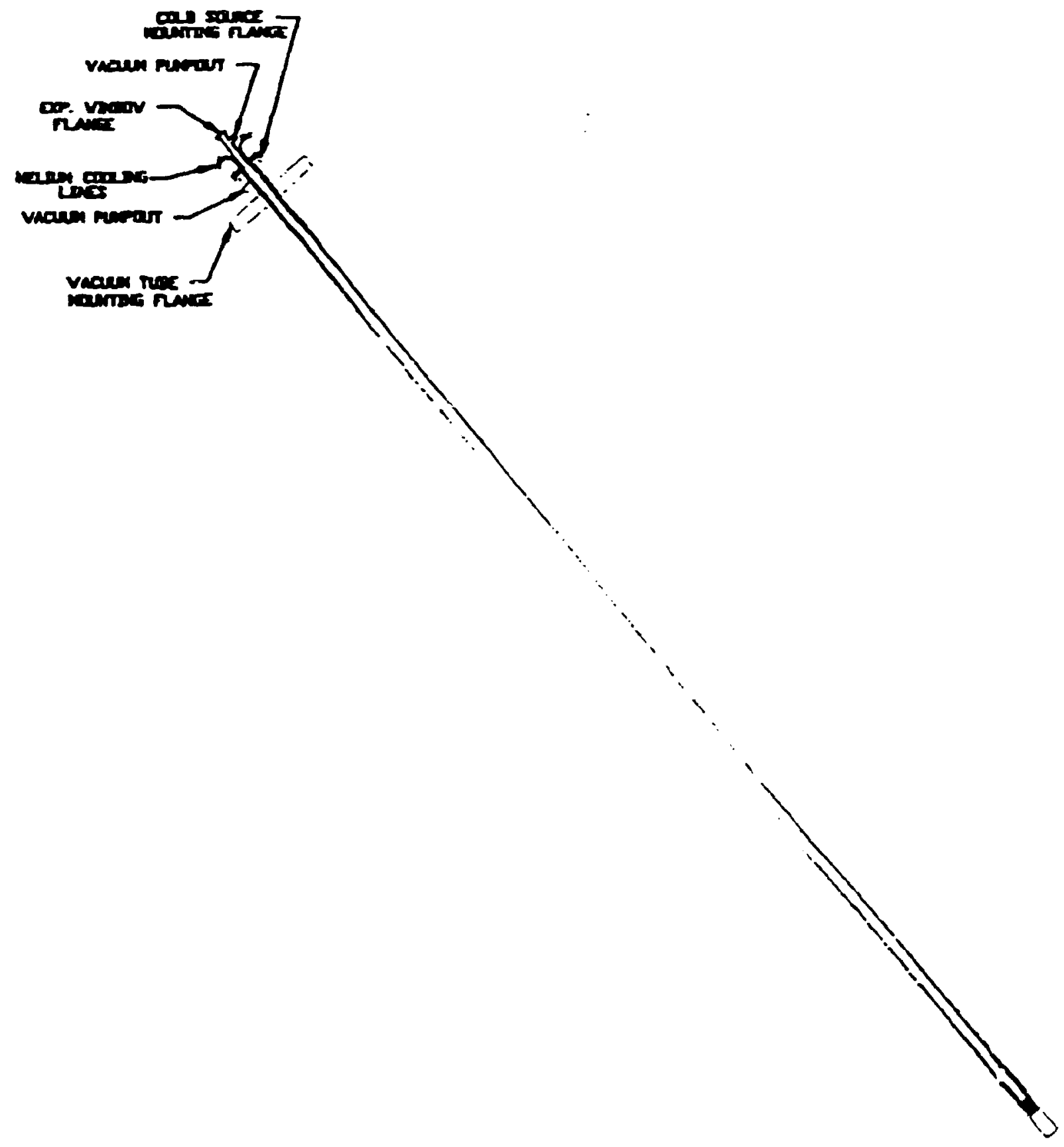




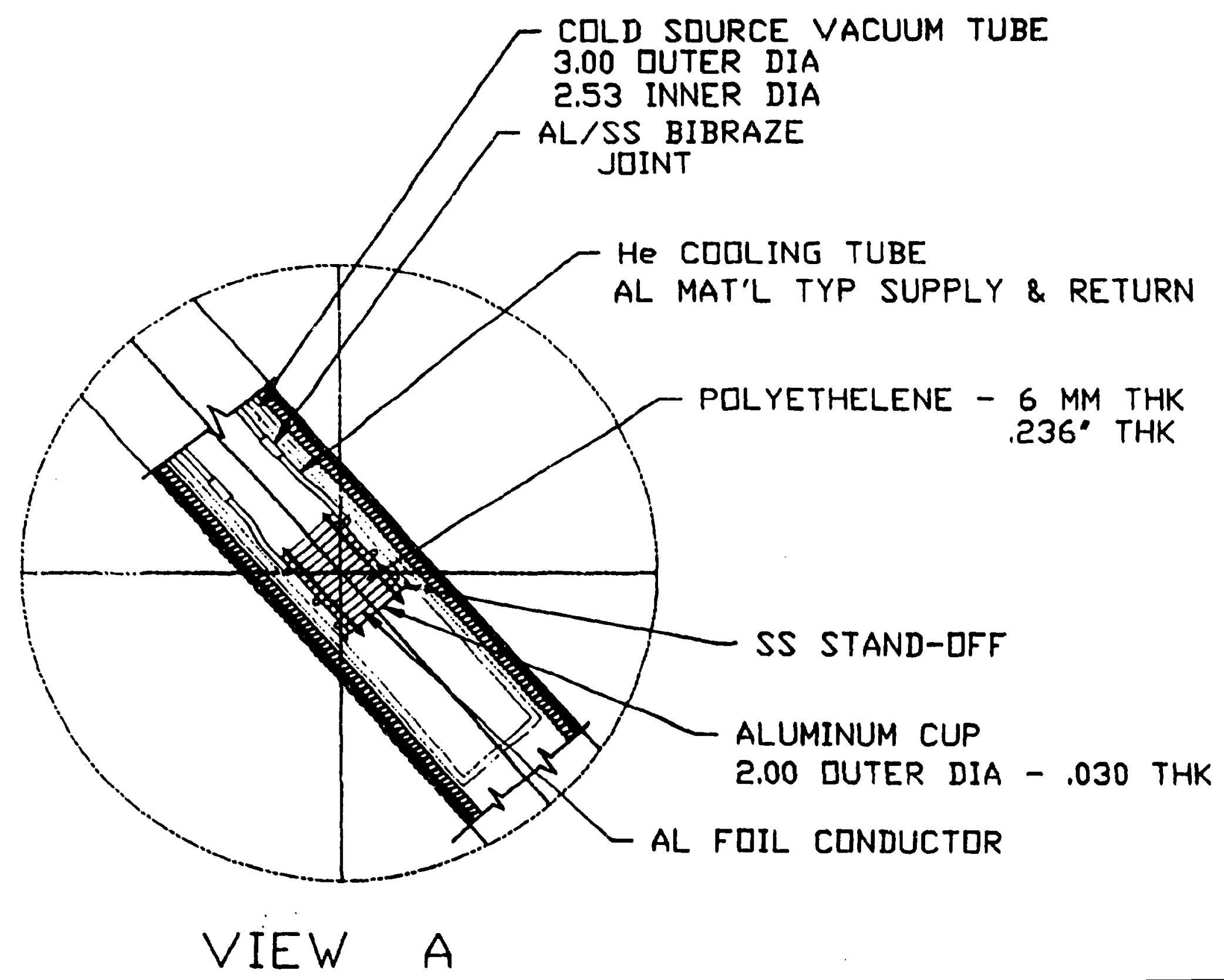




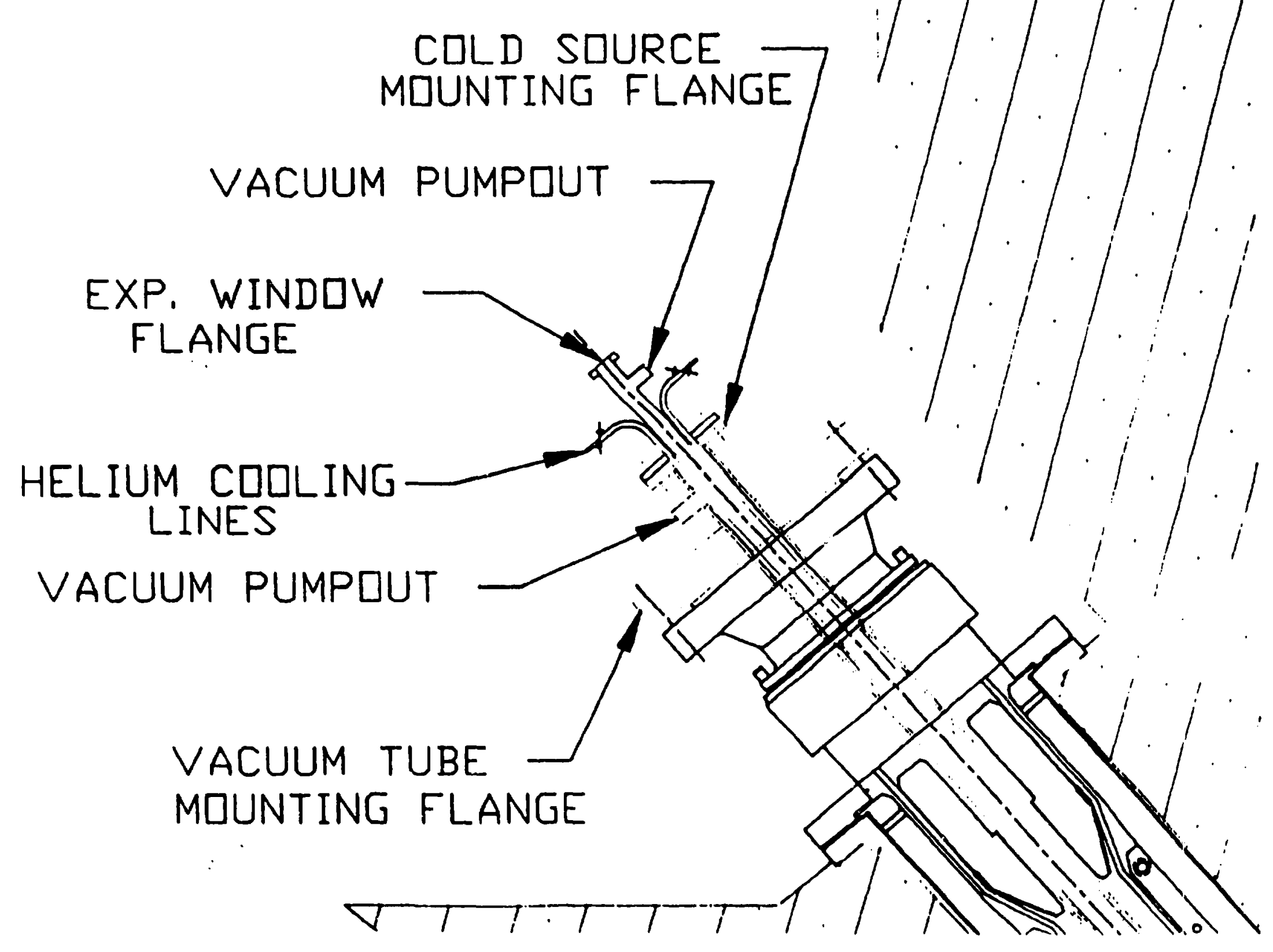




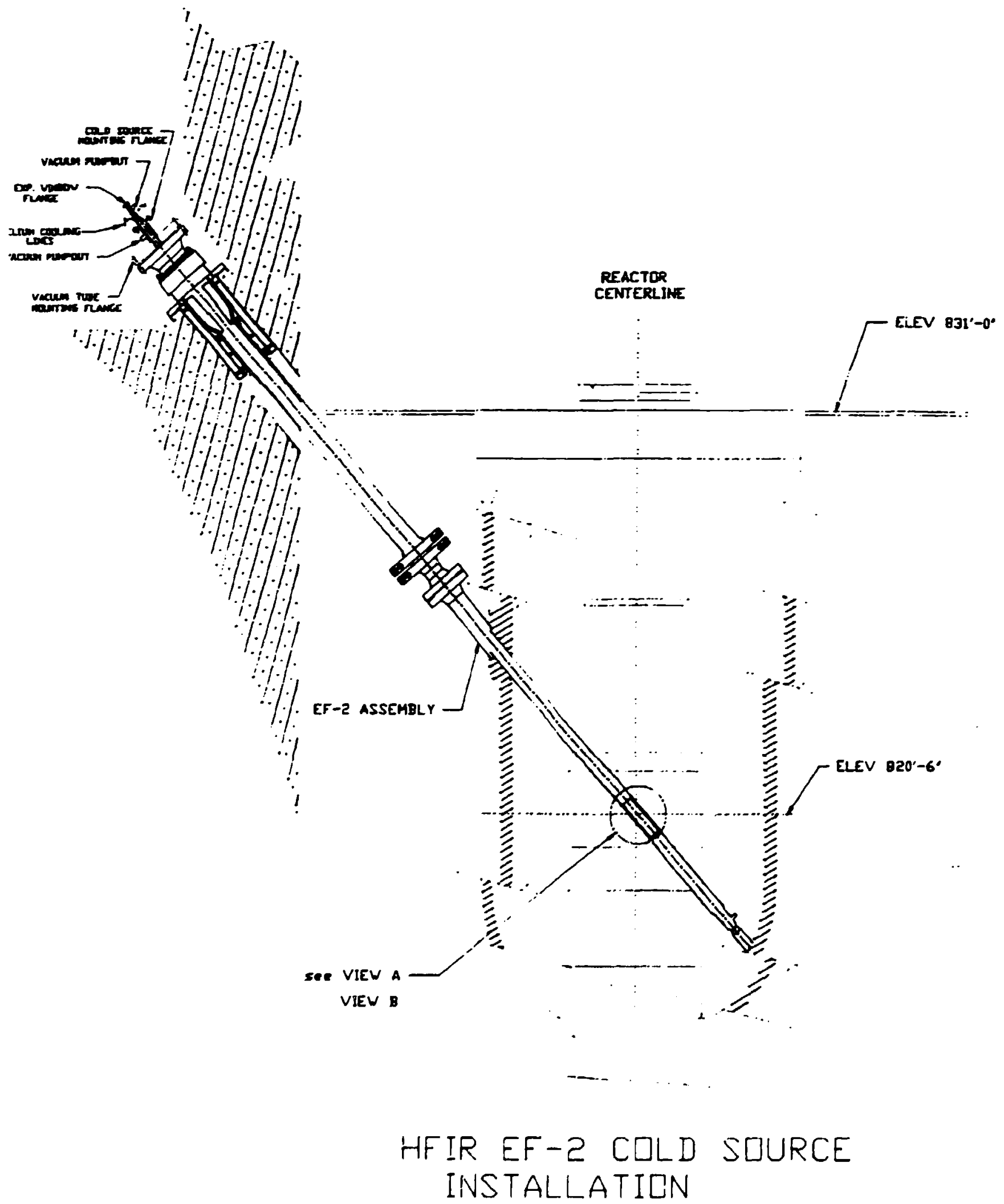



-. CIJIT SIUJRCE VACUUM TIJBE 3.00 DUUTER DIA 2.53 INNER DIA
- AL/SS BIBRAZE JIJINT

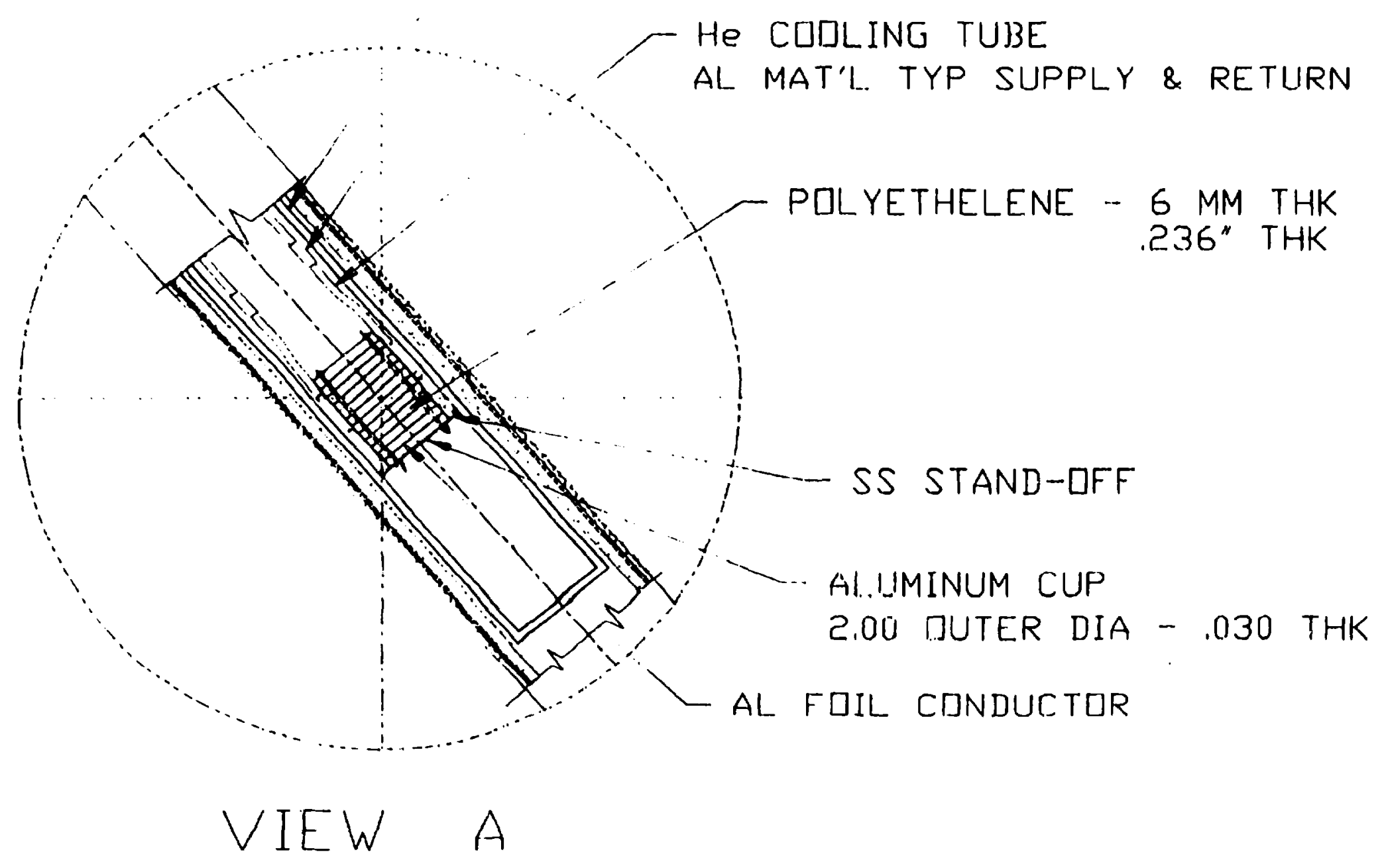




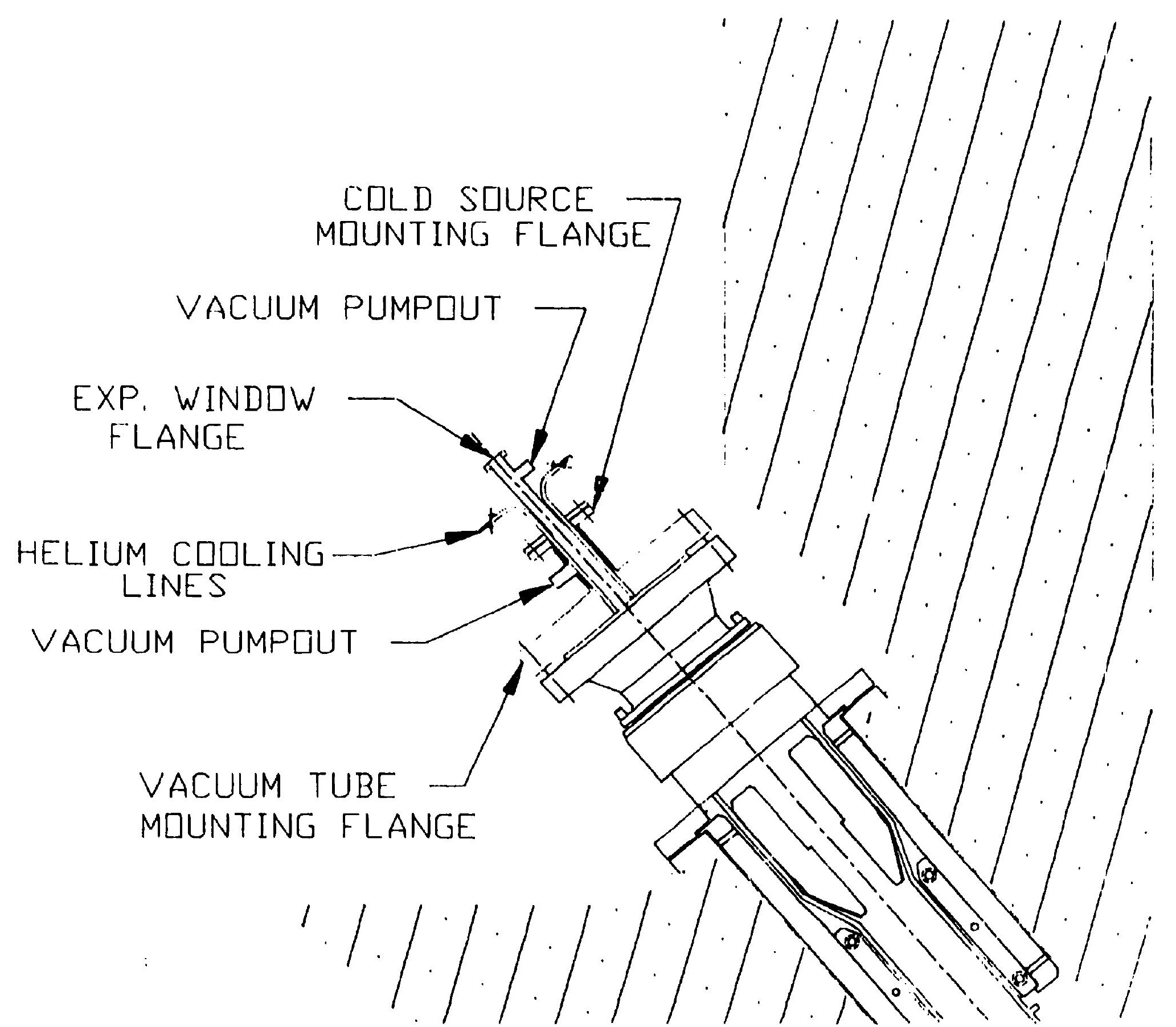




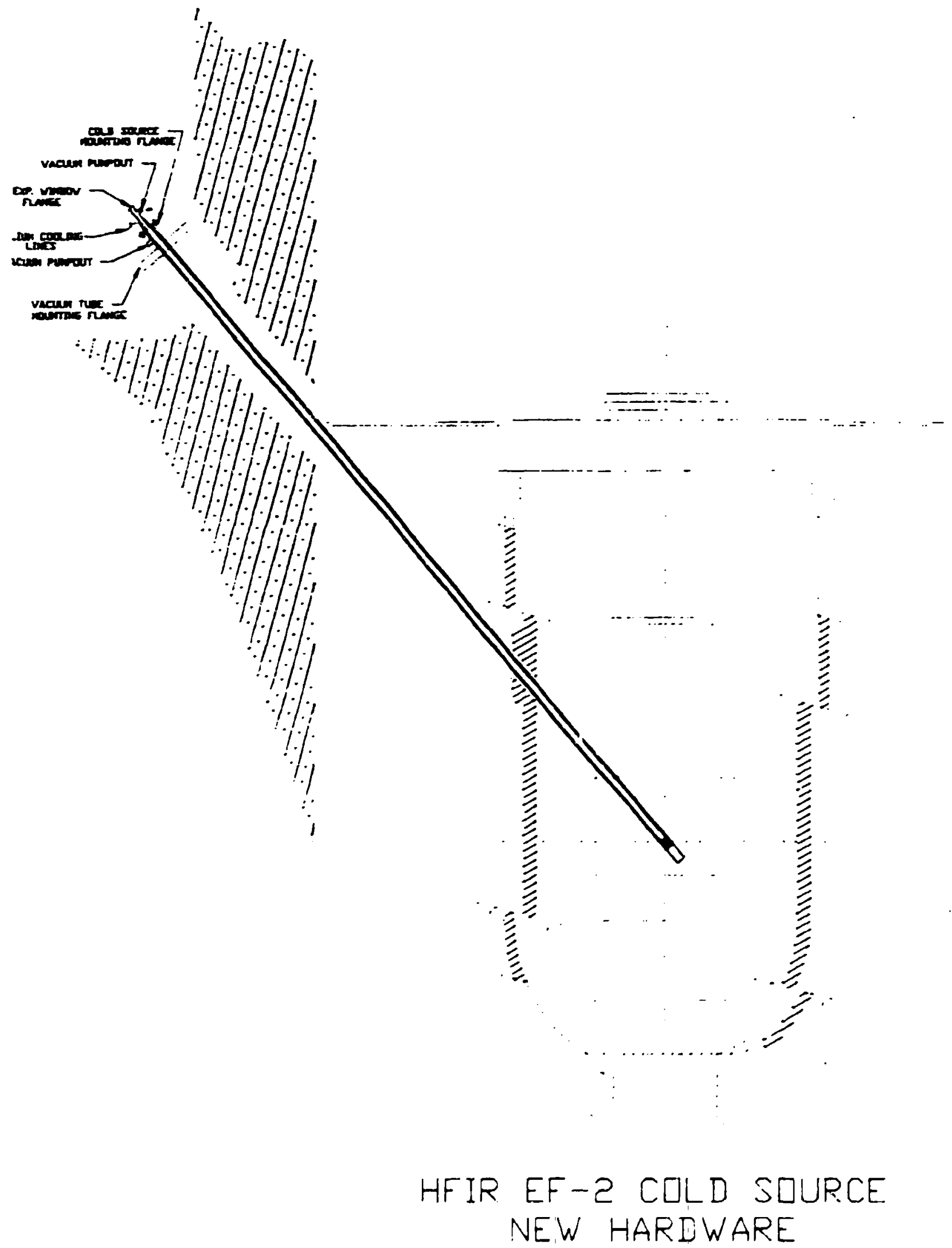




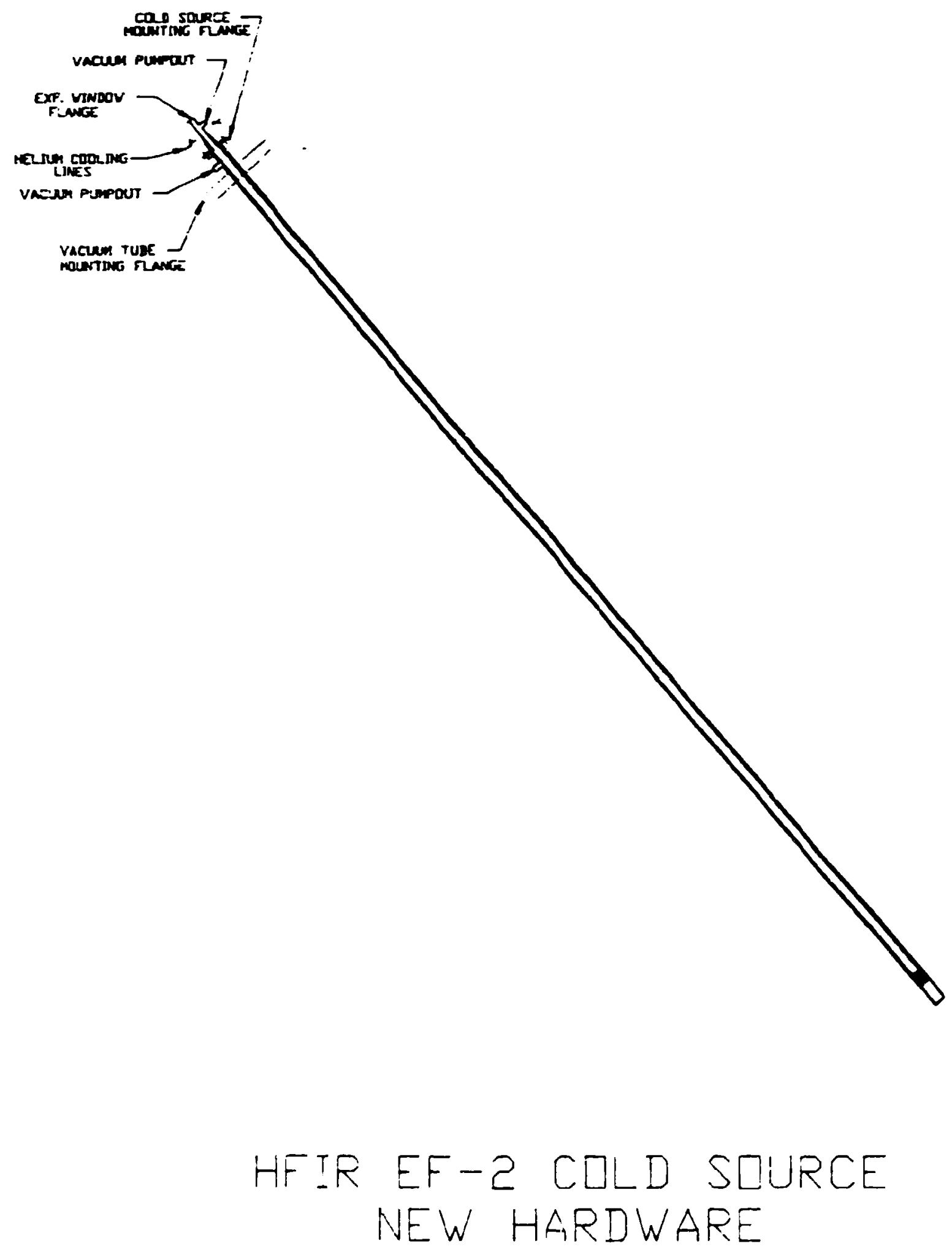




\section{STUDY ON THS HGH FLUX ISOTOYE REACTOR-CINIXR FOR NDOTRON RDSEARCA}

\section{PXSCUTTE SUMMARY}

What the Fight Fux Isotope Reactor-Caner for Nentron Reseurch (FIFIR-CNR) provider:

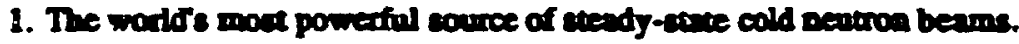

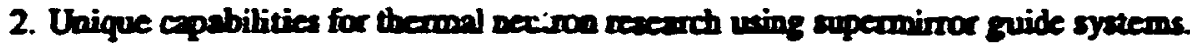

3. Production capabilities to meet the netional seed for ${ }^{20} \mathrm{Cf}$, a partable neutron cource with many industrial, medical, and security aplications.

4. A high-thux facility for materials inrediation studiea.

5. Bydrulic tube facilities for the production of key medical and indunetrial isolopes.

6. Activation andysis fecilisies with en unprecedented thamal nentron the.

7. A positron research facility with a positron beam intensity substantially greater than any available in the world.

8. The necosery support facilities and staff to serve as a true user facility.

What the HFIR-CalR is not:

1. The Advanced Neutron Source, as called for by the Seiz-Eastman report, repeated reports from the Baric Energy Sciences Advisory Committee, the Kohn panel, and as defined by the National Steering Commitue for the Advanced Neutron Source.

2. A low-powered research reactor.

3. A simple replacement for the copabilities that presendly exist at the Figh Flux Isolope Reactor at Oat Ridge National Laboratory and the Figh Flux Beam Reactor at Broolthaven National Laboratory

4. A facility for use only by the staff of Oat Ridge National Laboratory.

\section{Summary of the RFIR-CNR reactor, reactor cooling systems, and containment}

The HFIR-CNR neutron source is based on a 125 MW, heavy-water-cooled and-moderated, compact core reactor with the following features:

1. A three-element core using low- or medium-enriched unanium fuel in an aluminum matrix. The fuel is in the form of thin, involute-shaped plates that span between two concentric sideplates.

2. A large, heavy water reflector vessel that transpors thermal neutrons to beam and irradiation facilities. 
3. A liquid deuterium cold source thr alow the thermal seutrons down wo very low energies for transport in a cold eculren guide system to a guide hall locented oustide the reactor contsinment. Provisions are made in the design for the addition of a second cold source after the BFIR-CNR is constructed.

4. Five penetrations for thermal guide syetems that trenport themal neutrons to instruments in an experiment ball located cutaide the reactor contriniment.

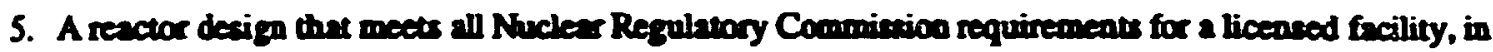
accordance with rescace enfery requixemente exblisbed by the Deparument of Enerey.

6. A reactor protection syetem that is redundant, diverse. and folly responsive to all challenges, including single failure criteria and enticipated trensients without ecrem of the primary shutdown system.

7. Systems to refuel and maintain the reactor while maintaining barriers between light and heavy wuter.

8. A cooling system that incorporates passive and inherent esfety features. These include coolent uplow through the core, decay heat transport by anturnl circulation, pasive sccumulators for inventory control and to maintain presure during poetulated transients, and no reliance an electrical pon st decay heat removal

9. A double-walled reactor contrinment structure with a filtered annulus. The deaign of the contsinment system is integrated with emengency planning activities ench that reslistic evacuation tirnes are provided for occupants of the Oak Ridge Reservation, including Oak Ridge National Laboratory, and no "immediate notification" of off-site residents is required sfrer a postulsted severe accident

Summary of the BFIR-CNR beam, instrument, irradiation, and user support facilities

The HFIR-CNR complex provides the following research facilities:

1. One cold source, seven cold quides with two or more split guides, five thermal guides, one remotelyoperated thermal beam, one alant beam tube. A second cold source and associated guides can be added later.

2. Seven thermal and eleveo cold ncutron scattering instruments.

3. A precision gamma-ray bolometer for nuclear physica, with the potential for adding a beam station and a radioactive ion beam facility in the future.

4. Thirty carget positions and a bydraulic rabbit tube for the production of transuranic isosopes, expecially ${ }^{20} \mathrm{Cf}$

5. Five instrumeated and five non-instrumented materials irradiation targets in a bard spectonm, with the necessary hot cell facilities to support their operation.

6. Three hydraulic rabbit wbe facilities for the production of key medical and industrial isotopes, along with the necessary hot cell facilities to support their operation. 


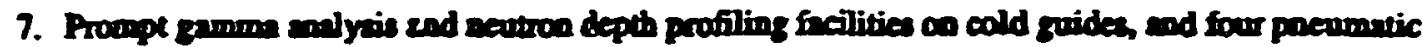

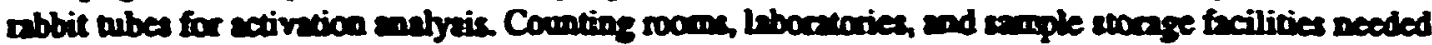
to euppart the activation amalyais facilities are also provided.

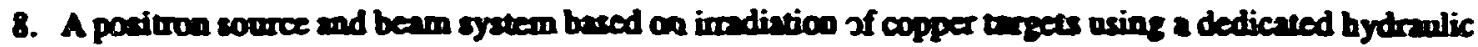
rabbit mbe.

8. Facilities for instrument setup and mantenanse, smple preparation, and dats collection.

9. Ueer support including office frcilities and remporry lodging, will be provided in a separate building to be courtructed by the State of Tenneance.

\section{Sumary of ohe BIFIR-CNR site and baillings}

The FFIR-CNR is located neat to (wett of) the present Figh Fix Isotope Reactoc (RIFIR) and Rediochemical Engineering Development Labortary (REDC) complex, 20 that maximam use may be made of existing facilities and infinstructure. The HFIR-CNR complex includes the following boildings and features:

1. A $30 \mathrm{~m}$ diameter resctor contsinment building the houses the FIFIR-CNR reactor, the primary cooling system, the fuel baniling and wet atorage systems, and the cold ecurce system.

2. A guide hall housing the cold neutron guides and instruments.

3. A thermal guide hall housing thermal ncutron scattering instruments.

4. A research support facility housing laboratories and shops needed to aupport research operations.

5. A reactor support building bousing equipment needed for operation of the reactor, and the refrigeration system needed for operntion of the cold source.

6. An interface building used for access control, bealth physics monitoring and control, and security control.

7. Process and service buildings that house the heavy water upende and detritiation process equipmeat.

8. Cooling towers, electrical substations, and other structures not available in the existing HFIR and REDC complex.

9. A seare pad that will be used to store dry casts containing the spent fuel generated during 40 yean of HFIR-CNR cperation.

10. Existing buildings in the HFIR and REDC complex sre used to houne the sperations, maintenance, technical, quality, security, and bealth physica staff.

11. Existing buildings in the FFIR and REDC complex provide the shops and wrebouses needed to suppor HFIR-CNR operations, and wo bouse the FFIR-CNR mockup and other training facilitiea. 


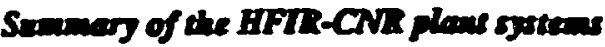

FFIR-CNR plane syctems inchude the following:

1. Relinble electrical porrex syutems.

2. Heating, ventilation and air conditioning syctems that mantain hebitability and that control tritium and other types of contuminution.

3. Plate water, nervicen, fire protection and wate system, including the cryogenic belivm refrigerator neceserry for the operetion of the cold eource.

4. A beavy wher procesaing plant that removes tritiun produced in the reactor heavy wrer and cold source deuterium, and that removes lighe water contamination from all beavy water supplies.

5. Advanced control, data and commenicaions syctems, including a digitrl control room, a comprehensive data network, and a complete electronic technical and busineas data syetem.

\section{Cost of BFIR-CNR}

Couts were developed by uxing the extremely well eatablished ANS CDR cost data base and proven tectniques described in the ANS Project Wothop on Cost Reductios performed in October 1992 Rists that may lead to coet innccurncies are documented in detril. Cout contingencies used were the anme as those used in the conceptual deaign coct entimate becunse it is felt that if the rists documented are ruccessfully avoided, the estimate scorracy is cimilat to that of the conceptual design. Total project couts are summarized in Tables 1.1 and 1.2. Anaul operating couts are aummarized in Table 1.3.

Table 1.1, Total project cost for HITR-CNR (all types of funding included)

\begin{tabular}{|l|r|r|}
\hline WBS element & $\begin{array}{c}\text { Fival year 1992 dollars } \\
\text { (\$ thousands) }\end{array}$ & $\begin{array}{c}\text { As-spent dollars } \\
\text { (\$ thousands) }\end{array}$ \\
\hline 1.1 Research \& development & $\$ 138,870$ & $\$ 171,866$ \\
\hline 1.2 Project suppor & $\$ 179,426$ & $\$ 231,493$ \\
\hline 1.3 Reactor systems & $\$ 114,226$ & $\$ 144,768$ \\
\hline 1.4 Experiment systems & $\$ 154,938$ & $\$ 200,588$ \\
\hline 1.5 Site and buildings & $\$ 188, \$ 90$ & $\$ 239,015$ \\
\hline 1.6 Plant systems & $\$ 319,856$ & $\$ 413,724$ \\
\hline 1.7 Operations & $\$ 128,560$ & $\$ 178,727$ \\
\hline 1.8 DOE support & $\$ 5.478$ & $\$ 7,087$ \\
\hline
\end{tabular}




\begin{tabular}{|l|r|r|}
\hline Total HFIR-CNR project coet & $\$ 1,232.036$ & $\$ 1.587,268$ \\
\hline
\end{tabular}

Does not include beavy water uperade and detritintion facility, licted in Table 12 below.

Table 12, Total project cont for the HIIR-CNR heary water upgrade and detritiation facisty (all types of tunding included)

\begin{tabular}{|c|c|c|}
\hline WBS element & $\begin{array}{c}\text { Fiscal year } 1992 \text { dollen } \\
\text { (S thousends) }\end{array}$ & $\begin{array}{l}\text { As-spest dolloss } \\
\text { (S thousonds) }\end{array}$ \\
\hline Detritistion buildings & $\$ 7,165$ & $\$ 9,081$ \\
\hline Detritiation process & $\$ 55,701$ & $\mathbf{5 7 2 , 1 1 0}$ \\
\hline $\begin{array}{l}\text { Toral } D_{2} O \text { uperade and detritiation } \\
\text { per : sct cost }\end{array}$ & $\$ 64,858$ & $\$ 81,191$ \\
\hline
\end{tabular}

Table 13, Annual opernting costs for HMR-CNR and for the beavy water upgrade and detrifiation fecility, thousands of fiscal year 1995 dollars

\begin{tabular}{|l|c|c|}
\hline & $35 \%$ conichment & $20 \%$ enrichment \\
\hline HFIR-CNR resctor and plant operating cost & $\$ 47,796$ & $\$ 54,056$ \\
\hline HFIR-CNR research suff cost & $\$ 13,556$ & $\$ 13,556$ \\
\hline Total, HFIR-CNR operations and research costs & $\$ 61,352$ & $\$ 67,612$ \\
\hline & & \\
\hline Detritiation facility operating cost & $\$ 1,671$ & $\$ 1,739$ \\
\hline
\end{tabular}

\section{Schedule for Construction of HFIR-CNR}

The project schedule is success oriented, as was that of the conceptual desijon. The most challenging schedule item is obtaining review and approval from DOE (or other regulating body) for covironmeatal, safety, and licensing documentation in a timely manner. While it is recognized that this ma; be difficult to achieve. we believe that if the Projeca, DOE and the licensing body wort together as a team, in the same manoer as was done on the Seawolf athack submarine propulsor fabrication project performed by MMES. HFIR-CNR can cerrainly be constructed on the schedule shown.

A list of key schedule dates is as follows:

Project authorization/begin Titie I

Industry ream in piace

National Environmental Policy Act

Record of Decision issued

Issue Preliminary Safety Analysis Repor
October 1995

Ocwober 1995

August 1997

Oclober 1997 
Begin Title II desiza

Surt non-auclear construction

Firt nuclear concrete

Complete Title II

lesue FSAR

bitial core load

hitial criticality

Project complete
October 1997

Merch 1998

October 1998

December 1999

Janury 2001

February 2002

May 2002

September 2002

\section{Method of Accomplishmeat for ahe HTIR-CNR Project}

1. Both programmatic direction and funding from DOE will be provided by Energy Research, os is done for their other lerge scientific facility projects (the Advenced Photon Source, the Relativistic Benvy Ion Collider, etc.)

2. The Project will be managed by Martin Marieta Encrgy Systems. Induserial participation (arcinitect enginecr, reactor manufacturar, and construction manager) will be oblained and managed directly by Martin Marietta Energy Systems.

\section{Comparison of the BFIR-CNR and ANS designs}

\section{Comparison of Capabilities}

1. The neutron flux diutribution in te HFIR-CNR reactor is generally similar to that in the ANS reactor, but is lower by the ratio of the fission power of the two designs. The power of the HFIR-CNR reactor, and therefore the fux avaibble at most beam stations and irradiation favilities, is about $40 \%$ that of the correspondine ANS facility. In many cases, the rescarch capability of the facility is directly proportional to the Aux. In some cases, the lower flux may preclude certain types of experiments. The performance of some irradiation facilities (especially the transuranium production facilities) is proportional to the flux raised 10 some power above one, and thus the performance is reduced further than the sinaple ratio of flux.

2. The following neutron scatrering instruments included in the ANS complement have been deleted (the method of funding in the ANS Project cost estimate is also indicated; instruments to be procured with line item funds were to be designed and installed as part of the ANS Project whereas those procured with operating funds were in many cases to be designed and installed by other research organizations):

L-5 High Resolution Powder diffractometer

T-6 Diffuse scattering time-of-Alight spectrometer

T-7 Diffuse scallering time-of-night spectrometer

T-8 Time-of-flight spectrometer

D-1 Multichopper time-of-flight spectrometer

L6 Time-focusing time-of-night spectrometer

H-4 Triple-2xis spectrometer

D-11 Triple-2xis spectrometer

L-9 Triple-2xis spectrometer

L-11 Double cystal SANS

D.S SANS 40m
Operating

Line item

Operating

Line ilem

Line item

Operating

Line item

Operating

Operating

Operating

Operating 

L-2 SANS 20m
Operating
D-6 SANS 20m
Operating
H-2 Ceneral pupose liquids diffretometer
Line item
D-10 Bachocuttering apectrometer
Operating
V-1 Very cold nevtrion optical bench
U-1 Ulureold neutron turbine
Operating
Line item
C-1 Slant cold neurron station
Openting

3. The following nuclear and fundamental physics instruments included in the ANS complement have been deleted (the method of funding in the ANS Project is also indicated):

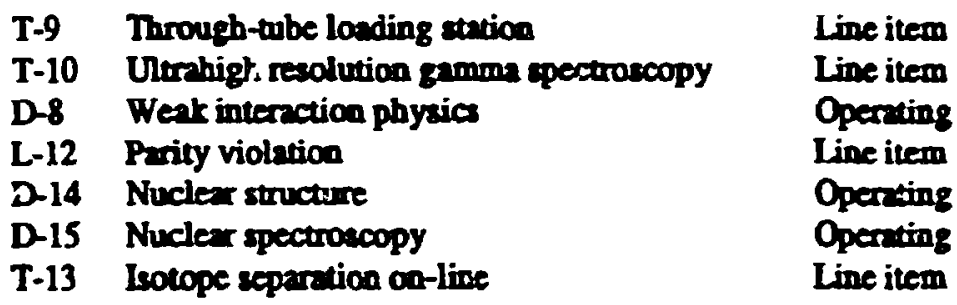

4. The two slant materials irradiation incilities included in the ANS design have been deleted.

5. The four vertical isotope production facilities inchuded in the ANS design have been deleted.

6. Three of the reven poesmatic rabbit bubes provided for activation analyais in the ANS deaign have been deleted. The support facilities for activation analysis have been rednced a comesponding amount.

7. Laboratories and shops that support research operations have been reduced in proportion to the number of insoruments.

\section{Comparison of Cost}

The design and estimate for HFIR-CNR was generated using the exceptionally detailed (and independently verified) conceptual design and cost information developed for ANS. In using the ANS design information to generate the design and estimale for HFIR-CNR, the following changes were made to the ANS dan:

Reactor, reactor cooling, and conteinment systems:

1. The reartor vessel design is simplified with respect to the ANS design by the reduction in the number of bean and irradiation facility penetrations. Thiz effect is offset by complications resulting from combining the primary and reflector cooling systems.

2. Because of the lower flux and heating rates in the HFIR-CNR reactor, a zirconium alloy is ueed for the core pressure boundary tube and possibly the beam tubes. Athough this may increase the direct cost of the reactor components, it increases reactivity and core life, and decreases the operaling cost.

3. Because the reactor power is reduced considerably, many accident scenarios are less challenging for the HFIR-CNR reactor. Thus, the required control rod response speed is less than in the ANS design, and the reactor control system costs are somewhat lower. 
4. One primary and ane secondary cooling aystem loop have been deleted. These loops were used as an on-line spare in the ANS design.

5. Cooling of the HFIR-CNR reflector is eccomplished using the primary cooling loops. Thus, the separate reflector couling loops provided in the ANS design are deleted.

6. Piate heat exchangers are used instead of aheil and tube designs to reduce the cost and size of the primary cooling loops in this lower pressure system.

7. Pony motns and exparate emergency beat exchangers are not needed for the HFIR-CNR cooling systems.

8. All primary and secondary cooling system components are reduced in size and cost using appropriate power scaling fectors.

9. The basic design of the reactor containment syetem remains the same. However, the coutainment structure is half the diameter and somewhat lower in height than the ANS design. This reduces the size and cost of the containment ventilation and filtration systems. The containment is not normally occupied during operation; the size, number, and cost of airlocks has been reduced. The number of other penetrations in the containment bas aleo been roduced.

\section{Research facilities and user support:}

1. Cne cold source and its associated cold neutron guides were deleted but provision is made for adding them later, after opentions have begun and the first guide hall is saturated.

2. 25 beam instruments were deleted, as described under research capabilities.

3. Two slant materials imadiation facilities, four vertical isotope facilities, and three pneumatic tubes were deleted, as described under research capabilities.

4. Laboratories and shops needed to support research operations were scaled with the number of instruments. A research support structure encircles the thermal instrument room outside containment. User support is provided in a building assumed to be constructed by the State of Tennessee.

Site, buildings, and plant systems:

1. The reactor containment building will bave a diameter half that of ANS.

2. The reactor support building will be half the size of the corresponding ANS building.

3. The guide hall will be $60 \%$ the size of the ANS guide hall. Provisions will be made for the construction of a second guide hall at a later time.

4. The office building bas been elininated; many of its functions will be provided by a guest facility expected to be constructed by the State of Tennessee and the rest by an interface building (see item 10).

5. The operations support has been eliminated (existing HFTR facilities are to be used instead) 
6. The mockup building has been eliminnted (existing HFIR frcilities are to be used instead)

7. The research support building will be $62 \%$ the size of the corresponding ANS building.

8. The detritiation buildings will be $80 \%$ the rize of the comesponding ANS buildings. The detritiation buildings are costed separately, 20 the the decision to construct the detritiotion facility can be mede eeparately from the decision to build HFIR-CNR

9. The positron facility will be $34 \%$ the size of the corresponding ANS building.

10. A new interface building bas been added. This vew 5,400 squere foot building replaces some of the functions of the ANS office building.

11. A pad for dry storage of a 40 year inventary of spent fuel has been added.

12. Most plant systems that support reactor opentions are reduced in cout using an appropriate power scaling factor.

13. The two independent $161 \mathrm{kV}$ lines supplying the site with electrical power in the ANS dexign have been deleted. A second $13.8 \mathrm{KV}$ line is broughe to the FFIR site to improve the reliability of the existing HFIR power supply.

14. Because the emergency power loads bave been reduced dramatically. Class 1E emergency diesel generators have been replaced by commracial grade emergency generator sets and Class $1 E$ becteries.

15. A processing plant is provided to remove tisium and light water contamination from the HFIR-CNR heavy water inventory. This plant will have other uses in the DOE complex as well. The detritiation process is costed sepantely, so that the decivion to construct the detritiation facility can be made seprately from the decision to build HFIR-CNR

16. The scope, and thus cost, of the plant control simulator has been reduced.

17. Many other minor changes to the ANS design are documented by WBS in the body of this repart.

Project cost:

1. Research and developinent costs are reduced because of a substantial increase in thermal margins, the elimination of the hot scurce, the elimination of the need for neutron poisons in the refueling proceas, and numerous other simp!ifications in the reactor design.

2. Other project support cost elements (administration, quality assurance, etc.) have been reduced as appropriate to correspond to the two-year reduction in the project schedule.

Summary cost estimates:

Costs for HFIR-CNR were generally eatimated by reviewing the ANS cost eatimate data, and hanging costs to reflet the specific differences between ANS and HFIR-CNR. The key assumptions and methodology used is described for each thind-level work breakdown system element in the body of this report. The overall spreadsheets developed to profile the ANS costs over time were then used to summarize costs for HFIR-CNR. A summary of the escalated costs for ANS and HFIR-CNR, and the 
difference between them, is included in Tables 1.4 and 1.5 .

Table 1A, Comparison of lotel conts for the ANS and HIIR-CNR Projects (all types of funding included; eccalated to year spent)

\begin{tabular}{|c|c|c|c|}
\hline WBS element & $\begin{array}{c}\text { ANS coet } \\
\text { (S thousends) }\end{array}$ & $\begin{array}{l}\text { GFR-CNR } \\
\text { (S thousends) }\end{array}$ & $\begin{array}{l}\text { Cost reduction } \\
\text { (S thousands) }\end{array}$ \\
\hline 1.1 Research \& development & $\$ 225,674$ & $\$ 171,866$ & 553,808 \\
\hline 12 Project support & $\$ 363,946$ & $\$ 231,493$ & $\$ 132,453$ \\
\hline I i Reactor systems & $\$ 188,960$ & $\$ 144,768$ & $\$ 44,192$ \\
\hline 1.4 Experiment systems & $\$ 365,471$ & 5200,588 & $\$ 164.883$ \\
\hline 1.5 Site and building & $\$ 536,887$ & $\$ 239.015$ & $\$ 297,872$ \\
\hline 1.6 Plant systems & $\$ 836,840$ & $\$ 413,724$ & 5423,116 \\
\hline 1.7 Operations & $\$ 422,373$ & $\$ 178,727$ & $\$ 243,646$ \\
\hline 1.8 DOE support & $\$ 7.598$ & $\$ 7,087$ & $\$ \$ 11$ \\
\hline Total project cost & $\$ 2,947,749^{\circ}$ & $\$ 1,587,268^{b}$ & $\$ 1,360,481$ \\
\hline
\end{tabular}

Does not include costs of the heavy water upgende and detritiation facility or funds previously spent on the Advanced Neutron Source R\&D and decigan. When heavy water upgende and detritiation cost (\$137 million) and prior year costs (\$123 million) are added to the ANS project cost, the total ANS Project cost comes 10 \$3.207 million.

Does not include heavy water upgrade and detritiation costs, listed in Table 1.5 below.

Table 15, Comparison of total casts for the ANS and HFTR-CNR heavy water upgrade and detritiajion facilities (all types of funding included; escalated to year spent)

\begin{tabular}{|l|r|r|r|}
\hline WBS element & $\begin{array}{c}\text { ANS cost } \\
\text { ( } \mathbf{\text { thousends) }}\end{array}$ & $\begin{array}{c}\text { HFIR-CNR } \\
\text { ( } \$ \text { thousunds) }\end{array}$ & $\begin{array}{c}\text { Cost reduction } \\
\text { (\$ thousands) }\end{array}$ \\
\hline Detritiation buildings & $\$ 10,749$ & $\$ 9,081$ & $\$ 1,668$ \\
\hline Detritiation process & $\$ 126,232$ & $\$ 72,110$ & $\$ 54,122$ \\
\hline Total project cost & $\$ 136,981$ & $\$ 81,191$ & $\$ 55,790$ \\
\hline
\end{tabular}

Comparison of Schedule 
The sctiedule for FFIR-CNR is two yeurs shoner then for the much lager ANS Project A ley element of this shortened echedule is the momption that the DOE office responsible for centifiation of EFIR-CNR will provide a stef co-located with the design team sarting Oct 1, 1995, to asrure carty and oa-going interections and continus review of the desigen ad enfety progense The certifying DOE office will wike so moce then one whole yex to review the PSAR and one year to review the FSAR.

A comparieco of key ectectule dutes in the ANS and BFIR-CNR schectules is as follows:

Projeca autharization/begin Title I Indiviry ceam in plece

Issue NDPA Recond of Decision

Iswe Preliminny Safety Andysis Report

Begin Title II deaign

Sert non-nuclear coastruction

First muclear concrete

Complete Title II

Isone FSAR

Initial core load

Initial criticality

Project complete
ANS echedule

October 1995

October 1995

November 1996

October 1997

October 1997

December 1997

November 1998

June 2001

Jemury 2003

March 2004

April 2004

September 2004
GER-ONR schetulic

October 1995

Octobe 1995

Angust 1997

October 1997

October 1997

March 1998

October 1998

December 1999

Jenuary 2001

Feburuary 2002

May 2002

Sepiember 2002 
ATTACHMENT 4 
Must de te continue operation

Get more enriched $\mathrm{U}_{3} \mathrm{O}_{4}$ for $\mathrm{B} \& W$

in-service inspection

Beryllium replacement

Facilitv or instrument

improvements

New instrument layout

New gamma-irradiation facility

Guide hall (building extension)

Positron source

Cold source in an existing (e.g., EF) facility

Replace and improve those systems that are limiting reactor availability

Operational and fuel fabricaunn changes

Fue! platc inspection/selection improvements to permit operation at $-10 \%$ higher power than now

\section{Benefits}

Avoids close down!

Avoids close down!

Avoids close down!

Much enhanced experimental capability for neutron scattering

An enhanced capability, c.f., the fuel element gammafacility

More space for more instruments

Could be worldbeating facility

Would establish ORNL as a credible national facility for major areas of neutron research

Could significantly enhance predictahility and reduce the cost per neutron

Higher power would provide more neutron nux for more sensituse experiments and/or shorter experiment umes
Notes

Needed by fall of 1995

Needed by 1996 or 1997 , but might be phased, with accessible :tems inspected by 1997 and inaccessible ones delayed until beryllium replacement

Needed by 1999 or 2000

No significant impact on any reactor systems

Couid be placed inside the HFIR building, or outside with a rabbit-tube connection

The highest short term priority for neutron scattering users?

Could make a significant change in the outside users' perceptions of HFIR
More accurate inspecuors are now possible using the recently-installed digital scanner at B\&W. Shorter experiment times would accommodate more users/ 
Oxprictical and fur!

year. Low cost action.

fabricarion changes (cont'd)

Seiect existing fuel elesuents that will permit operation at $-10 \%$ higher power than now

Core life extension through higher volume fraction of $\mathrm{U}, \mathrm{O}_{3}$ fuel

Core life extension and/or higher power and/or reduced enrichment through adoption of silicide fuel

Enhancements requiring some changes to the reacior

New through-tube and cold source

New irradiation holes in beryllium (requires new vessel hatch?)

Increase diameter of beam tubes

New hydraulıc rabbit tube
Higher power would provide more neutron flux, for more sensitive experiments and/or shorter times to accommodate more users/year

Longer core life could provide greater availability and predirtability; leads to more neutrons per year, lower operating cost, and therefore lower cost per neuton

Same advantages as previous item. Also, possibility of reducing enrichment if that becomes necessary or advantageous
Based on the measurements that were routinely made during fabrication. $L J w$ cost action.
Uses standard HFIR compound $\left(\mathrm{U}_{3} \mathrm{O}_{3}\right)$, but for these ruel densities the da:a base on silicide fuel may actually be more extensive
Silicide fuel is used worldwide, and the already extensive data base was further extended by ANS
Would make the HFIR a clear world beater in some very important areas

If we change the beryllium and the hatch why not change the whole vessel?
Higher useful flux for neutron scattering
Additional irradiation capabilives
Enhances isotope production and materials irradiation capabilities 
Major performance

enhancements/life extension

New, non-pressurized, nonsteel reflector tank

Replace beryllium reflector with $D_{2} \mathrm{O}$

Replace beryllium reflector with $D_{2} O$, and install a large, deuterium cold source

\section{Reactor vessel no \\ longer life-limiting. \\ Higher core power \\ possible with \\ existing primary \\ cooling system. Use \\ low activation \\ materials}

\section{Approximately \\ doubles the flux at the beam tubes. \\ No further need \\ for beryllium \\ replacement. More \\ flexible for future \\ changes.}

Using ANS cold sourcs design, would give a cold neutron flux 2-3 times that of $I L$
Can incorporate additional beam tubes, a cold source, and other experimental facilities to make HFIR the world's best in some importan! areas of neutron scattering

Would give a performance $50 \%-100 \%$ better than ILL (but, with many fewer instrument stations).

Easily the world's best facility, by a factor of two or three, fo- cold neutrons 
ATTACHMENT 5 
Items Identified by RRD Which Would

Benefit Material Irradiations and Probably Isotope Production (Gleaned from George Flanagan's handout at our last meeting)

- Build a hot cell over the old critical pool, including transfer door and elevator

- Move mockup/spare stack/alignment facility to a new building (radiologically clean) in the 7900 area

- Evaluate methods to reduce gamma heating rates

- Improve access to and efficency of present material irradiation facilities by making penetrations in reactor vessel top head line up vertically with the reflector irradiation positions

- Demonstrate the technical and efficient merits for increasing the operating power to $100 \mathrm{MW}$

- Evaluate the advantages of changing the HFIR core to a materials testing core (Recommended by MIFIC committee in 1985) 
March 21, 1995

HFIR Futures Group Meeting

Attendance

The HFIR Futures Group held its third meeting at 8:30 a.m. on Monday, March 20, 1995, in the Blue Room of the FEDC. Those in attendance were:

\author{
Bill Appleton \\ John Bigelow \\ Emory Collins \\ George Flanagan \\ John Hayter \\ Michele Houser \\ Peyton Moore \\ Larry Robinson \\ Ken Thoms \\ Colin West (chair).
}

\title{
Opening
}

Colin began the meeting with a review of the March 13 meeting minutes and an overview of the agenda shown in Attachment 1. John Hayter asked for a couple of amendments to be made to the minutes. The fact that Legionnaires' disease is not a concern in the refurbished HFIR cooling towers will be added to the discussion of that upgrade. Also, the fact that the neutron scattering group can prioritize staff assignments in order to be able to attend important meetings was mentioned as an addition to the previous week's meeti. a notes. George Flanagan also had a wording change for last week's meeting notes conceming the source of $\mathrm{U}_{3} \mathrm{O}_{8}$ for $\mathrm{B} \& \mathrm{~W}$.

\section{Improvements made in HFIR's material irradiation facilities}

Ken Thoms gave a presentation on improvements that have been made in HFIR's material irradiation facilities (see Attachment 2). In the late 1960's, the first instrumentation facility was installed. In addition to a shielded valve box and a gas clean up and supply system, it consisted of 8 instrumeniation panels for the operation of 2 capsules (these were in the RB positions of the reflector).

The next improvement Ken talked about was the HFIR Irradiation Facilities Improvement (HIFI) project. Phase 1, which consisted of the addition of instrumented target facilities, was completed in 1986. Phase 2, in which new RB facilities were added, was finished in 1987. The total cost for both phases of this project was about $\$ 2 \mathrm{M}$. New instruments and a data acquisition system (DAS) were installed in 1990, and the facility was upgraded to be able to operate 4 capsules. Further instrumentation upgrades tonk place in 1994, with the purchase of a gamma-ray spectrometer and an upgrade to permit operation of 6 capsules. These upgrades have put the material irradiation capabilities 
in a good, and in many cases, unique condition; however, some special experiments call for modification of existing facilities. Having the capability for more flexibility in configuration would be helpful.

\section{Improvements to HFIR beam instruments}

John Hayter next gave a presentation on improvements made to HFIR beam instruments (his slides are shown in Attachment 3). He remarked that incremental improvements are continually being made on instruments as the scientific needs require and as resources become available. The focus of these upgrades is on better using the available neutrons when a new component allows this capability.

Scientific programs have funded some new instruments. One such example is the support that the National Science Foundation gave for new small-angle scattering instruments a few years ago. The extended shutdown of HFIR in 1986 cut out the foundatiun's continued support, although the instrument is still there. The small-angle scattering program is now supported at NIST.

New instruments have also been funded in a DOE initiative involving reflectometry. In this joint program with the University of Tennessee, support has been given for work on anisotropy in colloids. This instrument only works on one wavelength of the neutron spectrum, and most of the HFIR's spectrum is available for other experiments. New instruments have also been funded in a DOE initiative in residual stress experiments. In a joint initiative between the Solid State Division and the Metals and Ceramics (M \& C) Division, work is being done on stress and texture. Successful proposals have been science-based and have beaten the competition in an open market.

\section{Hidden interfaces}

John $H$. went on to talk about possible hidden interfaces for proposed improvements to HFIR. He remarked that groups which may not currently use the facility, but which might have future use of the facility, should have the chance to review the plans the HFIR Futures Group devises. In particular, Physical Sciences and Advanced Materials (PSAM) Divisions, and also Biology and Chemistry, should be given this opportunity. John $H$. remarked that the $M$ \& $C$ Division was not a HFIR beam user until a few years ago. Now its work at HFIR is one of ORNL's showpieces: their work would have been prohibited by some of the smaller changes that the group is considering--care needs to be exercised that this does not happen in our study.

\section{Analytical chemistry upgrades}

Larry Robinson mentioned that his analytical chemistry group had done one major upgrade at the HFIR facility. In 1986, these users added a pneumatic tube and the EF-3 facility, with corresponding laboratory space, to the HFIR facility. This was largely brought about by a move from the ORR facility to the HFIR. At the time, these upgrade: cost $\$ 650 \mathrm{~K}$ and were paid for by ORNL funds.

\section{Administrative items (user perspective)}

Larry contunued with talking about HFIR upgrades which have to do with improved administrative practices for deain..g with uscrs (sec Attachment 4). His thoughts largely resulted from his experience at NIST, where he arrived one Monday morning and had the necessary training for the access he $\mathrm{n} r$ :ded by noon that same day. Larty told us that his training at that facility was made up of a personal computer-based modulc and an overview/tour by experts. The radiation worker training was tailored to mect the users' work scope at the facility. Gencral cmployec training and radiation workes training 
were combined and took little time to complete. This training is a lengthy process at the HFIR facility currently.

Other suggestions that Larty had were grouped as information exchange/communication items. These involved such ideas as making sure that operations personnel, including administrative/support staff, had more exposure to users' activities. This would entail helping users with paprerwork and notifying them sufficiently ahead of time about audits. Larry liked the telephone informati on line that the HFIR currently has which gives information about the HFIR startup and shutdown schedule. He suggested that HFIR look at obtaining a home page on the World Wide Web for advertisement of the facility's capabilities. It was noted that several user groups already had such a connection into the Internet. The marketing benefits of doing this were discussed.

Operations and ownership issues were considered next. Lany remarked that it would be good if the facility could push (or wait) for clarification of the management stnucture of DOE programmatic guidance groups (i.e., Nuclear Energy vs. Energy Research). Internally, ownership issues should also be addressed. Larry gave an example of Los Alamos being run by its users in 1983. Another example was given of operators at the ORR in 1987. The reactor was given the order to shut down by DOE; operators called the users before bringing the reactor down (they waited a few minutes until it was better for the experimenters). Larty said that a good practice now would be for Operations to contact the users before startup.

It was remarked that starting up the reactor at midnight on Friday was not always good from a user perspective. The users would like more flexibility from Operations concerning startup. George remarked that Operations needed better communication from the users on startup. The problem of muitiple users, each with different needs, compounds the difficulties associated with startup scheuuling. This was discussed again later on in the meeting.

Larry encouraged team-building among nembers of various groups. The users at times feel neglected by other groups--it is important to get the reactor up and running, but the users are the reason for the reactor running. It is difficult for researchers to get maintenance support from other groups. The first priority during shutdown is getting the reactor stared; therefore, craft support for the users is pushed into overtime work. If the groups were more integrated into one team, perhaps this would not be the case. (This issue was also mentioned in the "Assessment of the Roles of the Advanced Neutron Source Operators" repor, ORNL/M-3774, done for the ANS).

The last grouping of items mentioned by Lamy wete miscellaneous ones. He suggested that ORNL guest requirements be streamlined--for U.S. citizens, the time period for gaining access approval is currently around 2 weeks. A related item is the frisking requirement on exit from the HFIR facility, which can cause substantial time delays. Larty asked ir this really a "value added" process--it might be appropriate for the facility to examine if frisking is really a regulatory requirement and if it actually solves any problems.

The idea of improving the Work for Others process was also mentioned. This initiative is the mainstay of the future for many user groups. The large fraction of funding required "up front" is deterring many companies' involvement. Making the facility more attractive aesthetically (e.g., by entancing the dining facilities) was also mentioned. These last items led to a discussion of user support issues.

It was asked if not having a hackup facility deterred penple from using the HFIR. One question was whether the ORR in'sld be restarted and used as a hackup if the HFIR facility had to go down unexpectedly. Larry remarked that ORNL's industrial collaborators were lost in 1986 when the HFIR 
went down for an exiended time. These companies are now using another reactor or another method of experimentation. The difficultis were exacerbated when the reactor came back up for a little while after this down period and then went down again for some time. The HFIR has had a credibility problem since then; consequently, the user base had to be re-invented since 1986. Bill Appleton remarked that ORNL should focus on coordinating neutron science activities as a whole, rather than on "keeping the reactor nuning," as had been done in the past. Hopefully, those involved with decisionmaking conceming the HFIR facility had learned from the experiences of the previous extended shutdown.

\section{Discussion of scheduling}

The group then discussed issues associated with HFIR's scheduling. George reiterated the fact that RRD needs unified input from users on startup times. Emory Collins remarked that the downtime for the facility seems excessive--this might be due to HFIR being an older reactor or due to new maintenance requirements. Emory said that the average shutdown over the last year was 15 days, with some shutdowns going up ir 30 days long. Ken suggested that the group look at upgrades to the reactor facility itself to see what actually causes the extended shutdown periods. (George had addressed some of these issues at an earlier meeting).

John $H$. remarked that HFIR needed more people to be dependent upon it to provide a force to get some needed changes done. He gave as an example a visit from a person from DOE's Office of Nuclear Energy. There was $1 / 2$ day's notice of this official's visit, and the person could not get access in time (due to a short supply of dosimeters). It sometimes takes longer for a user to gain access to the facility than the experiment itself takes. George asked that users feed their concems to those grcups that give programmatic and regulatory guidance to the HFIR facility, as well as to RRD. RRD has certain operations practices mandated which may not be in the users' best interests.

It was suggested that a mechanism bx developed for feeding into the scheduling system at an early point the fact that each reactor cycle may be different, according to what the users need that cycle. Some regulatory bodies perceive flexibility in scheduling as being bad, whereas it may actually be good. If there is a problem at the facility, it usually results in a more rigid operational setup. This need for flexible scheduling should be communicated to RRD and DOE management.

Larry remarked that a regular schedule would be all right--it is longer-than-scheduled outages that really cause problems. A person coming in from outside may get bis/her experiment schedule shifted 2 or 3 times. Also, the schedule does not always take into account other factors. The reactor started back up around the beginning of Christmas vacation, and about 2 weeks' worth of experiment time was lost due to previously-scheduled private activities. This may also happen over the coming Easter holiday. George suggested that users communicate this problem to RRD and DOE management so that someihing could perbaps be done.

\section{Categorization of HFIR upgrades}

Colin next presented lists of HFIR upgrade categorizations, amended by input from the previous meeting. The first list contained benefits and notes for each proposed upgrade item (see Autachment 5). John Bigelow suggested that we add one item with two methods-of-accomplishment to "Enhancements requiring some changes to the reactor." He wanted us to add the item of "Harden the spectrum in the target island." This could be done, e.g., by taking the water cut and making full-length fins out of the targets, or by using stainless steel rather than aluminum for the target jackets (in effect, spectral tailoring). John B. also had a question about an item in "Facility or instrument improvements." He 
suggested that we split "Hot cell (can buy portable one or use HRLEL)" into two items. The first will

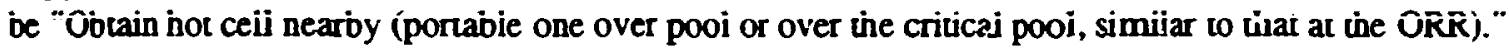
The second item will be "Improve transport methods from the HFUR to the HRLEL."

Ken suggested we add another item to "Enhancements requiring some changes to the reactor." He wanted the group to add "Modify reactor top heal for better access to reflector positions" in this category. The updated list will be sent out before the next meeting.

Colin then went over anotner table of HFIR upgrade categorizations which dealt with duration, gross cost, and net cost for each upgrade suggested. He urged all of the attendees to provide input on costs for these changes. The clarification was made that the wording "approx. same" on the table nueant that the net c st was equal to the gross cost. George said that the total beryllium replacement cost was $\$ 9$ $\mathrm{M}$--the $\$ 700 \mathrm{~K}$ cost was just for beryllium fabrication. The extra cost was for additional labor, new tools, and extra outside covcrage. John $\mathrm{H}$. remarked that the $\$ 12 \mathrm{M}$ was not the science driven cost of the new, modern scattering instruments. but represented a figure defined by DOE: he will do more work on the new figure for this item. The cost of putting new irradiation holes in the beryllium was raid to be $\$ 200 \mathrm{~K}$, as this item has already been estimated by another group.

There was some questior about the costs cited for a new, non-pressurized, non-steel reflector tank. Colin said thai iuse estimate was based on information obtained from the Institut Laue Langevin (ILL), which has just changed out its reflector, and from information acquired for the ANS reflector vessel. George thought that the costs would be greater than those cited since ILL did not change its conceptual design. George remarked that this would be a large change to HFIR's design and would require quite a bit of work. Colin said he would let George ste the estimate and review the components for applicability to HFIR. A revised copy of this table will be distributed before the next meeting.

It was again remarked that if the instruments are ce-arranged, it will have to be decided among the users how to prioritize the science involved. $A$. reminder $w$. $s$ given that if the group decides upon a vertical cold source, this will have to be allowed for in finalizing the beryllium design, which will be frozen soon. If extra, or cifferent, holes are decided upon, input will need to be given to the separate effort underway on designing the beryllium.

\section{Requirements for near-term installation of a HFIR cold neutron source}

Colin then presented some possible requirements for near-term installation of a cold neutron source at HFIR (see Attachment 6). The possibility of using nitrogen-15 (an idea of John Hayter's) was suggested due to safety considerations (i.c., no hydiogen present to bother safety analysts); however, if nitrogen is used as a cryogen, the cold source would have in . : really large, and there may not be enough space at the HFTR. Mrire study needs to be done befo:e this can be determined. Questions to be answered concerning a cold source were then presented, with various people agreeing to make input. These questions will be addressed in next week's meeting. Other considerations mentioncd were only incurring a minimal downtime for installation and minimal technical risk and research and development (R \& D) needs.

Closin

Coliu remarked that Bill had emphasized the point that a near-term cold source is a his,h priority for upgrades. Other improvements involving a low cost and high retum may also be accomplished, and new techno!: $: ;$ and user demand are good reasons for upgrades. The group 'will need a ito of input from RRD, as familiarity with the physical configuration of the facility is essential. The possibili'y of 
presenting the group's ideas to other groups was mentioned, as we!l as the possible idea for a workshop

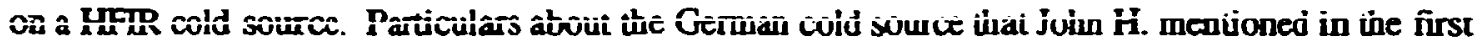
meeting were discussed, and George emphasized the importance of the layout and space constraints at the HFIR. The possibility of using hardware and technology from the Superconducting Super-Collider project was mentioned, and questions were aired about the usefulness of a low-temperature materials irradiation capability. The group adjourned until March 27.

\section{ACTION ITEMS}

All will review the two tables of categorizations of HFIR upgrades and provide cost and schedule input, as well as any other information judged to be helpful.

John Hayter, Michele Houser, Trevor Lucas, and Colin West will address the questions on the installation of a HFIR cold source in the next meeting.

Colin West will provide the basis for the estimate of the new reflector vessel for review.

M. M. Houser, March 21, 1995 
Distribution

HFIR Futures Group (notes for record only)

J. E. Bigelow, 7930 , MS- 6385

E. D. Collins, 7930, MS-6385

G. F. Flanagan, 7917, MS-6398

R. M. Harrington, FEDC, MS-8218

J. B. Hayter, FEDC, MS-8218

M. M. Houser, FEDC, MS-8218

J. P. Moore, 4508 , MS- 6080

L. Robinson, 4500S, MS-6128

K. R. Thoms, 9108 , MS-8087

C. D. West, FEDC, MS-8218

For information (notes for record + all attachments)

B. R. Ajpleton, $4500 \mathrm{~N}, \mathrm{MS}-6240$

J. S. Ball, $4500 \mathrm{~N}$, MS- 6182

R E. Battle, FEDC, MS-8218

I. A. Glovier, 7917, MS-6398

H. A. Mook, 7962, MS-6393

J. B. Richard, 7962, MS-6391 
ATTACHMENT 1 


\section{ÁGEIVDÁ FÔR \\ HFIR FUTURES GROUP MEETING}

Monday, March 20, 1995

$8: 30$ a.m.

FEDC, Blue room

- Discussion: Changes or corrections to 3/13/95 meeting notes for the record

- Presentation: Improvements already made in HFIR's experiment systems

L. Robinson, K. R. Thoms,

J. B. Hayrer

- Presentation: Possible actions in the category

L. Robinson

"Administrative Changes" which would be helpful to HFIR users

- Discussion: Amended lists of HFIR upgrade proposals

- Requirements for near-term installation of a HFIR cold

C. D. West neutron source

- Any other business 
ATTACHMENT 2 


\section{Improvements Made In HFIR's Materia! Irradiation Facilities}

- Late 1960's - Instrumentation facility is installed

- Shielded valve box

- Gas clean up and supply system

- Instrumentation panels for operation of 2 capsules

- 1986 - Completion of Phase 1 of the HFIR Irradiation Facilities Improvement (HIFI) Project

- Instrumented Target Facilities

- fuel grid

- target holder

- outer shroud

- target tower

- target hole plug

- quick access hatch

- rabbit facility U-bend

- tools 


\section{Improvements Made In HFIR's Material Irradiation Facilities (Continued)}

- 1987 - Completion of Phase 2 of the HIFI Project

- New RB Facilities

- increased number of large RB's from 4 to 8

- increased diameters from 37 to 48 $\mathrm{mm}$

- straight line access

- 1990 - New Instrumentation Installed

- State of the art instruments and DAS

- Ability to operate 4 capsules

- 1994 - Further Instrumentation Upgrades

- $\mathrm{y}$-ray spectrometer

- Ability to operate 6 capsules 
ATTACHMENT 3 
Improvements to HFIR Beam Instruments

$\square$ Small incremental improvements are continuously made to all instruments, as resources allow. These improvements are driven by need, as the science becomes more challenging.

- This approach is always highly leveraged in terms of a lot of bang for the buck. It is usually based on making better use of the neutrons we have, when a new component makes this possible.

$\square$ Some new instruments have been funded since the first suite, because they were required by new scientific programs:

$\square$ Small-Angle Scattering [ Polymers ]

- [National scienceFoundation - Koehler]

Continued support was lost to NIST during long and unpredictable HFIR shutdown

$\square$ Reflectometry [ Anisotropy in Colloids ]

- [DOE New Initiative - Hayter ]

$\square$ Residual Stress [ Stress and Texture ] - [DOE New Initiative - Spooner \& Hubbard] ]

$\square$ The key to successful proposals has been that they were science-based, and won in open competition. 


\section{Hidden Interfaces.}

Groups which currently use HFIR are represented at these meetings, but Divisions not represented by these Groups may be developing new scientific proposals of their own. If these assume the existence of HFIR beams and instruments in their present form, they represent hidden interfaces we must consider.

An example is that Metals\&Ceramics was not generally considered a HFIR user until it developed a new initiative a few years ago. Now, what they do at HFIR is one of ORNL's showpieces, but would have been prevented by even some of the smaller changes we are considering.

I propose that when we develop a plan in Draft form, it be submitted for comment to all PSAM Divisions. Any comments would be incorporated in the Final Draft. Conflicts would have to be resolved in the context of ORNL's overall priorities.

JBH

3/19/95 
ATTACHMENT 4 


\section{HFIR UPGRADES \\ ADMINISTRATIVE ITEMS (USER PERSPECTIVE)}

- TRAINING

-ACCESS TRAINING UPON DEMAND

-PC BASED MODULE + OVERVIEW / TOUR FROM EXPERTS

-RWT TAILORED TO MEET USERS' WORK SCOPE

-COMBINE GET/RWT ?

- INFORMAL INFORMATION EXCHANGE / COMMUNICATION

-OPERATOR'S EXPOSURE TO USER'S ACTIVITIES

(EXPAND TO ADMINISTRATIVE / SUPPORT STAFF)

-HOW BEST CAN USERS GET THINGS DONE (WORK PACKETS, ETC.)

-PUBLISH / ADVERTISE AUDIT / SELF ASSESSMENT SCHEDULE

-DEVELOP A "HOME PAGE" ON THE WEB OR CYBERSPACE 


\section{HFIR UPGRADES ADMINISTRATIVE ITEMS - 2}

- OPERATIONS / OWNERSHIP

-EXTERNALLY: PUSH FOR CLARITY OF NE/ER (OR WAIT)

-INTERNALLY: OPERATIONAL CONSORTIUM

A. LOS ALAMOS EXAMPLE (1983)

B. ORR EXAMPLE (1987)

- MAINTENANCE

-LIFT USERS FROM SECOND CLASS CITIZENSHIP

-ENCOURAGE TEAM BLDG RRD/P\&E/I\&C/ES\&H/USERS

- OTHER

-STREAMLINE LABORATORY GUEST REQUIREMENTS

-FRISKING REQUIREMENT ON HFIR EXIT (VALUE ADDED)

-GET IN A SHOT ON WFO PROCESS

-ENHANCE DINING FACILITIES 
ATTACHMENT 5 


\section{Categorization of HFTR Upgrades}

Muse do to continue operation

Get supplies of enriched $U_{3} \mathrm{O}_{2}$ for B \& W

Inservice inspecticn

Beryllium replacement

Facility or instnument improvements

New instrument layout

New gamma-irradiation facility

Guide hall (building extension)

Positron source

Cold source in an existing (e.g., beam tube) facility

Replace and improve those syrtems that are limiting reactor availability

Hot cell (can buy portable one uver pool or use HRLEL)

New, mocem scattering instruments
Benefits

Avoids closedown!

Avoids closedown!

Avoids closedown!

Benefits

Much enhanced experimental capability for neutron scattering

An enhanced capability, c.f., the fuel element gammafacility

More space for mare cold neutron instruments

Could be world-beating facility

Would augment ORNL's reputation as a credible nat:onal facility for major areas of neutron research

Cou!d significantly cohance predictability and reduce the cost per neutron

Could shorien tumaround time for isotope production. Would streamline operations for storing spent fuel elements.

Could improve performance on existing beams.
Notes

Needed by fall of 1995

Needed by 1996 or 1997 , but might be phased, with accessible items inspected by 1997 and inaccessible ones delayed unil beryilium replacement

Needed by 1999 or 2000

Notes

No significant impact on any reactor systems

Could be placed inside the HFIR building, or outside with a rabbit-tube connection

The highest short-term priority for neutron scattering and neutron actuvation users

Could make a significant change to the outside users' perceptions of HFIR

Could be used by both isotope production and materials testing users (to cut open capsules) and operations staff (to can fuel elements) 
Qperational and fuel fabrication changes

Fuel plate inspection/selection improvements to permit operation at $-10 \%$ higher power than row

Select existing fuel elements that will permit operation at $-10 \%$ higher power than now

Core life extension through higher volume fraction of $\mathrm{U}_{3} \mathrm{O}_{8}$ fuel

Core life extension and/or higher power and/or reduced enrichment through adoption of silicide fuel.

Enhancements requiring some changes to the reactor

New through-tube and cold source

New irradiation holes in beryliium

Increase diameter of beam wubes

New hydraulic rabbit tube

Add capability for additional hydraulic rabbits in the target island
Benefits

Higher power would provide more neuron flux, for more sensitive experiments and/or shorter experiment times

Higher power would provide more neutron flux, for more sensitive experiments and/or shorter tin.es to accommodate more users/year

Longer core life could provide greater availability and predictability; leads to more neutrons per year, lower operating cost, and therefore lower cost per neutron.

Same advantages as previous item. Also, possibility of reducing enrichment if that becomes necessary or advantageous.

Benefits

A really major enhancement of neutron scattering capabilities

For enhanced Pu production capabilities

Higher useful flux for neutron scattering

Additional irradiation capabilities

Additional irradiation capabilities
Notes

More accurate inspections are now possible using the recently-installeci digital scanner at B \& W. Shorter experiment times would accommodate more users/year. Low cost action.

Based on the measurements that were routinely made during fabrication. Low cost action.

Uses standard HFIR compound $\left(\mathrm{U}_{3} \mathrm{O}_{8}\right)$, but for these fuel densities the data base on silicide fues may actually be more extensive.

Silicide fuel is used worldwide, and the alredy extensive data base was further extended by ANS.

Notes

Would make the HFIR a worldbeater in some very important areas

Could also be used for production of other isotopes

Enhances isotope production and materials irradiation capabilities

Enhances isotope production and materials irradiation capabilities 
Enhancements requining some changes to the reactor (cont)

Provide capability for hyoraulic rabbits in the $R B$ and VXF positions

Provide more convenient access to capsules in PTP positions

Restore HFIR-REDC hydraulic transport facility

Major performance enhancementslife extension

New, non-pressurized, nonsteel reflector tank

- Replace beryllium reflector with $\mathrm{D}_{2} \mathrm{O}$

Install a large, deuterium cold source in the new $\mathrm{D}_{2} \mathrm{O}$ reflector
Benefits

Additional irradiation capabilities

Could shorten turnaround time for materials irradiation and isolope production.

Benefits

Higher core power possible with existing primary cooling system. Use low activation matiorials.

Approximately doubles the flux at the beam tubes. No further need for beryllium

replacement. More flexible for future changes.

Using ANS cold source design, would give a cold neutron flux 2-3 times that of $\mathrm{DL}$

Benefits
Enhances isotope production and materials irradiation capabilities

Enhances isotope production and materials irradiation capabilities

Notes

Notes

Can incorporate additional beam ubes, a cold source, and other experimental facilities to make HFIR the world's best in some important areas of neutron scattering

Would give a performance $50 \%$ - 100\% better than IL (but. witt many fewer instrument stations)

Easily the world's best facility, by a factor of two or three, for cold neutrons

Notes

Administrative

- 
Preliminary Categorization of HFIR Upgrades

\begin{tabular}{|c|c|c|c|}
\hline Must do to continue operation & Duration & Gross Cost & Net Cost ${ }^{\circ}$ \\
\hline $\begin{array}{l}\text { Get more enriched } U_{3} \mathrm{O}_{2} \text { for } \\
\text { B \& W }\end{array}$ & & $0 ?$ & $0 ?$ \\
\hline Inservice inspection & $21 / 2$ months (first phase) & $\$ 1 \mathrm{M}$ (in 1997) & approx. same \\
\hline Beryllium replacement & 6 months & $?$ & $\$ 700 \mathrm{~K}$ \\
\hline Facility or instrument improvements & Duration & Gross Cost & Net Cost ${ }^{\circ}$ \\
\hline \multicolumn{4}{|l|}{ New instrument layout } \\
\hline \multicolumn{4}{|l|}{ New gamma-irradiation facility } \\
\hline \multicolumn{4}{|l|}{ Guide hall (building extension) } \\
\hline Positron source & $\begin{array}{l}3 \text { years before } \mathrm{Be} \\
\text { changeuut }\end{array}$ & $\$ 17 \mathrm{M}$ & apnrox. same \\
\hline Cold source in an existing (e.g., beam tube) facility & -1 year & $<\$ 5 \mathrm{M}$ & approx. same \\
\hline \multicolumn{4}{|l|}{$\begin{array}{l}\text { Replace and improve those systems that are limiting } \\
\text { reactor availability }\end{array}$} \\
\hline \multicolumn{4}{|l|}{ Hot cell (can buy portable one or use HRLEL) } \\
\hline New, modern scattering instruments & & $\$ 12 \mathrm{M} ?$ & approx. same \\
\hline Operational and fuel fabrication changes & Duration & Gross Cost & Net Cost ${ }^{\circ}$ \\
\hline $\begin{array}{l}\text { Fuel plate inspection/selection improvements to } \\
\text { permit operation at }-10 \% \text { higher power than now }\end{array}$ & & & 0 \\
\hline $\begin{array}{l}\text { Select existing fucl elements that will permit operation } \\
\text { at }-10 \% \text { nigher power than now }\end{array}$ & & & 0 \\
\hline
\end{tabular}


Prelininary Categorization of HFIR Upgrades (cont.)

\begin{tabular}{|c|c|c|c|}
\hline Operational and fuel fabrication changes (cont.) & Duration & Gross Cost & Net Cost ${ }^{\circ}$ \\
\hline \multicolumn{4}{|l|}{$\begin{array}{l}\text { Core life extension through higher volume fraction of } \\
\mathrm{U}, \mathrm{O}_{\mathrm{s}} \text { ?uel }\end{array}$} \\
\hline \multicolumn{4}{|l|}{$\begin{array}{l}\text { Core life extension and/or higher power and/or } \\
\text { reduced enrichnent through adoption of silicide fuel }\end{array}$} \\
\hline $\begin{array}{l}\text { Enhancements requiring some changes to the } \\
\text { reactor }\end{array}$ & Duration & Gross Cost & Net Cost ${ }^{\circ}$ \\
\hline \multicolumn{4}{|l|}{ New through-lube and cold source } \\
\hline New irradiation holes in beryllium & & $\begin{array}{l}0 \text { (if decision is made } \\
\text { soon) }\end{array}$ & 0 \\
\hline \multicolumn{4}{|l|}{ Increase dianeter of beam tubes } \\
\hline \multicolumn{4}{|l|}{$\begin{array}{l}\text { Add capability for additional hydraulic rabbits in the } \\
\text { target island }\end{array}$} \\
\hline \multicolumn{4}{|l|}{$\begin{array}{l}\text { Provide capability for hydraulic rabbits in the RB and } \\
\text { VXF positions }\end{array}$} \\
\hline \multicolumn{4}{|l|}{$\begin{array}{l}\text { Provide more convenient access to capsules in PTP } \\
\text { positions }\end{array}$} \\
\hline Restore HFIR-REDC transport facility & & & \\
\hline
\end{tabular}

bryond normal HIIR staff and operating costs 
Preliminary Categorization of HFIR Upgrades (cont.)

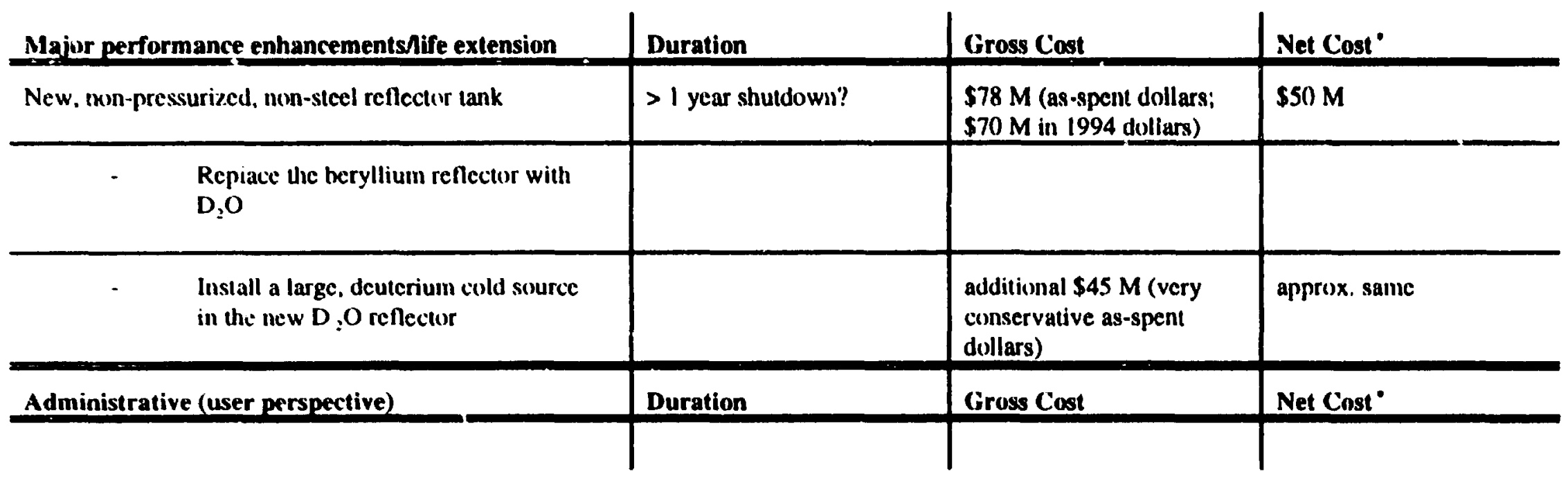


ATTACHMENT 6 
- Minimal safety issues

- use JBH's idea of an L 's $N$ cryogen? (no explosive hazard per HFIR Tech Specs)

- but, liquid hydrogen works betuer and would have a much smaller inventory

- design so that the reactor can continue to operate even if cold source refrigeration is lost

- make sure that core reactivity impacts are very small

- Minimal HFIR downtime required for installation

- prefabricated, tested assembly for insertion in an existing beam tube

- Minimal technical risk and R\&D needs

- forced circulation, single phase (also minimizes the space inside the beam tube taken up by pipework and insulation)

- use a relatively high temperature liquid (e.g., nitrogen?) with simple, off-the-shelf refrigeration needs?

- avoid organic cryogens (risk of blockage due to radiation induced hemical changes)?

- Even if we were to start off with e.g., nitrogen, keep open the option of later going to a hydrogenous, lower temperature cryogen

- e.g., liquid hydrogen, solid methane, silane (JBH) or frozen methane pellets (ATL)

- design the in-beam-tube part of the system for easy removal and replacement 
Compound

Liquid methane

Solid methane

Solid silane

Liquid " $\mathrm{N}_{2}$

Solid 'N:

Supercritical hydrogen

Liquid hydrogen
M.P.K

91

109

100

$<90 \mathrm{~K}$

?

63

77

70

$<60$

n.a.

n.a.

28

14

20

17 


\section{SOME QUESTIONS}

JBH - Would the gain factor from an LN : source be worthwhile scientifically

- or should we go immediately to one of the more difficult cryogens?

JBH - Which beam tube should be used?

MMH- How much does nitrogen-15 cost, and is it readily available?

ATL - What is the minimum system inventory, assuming a cryostat volume of 0.5 litres or 5.0 litres?

CDW - Could we use an Ageron system (ANS/Los Alamos cold source workshop) to minimize cryostat wall thickness and heat load?

- this may also be a way to avoid having to scram following loss of refrigerators 


\title{
nternal Correspondence
}

March 30, 199:

HFIR Futures Grmap Meeting

Autendance

The HFIR Futures Group held its fourth meeting at 8:30 a.m. On Monday, March 27, 1995, in the Blue Room of the FEDC. Those in attendance were:

\author{
Bill Appleton (observer) \\ Jim Ba!! (observer) \\ John Bigelow \\ Emory Collins \\ George Flanagan \\ Mike Harrington \\ John Hayter \\ Michele House: \\ Ken Thoms \\ Colin West (chair).
}

\section{Opening}

The meeting began with a review oi the minutes of the previous meeting, as is shown in the agenda in Attachment 1 . No suggestions were made for the revision of the meeting minutes. John Hayter did bring in a package of drawings from 1961 which were the "Certified for Construction" drawings for the HFIR, which be thought might be good for the group to have. Bill Appleton suggested we send the packet to Reproduction so that the original could be arch.ved. John H. reported that a small cold source in tube HB-4 would not be incompatible with the instrument upgrade. ideas.

\section{User Group}

Issues having to do with th: users were next discussed. John $\mathrm{H}$. remarked that another hidden interface might be people who use the HFIR who are not from ORNL. He highlighted the importance of communicating the groups ideas to those users. The fact that currently there is not a good forum for establishing consensus among users was mentioned. Bill suggested perhaps using Lee Magid, a user froin the University of Tennessee, as a coordinator for such a forum. The vehicle of electronic mail was proposed as one method of conumunication. This led to a discussion of the composition of a user organization.

The question was posed as to how formal a user organization was needed. George Flanagan mentioned that there was currently a user coordination group at the HFIR, having Randy Hobbs as its head. Jim Ball mentioned that it was important to have a user group with a user as its head. Several of those present at the meeting remarked that the users don't currently feel as if they are a unified group. Having some sort of group which could represent users in gencral on 
issues which arise would be very helpfu. There is not a good mechanism for communicating startup needs right now. Incidentally, John $\mathrm{H}$. reinarked that the Institurt Lave Langevin (ILL) had changed its startup cycle (no more Tuesday/Thursday starup and shutdown): after having been down for a whilu, it was probably important for that facility to produce neustrons period than to have a good paper schedule.

Bill remarked that Iran Thomas at DOE headquarters had been propounding the idea of having a joint advisory groun fir both HFBR and HFIR. He suggested that having a joint user group might be another option to ccnsider. Looking at HFIR upgrades might be a good rallying call for users; therefore, now is mopportume time for looking at user organizations. It was remarked that HFBR might also be looking at producing isotepes in the near future. The response was that both facilities werc currently examining many different options for the future.

\section{Catequization of HFIR Upgrades}

Colin next presented the updated list of the categorization of HFIR upgrades (see Attachment 2). George remarked that the addition of a positron source or cold source would bave a major effect on the reactor. Colin said that these iwo items world not have as large in effect on the reactor as would some other items, although he would not want to mirimize the effort involved to bring either of those things to pass.

John H. remarked that Larry Robinson's list of administrative upgrades could be tone tasily and at low cost. Colin pointed out that those items had been added to the list. The reryurrement for exit frisking was discussed further. John $\mathbf{H}$. described a turnstile surround monitor which could be calibrated to some sort of time-based frisking. This would be more streamlined than the current process, which at times generates a substantial line of people waiting to leave, and it might actually be safer. It was brought up that the site office contamination control requirements would need to be examined to see if they would allow such a turnstile system. Bill remarked that there needed to be a lot of discussion with the site office on these issues to try and reach an understanding of each others' needs.

Jim Ball suggested that the wording concerning the berylliun changeout be re-done. According to his reading of the rules, Jirn says that the inservice inspection (IS!) only requires inspection of accessible components-there is no requirement for the inspection of inarcessible ones. It is a local interpretation that has placed the need on th: HFIR of inspecting inaccessiblt: components; there needs to be communication with the site office about this too.

George said that a white paper went out last Friday to the site office stating that the Research Reactors Division (RRD) postion was to perform the 2-phase ISI. The division is now awaiting DOE support of this plan. Bill said he would try to get some help from MMES management on this.

\section{Preliminary catcogrization of HFR uporade, (costs)}

Colin continues with the list of the preliminary cost categonization of HFIR upgrades (see Attachment

3). George said that he had some new cost figures to share with the grouf: it was agreed that Colin and George would discuss them sometime during the next week, and the new costs would be presented at the next meeting.

John $\mathrm{H}$. semarked that it might be good to add another column to the list, given that research facilities are now in a somewnat competitive situation. His proposal was to add another column describing why the HFIR would be the bert location for certain types of facilities. This was judged to be an imporant point, especially given the situation conceming the possible spallation source for ORNL, and will be 
explored further in the future. The need for getting a group of MMES and DOE staff together to discuss the administrative changes was again highlighted.

Requirements for near-term installation of a HFIR cold neutron source

Next, Colin presented information about the installation of a cold source at the HFIR, including attention oeing paid to the questions raised in last week's meeting. First, however, be showed some asbuilt drawings of the HFIR veam tubes (see Attachment 4). HB-1 and HB-4 have extension tubes from the vessel in the region of the through tube. Details were shown of the non-reactor ends of these tubes. There is the physical possibility of having a $41 / 2^{\prime \prime}-5^{\prime \prime}$ diameter space near the center of the through tubes for a cold source. The preferre. 1 beam tube for the cold source is $\mathrm{HB} 4$, according to the needs of the users. There was some discussion about the composition of the plug at the ends of the two beams. George and Colin had thought they were made out of beryllium, although Colin had found it to be shown as aluminum in the drawings. George said he would check on this. John $H$ remarked that the composition of the plug would make a difference in the flux of the cold neutrons.

Colin remarked that the ANS had a single-phase, forced convection, cold source design. This is significant for the HFIR for 2 reasons-1) it allows for the maximum possible density of the cryogen, and 2) the lines to the cryostat can be small (some $\Delta p$ can be accommodated), allowing for more space for the beam. However, if one has some $\Delta p$, then a corresponding $\Delta T$ is experienced. Care must be exercised so that the temperature is not elevated.

A question was asked if the beam tubes could be pulled out while the reactor was kept running (i.e., without a shutdown while the tubes that had been removed were replaced). George said that mechanically it could be done, although perturbations in the flux might be experienced. Also, the beam tubes can be flooded with water and the reactur still nun. Another operation is to block off the beam tubes to allow the reactor to num.

Other suggestions were to make the beam tubes larger toward the outside of the vessel or make the cold source vertical (better space tor lines). Jim Ball remarked that the HFBR beams "fan out" as they leave the vessel. It was again emphasized that the design should be formulated to serve the users and minimize lost time due to stopping the reactor.

Colin then addressed the questions raised in last week's meeting (see Attachment 6 from last week's meeting notes). It was thor:ght that liquid or solid $\mathrm{N}-15$ would be about as good a moderator as deuterium, except that it operates at a higher temperature. The square law relating temperature and flux can be a problem. Discussion of the properties of $\mathrm{N}$-15 led to reference to a slide shown last week (see Attaciment 6 from last week's meeting notes). Colin remarked that there were problems with looking at methane as a styogen, although Trevor Lucas had given it some consideration: Trevor has had ideas on using methane pellets in a cryogenic process. The question was raised if there were other isotopes which could be used. Palladium, with adsorbed hydrogen, was mentioned, but it was remarked that it had a high hydrogen density, but it would probably not remove enough energy for scatiered neutrons.

Colin concluded that for the size cold source that could be put in the through tube, there would not be enough cold flux gain from using $\mathrm{N}$-15, and hydrogen would be preferred (despite the more arduous safety requirements). John $\mathbf{H}$. also mentinned the rotational ground state uncertainty associated with $\mathbf{N}$ 15. Colin said that he reconumended looking at hycirogen right away as the cryogen of the potential cold source. 
Michele Houser reported that both she and Trevor had been lookiug into the availability of N-15. Michele said that she and Trevor had both been referred to the Mound facility, who then referned the question to the Los Alamos plant. Trevor was expecting further contact from Los Alamos. Michele said that her industrial contacts did not have N-15 readily available either, but that it could be acquired, if requested. Trevor had gotten much the same response from Mound before he got referred to Los Alarros. No cost information had been obtained. N-15 is not readily available, in the sense of it being an on-tti-shelf commodity, but it can be made if specially requested. John Bigelow remarked that someone at Los Alamos had devised a clever process for mamufacturing N-15 and had gone into business doing this. $\mathrm{N}-15$ had been available in the past and probably could be obtained again if the right people are contacted.

Colin remarked that Trever is doing some caiculations on the system inventory and would have results soon. He then talked a bit about the Ageron system. Although it has several advantages, he concluded that it would be difficult to implenent such a system in this particular case. We will look at cold source ideas further.

Ideas about cost associated with the installation of a cold source were next debated. Colin thinks that a cold source could be installed for less than $\$ 5 \mathrm{M}$. Colin stated that NIST recently designed, built, and installed a new cold source for around $\$ 2 \mathrm{M}$. An earlier study cone of a cold source in one of the EF facilities at HFIR yielded a cost of the same order of magnitude. John $\mathbf{H}$. remarked that he thougit it took around $\$ 1.2 \mathrm{M}$ for NIST to buy the refrigerators, and that they spent around $\$ 400 \mathrm{~K}$ for testing. He projected that this might increase to $\$ 1 \mathrm{M}$ to do testing under DOE.

George said that the RRD component of installing a cold source at HFIR might be around \$1 M - 1.5 $M$, most of which vould be for an:'ysis for modifications to the S.AR. Colin asked how much of this would be for people already in RRD. George remarked that the work could be done with people in RRD, but the staff would have to be replaced with people from other divisions, unless other work were foregone. This complicates the costing process. George suggested that as much as possible of the system be mocked up and tested prior to installation-this would belp with technical specification and document changes.

John H. commented that the University of Texas at Austin had just retrofitted a cold source in its research reactor. They used methatylene, which evidently has some useful properties, as the cryogen. It might be helpful to visit the University of Texas at some point.

The possibility that the NRC might take over regulation of the DOE research reactors was discussed. It was remarked that this might not be a bad thing if the HFIR ended up on the Rescarth Reactoi side of the NRC. It could be bad if the NRC looked upon grandfathering regulations differently ic.g., HFIR has no contairment). There could possibly be several million dollars of savings if HFIR weie regulated by the NRC, as long as it was not regulated by DOE as well.

Jim remarked that DOE was assuming NRC regulation by 1997 in its planning base. It was also remarked that HFBR was already talking with the NRC about future regulation. Jim suggested that George talk with his counterparts at HFBR to gain some idea of the regulation situation there. It was suggested that the group find out who NIST dealt with in the NRC and talk with those staff members also.

A question arose as to the timing of the installation of the cold source at HFIR. Jim said he thought it should be in and running at the end of 1996. Bill said the publicity from the cold source would be good for ORNL. George asked a few questions about the \$5 $\mathrm{M}$ cost estimale and agreed with Colin that a 
cold soxrce could be installed for that amount. Colin remarked that his figure had quite a large margin of contingency in it and so should be adequate for HFIR's nueds.

\section{Qther business}

Geuge brought up some thoughts about the $U,{ }_{3}$, situation. He gave a cost estimate of $\$ 2.5 \mathrm{M}$ for $\mathrm{B} \&$ $W$ to process enriched uranyl nitrate that they have on hand. This is a cost of $\$ 16,000 / \mathrm{kg}$, about ten times that at $Y-12$. There is not exough money in the budget for $B$ \& $W$ to process the material for HFIR, NST, and HFBR. If the $U{ }_{3} \mathrm{O}_{2}$ camnot be gotten out of $Y-12$, the $B$ \& $W$ production line will have to be shut down in February 1996 . It will then cost $\$ 1.5 \mathrm{M}-2 \mathrm{M}$ to re-open the line. The office of Defense Prograras (DP) is blocking tie effarts to get fuel feed stock out of $Y-12$ quicldy, since fued processing is not a DP program.

There is $41 / 2$ years' worth of fabricated fuel elements inside the $Y-12$ facility. Also, there is a 3-4 month supply of $U_{3} \mathrm{O}_{2}$. B \& W is 3 elements ahead of use in its fabrication. There is some $U{ }_{3} \mathrm{O}_{2}$ stored at Y-12 uhich needs to be processed a bit more. George said they thought B \& W could do this for about $\$ 200 \mathrm{~K}$. However, this material would still have to be gotten out of Y-12. The facility where this material is stored is almost last on the list of facilities to be cleared for restart. It was remarked that all of the research reactors affected needed to work together at a high level on this. George remarked that there was a meeting in Idaho this week with reports from difierent reactors and that hopefully the issue would be discussed there.

The meeting closed with the comment that the ISI situation was pretty we!l resolved, although not as much beadway was being made with the $\mathrm{U}{ }_{3} \mathrm{O}_{8}$ situation. Reservations about the cost figures in the list would be discussed during this coming week The meeting adjoumed until April 3.

\section{ACTION ITEMS}

George Flanagan will check to confirm if the plug on the beams of the through tube is made out of aluminum, rather than beryllium.

George Flanagan and Colin West will communicate about cost figures, and a new table will be presented.

M. M. Houser, March 30, 1995 
Distribution

HFIR Fumres Group ínotes for record + aunchmen(s)

J. E Bigelow, 7930, MS-6385

E. D. Coi:ns, 7930, MS-6385

G. F. Flanagan, 7917, MS-6398

R. M. Harrington, FEDC, MS-8218

J. B. Hayter, FEDC, MS-8218

M. M. Houser, FEDC, MS-8218

J. P. Moore, 4508, MS-6080

L. Robinson, 4500S, MS-6128

K. R. Thoms, 9108, MS-8087

C. D. West, FEDC, MS-8218

For information (notes for record + attachinenis)

B. R. Appleton, $4500 \mathrm{~N}, \mathrm{MS}-6240$

J. B. Ball, 4500 N, MS-6182

R. E. Battle, FEDC, MS-8218

H. A. Glovier, 7917, MS-6398

H. A. Mook, 7962, MS-6393

J. B. Richard, 7962, MS-639i 
ATTACHMENT 1 


\section{AGENDA FOR \\ HFIR FUTURES GROUP MEETING}

Monday, March 27, 1595

8:30 a.m.

FEDC, Blue room

- Discussion: Changes or corrections to 3/20/95 meeting notes for the record

- Discussion: Amended lists of HFIR upgrade proposals

- Questions on requirements for near-term installation of a HFIR cold neutron source

J. B. Hayter, M. M. Houser,

A. T. Lucas,

C. D. West

- Any other business 
ATTACHMENT 2 
Must de to continue operation
Get supplies of enriched U, $\mathrm{O}_{3}$
for $\mathrm{B} \& \mathrm{~W}$
Inservice inspection

Beryllium replacement

Facility or instrument improvements

New instrument layout

New gamma-irradiation facility

Guide hall (building extension)

Positron source

Cold source in an existing (e.g., beam tube) fac lity

Replace and improve those systems that are limiting reactor availability

Obtain hot cell nearby (portable one over pool or over the critical pool, similar to that at the ORR)

Improve transport methods from the HFIR to the HRLEL

New, modem scaltering instruments
Benefits

Avoids closedown!

Avoids closedown!

Avoids closedown!

Benefits

Much enhanced experimental capability for neutron scattering

An enhanced capability, c.f., the fuel element ganmafacility

More space for more cold neutron instruments

Could be world-beating facility

Would augment ORNL's reputation as a credible national facility for major areas of neutron research

Could significantly enhance predictability and reduce the cost per neutron

Could shorten turnaround time for isotope production. Would streamline operations for storing spent fuel elements.

Could shorten turnaround time for isotope production.

Could improve performance on existing beams.
Notes

Needed by fall of 1995

Needed by 1996 or 1997, but might be phased, with accessible items inspected by 1997 and inaccessible ones delayed until beryllium replacement

Needed by 1999 or 2000

Notes

No significant impact on any reactor systems

Could be placed inside tine HFIR building, or outside with a rabbit-tube connection

The highest short-term priority for neutron scattering and neutron activation users

Could make a significant change to the outside users' perceptions of HFIR

Could be used by both isotope production and materials testing users (to cut open capsules) and operations staff (to can fuel elements) 


\author{
Qperational and fuel fabrication \\ chmees \\ Fuel plate inspection/selection \\ improvements to permit \\ operation at $-10 \%$ higher \\ power than now
}

Select existing fuel elements that will permit operation at $-10 \%$ higher power than now

Core life extension through higher vohume fraction of $U_{3} \mathrm{O}_{2}$ fuel

Core life extension and/or higher power and/or reduced earichment through adoption of silicide fuel.

\section{Enhancements requiring some chanpes to the reactor \\ New through-tube and cold source}

New irradiation holes in beryllium

Increase diameter of beam ubes

New hydraulic rabbit tube

Add capability for additional hydraulic rabbits in the target island
Benefits

Higher power would provide more neutron flux, for more sensitive experiments and/or shorter experiment times

Higher power would provide more neutron flux, for more sensitive experiments and/or shorter times to accommodate more userstyear

Longer core life could provide greater availability and predictability; leads to more neutrons per year, lower operating cost, and therefore lower cost per neutroo.

Same advantages as previous item. Also, possibility of reducing enrichment if that becomes necessary or advantageous.

Benefits

A really major enhancement of neutron scattering capabilities

For enhanced Pu production capabilities

Higher useful flux for neutron scattering

Additional irradiation capabilities

Additional irradiation capabilities
Notes

More accurate inspections are now possible using the recendly-installed digital scanner at B \& W. Shorter experiment times would accommodate more users/year. Low cost action.

Based on the measurements that were routinely made during fabrication. Low cost action.

Uses standard HFIR compound $(\mathrm{U}, \mathrm{O}, \mathrm{s}$, but for these fuel densities the data base on silicide fuel may actually be more extensive.

Silicide fuel is used worldwide, and the alredy extensive data base was further exiended by ANS.

Noves

Would make the HFIR a worldbeater in some very important areas

Could also be used for production of other isotopes

Enhances isotope production and malerials irradiation capabilities

Enhances isotope production and materials irradiation capabilities 
Enhangements reauining some changes to the reactor (cont)

Provide capability for hydraulic rabbits in the RB and VXF positions

Provide more convenient access to capsules in PTP positions

Harden spectrum in taget islond

Modify reactor top bead for better access to reflector positions

Restore HFIR-REDC hydraulic uransport facility

Major performance Enhancements/ife extension

New, non-pressurized, nonsteel reflector tank
Benefits

Additional irradiation capabilities
Notes

Enhances isotope production and materials irratiation capabilities

Enhances isotope production and materials intadiation capabilities

e.g., Take water out and make full-length fins out of targets or use stainless steel, rather then aluminum, for triget jactet (spectral tailoring)
Could shorten turnaround time for materials irtediation and isotope production.

Benefits

Higher core power possible with existing primary cooling system. Use low activation materials.

Approximately doubles the flux at the beam tubes. No further need for beryllium

replacement. More flexible for future changes.

Using ANS cold source design, would give a cold neutron flux 2-3 times that of IIL
Notes

Can incorporate additional beam tubes, a cold source, and other experimental facilities to make HFIR the world's best in some important areas of neutron scautering

Would give a performance $50 \%$ $-100 \%$ better than IIL (but, with many fewer instrument stations)

Easily the world's best facility. by a factor of two or three, for cold neutrons source in the new $\mathrm{D}_{2} \mathrm{O}$ reflector 
Administrative (user

enspective)

Improve training for users and streamline ORNL guest

requirements

Improve commmication and information exchenge

HFIR home page on World Wide Web

Team-building for users, RRD, crafts, and Health and Safety

\section{Examine exit frisking}

requirements

Soudy the Work for Others

process for improvements

Enhance the facility's aesthetics (e.g., the dining facilities)

Operations ownership clarification
Benefius

Save cost and time for both visiting users and resideat staff.

Improve effectiveness and performance of users and operacions personnel.

Possible marketing tool for ORNL.

Save cost and time for both users and operations personnel. Improve job satisfaction.

Save cost and time for both users and operations personnel.

Better industrial, university, and in-house user support for the HFIR.

Better industrial and university supporn for the HFR.

More efficient scheduling. more responsive regulations, more uniform guidance
Nores

Improves ourside users" perception of HFIR. Could also improve scheinuling problems.
Improves ouside users' perception of HFIR.

Obviously a good thing!

$$
\begin{aligned}
& \text { NE/ER } \\
& \text { responsibility } \\
& \text { split } \\
& \text { Relationships } \\
& \text { and } \\
& \text { communication } \\
& \text { amnong RRD, } \\
& \text { users, and site } \\
& \text { office } \\
& \text { Informal } \\
& \text { Operational } \\
& \text { consortium } \\
& \text { (e.g. Los } \\
& \text { Alamos and } \\
& \text { ORR } \\
& \text { examples) }
\end{aligned}
$$


ATTACHMENT 3 
Preliminary Categorization of HFIR Upgrades

\begin{tabular}{|c|c|c|c|}
\hline Must do to continue operation & Duration & Gross Cost & Net Cost. \\
\hline $\begin{array}{l}\text { Get more enriched U, } 0, \text { for } \\
\text { B \& W }\end{array}$ & & $0 ?$ & $0 ?$ \\
\hline Inservice inspection & $2 / / 2$ months (first phase) & $\$ 1 \mathrm{M}$ (in 1997) & approx, same \\
\hline Beryllium replacement & 6 months & $?$ & $\$ 700 \mathrm{~K}$ \\
\hline Facility or instrument improvements & Duration & Gross Cost & Net Cost. \\
\hline \multicolumn{4}{|l|}{ New instriment layout } \\
\hline \multicolumn{4}{|l|}{ New gamma-irradiation facility } \\
\hline \multicolumn{4}{|l|}{ Guide hall (building extension) } \\
\hline Positron source & $\begin{array}{l}3 \text { years before Be } \\
\text { changeout }\end{array}$ & $\$ 17 \mathrm{M}$ & approx. same \\
\hline Cold source in an existing (c.g., bean tube) racility & - I year & $\leq \$ 5 M$ & approx. same \\
\hline \multicolumn{4}{|l|}{$\begin{array}{l}\text { Replace and improve those systems that are limiting } \\
\text { reactor availability }\end{array}$} \\
\hline \multicolumn{4}{|l|}{$\begin{array}{l}\text { Obtain hot cell nearby (portable one over pool or over } \\
\text { the critical pool, similar to that at the ORR) }\end{array}$} \\
\hline \multicolumn{4}{|l|}{$\begin{array}{l}\text { Improve transport methods fiom the HFIR to the } \\
\text { HRLEL }\end{array}$} \\
\hline New, modern scattering instruments & & & \\
\hline
\end{tabular}


Preliminary Categorization of HFIR Upgrades (cont.)

\begin{tabular}{|c|c|c|c|}
\hline Operational and fuel fabrication changes & Duration & Gross Cost & Net Cost" \\
\hline $\begin{array}{l}\text { Fuel plate inspection/selection improvements to permit } \\
\text { operation at }-10 \% \text { higher power than now }\end{array}$ & & & 0 \\
\hline $\begin{array}{l}\text { Select existing fuel elements that will permit operation } \\
\text { at }-10 \% \text { higher power than now }\end{array}$ & & & 0 \\
\hline \multicolumn{4}{|l|}{$\begin{array}{l}\text { Core life extension through higher volume fraction of } \\
\mathrm{U}_{3} \mathrm{O}_{3} \text { fuel }\end{array}$} \\
\hline \multicolumn{4}{|l|}{$\begin{array}{l}\text { Core life extension and/or higher power and/or } \\
\text { reduced enrichment through adoption of silicide fuel }\end{array}$} \\
\hline $\begin{array}{l}\text { Enhancements requiring some changes to the } \\
\text { reactor }\end{array}$ & Duration & Gross Cost & Net Cost" \\
\hline \multicolumn{4}{|l|}{ New through-tube and colu source } \\
\hline New irradiation holes in beryllium & & $\$ 200 \mathrm{~K}$ & approx. same \\
\hline \multicolumn{4}{|l|}{ Increase diameter of beam tubes } \\
\hline \multicolumn{4}{|l|}{ New hydraulic rakbit tube } \\
\hline \multicolumn{4}{|l|}{$\begin{array}{l}\text { Add capability for additional hydraulic rabbits in the } \\
\text { target island }\end{array}$} \\
\hline \multicolumn{4}{|l|}{$\begin{array}{l}\text { Provide capability for hydraulic rabbits in the RB and } \\
\text { VXF positions }\end{array}$} \\
\hline $\begin{array}{l}\text { Provide more convenient access to capsules in PTP } \\
\text { positions }\end{array}$ & & & \\
\hline
\end{tabular}




\section{Preliminary Categorization of HFIR Upgrades (cont.)}

\begin{tabular}{|c|c|c|c|}
\hline $\begin{array}{l}\text { Enhancements requiring some changes to the } \\
\text { reactor }\end{array}$ & Duration & Gross Cost & Net Cost ${ }^{\circ}$ \\
\hline \multicolumn{4}{|l|}{ Harden spectrum in target island } \\
\hline $\begin{array}{l}\text { Take water out and make full-length } \\
\text { jins out of targets }\end{array}$ & & & \\
\hline $\begin{array}{l}\text { Use stainless steel, rather than } \\
\text { aluminum, fur target jacket (spectral } \\
\text { tailoring) }\end{array}$ & & & \\
\hline \multicolumn{4}{|l|}{$\begin{array}{l}\text { Modify reactor top head for better access to reflector } \\
\text { positions }\end{array}$} \\
\hline \multicolumn{4}{|l|}{ Restore HFIR-REDC transport facility } \\
\hline Major performance enhancementshife extension & Duration & Gross Cost & Net Cost ${ }^{\circ}$ \\
\hline New, non-pressurized, non-steel reflector tan'- & $>1$ year shutdown? & $\begin{array}{l}\$ 78 \mathrm{M} \text { (as-spent dollars; } \\
\$ 70 \mathrm{M} \text { in } 1994 \text { dollars) }\end{array}$ & $\$ 50 \mathrm{M}$ \\
\hline $\begin{array}{l}\text { Replace the beryllium reflector with } \\
\mathrm{D}_{2} \mathrm{O}\end{array}$ & & & \\
\hline $\begin{array}{l}\text { Install a large, deuterium cold source } \\
\text { in the new } \mathrm{D}_{2} \mathrm{O} \text { reflector }\end{array}$ & & $\begin{array}{l}\text { additional \$45 M (very } \\
\text { conservative as-spent } \\
\text { dollars) }\end{array}$ & approx, same \\
\hline Administrative (user perspective) & Duration & Gross Cost & Net Cost ${ }^{\circ}$ \\
\hline \multicolumn{4}{|l|}{$\begin{array}{l}\text { Improve training for users and streamline ORNL guest } \\
\text { requirements }\end{array}$} \\
\hline Improve communication and information exchange & & & \\
\hline
\end{tabular}

Deyond normal HFIR staff and operating costs 
Preliminary Categorization of HFIR Upgrades (cont.)

\begin{tabular}{l|l|l|l} 
Administrative (user perspective) & Duration & Gross Cost & Net Cost* \\
\hline HFR home page on World Wide Web & & & \\
\hline $\begin{array}{l}\text { Team-building for users, RRD, crafts, and Hcalth and } \\
\text { Safety }\end{array}$ & & & \\
\hline Streamline ORNL guest requirements & & & \\
\hline Examine exil frisking requirements & & & \\
\hline Study the Work for Others process for improvements & & & \\
\hline $\begin{array}{l}\text { Enhance the facility's aesthetics (e.g., the dining } \\
\text { facilities) }\end{array}$ & & & \\
\hline $\begin{array}{l}\text { Operations ownership clarification } \\
-\quad \text { NE/ER responsibility split }\end{array}$ & & & \\
\hline$\quad$ among RRD, users, and site office & & & \\
\hline$\quad \begin{array}{l}\text { Informal operational consortium (e.g., } \\
\text { Los Alamos and ORR examples) }\end{array}$ & & & \\
\hline
\end{tabular}

beyond normal HFIR staft and operating costs 
ATTACHMENT 4 


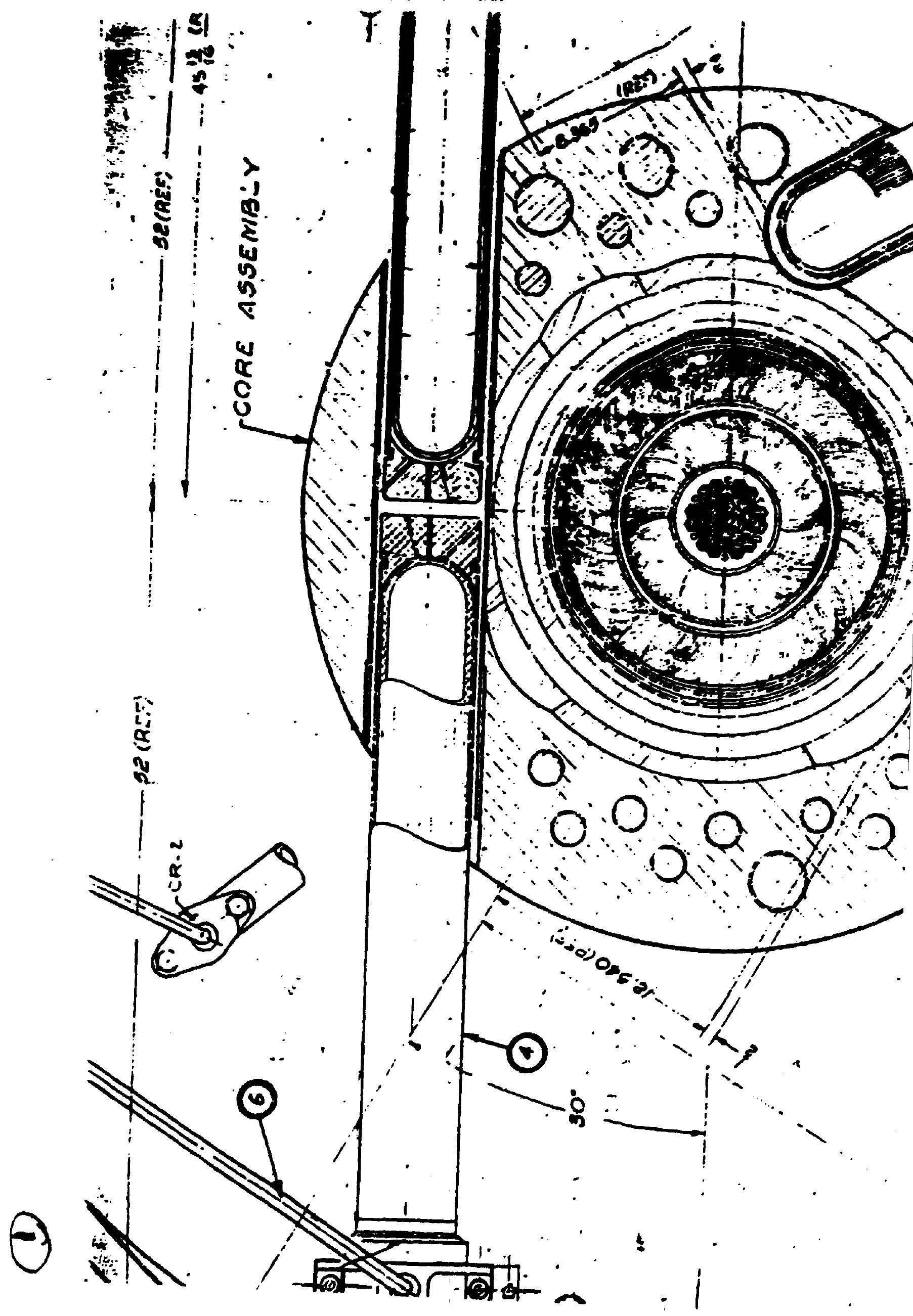




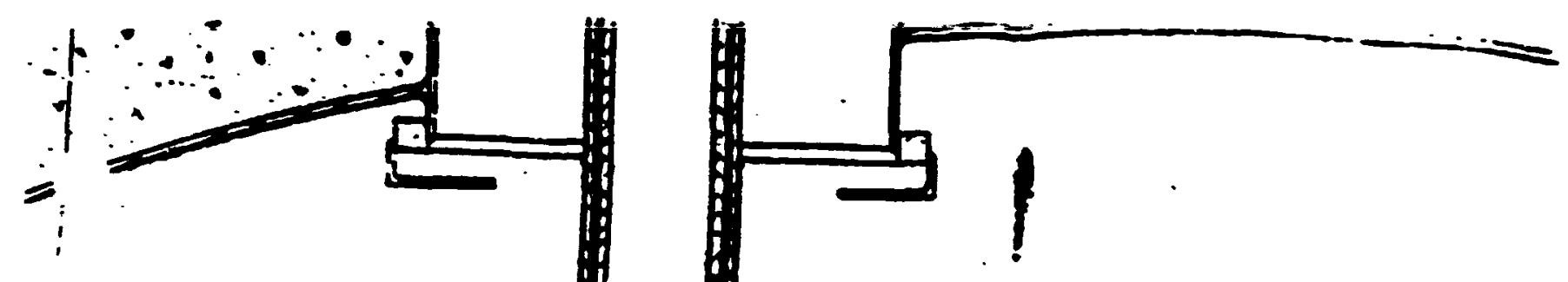

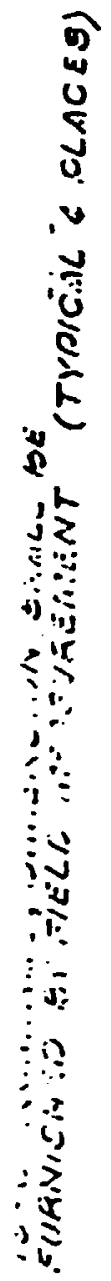




\section{nternal Correspondence}

April 4, 1995

HFIR Futures Group Meeting

Altendance

The HFIR Futures Group held its fifth meeting at 8:30 am. on Monday, April 3, 1995, in the Blue

Room of the FEDC. Those in attendance were:

John Bigelow

George Flanagan

Michele Houser

Hert Mook

Peyton Moore

Larry Robinson

Ken Thoms

Colin West (chair).

\section{Opening}

Colin West began the meeting by asking if there were any changes in the minutes from the last meeting. None were mentioned, so Colin proceeded with the meeting as shown in the agenda in Attachment 1.

\section{Yet another list and categorization}

Colin presented an updated and reorganized version of the HFIR upgrades list in a presentation shown in Autachment 2. He grouped the items into three categeries according to cost. These calegories were: minor costs--costs for materials and labor from outside RRD are less than or equal to $1 \%$ to $2 \%$ of HFIR's annual operating budget; significant costs--costs outside of RRD are in the range of $2 \%$ to $10 \%$ of the annual operating budget; and major costs--costs outside of RRD are greater than or equal to $\$ 5$ M. See Attachment 2 for the breakdown of items into these categories.

Colin asked that group members review his list and give more input into items under the "Benefits" column. He stated that the group needed to make the strongest case possible for these benefits, especially taking into account the effects of each idea on other users. John Bigelow remarked that he might need some input from RRD on formulating his ideas for hardening the spectrum in the targets. Lamy Robinson commented that larger holes in the beryllium might also help the analytical chemistry users in that it would allow them to increase the size of their pneumatic tube. Colin highlighted the fact that any upgrade which would benefit more than one user would have a greater probability of support.

When the list of administrative changes was presented, Colin remarked that it seemed rather long. He suggesied that the group try to collapse the list. Larry agreed to try to do that before the 
next meeting. John B. suggested that "Operations ownership clarification" become its own major heading, thereby shortening the list somewhat. Colin agreed to do that.

Colin then proposed that a new item be added to the list of low-cost, no-impact-on-reactor items. He suggested that a very detailed MCNP/MOCUP model be created, benchmarked thoroughly, and maintained for the HFIR (see Attachment 3). MCNP is a Moute-Carlo code which had been used on the ANS. It can be used to predict neutronics, flux, core life, and other parameters of reactor operation, thus showing the effect of any changes on the reactor configuration. This would be of service both to the users and to the designers. Ken Thoms remarked that there was already an MCNP model for the HFIR, and George Flanagan added that there was a program to do some benchmarking with it. Colin was aware of this, so he added that the current MCNP nodel for HFIR mainly needed to be enhanced and made more detailed.

On the first page of the "Significant Cost" category, George asked that we take out the word "rad." in the cold source item: the estimate was for all work done by RRD. Colin remarked that there was still no cost for the "Guide hall (building extension)" item. Herb Mook said that a number of \$15 M had been estimated a few years ago for a guide hall expansion, but it had not included a cold source. He thought we should examine that \$15 M figure, so Colin asked that he check into that

Another option mentioned was to look at using GPP funds for some of the upgrades having to do with the guide hall extension. The limit to these funds is $\$ 2 \mathrm{M}$, and the project has 10 involve several different divisions and programs. Colin said that it might be possible to separate the guide hall structure from the rest of the project and stay under the $\$ 2 \mathrm{M}$ mark. Even at the current high rate of around $\$ 20 \mathrm{~J} / \mathrm{ft}^{2}$, this would yield $10,000 \mathrm{ft}^{2}$ of space.

George said that perhaps the transformers, which are occupying the space where a guide hall might be located, could be moved with maintenance funding. These are internal ORNL dollars that are earmarked for high-voltage and other electrical upgrade:: it would be beneficial in many ways for the HFIR to get ORNL to spend existing funds on neutron science.

The high price of doing contract work was discusser. George repeated a point he had made in earlier meetings that having to contact out construction work through MK Ferguson raised prices by a factor of 2 or 3. If the Davis-Bacon Act is rescinded and HFIR can let its uwn contracts, a subetantial saving could result.

Colin requested more information on the benefits associated with modifying the reactor top head and restoring the HFIR-REDC hydraulic transport facility. Ken agreed to write up some benefits for the reactor top head, and John B. will more fully explain the hydraulic transport benefits. John B. remarked that the costs of the first two items on the page were $\$ 1 \mathrm{M} /$ rabbit, not $\$ 1 \mathrm{M}$ total. The list will be amended accordingly.

The major cost items were then discussed. Herb questioned the $\$ 9.4 \mathrm{M}$ for the beryllium replacement, because that figure also includes some inservice inspection (ISI) work, but George said that the ISI was only a small amount. With escalation to the year 1999, the cost would still be around $\$ 9.4 \mathrm{M}$. Colin asked for better wording on wie benefits of installing a nearby hot cell (e.g., why it is important to have quick turnaround on isotopes).

The last category addresser was a list of items with no cost estimate yet available. According to Herb, the new, modern scattering instruments and the new instrument layout should have minor costs, and some mone; :s available for doing upgrades such as these. John B. agreed to write up the benefits of 
improving the HFIR-HRLEL transportation methods. The issuce of what was going to happen if there was nok enough room to stare spent fuel elements was also mentioned. There are several options for dealing with spent fuel eliments, and George agreed to write them up for the "Must do to continue operaion" category.

The timing of the study completion was then mentioned, and Colin told the group about a meeting in Washington on April 25 between DOE and several reseanch reactors for which it might be good to have some recommendations for HFIR (see Auschment 4). The feasibility of doing this will be explored in the next few days by Colin. He also agreed to create a draft outline of the study group's report for review by the group, hopefully this week

\section{Clarification on fectures of HFIR's through-nibe configuration}

George then talked about features of HFR's through-tube configuration. In response to a question from last week, George remarked that the nose-piece scatterblock on both HB-1 and HB-4 is made out of beryllium, not aluminum as was thought last week (see Altachment 5). There is an aluminum bousing around the beam tube, and the heavier aluminum tube is the containment boundary. The beam tube is bollow until it gets toward the nozale of the vessel, and it is filled with belium. There was some discussion of the best location and the best moderator for a cold source. It is thought that water would be a good moderator, as beryllium does not scatter cold neutrons. Ken asked about the feasibility of having one long beam tube going through both HB-1 and HB-4. George said that insertion and removal difficulties would likely prohibit that configuration.

\section{Possible extra space for beam and scatrering insmments}

George went on to present an idea that $R R D$ staff had for creating extra space for beam and scattering instnuments. It would involve moving the battery room and electrical equipment room from the groumd floor of the reactor building to the first floor, in the old fuel vault storage area isee Attachment 6). This would actually provide more direct access from the battery room to the pony motors. Access to the sub-pile room would be from the first floor, rather than from the ground floor. There would be some cost associated with this rearranging.

Larry mentioned the possible rearrangement of space near the first floor main entrance experiment room. There is evidently some storage space right at the entrance which contains janitorial supplies and other equipment that the analytical chemistry users would like to use for a taboratory. George said there should be no problem in relocating that material so that Larry and his staff could use the space.

Larry also mentioned that the paeumatic tubes go across the main thoroughfare in the experiment room. This could cause ALARA concerns, due to activated material being present in the rabbits. Larry said it would be much more efficient to bave the place the samples returned to be near to the face of the reactor wall. Colin asked Larry to write up his needs to add to the list of upgrades.

\section{Oaher business}

Herb brought up his concerns about the feasibility of putting a cold source in the through-tube of the HFIR. He asked about calculations done on the location of the cold source, and Colin informed him of Trevor Lucas' rough calculations and sketches which are currently underway. Colin asked if there were any simple ways of doing lests in the beam tubes currently, i.e., such as putting a can of water in a beam tube. He was told by several that such an experiment could not be done easily. 
Questions arose about the funding for studying upgrades, and Colin remurked tha Jim Ball had provided \$10,000 of Associnte Director Programmatic Funds for this (the lerer anended this to $\$ 40,000$ ). This should allow work to be done on a proposal and program for putting a cold source into the HFIR. Colin thought thax around $\$ 100,000$ would be needed to really study the situation to get the best performance and design. The possibilities of using New Facilities Initiative andi ORNL internal funds were discussed.

Ken asked about the possibility of installing a cold source vertically. Several thought this would be even a bigger change to the reactor, consequently maling it hader to realize in the short cerm. Putting a hole for this in the beryllium was debeted, since the beryllium is to be machined soon. Since the beryllium replacement may be delayed until 1999 or 2000 , the beryllium machining may be correspondingly postponed.

The pros and cons of having a cold source that is less powerful than ILL were debated, and George explained HFIR's position on the ISI and beryllium replacement to Herb. The possibilities of dealing with NRC, rather than DOE, were again mentioned. Copies of the updated list of upgrades were handed our (see Attachment 7), and the meeting adjourned until April 10.

\section{ACTION TTEMS}

Larry will combine items in the list of administrative changes and write up the needs of analytical chemistry users for space in the reactor building.

Michele will re-do the list of HFIR upgrades to incorporate the changes mentioned in the April 3 meeting.

Herb will investigate the cost of guide hall expansion.

Ken will write up the benefits of modifying the reactur top head.

John B. will write up the benefits for the HFIR-REDC transport facility restoration and for the improvement of the HFIR-HRLEL transportation methods.

George will write up the options, with associated benefits, for dealin-s with HFIR's spent fuel elements. Colin will address issues conceming the April 25 meeting and will also create a draft outline of the group's study report.

M. M. Houser, April 3, 1995 
Distribution

HIFIR Futures Group Attendees (notes for record only)

J. E. Bigelow, 7930, MS-6385

G. F. Flanagan, 7917. MS-6398

M. M. Houser, FEDC, MS-8218

H. A. Mook, 7962, MS-6393

J. P. Moore, 4508, MS-6080

L. Robinson, 4500S, MS-6128

K. R. Thoms, 9108, MS-8087

C. D. Wesh, FEDC, MS-8218

For information (notes for record + altachments)

B. R. Appleton, 4500N, MS-6240

J. B. Ball, $4500 \mathrm{~N}, \mathrm{MS}-6182$

R. E. Battle, FEDC, MS-8218

E. D. Collins, 7930, MS-6385

H. A. Glovier, 7917, MS-6398

R. M. Harrington, FEDC, MS-8218

J. B. Hayter, FEDC, MS-8218

J. B. Richard, 7962, MS-6391 
ATTACHMENT 1 


\section{AGENDA FOR \\ HFIR FUTURES GROUP MEETING}

Monday, April 3, 1995

8:30 a.m.

FEDC, Blue room

- Discussion: Changes or corrections to 3/27/95 meeting notes for the record proposals

- Clarification on features of HFIR's through-tube

G. F. Flanagan configuration

- Possible extra space for beams and scattering instruments

G. F. Flanagan

- Any other business 
ATTACHMENT 2 


\section{YET ANOTHER LIST AND CATEGORIZATION!}

C. D. West

Monday, April 3, 1995 


\section{EXTRA COSTS (costs other than RRD staff)}

Minor

Costs for materials and labor from outside RRD $\leq 1 \%-2 \%$ annual operating budget

Significant

Cost outside RRD in the range $2 \%-10 \%$ of annual operating budget - would require substantial and determined reprioritization of other work to accomplish without additional funding

Major

Extra costs $2 \$ 5 \mathrm{M}$ (the amount potentially available under the facilities initiative); would definitely require specific exira operating/capital equipment funds, or line item funds 


\section{MINOR COST ( $<1 \%$ to $2 \%$ of HFIR ANNUAL OPERATING BUDGET) CHANGES (1)}

Facility or Instrument

Improvements

New gamma irradiation facility
Benefits

An enhanced capability compared with the present fuel element gamma facility

Operational and Fuel

Eabrication Changes

Select existing fuel elements that will permit operation at $10 \%$ higher power

Higher power would provide more neutron flux for more sensitive experiments and/or shorter experiment times

Fuel plate inspection/selection improvements to permit operation at $10 \%$ higher power 


\section{MINOR COST ( $<1 \%$ to $2 \%$ of HFIR ANNUAL OPERATING BUDGET) CHANGES (2)}

Enhancements Requiring Some

Changes to the Reactor

Harden spectrum in targets

- displace some light water from the target island (add full length fins to targets)

- use stainless steel target jackets (spectral tailoring)

New irradiation holes in beryllium (when Be is changed out)

Increase diameter of some beam ubes (when $\mathrm{Be}$ is changed)"

Provide more convenient access to capsules in PTP positions (during shutdowns)

\author{
Benefits
}

?
Enhanced isotope production materials irradiation capabilities

More neutrons on sample

Enhanced isotope production and materials irradiation capabilities

If SAR's done in-house. 


\section{MINOR COST ( $<1 \%$ to $2 \%$ of HFIR ANNUAL OPERATING BUDGET) CHANGES (3)}

Administrative Changes (User

Perspective)

Improve training for users and streamline ORNL guest

requirements

Improve communication and information exchange

HFIR home page on World Wide Web

Team-building for users, RRD, crafts, and Health and Safety

Examine exit frisking requirements

Study the Work for Others process for improvements

Enhance the facility's aesthetics (e.g., the dining facilities)

Operations ownership clarification
Benefits

Improves outside users perception of HFIR. Could also improve scheduling problems
More efficient scheduling, more responsive regulations, more uniform guidance

- NE/ER responsibility split

- Relationships and communication among RRD, users, and site office

- Informal operational consortium (e.g., Los Alamos and ORR examples) 
SIGNIFICANT COST (COSTS OUTSIDE RRD IN THE RANGE 2\%-10\% OF ANNUAL OPERATING BUDGET - WOULD REQUIRE SUBSTANTIAL AND DETERMINED REPRIORITIZATION OF OTHER WORK TO ACCOMPLISH WITHOUT ADDITIONAL FUNDING, OR PERHAPS USE OF FACILITIES INITIATIVE FUNDS OR GPP) (1)

Minst do to continue operation

Get supplies of enriched $U_{3} O_{\varepsilon}$ for $B \& W$

Inservice inspection

Eacility or Insmument

Improvements

Cold source in an existing (e.g., HB-4 beam tube) facility

Gride hall (building extension)

Replace and improve diesels $\quad \$ 0.7 \mathrm{M}$
Cost guess

$\$ 0.5-\$ 5.0 \mathrm{M}$

$\$ 1 M$ in 1987

$\$ 3 \mathbf{M}+\$ 2 M$ rad work by

RRD

?

More space for cold neutron instruments and users

Enhanced reliability and availability

Would qualify for GPP, since many different civisions and programs would use the instruments housed in this extension. 
SIGNIFICANT COST (COSTS OUTSIDE RRD IN THE RAISGE 2\%-10\% OF ANNUAL OPERATING BUDGET - WOULD REQUIRE SUBSTANTIAL AND DETERMINED REPRIORII IZATION OF OTHER WORK TO ACCOMPLISH WITHOUT ADDITIONAL FUNDING, OR PERHAPS USE OF FACILITIES INITLATIVE FUNDS OR GPP) (2)

Operational and Fuel

Eabrication Changes

Core life extension through higher volume fraction of $\mathrm{U}, \mathrm{O}_{8}$ fuel

Core life extension and/or higher power and/or reduced enrichmert through adoption of silicide fuel
Cost quess

\$0.8 M R\&D and tooling + $\$ 0.5 \mathrm{M}$ for

SAR

preparation

in $R R D$

$\$ 2.1 \mathrm{M}$ for development and tooling + $\$ 1.8 \mathrm{M}$ for SAR prepared by RRD and an environmental assessment (HEU) plus an additional $1.5 \mathrm{M}$ for reactor mods and critical experiments (if enrichment is reduced)
Benefits

Lower operating costs and higher availability

Lower operating costs and higher availabilityl higher flux/nonproliferation policy response 
SIGNIFICANT COST (COSTS OUTSIDE RRD IN THE RANGE 2\%-10\% OF ANNUAL OPERATING BUDGET - WOULD REQURE SUBSTANTIAL AND DETERMINED REPRIORITIZATION OF OTHER WORK TO ACCOMPLISH WITHOUT ADDITIONAL FUNDING, OR PERHAPS USE OF FACILITIES INITIATIVE FUNDS OR GPP) (3)

Enhancements Requiring Some

Changes to the Reactor

Add capability for additional

rabbit tubes in target island

Provide capability for

hydraulic rabbits in the $\mathbf{R B}$

and VXF positions

Provide more convenient access to capsules in PIP positions while reactor is operating

Modify reactor top head for better access to reflector positions

Restore HFIR-REDC

hydraulic transport

facility
Cost guess Benefits

$\$ 1 \mathrm{M}$ Enhances isotope production and materials irradiation capabilities

\$1 M

$\$ 1 \mathrm{M}$

$\$ 0.5 \mathrm{M}-\$ 2 \mathrm{M}$

$?$

$\$ 0.5 \mathrm{M}-\$ 1 \mathrm{M}$

$?$ 
MAJOR COST ITEMS ( $2 \$ 5 \mathrm{M}$, THE AMOUNT POTENTLALLY AVAILABLE UNDER THE FACILITIES INITIATIVE - WOULD DEFINITELY REQUIRE SPECIFIC EXTRA OPERATING, CAPITAL EQUIPMENT, OR LINE ITEM FUNDS)

Must do to continue operation

Beryllium replacement

Eacility or Instrument

Improvements

Replace and upgrade I\&C systems

Install nearby hot cell (portable one ovei the pool, similar to that in the ORR)

Positron source

Enhancements Requiring Some Changes to the Reactor

New, larger through-tube and vertical cold source (at beryllium changeout)
Cost quess

$\$ 9.4 \mathrm{M}$

$\$ 5 M$

$\$ 10 M$

$\$ 17 \mathrm{M}$

$\$ 25 \mathrm{M}$

$2 \$ 79 \mathrm{M}^{\circ}$

New, non-pressurized, non-
steel reflector tank with $D_{2} O$
instead of beryllium

New, non-pressurized, non-
steel reflector tank with $D_{2} O$
instead of beryllium

New, non-pressurized, non-
steel reflector tank with $D_{2} O$
instead of beryllium

MaiorPerformance

Enhancements
Benefits

Avoids closedown!
Enhanced reliability and availability

Would shorten turnaround time for isotope production and materials testing uses. Could be used to can fuel elements for storage

A world-beating facility

Would require additional guide hall space, more flux, more beam tubes, large cold source, and other new facilities. Would make HFIR 2-3 times better than ILL (although still with fewer instrument stations).

Large deuterium cold source $\$ 45 \mathrm{M}$ in the new $\mathrm{D}_{2} \mathrm{O}$ reflector 


\section{ITEMS WITH NO COST GUESS AVAILABLE YET}

Eacility or Instrument

Improvements

New, modern scattering instruments

New instrument layout

Improve transportation methods from HFIR to HRLEL
Benefits

Could improve performance on existing beams

Much enhanced experimental capability for neutron scattering 
ATTACHMENT 3 


\section{Additional low-cost, no-impact-on- reactor item?}

* Create, benchmark thoroughly, and maintain a very detailed MCNP/MOCUP model of the HFIR.

- A service to users and designers. 
ATTACHMENT 4 


\section{Timing for a preliminary report?}

* On April 25, a meeting is planned in Washington to discuss the future possibilities for ATR, HFBR, and HFIR.

- The other labs have proposals for enhancements, and we should too. 
ATTACHMENT 5 
ATTACHMENT 6 
Date: $\quad$ March 30, 1995

To: $\quad$ HFIR Futures Group

c/o G. F. Flanagan

From: E. Burnette, 7910, MS-6387, 6-0214
D. H. Cook, 7917, MS-6399, 4-5690 A.t.

R. W. Hobbs, 7910, MS-6387, 4-8789 Q.w thth

Subject: Reconfiguration of the Sontheast Quadrant of the HFIR Reactor Building to Support a HB-4 Cold Sonree

It has been proposed that a new cold neutron source be installed in the HB-4 beam tube of the HFIR. Realization of the full potential of the HB-4 cold source facility, however, requires the creation of a substantial amount of new experimental floor space to accommodate both the cold source cryogenic support equipment and the scattering instrumentation to be placed on the beam line.

As a means of providing the needed additional floor space, it has been previously proposed by the SSD that a building extension be added on the southeast corner of the reactor building. As a complement to this proposal, the Research Reactors Division has briefly looked at the possibility of providing additional floor space within the HFIR building.

Specifically, the idea involves moving the pony motor batteries in Room G-13 and most of the electrical equipment in Room G-12 to the old fuel vault area. In addition, it may be possible to move the stairwell connecting these two areas. Figures 1 and 2 show the current configuration of the ground floor and first floor, respectively. The columns that are circled must remain, but it is possible that the interior walls can be rearranged to provide support for the HB-4 cold source.

Access to the subpile room must be provided, successful relocation of the electrical room equipment must occur (which will involve a considerable amount of plant modification), and acceptable rearrangement of the first floor computer room and biology lab must be achieved. Howe er, there is a good possibility that some valuable floor space can be made available on the ground floor beam room that fans out from HB-4.

Research Reactors Division is looking forward to the installation of a cold source in HB-4, and is willing to provide input to the preconceptual design. Please call D. H. Cook (4-5690), S. E. Bumette (6-0214), or R. W. Hobbs (4-8789) for more information regarding this subject.

DHC:mw

Attachments: (1) Figure 1, Ground Floor Plan

(2) Figure 2, First Floor Plan 


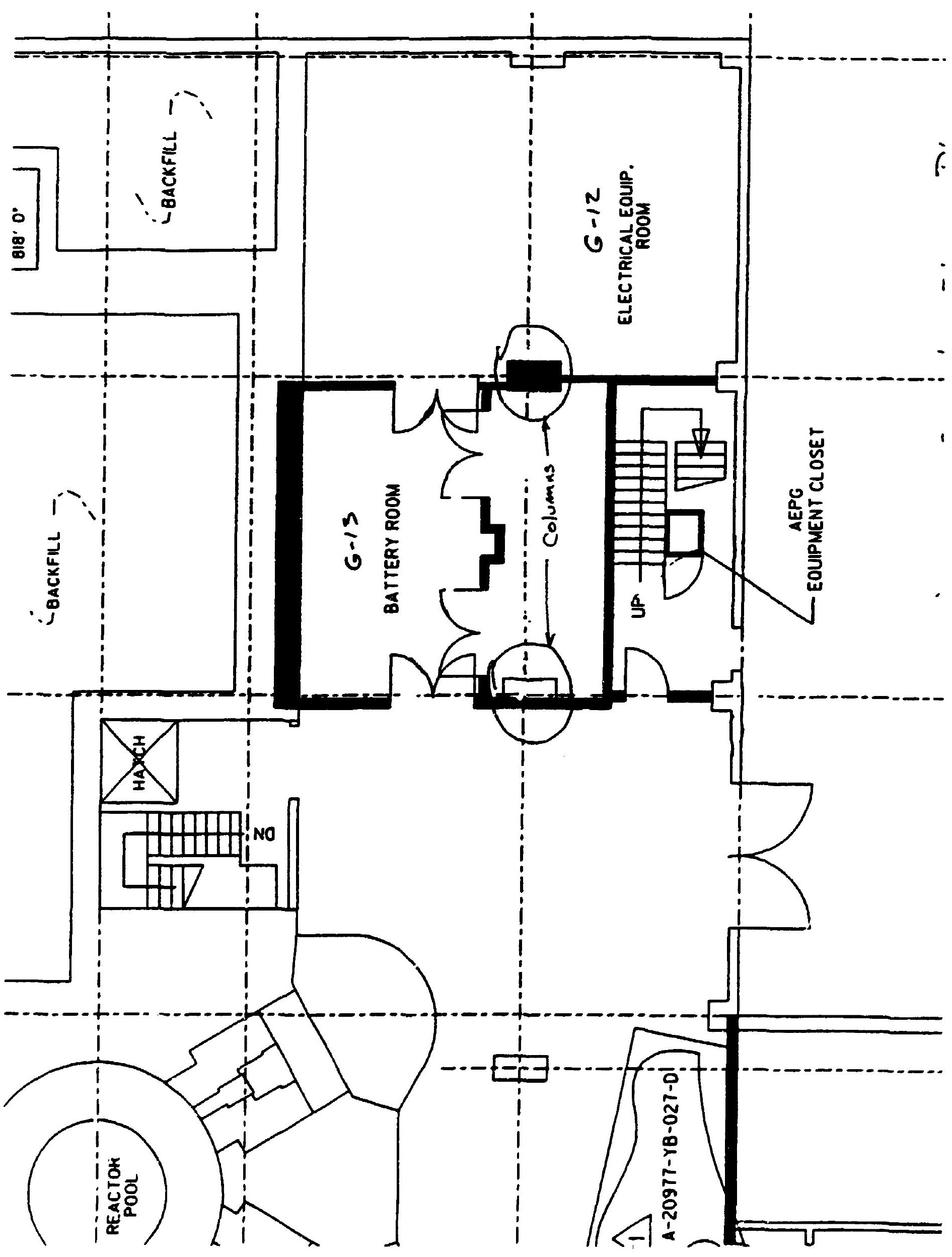




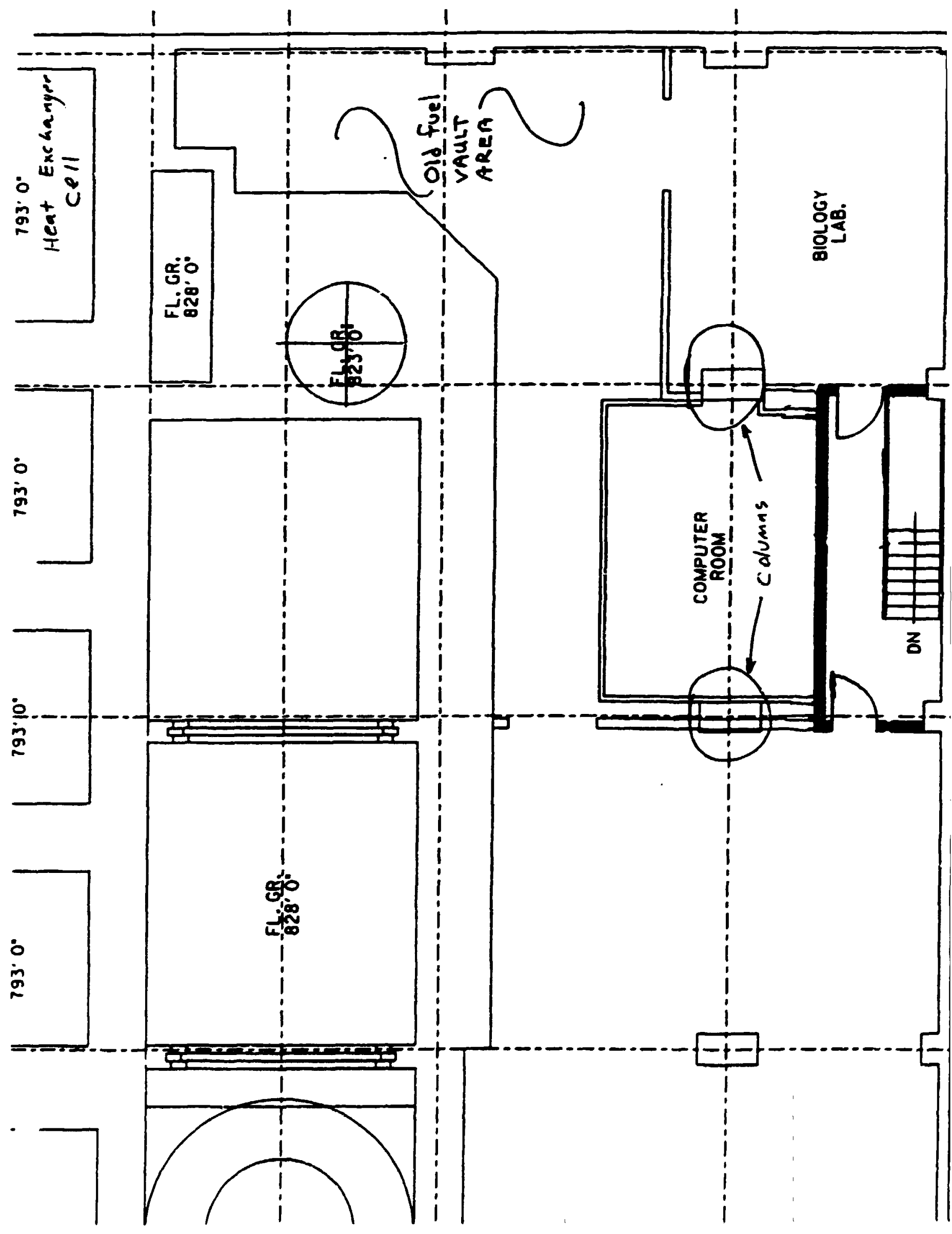


ATTACHMENT 7 
Preliminary Categorization of HFIR Upgrades

\begin{tabular}{|c|c|c|c|}
\hline Must do to continue operation & Duration & Gross Cost & Net Cost ${ }^{\circ}$ \\
\hline Beryllium replacement & 6 months & $\$ 9.4 \mathrm{M}$ & approx. same \\
\hline New ganma-irradiation facility & & $\$ 100 \mathrm{~K}$ & approx. same \\
\hline Guide hall (building extension) & & $\$ 3 M-5 M$ & approx. same \\
\hline Positron source & $\begin{array}{l}3 \text { ycars heforc Bc } \\
\text { changeoul }\end{array}$ & $\$ 17 \mathrm{M}$ & approx. same \\
\hline $\begin{array}{l}\text { Obtain hot cell nearhy (portable one over pool or } \\
\text { over the critical pool, similar to that at the ORR) }\end{array}$ & & $\$ 10 \mathrm{M+}$ & approx. same \\
\hline \multicolumn{4}{|l|}{$\begin{array}{l}\text { Improve transport methods from the HFIR to the } \\
\text { HRLEL }\end{array}$} \\
\hline New, nuxdern scattering instruments & & & \\
\hline
\end{tabular}




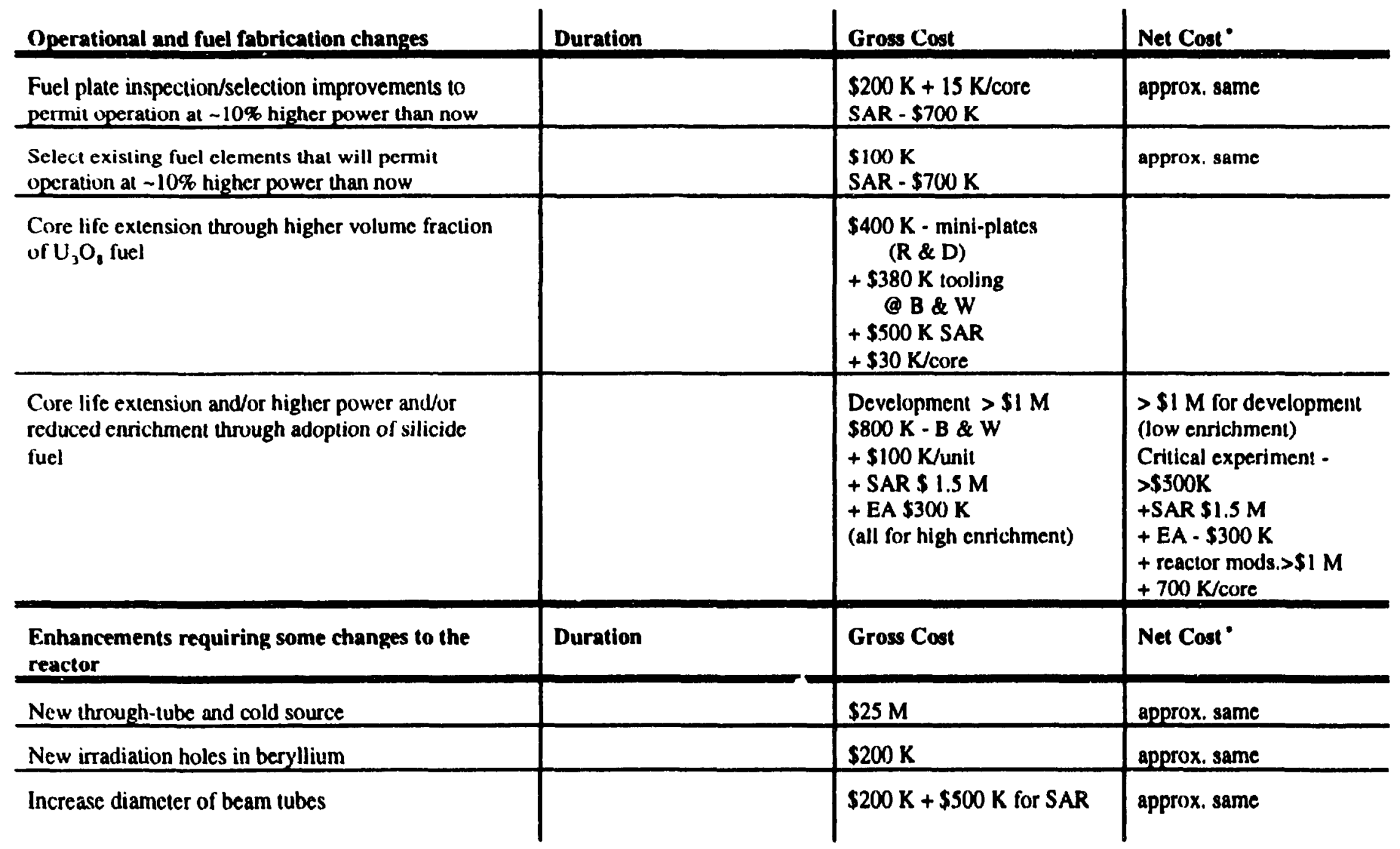


Preliminary Categorization of HFIR Upgrades (cont.)

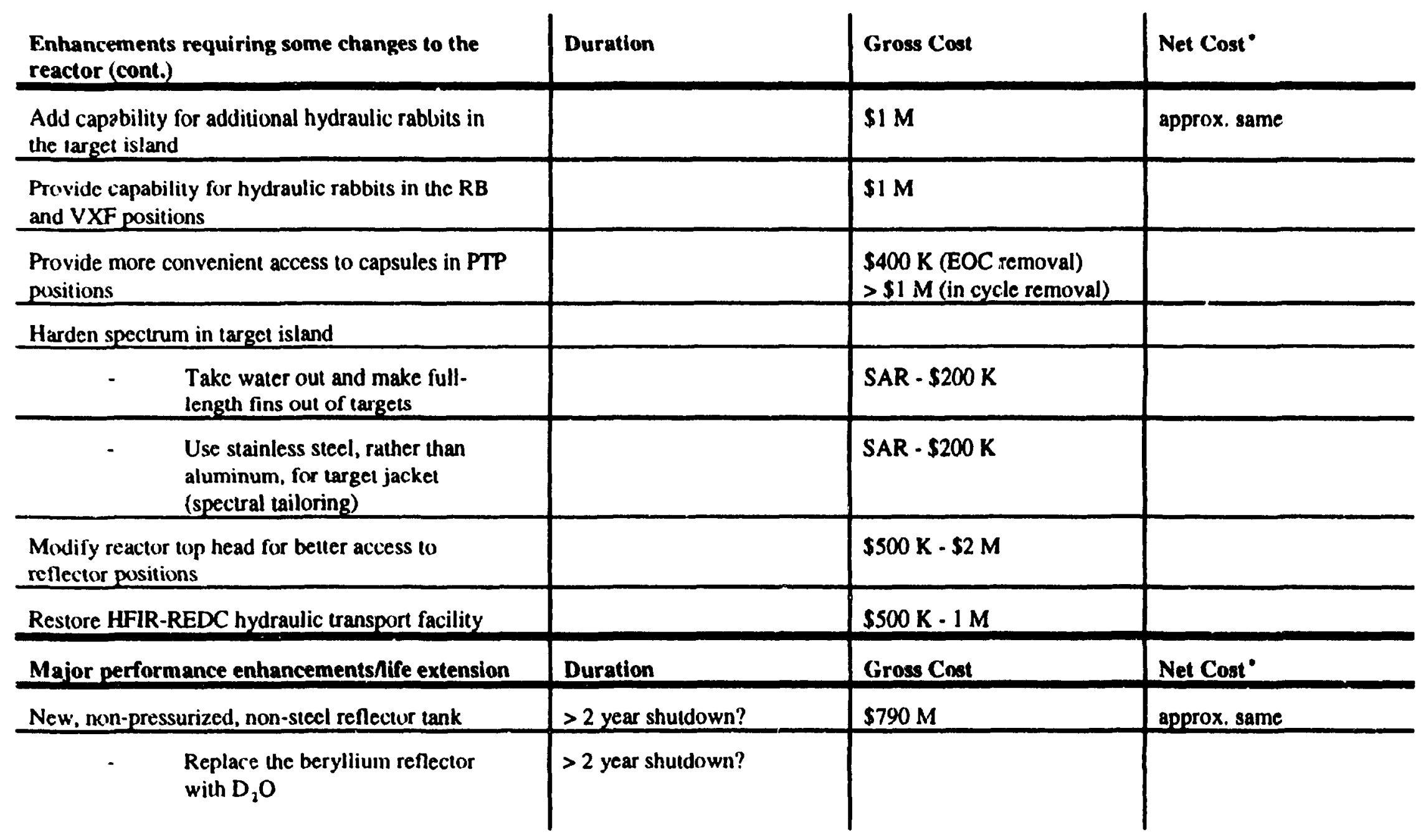


Preliminary Categorization of HFIR Upgrades (cont.)

\begin{tabular}{|c|c|c|c|}
\hline $\begin{array}{l}\text { Install a large. deuterium cold } \\
\text { source in the new } D_{2} 0 \text { reflector }\end{array}$ & & $\begin{array}{l}\text { additional \$4S M (very } \\
\text { conservative as-spent } \\
\text { dollars) }\end{array}$ & approx. same \\
\hline Administrative (user perspective) & Duration & Gross Cost & Net Cost ${ }^{*}$ \\
\hline \multicolumn{4}{|l|}{ Improve communication and information exchange } \\
\hline \multicolumn{4}{|l|}{ HFIR home page on World Wide Web } \\
\hline \multicolumn{4}{|l|}{$\begin{array}{l}\text { Team-building for users, RRD, crafts, and Health } \\
\text { and Safety }\end{array}$} \\
\hline \multicolumn{4}{|l|}{$\begin{array}{l}\text { Study the Work for Others process for } \\
\text { improvements }\end{array}$} \\
\hline \multicolumn{4}{|l|}{$\begin{array}{l}\text { Enhance the facility's aesthetics (c.g., the dining } \\
\text { facilities) }\end{array}$} \\
\hline \multicolumn{4}{|l|}{ Operations ownership clarification } \\
\hline NE/ER responsibility split & & & \\
\hline $\begin{array}{l}\text { Relationships and communications } \\
\text { among RRD, users, and site office }\end{array}$ & & & \\
\hline
\end{tabular}


Preliminary Categorization of HFIR Upgrades (cont.)

Administrative (user perspective)

\section{Duration}

Grose Cost

Net Cost $^{\circ}$

Informal operational consortium

(c.g., Los Alamos and ORR

cxamples)

1


April 24, 1995

HFIR Futures Group Meeting

Altendance

The HFIR Futures Group held its sixth meeting at 8:30 2.m. on Monday, April 10, 1995, in the Blue Room of the FEDC. Those in attendance were:

John Bigelow

Enory Collins

Mike Farrar

George Flanagan

John Hayter

Michele Houser

Herb Mook

Ken Thoms

Colin West (chair)

Ken Farrell (observer).

Qpening

Colin West began the meeting with a reference to a revised agenda (see Atachment 1). Some concern had been expressed by RRD management about the HFIR Futures Group's proposed administrative changes, so a talk from an Operations representative from RRD was added to the agenda. Also, Colin had received an invitation to present the status of our work to the ORNL Executive Committee meeting on April 12, so he added an item baving to do with this invitation to the agenda.

The group was asked for any changes or corrections to the notes for the April 3 meeting. George Flanagan requested that the wording pertaining to the diesel generators be clarified: these generators could have the potential to cause availability problems in the future; they have not yet caused problems, although other components have. The lists will be examined and revised accordingly.

\section{Executive Committee oresentation}

Since the RRD Operations representative was not yet at the meeting, Colin went on to talk about his invitation to the ORNL Executive Committee meeting. His proposed viewgraphs and handouts were discussed: he subsequently modified them in light of the discussion. The detailed handout used at the Executive Committee meeting is shown in Attachment 2 (the verbal presentation was condensed, compared with the handout). 
In the process of getting comments on the draft report from the Futures Group, Colin said that it had been pointed out to hir by Mike Harrington that the items in the "Must do to continue operation" category were not really enhancements. They were certainly important, but they perhaps warrant a special category apart from enhancements. The group agreed with this, so the upgrade lists will be changed accordingly.

The administrative changes were discussed somewhat further. George remarked that the concerns that RRD management had with these changes were connected with the fact that they were items which the division had been working on for a long time. They are internal problems and should be addressed by internal means ( $\mathbf{R}^{2}$ or $M C^{2}$ processes?), not by the HFIR Futures Group. Colin replied that the function of the group was identifying areas to be addressed and not addressing the problems themselves; upon inquiring, the majority of the members felt that these suggestions should be given to ORNL management.

Some discussion of low cost changes next ensued, especially those having to do with operational and fuel fabrication changes. Colin said he was currently disposed to recommend that these low cost enhancements be implemented. John Hayter remarked that operating costs might demand some attention: in 1984, the annual operating cost of HFIR was $\$ 8 \mathrm{M}$. Now, it is on the order of $\$ 28 \mathrm{M}$. John $\mathrm{H}$. said it might be enlightening to see the areas in which the change in cost took place (some of them obviously in areas related to regulation). It might be possible to look at ways to quietly tighten the HFIR annual operating budget in (irder to set aside funds for future improvements. The differences, including the expected operating cost advantages, in being regulated by the NRC non-power reactor group, versus DOE, were again highlighted.

George remarked that part of the process would be to set priorities for the HFIR facility and get DOE agreement on these priorities. The facility currently has personnel resource limitations--if there is an extra piece of work to be done, something else has to remain undone. RRD is currently working on how to best streamline this process, such as not going to Washington to get funding for small jobs.

Emory Collins commented that it would not be profitable to get piece-meal improvements on HFIR in lieu of the ANS. The relationship between HFIR upgrades and the proposed accelerator for ORNL was discussed. John $\mathrm{H}$. remarked that having an accelerator at ORNL, as well as cold neutrons at the HFIR, could be a great advantage for Oak Ridge, especially given some type of combiued guide hall for both machines. It was remarked that it would probably be possible to have a $\$ 50 \mathrm{M}$ line item to upgrade the HFIR if the vessel replacement were not included as part of it. Competition from other DOE facilities was mentioned, as well as competing programs within ORNL. Several of the group expressed concern over the HFIR's future, given the number of competing programs within the DOE complex. Colin emphasized the importance of working with the DOE field office, especially considering the number of changes taking place there lately.

Colin had told the group that he proposed to have only the title of the upgrades proposed on his viewgraphs for the Executive Committee, whereas the handouts would alsc portray the benefits of each proposal. John H. suggested that a set of "benefit areas" be identified and connected with the ORNL policy that goes with those areas. George also suggested tying benefits back with the Galvin Report (e.g., the "core competency" areas), perhaps even highlighting those portions of the report which deal with the HFIR.

The fact that HFIR is a rundamental facility for neutron science was accentuated. It was suggested that HFIR's capabilities be highlighted. Colin, suggested that the group give any ideas it had on how the benefits proposed from the upgrades cross-reference with the scientific fields. George suggested that a 
pictorial representation of activities feeding into HFIR would be belpful for the Futures Group's report. Colin asked for input on this from group members. The possibility of revising some ANS material for HFIR was mentioned. Colin said he would report back to the group after the Executive Committee meeting.

\section{HFIR Futures Groun schedule}

Colin mentioned that this coming weekend was the Easter weekend and asked if the group wished to meet next week. He said that he himself would not be at work on April 17. The group agreed to dispense with the meeting scheduled for April 17 and have its next meeting on April 24.

\section{User/RRD input}

Colin mentioned that RRD had a lot of good ideas and had formed a group to look at estimates to replace the HFIR reflector vessel. Colin is attending this group's meetings, which are informal lunch meetings having George as the group's chair. Ken Thoms asked if other facilities who had just gone through reflector vessel replacement had been invited to the meetings. Since the group is currently informal, no other facilities had been invited to meetings, but information had been gathered from other reactors. Ken T. recommended getting advice from places such as the Petten facility (Colin had already requested this information from Dr. Ahlf at Petten); George said he had information on the Seabrook vessel. John Bigelow said there were to be visitors from Dimitrovgrad at ORNL the week of April 17-it might be useful tr, ialk with them. Colin said that people from Petten might be at Oak Ridge for the IGORR meeting next month.

Mike Farrar from RRD Operations had come the meeting and was invited to speak: Mike said that he had not had much notice of the meeting but that he would be glad to address questions the group had. He started out by saying that he didn't think that the continual upgrades which take place at the HFIR have to be independent of the HFIR Futures Group.

Mike taliked a bit about the availability problems at the HFIR, most of which he thought were due to i)60's technology in a 1990's world. He remarked that he thought the users' group should be strengthened, and issues having to do with exit frisking were debated. The impart of regulations on this :equirement was discussed. Mike said that RRD did not necessarily think the exit frisking requirements were appropriate, either, but he wasn't sure it was something for the Futures Group to address. Colin repeated his earlier comment that the purpose of the group was to identify issues for management decision-making, not. necessarily to solve them outright. The importance of negotiating compliance to regulations with the site office was highlighted. John $\mathrm{H}$. cited an example from the Conduct of Operations portion of the Workshop on ES \& H Requirements for the Office of Basic Energy Sciences (OBES) Programs he had attended in Gatlinburg a while back: he said that all agreed to follow the rules thien--it was the method of following them which needed to be negotiated.

The differences between HFIR and other DOE facilities was discussed, particular:y the types of security and safety barriers. It was suggested that thece be studied for possii .e applicability to HFIR. Colin stressed that RRD was not an enemy to the users--the division oftentimes falls ivto the role of "hammer wielder" of regulatory compliance for users, but RRD is merely enforcing the regulation it has been told to follow. The suggestion was repeated to sirengthen RRD-user interaction on all operational issues. 
Michele Houser briefly went over the main changes made on the upgrade lists since the last meeting (see Attachment 3). Larry Robinson had grouped the items under "Administrative Changes," as well as writing up his requests for laboratory space and pneumatic tubes. (Colin gave out Larry's fax at the end of the meeting [see Attachment 4]). While looking at the "Administrative Change" page of the list, Colin suggested that the "WFO" item be deleted, as it was not peculiar to the HFIR facility. The group agreed to this change. The "Regulatory Ownership" item was then debated. RRD management did not really want that item to appear on the list. The different methods of dealing with this problem at other DOE facilities were considered, and Colin asked the group about leaving the item on the list. Most of the group wanted the item left on the list. He said he would leave it on the list for now, with the group parhaps examining its inclusion again in the future.

\section{Cost of guide hall expansion}

Hexb Mook next spoke about the cost of guide hall expansion. He repeated the cost of $\$ 2 M$ for the guide hall building itself. Herb mentioned the moving of the transformers, which George said could be probably accomplished with maintenance funding.

Facilities Initiative

Herb went on to talk about some Facilities Initiative funding which was programmed for the HFIR. He said the amount of funding appeared to be $\$ 5.4 \mathrm{M}$, but that in reality the situation was a bit different. $\$ 2 \mathrm{M}$ of that funding is operating money, but the remaining $\$ 3 \mathrm{M}+$ is discretionary money of the kind given to universities. The researchers currently working with synchrotrons think they will be receiving the $\$ 3 \mathrm{M}$ amount. Herb thinks that having a cold source is the best option for placing ORNL in a position to receive this money, as well as giving it more credibility as a national facility.

Herb put forth a request for more information in order to market HFIR's capabilities and needs for these funds. He said that a study looking at the viability and effectiveness of a HFIR cold source is essential. University support would be needed for this report, also. Herb thinks that the window of opportunity would be until the end of the summer (end of August) $w$ co this proposal and get university support.

Colin remarked that he had done some study with others looking at fluxes for the HFIR. At the center of the through-wbe, a cold source would be in a higher neutron flux than the ILL vertical cold source, but the HFIR cold source would, of necessity, be much smaller: detailed calculations are needed to ascertain how the cold neutron fluxes from the two facilities would compare. In addition, the HFIR would have the newest cold source available. The Facilities lnitiative money is for the 1996 budget, so work would have to be done quickly. The best option appears to be putting a cold source in an existing beam tute in $\mathbf{H B}-4$.

A guide hall study was already done a few years back (1990?), so the cold source work would be the biggest level of effort left to accomplish. John $\mathrm{H}$. commented that there had been work done associated with the super-mirror thermal neutron guides since the older guide hall studies that could lead to a qualitative change in the report; therefore, more revision of the previous guide hall studies may be needed thas at first estimated. 


\section{Reactor top head modification}

Ken Thoms next presented a slide showing the benefits of modifying the reactor top head for betier acoess to reflectar positions (see Attachment 5). After some discussion, group mambers asked Ken to remove the wording "Could make HFIR a Mo-99 producer." Ken will also modii; wording to strengthen the portrayal of the benefits. The table will be modified accordingly.

Ken T. asked if it would be possible to re-design the quick-opening hatch, if the reactor top bead were being re-designed, so that capsules in the $\mathbf{R B}^{*}$ positions would not have to be removed each refueling. Other options would be 10 install sequential quick access latches and/or put hydraulic rabbits in the RB* positions. Colin asked Ken T. to write up his ideas on this.

\section{Transport issues}

John Bigelow was to report the benefits of the HFIR-REDC transport facility restoration and the improvement of HFIR-HRLEL transportation methods. He had computer problems and was not able to report to the group this meeting. He said be would work on them again and fax or e-mail them to the group chair or secretary.

\section{Spent fuel storage}

George then told the group some more about the spent fuel storage issues. There are currently 3 options for dealing with HFIR spent fuel. They are:

1) istore the fuel in new 3-tier storage arrays in the spent fuel pool. There is enough room for elements (but not necessarily enough working and laydown space) there until app.roximately the year 2005 .

2) Ship the spent fuel to Savannah River whenever possible. There is currently a onemonth turnaround for the spent fuel shipping cask, i.e., we could only ship around one element/month, barely enough to keep up with the usage $\mathrm{ra}^{*} \ldots$ and not enough to make a big difference, in a short time, to the pool inventory of spent fuel. There, are currently problems with shipment with the Tennessee Emergency Management group. This group wants a presentation about the cask and want to start training campaigns for the states through which the fuel is transported (Tennessee, North Carolina, South Carolina, and Georgia). The group got this idea from foreign fuel shipment, for which the Office of Defense Programs had money for emergency response. Since HFIR's fuel transport falls in the Office of Environmental Restoration, there is no funding for this training. RRD is currently negotiating options for shipment.

3) Place the spent fuel in dry storage somewhere near the HFIR facility. RRD is currently working with Waste Management on this. A dry storage facility would be regulated by the Office of Environmental Management (the home office of the EH-32 group which made the licensing of shipping casks so difficult for RRD). RRD wanted to license the cask through NRC, but this may not be possible due to HFIR's unique fuel configuration.

The current plan is to store the fuel in the spent fuel pool. This is not without its problems, however. The more fuel that is added to the pool, the less footprint there is for other work. Mike told us that the 2005 year quoted is the year that the puols will be full of fuel. Before that, HFIR will probably nun out 
of room for doing other things in the pool. The beryllium changeout in 1999 may even be spaceconstrained due to the spent fuel stored in the pool at that time.

\section{Draft outline of study report}

Colin passed out handouts of Larry Robinson's fax to him (see Attachment 4), and then asked for comments on his draft outline of the suidy report. He had comments already from Mike Harrington. Colin showed a modified table of the upgrade lists that contained questions and notes (see Attachment 6). Herb had some questions about calculations to do with the cold source, accentuating the need for the Monte-Carlo model of the HFIR. Colin remarked that RRD needed to have a dedicated workstation for ruming this model, and he and George discussed some options for obtaining one. This model would have long-term benefits for users and designers.

Sohn $\mathrm{H}$. observed that the question on Colin's viewgraphs of "Do we have any customer or sponsor ready to use the new facility" should be asked of all of the upgrade items. The group agreed that would be a helpful thing to document. George said that Mike had a contact in Environmental Science and Biology who wanted to use the proposed new large, high intensity, gamma facility to recluce plastics to their fundamental forms for waste disposal (tar for microbes 10 consume). Colin said this was an encouraging contact and that having more instances like this would be belpful for promoting upgrades. The political requirements for customer-driven enhancements without funding favor upgrades that would benefit more than one customer.

\section{Closing}

John $H$. brought out a repont from the National Bureau of Standards on the new cold source and guide hall installed in 1987. The complete cost of that upgrade was then $\$ 25 \mathrm{M}$ under NRC. The group discussed parameters having to do with NIST and HFBR. Colin provided a handout on the flux associated with a HFIR cold source (see Attachment 7), and the group adjourned until April 24.

\section{ACTION ITEMS}

Ken Thoms will strengthen his wording about the benefits of modifying the reactor top head.

Ken Thoms will write up his thoughts about re-designing the quick-opening latch on the reactor top head.

John Bigelow will send a writeup on the benefits of the HFIR-REDC transport facility restoration and the improvement of the HFIR-HRLEL transportation methods.

Colin West will report back after the Executive Committee meeting.

All will review upgrade lists and provide comments to Colin or Michele. 
All will review the draft outline of the study report and provide comments to Colin or Michele.

M. M. Houser, April 13, 1995

Distribution

HFR Fumres Group Autendes (notes for record only)

J. E. Bigelow, 7930, MS-6385

E. D. Collins, 7930, MS-6385

M. B. Farrar, 7910, MS-6387

K. Farrell, 5500, MS-6376

G. F. Flanagan, 7917, MS-6398

J. B. Hayter, FEDC, MS-8218

M. M. Houser, FEDC, MS-8218

H. A. Mook, , 962, MS-6393

K. R. Thoms, 9108, MS-8087

C. D. West, FEDC, MS-8218

For information (notes for record + attachments)

B. R. Appleton, 4500N, MS-6240

J. B. Ball, $4500 \mathrm{~N}, \mathrm{MS}-6182$

R. E. Battle, FEDC, MS-8218

H. A. Glovier, 7917, MS-6398

R. M. Harrington, FEDC, MS-8218

J. P. Moore, 4508, MS-6080

D. E. Reichle, 4500-N, MS-6253

J. B. Richard, 7962, MS-6391

L. Robinson, 4500S, MS-6128 
ATTACHMENT 1 


\section{AGENDA FOR \\ HFIR FUTURES GROUP MEETING}

Monday, April 10, 1995

8:30 a.m.

FEDC, Blue room

- User Input

J. E. Lee/RRD

- Discussion: Changes or corrections to 4/3/95 meeting notes for the record

- Executive Committee presentation

C. D. West

- Discussion: Amended lists of HFIR upgrade

All proposals

- $\quad$ Changes made due to April 3 meeting

M. M. Houser

- $\quad$ Revised list of administrative changes

L. Robinson

- Space needs for analytical chemistry users

L. Robinson

- $\quad$ Cost of guide hall expansion

H. A. Mook

- Benefits of modifying reactor top head

K. R. Thoms

- Benefits of HFIR-REDC transport facility restoration

J. E. Bigelow

- Benefits of improvement of HFIR-HRLEL transportation methods

J. E. Bigelow

- Issues and options having to do with spent fuel storage

G. F. Flanagan

- Draft outline of study report

C. D. West

- Any other business 
ATTACHMENT 2 


\title{
PRESENTATION TO ORNL EXECUTIVE COMMITTEE
}

\author{
C. D. West \\ for HFIR Futures Group
}

April 12, 1995 


\section{ORIGIN OF THE HFIR FUTURES GROUP}

- ORNL Deputy Director called a meeting to discuss, briefly, the importance of maintaining and upgrading the capabilities of the HFIR following the termination of the ANS Project

- members of several of the groups who use and operate the HFIR were present

- Van Hook asked Colin West to lead a group, representative of the interests of all parties at the laboratory, to enumerate and document the possibilities for consideration by ORNL management

- A team of willing participants was quickly identified; they called themselves the HFIR Futures Group and wrote a charter for the study 
THE FUTURES GROUP WISHES TO HELP RRD DRAW SPECIAL ATTENTION TO CERTAIN ACTIONS THAT ARE NOT ENHANCEMENTS OR IMPROVEMENTS, BUT WHICH MUST BE DONE TO AVOID AN INEVITABLE SHUTDOWN BY CERTAIN DATES

- Get supplies of enriched $\mathrm{U}_{3} \mathrm{O}_{\mathrm{s}}$ for $\mathrm{B} \& W$

- at present, this material is at $Y-12$ and cannot be shipped

- In-service inspection of certain reactor components

- must be done in 1997 at the latest (cost $\sim \$ \mathrm{M}$ and 2 1/2 months downtime)

- Replace "permanent" beryllium when inspection shows it to be necessary

— will become necessary in 1999—2000

- cost will be about $\$ 9.4 \mathrm{M}$ and six months downtime

- the new reflector should have design modifications to enhance HFIR capabilities (larger irradiation holes, possibly larger beam tubes, possibly a large vertical hole for installation of a big cold source) 


\section{HFIR FUTURES GROUP}

\section{Membership and Areas of Interest}

J.E. Bigelow

E.D. Collins

G.F. Flanagan

R.M. Harrington

J.B. Hayter

M.M. Houser

J.P. Moore

L. Robinson

K.R. Thoms

C.D. West
Transuranic isotope production

Light isotope production

Research Reactor Division

Reactor safety

Neutron scattering

Technical Secretary

Pu 238 production

Materials analysis

Materials irradiation testing

Chairman

\section{Meeting Schedule}

Each Monday morning, beginning March 6, 1995, at 8:30 a.m. in the FEDC Blue room.

\section{Information Copies}

B.R. Appleton

J.B. Ball

R.E. Battle

H.A. Glovier

H.A. Mook

J.B. Richard 


\section{HFFIR FUTURES GROUP CHARTER}

- To identify and characterize the range of possibilities and necessities for keeping the HFIR operating for at least the next 15 years

- To identify and characterize the range of possibilities for enhancing the scientific and technical utility of the HFIR

- To evaluate the benefits or impacts of these possibilities on the various scientific fields that use the HFIR or its products

- To evaluate the benefits or impacts on the operation and maintenance of the HFIR facility and on the regulatory requirements

- To estimate the costs, including operating costs, and the schedules, including downtime, for these various possibilities

- One possible impact of proposed changes may be to estimate increased pressure for a reduced enrichment fuel for HFIR; the performance and cost impacts of this should be evaluated 


\section{CATEGORIES OF FACILITY, CFERATIONAL, AND REACTOR ENHANCEMENTS}

\section{Category}

Facility or instrument improvements

Operational and fuel fabrication changes

Enhancements requiring some changes to th e reactor Major performance enhancements/life extension 


\section{USERS AT THE HFIR FUTURES GROUP MADE SOME SUGGESTIONS FOR CONTINUED ADMINISTRATIVE CHANGES}

Category

Administrative changes (user perspective)

- communications

- operations

— training

- regulatory ownership 
ATTACHMENT 3 


\section{EXTRA COSTS (costs other than RRD staff)}

Minor

Costs for materials and labor from outside RRD $\leq$ $1 \%-2 \%$ annual operating budget.

Significant

Cost outside RRD in the range $2 \%-10 \%$ of annual operating budget - would require substantial and determined reprioritization of other work to accomplish without additional funding

Major

Extra costs $\geq \$ 5 \mathrm{M}$ (the amount potentially available under the facilities initiative); would definitely require specific extra operating/capital equipment funds, or line item funds 


\section{MINOR COST ( $<1 \%$ to $2 \%$ of HFIR ANNUAL OPERATING BUDGET) CHANGES (1)}

Eacility or Instrument Improvements

New gamma irradiation facility

Expanded laboratory facilities for material analysis on HFIR ground floor

Complete preparation and benchmarking of the detailed MonteCarlo model of the HFIR, and couple it to the Idaho MOCUP depletion code

Qperational and Fuel Fabrication

Changes

Select existing fuel elements that will permit operation at $10 \%$ higher power

Fuel plate inspection/selection

\footnotetext{
improvements to permit operation at $10 \%$ higher power
}

Benefits

An enhanced capability compared with the present fuel element gamma facility

Solves office space deficiency and improves building aesthetics

This model will be invaluable to users and designers planning changes to experimental and other facilities, and for preparing safety analyses

Higher power would provide more neutron flux for more sensitive experiments and/or shorter experiment times

$"$ 


\section{MINOR COST ( $<1 \%$ to $2 \%$ of HFIR ANNUAL OPERATING BUDGET) CHANGES (2)}

Enhancements Requiring Some

Changes to the Reactor

Harden spectrum in targets

- displace some light water from the target island (add full length fins to targets)

- use stainless steel target jackets (spectral tailoring)

New irradiation holes in beryllium (when $\mathrm{Be}$ is changed out)

Increase diameter of some beam tubes (when $\mathrm{Be}$ is changed)

Provide more convenient access to capsules in PTP positions íduring shutdowns)

'If SAR's done in-house.
Benefits

?
Enhanced isotope production materials irradiation capabilities

More neutrons on sample

Enhanced isotope production and materials irradiation capabilities 


\section{MINOR COST ( $<1 \%$ to $2 \%$ of HFIR ANNUAL OPERATING BUDGET) CHANGES (3)}

Administrative Changes (User

Perspective)

Communication

- Strong, influential, user-driven users' group

- External "marketing" of HFIR

- Brown baggers by users for RRD (DOE) staff and vice versa

- Advertise audit schedules when appropriate

- Publish annual report with user input

- Increased user interaction with site office

\section{Operations}

- Informal operational consortium? (see ORR, Los Alamos examples)

- User input on scheduling

- Greater priority for users' maintenance needs

- Team-building: users, RRD, crafts, ESH\&Q

- Examine building egress frisking requirements

- Improve HFIR dining facilities
Benefits

Improves outside users' perception of HFIR. Could also improve scheduling problems. 


\section{MINOR COST ( $<1 \%$ to $2 \%$ of HFIR ANNUAL OPERATING}

BUDGET) CHANGES (4)

Administrative Changes (User

Perspective) [cont.]

Training

- Streamline

- Enhanced availability

- Utilize area specific experts (HPs, etc.) and users!

\section{Other}

- Streamline WFO process

Regulatory Ownership

- Push for clarity of DOE management - NE/ER split is counterproductive

- Find the correct place in the NRC
Benefits

Improve outside users' perception of HFIR. Could also improve scheduling problems.

ง

1

$\boldsymbol{1}$

"

More efficient scheduling, more responsive regulations, more uniform guidance 
SIGNIFICANT COST (COSTS OUTSIDE RRD IN THE RANGE 2\%-10\% OF ANNUAL OPERATING BUDGET - WOULD REQUIRE SUBSTANTIAL AND DETERMINED REPRIORITIZATION OF OTHER WORK TO ACCOMPLISH WITHOUT ADDITIONAL FUNDING, OR PERHAPS USE OF FACILITIES INITIATIVE FUNDS OR GPP) (1)

\author{
Must do to continue operation \\ Cost guess \\ Benefits \\ Get supplies of enriched $\mathrm{U}_{3} \mathrm{O}_{3}$ \\ $\$ 0.5-\$ 5.0 \mathrm{M}$ \\ Avoids closedown! \\ for $B \& W$ \\ $\$ 1 M$ in 1987 \\ Avoids closedown! \\ Inservice inspection \\ Eacility or Instrument \\ Improvements \\ Cold source in an existing (e.g., \\ $\$ 3 M+\$ 2 M$ \\ work by \\ RRD \\ The highest short-term \\ priority for neutron \\ scattering and neutron \\ activation users \\ Guide hall (building extension) \\ $?$ \\ More space for cold \\ neutron instruments and \\ users" \\ Replace and improve diesels \\ $\$ 0.7 \mathrm{M}$ \\ Enhanced reliability and \\ availability \\ Would qualify for GPP, since many different divisions and programs would use the instruments \\ housed in this excension.
}


SIGNIFICANT COST (COSTS OUTSIDE RRD IN THE RANGE 2\%-10\% OF ANNUAL OPERATING BUDGET - WOULD REQUIRE SUBSTANTIAL AND DETERMINED REPRIORITIZATION OF OTHER WORK TO ACCOMPLISH WITHOUT ADDITIONAL FUNDING, OR PERHAPS USE OF FACILITIES INITIATIVE FUNDS OR GPP) (2)

Operational and Evel

Eabrication Changes

Core life extension through higher volume fraction of $\mathrm{U}_{3} \mathrm{O}_{8}$ fuel

Core life extension and/or higher power and/or reduced enrichment through adoption of silicide fuel
Costguess

S0.8 M R\&D and tooling + $\$ 0.5 \mathrm{M}$ for SAR preparation in $R R D$

$\$ 2,1 \mathrm{M}$ for development and tooling + $\$ 1.8 \mathrm{M}$ for SAR prepared by RRD and an environmental assessment (HEU) plus an additional $1.5 \mathrm{M}$ for reactor mods and critical experiments (if enrichment is reduced)
Benefits

Lower operating costs and higher availability

Lower operating costs and higher availability/ higher flux/nonproliferation policy response 
SIGNIFICANT COST (COSTS OUTSIDE RRD IN THE RANGE 2\%-10\% OF ANNUAL OPERATING BUDGET - WOULD REQUIRE SUBSTANTIAL AND DETERMINED REPRIORITIZATION OF OTHER WORK TO ACCOMPLISH WITHOUT ADDITIONAL FUNDING, OR PERHAPS USE OF FACILITIES INITIATIVE FUNDS OR GPP) (3)

Enhancements Requiring Some

Changes to the Reactor

Add capability for additional rabbit tubes in target island

Provide capability for hydraulic rabbits in the $\mathbf{R B}$ and VXF positions

Provide more convenient access to capsules in PTP positions while reactor is operating

Modify reactor top head for better access to reflector positions

Restore HFIR-REDC hydraulic transport facility
Cost guess

$\$ 1$ M/rabbit

$\$ 1 \mathrm{M}$

$\$ 0.5 \mathrm{M}-\$ 2 \mathrm{M}$

$?$

$\$ 0.5 \mathrm{M}-\$ 1 \mathrm{M}$
$\$ 1 \mathrm{M} / \mathrm{rabbit}$

n

n
Benefits

Enhances isotope production and materials irradiation capabilities 
Must de to continue operation

Beryllium replacement

Eacility or Instrument

Improvements

Replace and upgrade I\&C

systems

Install nearby hot cell

(portable one over the pool, similar to that in the ORR)

Positron source

Enhancements Requiring Some

Changes to the Reactor

New, larger through-tube and

vertical cold source (at

beryllium changeout)
Costguess Benefits

59.4 M Avoids closedown!

Enhanced reliability and availability

$\$ 10 M$

Would shorten turnaround time for isotope production and materials testing uses. Conld be used to can fuel elements for storage

$\$ 17 \mathrm{M}$

A world-beating facility

$\$ 25 \mathrm{M}$

A really major enhancement of neutron scattering capabilities would make HFIR a world-beater in some very important areas

Major Performance

Enhancements

New, non-pressurized, non- $\quad 2 \$ 79 \mathbf{M}^{*}$ steel reflector tank with $\mathrm{D}_{2} \mathrm{O}$ instead of beryllium

W'ould require additional guide hall space, more flux, more beam tubes. large cold source, and other new facilities. Would make HFIR 2-3 tinies better than ILL (although still with fewer instrument stations).

Large deuterium cold source in the new $D_{2} O$ reflector

Further work on this estimate is underway. 


\section{ITEMS WITH NO COST GUESS AVAILABLE YET}

Eacility or Instnument

Improvements

New, modern scattering

instruments

New instrument layout

Improve transportation methods from HFIR to HRLEL

Increased capacity of pneumatic tubes for material analysis

\section{Benefits}

Could improve performance on existing beams

Much enhanced experimental capability for neutron scattering

$?$

Faster experimental tumaround, greater accuracy and sensitivity, more efficient use of personnel time, and cost savings 
Preliminary Categorization of HFIR Upgrades

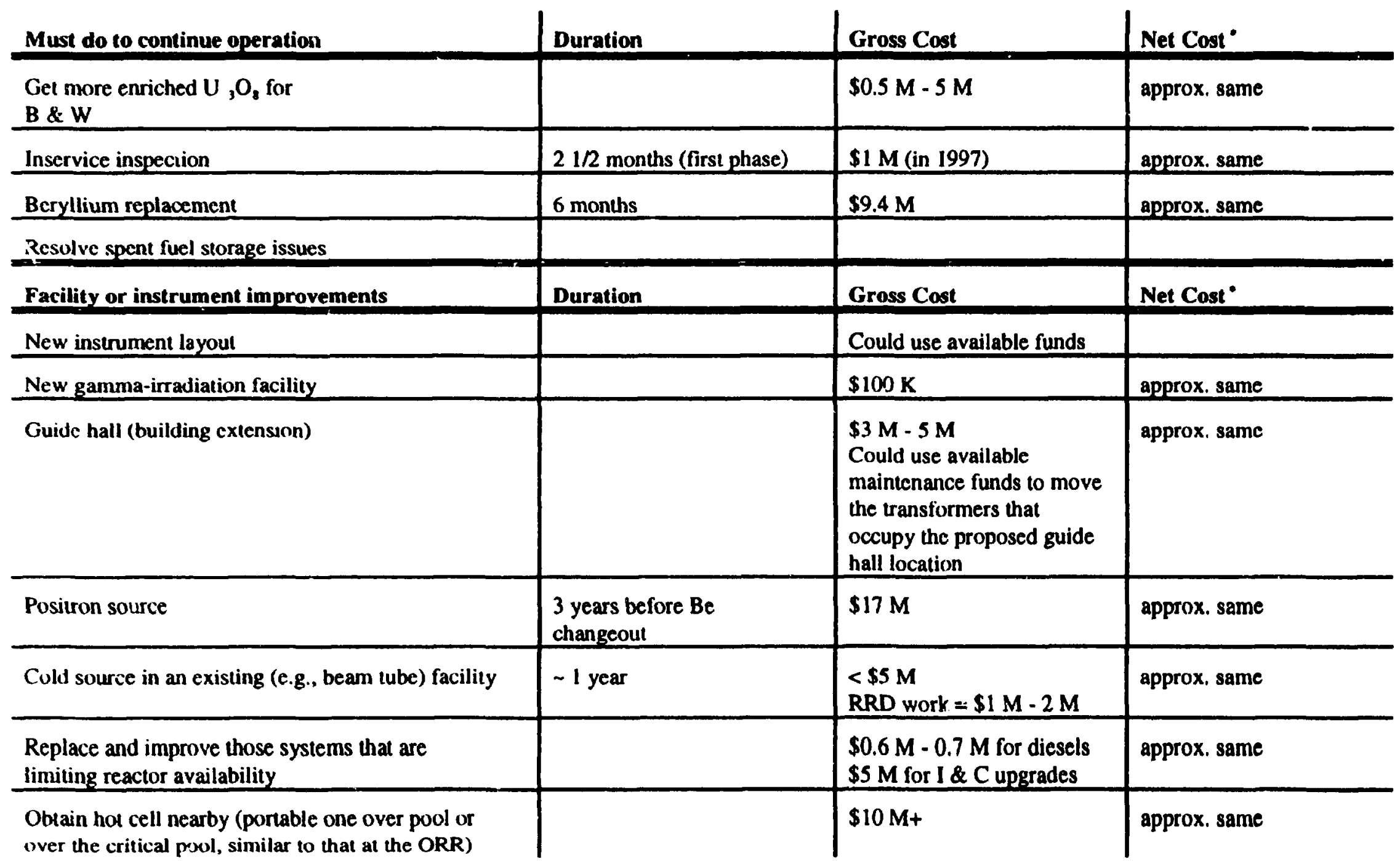

"beyond normal HFIR staff and operating costs

"Approx. same" signifies that Gross Cost=Net Cost. 


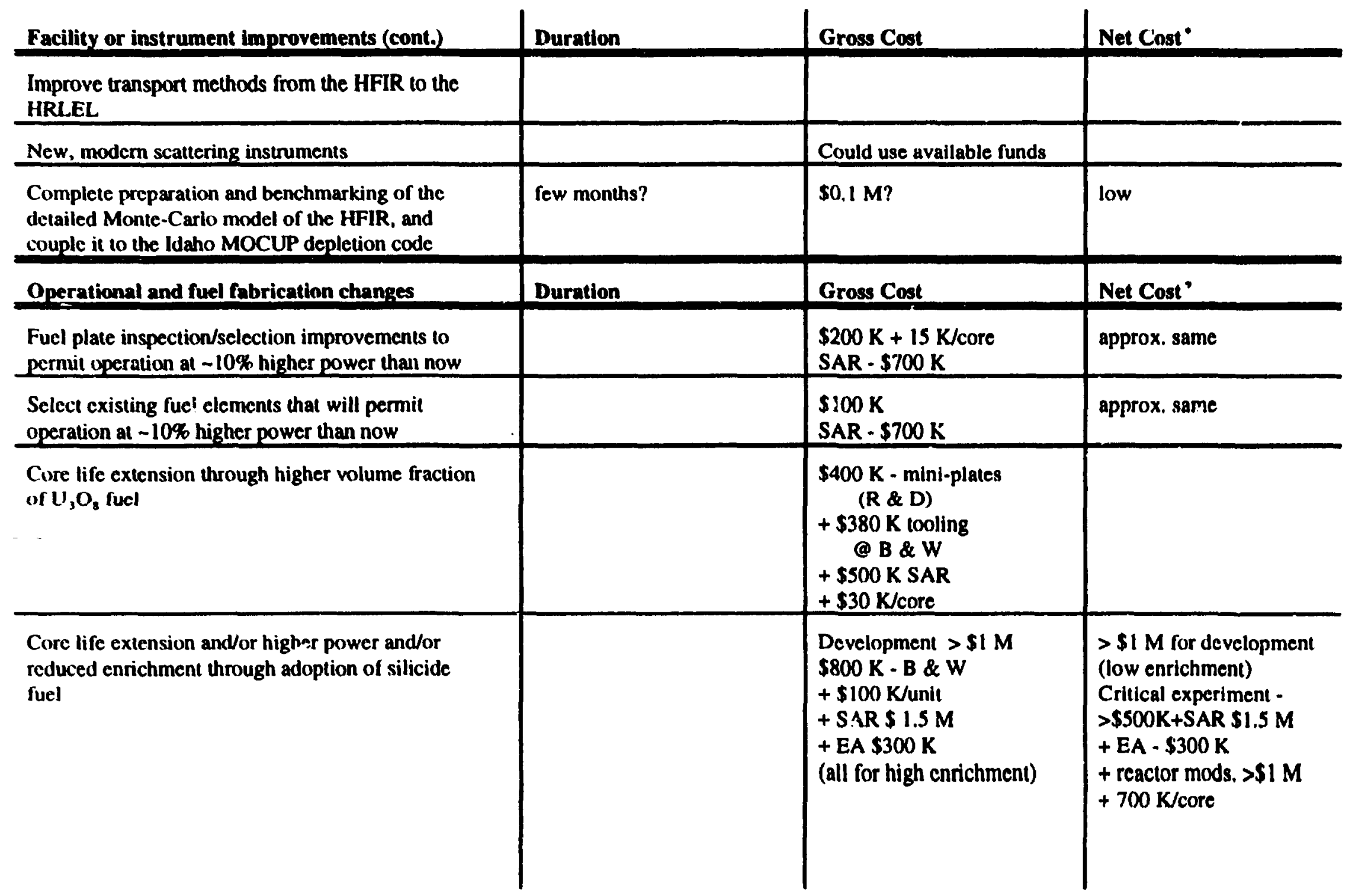


Preliminary Categorization of HFIR Upgrades (cont.)

\begin{tabular}{|c|c|c|c|}
\hline $\begin{array}{l}\text { Enhancements mojuiring some changes to the } \\
\text { reactor }\end{array}$ & Duration & Gross Cost & Net Cost ${ }^{\circ}$ \\
\hline New through-tube and cold source & & $\$ 25 \mathrm{M}$ & approx. same \\
\hline New irradiatior. holes in beryllium & & $\$ 200 \mathrm{~K}$ & approx. same \\
\hline Increase cuiameter of beam tubes & & $\$ 200 K+\$ 500 K$ for SAR & approx. same \\
\hline $\begin{array}{l}\text { Acdd capability for additional hydraulic rabbits in } \\
\text { the target island }\end{array}$ & & $\$ 1$ M/rabbil & approx. same \\
\hline $\begin{array}{l}\text { Provide capability for hydraulic rabbits in tiạ RB } \\
\text { and VXF pesitions }\end{array}$ & & $\$ 1$ M/rabbit & \\
\hline $\begin{array}{l}\text { Provide more convenient access to capsules in PTP } \\
\text { pusitions }\end{array}$ & & $\begin{array}{l}\$ 400 \mathrm{~K} \text { (EOC removal) } \\
>\$ 1 \mathrm{M} \text { (in cycle removal) }\end{array}$ & \\
\hline \multicolumn{4}{|l|}{ Harden spe :trum in target island } \\
\hline $\begin{array}{l}\text { Take water out and make full-length fins } \\
\text { out of targets }\end{array}$ & & SAR - $\$ 200 \mathrm{~K}$ & \\
\hline $\begin{array}{l}\text { Use stainless steel, trither than } \\
\text { aluminum, for target jacket (spectral } \\
\text { lailoring) }\end{array}$ & & SAR $-\$ 200 \mathrm{~K}$ & \\
\hline $\begin{array}{l}\text { Modify reactor top head for better access to } \\
\text { reflector positions }\end{array}$ & & $\$ 500 \mathrm{~K}-\$ 2 \mathrm{M}$ & \\
\hline Restore HFIR-REDC hydraulic transport facility & & $\$ 500 \mathrm{~K}-1 \mathrm{M}$ & \\
\hline
\end{tabular}




\section{Preliminary Categorization of HFIR Upgrades (cont.)}

\begin{tabular}{|c|c|c|c|}
\hline Major performance enhancementshife extension & Duration & Gross Cost & Net Cost ${ }^{\circ}$ \\
\hline New, non-pressurized, non-stoel reflector tank & $>2$ ycar shutdown? & $\$ 790 \mathrm{M}$ & approx, same \\
\hline Replace the beryllium refector with $\mathrm{D}{ }_{2} \mathrm{O}$ & $>2$ year shutdown? & & \\
\hline $\begin{array}{l}\text { Install a large, deuterium cold source in } \\
\text { the new } \mathrm{D}_{2} \mathrm{O} \text { reflector }\end{array}$ & & $\begin{array}{l}\text { additional \$45 M (very } \\
\text { conservative as-spent } \\
\text { dollars) }\end{array}$ & approx. same \\
\hline Administrative (user perspective) & Duration & Gross Cust & Net Cost" \\
\hline Communication & & & \\
\hline $\begin{array}{l}\text { - } \quad \begin{array}{l}\text { Strong, influential, user-driven users' } \\
\text { group }\end{array} \\
\end{array}$ & & & \\
\hline External "marketing" of HFIR & & & \\
\hline $\begin{array}{l}\text { Brown baggers by users for RRD (DOE) } \\
\text { staff and vice versa }\end{array}$ & & & \\
\hline $\begin{array}{l}\text { - Advertise audit schedules when } \\
\text { appropriate }\end{array}$ & & & \\
\hline Publish annual repon with user input & & & \\
\hline Increased user interaction with site office & & & \\
\hline
\end{tabular}


Preliminary Categorization of HFIR Upgrades (cont.)

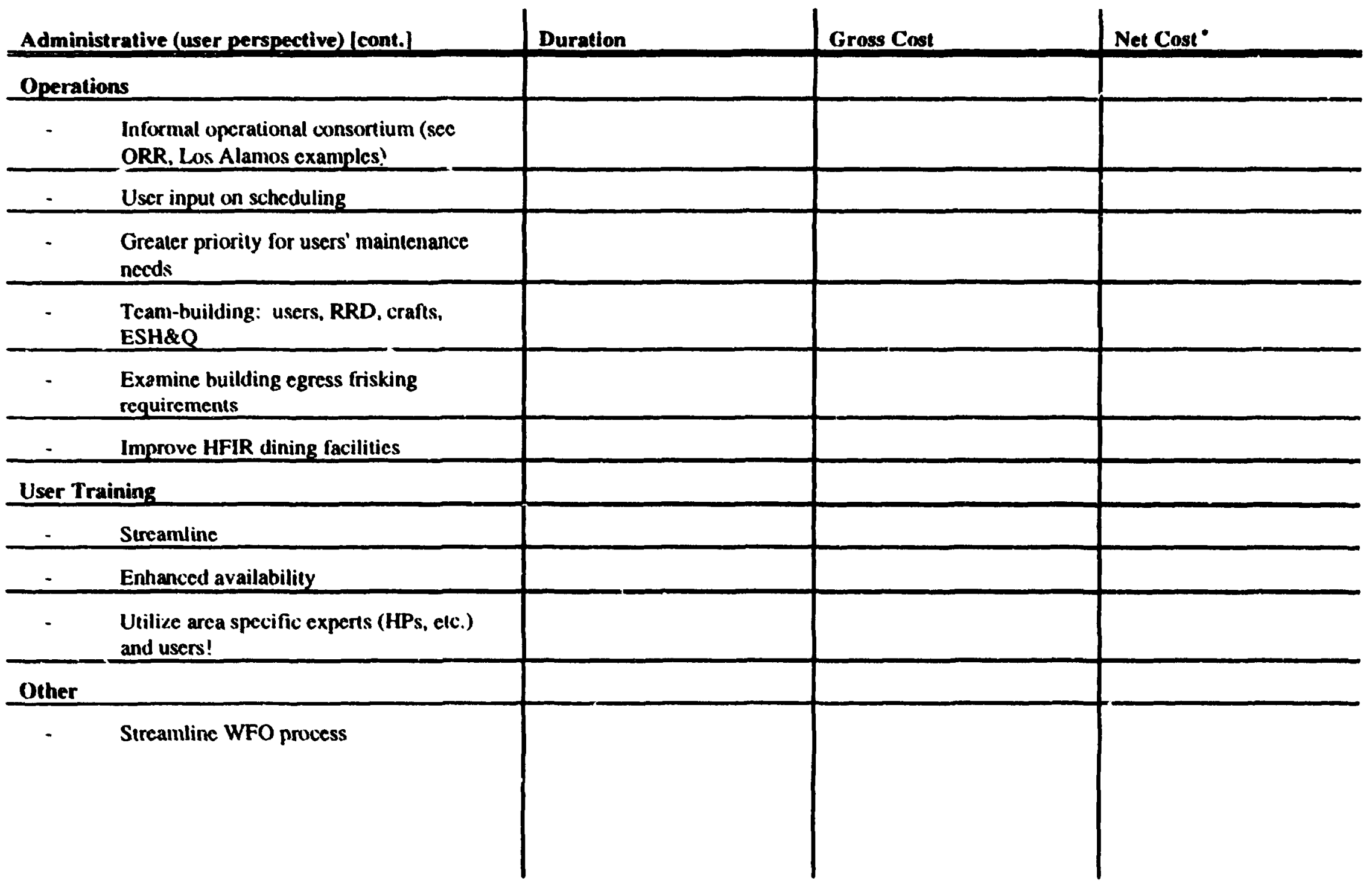


Preliminary Categorization of HFIR Upgrades (cont.)

\begin{tabular}{c|l|l|l} 
Regulatory ownership & Duration & Gross Cost & Net Cost \\
\hline $\begin{array}{c}\text { Push for clarity of DOE management - } \\
\text { NE/ER split is counterproductive }\end{array}$ & & & \\
\hline Find the correct place in the NRC & & &
\end{tabular}


ATTACHMENT 4 


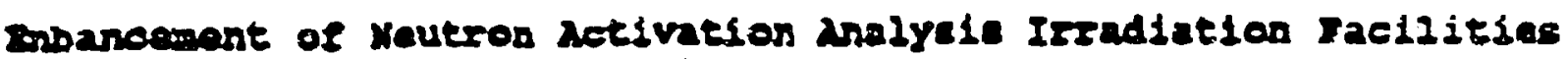
and orfles space

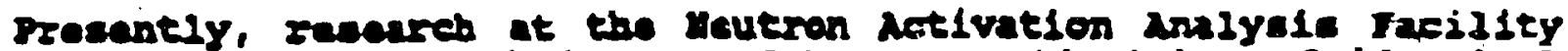

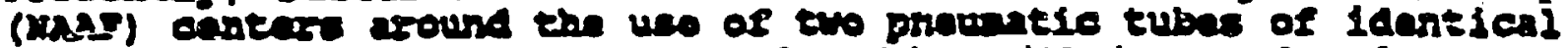

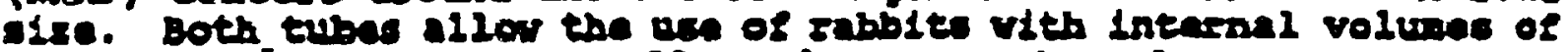

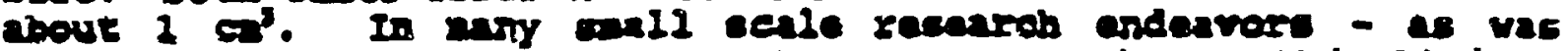

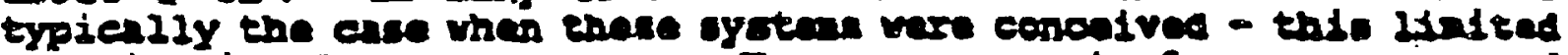

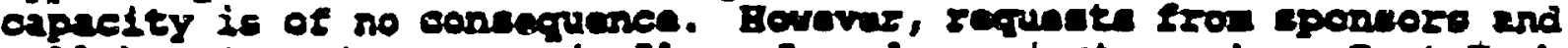

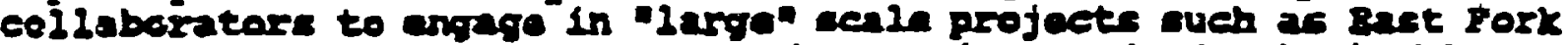
Poplar creak unve grow. It an boon incrensingly dacirable to

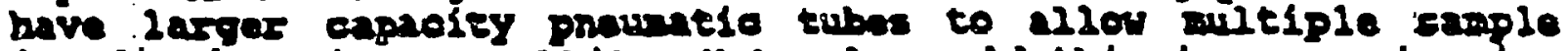

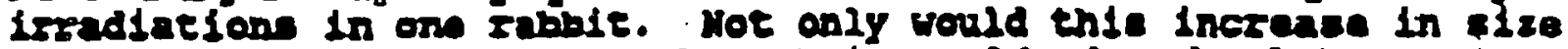
resule in Eancer urm-around, but it would aleo dead to grester accurnoy, eansitivity, eore efflelent uso of paraonnal tive, and cost cavinge thet coula pasued on to our ouotonare.

One of the two pamatie tuber, Prol, is located in the pespanent

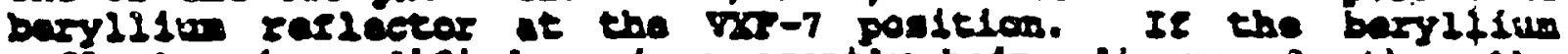
refleceor is nodified as is presently being disounced, than the opportunity axiste to pue is a prountie tub witb couble the appasty of zabbits una in the prosent oyeter.

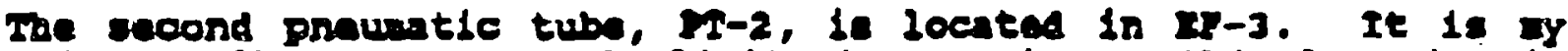

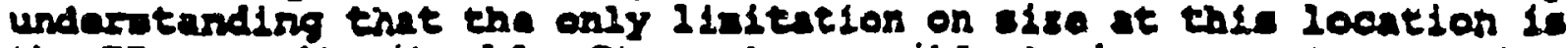
the sf eapeciey Itecle. It any be poscible to incorporate a syster that would acconodate 20 - 40 cil rabbite indapandant of otber modificatian to the renctor.

Just irside the eirct eloor experimant room is area ldanliy (with axception that (t dase not have vindovel) aulted for the nataral extertion of tbe mas offico aren. Pracently, this epace is being uned as repository for Janitorial upplias, file oubinets, and an ascorthant of ltwin not leantielable. If this area was converted to offlo opuce it vould halp colve our ofelon opece defleloncy, and inprove the aestation of the building for ald concarned. 


\section{Mtaindertative opgrades}

Bagulatary armabip

- munin sar ciarity of mo's the base - $\mathrm{m} / \mathrm{m}$

-FInd the correct place in the inc

oparations

- Insaral oparational cansortiua

- Dear loput on echeduling

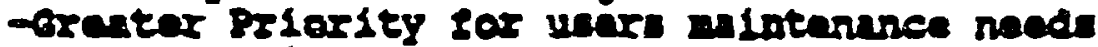

-Teso-busddingl unere, asd, erafte, Estce

Traloing

- Etreasiline

- Enbanced Availability

- Oe11180 aran opeclelo exparte (IPe, atc.) and usera!

cominieation

- Drtarmal marketsog" of bord (min)

- Dear Drivan teure exoup

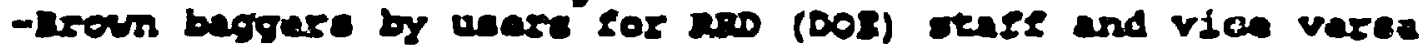

- Devertice audit sebodused wad approprilate

- Publiab ansual repost vith user lapert

-Increaced uear intaraction wieb ite offica

othar

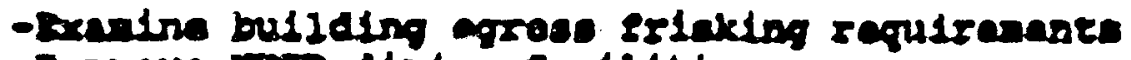

- Improve Ire diniong Inollities

- Btreanline wro process 
ATTACHMENT 5 
Enhancements Requiring Some Changes to the Reactor Cost Guess

Modify reactor top head for better access to reflector positions

$\$ 0.5 M-\$ 2 M$

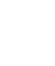


ATTACHMENT 6 


\section{EXAMPLE}

\section{EVALUATION OF MINOR COST PROPOSALS - Facility or Instrument Improvements}

\begin{tabular}{ll}
\multicolumn{1}{c}{ Minor cost iems } & Questions/Notes \\
\hline $\begin{array}{l}\text { Complete preparation and benchmarking of the } \\
\text { detailed Monte-Carlo model of the HFIR, and } \\
\text { couple it to the ldaho MOCUP depletion code }\end{array}$ & $\begin{array}{l}\text { Could be used immediately for HFIR } \\
\text { Futures Group follow-up activities. } \\
\text { Does RRD have a workstation } \\
\text { available for this? }\end{array}$ \\
$\begin{array}{ll}\text { Expanded laboratory facilities for materials } \\
\text { analysis }\end{array}$ & $\begin{array}{l}\text { Do we have equipment and funded } \\
\text { work to utilize the new facilities right } \\
\text { now? }\end{array}$ \\
New' gamma irradiation facility & $\begin{array}{l}\text { Do we have any customer or sponsor } \\
\text { ready to use the new facility? }\end{array}$
\end{tabular}




\section{EVALUATION OF MINOR COST PROPOSALS - Operational and Fuel Fabrication Changes}

Select existing fuel elements that will permit operation at $10 \%$ higher power

Modifications and improvements to fuel plate inspection/selection procedures to permit operation at $16 \%$ higher power
Calculations and safety analysis scoping work could begin immediately after discussions with ORO (does ER or NE need to be direcily involved?)

Follow on to the item abcve to allow continued operation at higher power after existing fuel elements are used up 
ATTACHMENT 7 


\section{POTENTIALLY, THE THERMAL FLUX AT A COLD SOURCE LOCATED IN THE HFIR THROUGH TUBE IS HIGHER THAN AT THE ILL VERTICAL COLD SOURCE}

- Unperturbed flux at location of center of HFIR through tube. $\approx 9.5 \times 10^{18} \mathrm{~m}^{-2} \cdot \mathrm{s}^{1}$ $85 \mathrm{MW}$

- Unperturbed flux at location of center of ILL vertical coid source $\quad \approx 5.7 \times 10^{\prime \prime} \mathrm{m}^{2} . \mathrm{s}^{\prime \prime}$

- BUT, the big L.D: cold source at ILL has a larger gain than we could get from a small $\mathrm{LH}_{2}$ source

- I inave no figures yet for the difference in gain

- as a guess, I would hope that a HFIR through tube $\mathrm{LH}_{2}$ source would give about the same cold flux as the ILL source (same order of magnitude, anyway)

C. D. West/4-7-95 
May 10, 1995

\section{HFIR Futures Group Meeting}

Attendance

The HFIR Futures Group held its seventh meeting at 8:30 a.m. on Monday, April 24, 1995, in the Blue Room of the FEDC. Those in attendance were:

John Bigelow

Emory Collins

George Flanagan

Mike Harrington

John Hayter

Michele Houser

Larry Robinson

Ken Thoms

Colin West (chair)

Ken Farrell (observer).

\section{Opening}

The meeting began with Colin showing a revised meeting agenda (see Attachment 1) and asking if there were any changes to the meeting minutes of April 10. Some spelling changes were pointed out, and a typographical error was identified. John Hayter had some information conceming the Conduct of Operations workshop he had attended in Gatlinburg. Ternessee, and wanted the fact that this was an important meeting to be noted (see Attachment 2). South Carciina was added to the list of states that shipments of spent fuel sometimes travel through. Also, the fact that qualitative changes in the potential uses of a guide ha'l were the result of super-mirror work was mentioned for addition. John $H$. then handed out a report from the Jap.in Atomic Energy Research Institute (JAERI) (see Altachment 3). Ken Thoms mentioned that he had a report on the Petten vessel changeout; Colin asked for it, and said he would make a few copies of it for distribution. John Bigelow had some questions after last week about the idea of a reactor and a spallation source sharing a guide hall. John $H$. explained that one could use several targets in a spallation source and the targed paticle beams could be easily deflected between two targets in any particular direction, thus allowing a possibility of sharing space.

\section{Executive Commiltee presentation}

Colin reported back to the group that he thought his meeting with the Executive Cornmittec went well (see Attachment 4). Reports from RRD management to George Flanagan confirmed this impression. Colin again mentioned that there had heen some discussion on how to treat the administrutive upgrades. duc to the sensitivities of Cealing with DOE. The Futures Group will 
probably report these proposals to the Executive Committee, but they may or may not be written in the published repor.

\section{April 25 - eseniation to DOE headquarters}

There is a meeting to be be!d on April 25 between DOE and some of its national laboratories on the operation and future of some of DOE's research reactors: both the Office of Nuclear Energy and the Office of Energy Research are supposed to be involved in the meeting. George is $u$ attend the meeting to represent HFIR and to talk a bit about proposed HFIR upgrades. Colin had some proposed viewgraphs for this meeting and asked for the group's comments on them. The slides were changed according to comments made. The revised viewgraphs are shown in Atuachment 5.

Amended lists

\section{Reactor top head redesign}

Ken $T$. had the action item of writing up in more detail the benefits to be accrued from the reactor top head redesign, as well as drafting some wording concerning a redesign of the quick-opening 'atch. Ken $T$. handed out the material shown in Attachment 6.

\section{Benefits of HFIR-REDC transport facility restoration and improvement of HFIR-HRLEL transportation methods}

John B. had the action item of writing up some information concerning the benefits of the HFIR-REDC transpor facility restoration and the improvement of the HFIR-HRLFL transp iation methods. John B. had faxed the information to Michele, but, due to an unknown operating problem with the fax equipment, she had not received it. John B. sent her the material after the meeting, and it is shown in Attachment 7. It was remarked that the name of the HRLEL (high radiation level examination lab) had been changed to IFEL (irradiated fuels examination lab).

\section{Alternative to HFIR vessel replacement}

George then made a presentation on an alternative to the HFIR vessel replacement. In order to use $\mathrm{D}_{z} \mathrm{O}$, rather than beryllium as the moderator, the HFIR vessel may not have to be replaced. The embritted vessel is strong enough for operation if it does not have to function as a pressure vessel. George said that if pressure falls below a certain psi level, the structure is no longer a "vessel," but a "tank," and subject to different (and less stringent) requirements. The proposed new configuration is shown in Altachment 8.

George remarked that one would not want to change the control drives or the rest of the control system. but to keep things as much the same as possible. There would be no need for $\mathrm{D}=\mathrm{O}$ in the area above the center of the core, so an annular tank of appropriate heighı can be dropped inside the existing essel. This tank-inside-a-tank could have predetermined windows for beam tubes, as well as thimbles. A lot of the building and refurbishment could be done away from the vessel, making the tank replacement similar to the berylliuin replacement (built away from the vessel and having holes pre-cut in it). The $\mathrm{D}_{2} \mathrm{O}$ tank would then be removed for the $\mathrm{D}{ }_{2} \mathrm{O}$ to be replaced. Light water will probably he inside the vessel above and below the $\mathrm{D}, \mathrm{O}$ tank. The reactor pon! would be used as the heat sink for the reflector conling system. The $D, O$ would be a self-contained system with a "box" filter demincralizer unit. 
It was remarked that this modular appr ach was probably gons and would minimize the downtime for a change in the vessel from years to less than a year. There were some questions about the equilibrium tritium level. Colin remarked that the HFBR facility ships its beavy water off-site periodically for detritiation. The HFIR facility could do likewise, or perhaps look at biilding its ovrn.

Emory asked George if these new ideas could be implemented $\because 1999$, rather than changing out the beryllium. The \$10 M allorated for the beryllium replacement could thus be saved. George replied that he thought such a change was possible, bui it would require a change in the direction in which the facility is currently moving for 1999.

John $H$. asked if there was ever another HFIR vessel found--there had been a rumor tinat more than onse had been manufactured when the original one was made. George said thal, as far as he knew, no other copy of the vessel had been found.

George went on to say that the $\mathrm{H}{ }_{2} \mathrm{O}$ would still be used for cooling, and parts could be fabricated out of aluminum or steel, as needed. The new design would give more space around the core. as well as affording more flexibility in refueling. The $\mathrm{D}{ }_{2} \mathrm{C}$ tank would be pre-sealed and pre-testing, thereby minimizing the time for installation. Colin asked that George write up a page of explanation for this most recent addition to the list of HFIR upgrade proposals.

There were some questions for George about how the irradiation targets would fit in this new configuration, and he described six rabbits on an indexing system. Mike then questioned George about safety issues which might arise from this new arrangement. Going to upflow. rather than keeping the existing downflow configuration, might call for a flow testing program. It is not thought that the pool will have to be made deeper for this new design.

Ken $T$. inquired as to where the materials irradiation facility would be in the new design. George said it would be in the tank, with the targets remaining just as they are now. The RB* positions in the fastfux region can still be there. Ken F. remarked that there might be proolems joining a stainless steel core pressure boundary tube with aluminum seals. He suggested as an altemative making the entire tube from aluminum.

Questions were raised about the core. George said they were considering using the same core, except perhaps making its vertical dimension longer. They were looking at the same core concept of a double core with a target in the middle. Inquiries werc then made about what a new cure would mean with respect to burnable poison and low-enriched uranium fuel. George said the concept was not far enough along to address these issues yet

Mike asked if the RRD study group had allotted resources for major safety questions to be addressed. George said he was aware that the Safety Analysis Report would probably have to be re-written, due to the new neutronics involved. Mike said that although this concept is a minimum change when compared with the replacement of the entire vessel, it is not a minimum change from the standpoint of the safety reviewers.

It was remarked that an acivantage of the HFIR over the HFBR was the fact that the beam iubes were flanged, rather than welded. Also, the bottom of the vessel is bolted, not welded. Larry said he saw no major problems with the proposed design from the standpoint of an aly':cal chemistry users. 


\section{Comments}

Colin asked for commenis on the draft outline of the study report, saying he had not been able to proceed much further on it since last meeting. He also asked for comments on the viewgraphs for the Washington meeting. George remarked that he was leaving at $3: 00$ that day to prepare for his trip, so cummen's would have to be given soon.

\section{Coid source design}

Colin said that Trevor Lucas has been thinking about cold source options and has 4-5 different configurations in mind. Each arrangement has progressively more modifications, with progressively better results. He said that Trevor needs to meet with RRD to discuss his ideas. George suggested that Colin call Dave Cook and Steve Burnetue to fix that mezting.

\section{Closing}

John $H$. had brought a copy of some "Certified for Construction" drawings for the HFIR and asked about movirg the battery room and the electrical room to allow more space on the heam room floor. It was remarked that this had teen discussed in one of the weeks that John was absent and was on the list as an "incremental improvement." The drawings John $\mathrm{H}$. brought could be good historical references ior the group's work, although they might not necessarily reflect what was actually built at the facility.

\section{ACTION ITEMS}

George will complete a shon write-up explaining RRD's concept for the altemative to the HFIR vessel replacement.

Michele will revise the proposed upgrade lists, incorporating John B.'s and Ken T.'s inputs, and see that the group reciives them.

Ken T. will give Colin a copy of the Petten upgrade repor.

Colin will contact Dave Cook and Steve Burneue to arrange a meeting with Trevor Lucas.

Gedige will repor on the April 25 presentation.

M. M. Houser, April 25, 1995 
Distribution

HFIR Futures Group Attendees (notes for record + Attachments 5.7. and 8)

J. E. Bigelow, 7930, MS-6385

E. I). Collins, 7930, MS-6385

K. Farrell, 5500, MS-6376

G. F. Flanagan, 7917, MS-6398

R. M. Harrington, FEDC, MS-8218

J. B. Hayter, FEDC, MS-8218

M. M. Houser, FEDC, MS-8218

L. Robinson, 4500S, MS-6128

K. R. Thoms, 9108 , MS- 8087

C. D. West, FEDC, MS-8218

For information (notes for record + all attachments)

B. R. Appleton, $4500 \mathrm{~N}, \mathrm{MS}-6240$

J. B. B.all, 4500 N, MS-6182

R. E. Battle, FEDC, MS-8218

H. A. Silovier, 7917, MS-6398

H. A. Mook, 7962, MS-6393

J. P. Moore, 4508, MS-6080

D. E. Reichle, 4500-N. MS-6253

J. B. Richard. 7962, MS-6391 
ATTACHMENT 1 


\section{AGENDA FOR \\ HFIR FUTURES GROUP MEETING}

Monday, April 24, 1995

8:30 a.m.

FEDC, Blue room

- Discussion: Changes or corrections to $4 / 10 / 95$ meeting notes for the record

- Executive Committee presentation (past)

C. D. West

April 25 presentation (to come)

C. D. West

- Discussion: Amended lists of HFIR upgrade proposals

- $\quad$ Revised write-up concerning reactor top

K. R. Thoms head (benefits + re-design of quick-opening latch)

- Benefits of HFIR-REDC transport facility

J. E. Bigelow restoration

- Benefits of improvement of HFIR-HRLEL

J. E. Bigelow transportation methods

- Alternative to HFIR vessel replacement

G. F. Flanagan

- Discussion: Comments on draft outline of study repor

- Any other business 
ATTACHMENT 2 


\section{WORKSHOP ON ES\&H REQUIREMENTS FOR OBES PROGRAMS}

Garlinberg. Tannessee

May 6-10, 1991

\section{PROGRAM}

Mondey Aftermoon, May 6

3:00-8:00 Registration (Presidential Suare, Room 343)

8:00-10:00 Infamal Reception (Mountaineer I and II Rooms)

Tuesday Morning, Mey 7

7:00-8:00 Registration (Faiview I)

7:00-8:00 Brealfass (Mountaineer I and II Rooms)

Environment, Safety and Health - Bill R. Appleton, Presiding (Fainview II and III Rooms)

8:00 Welcome

8:10 Opening Remarks

8:30 OBES Expectations for ES\&H

9:00 ES\&H in the Office of Energy Research

9:40 Break

10:00 The Performance Indicator Program

11:00 Cradle-to-Grave Control of Hazardous Materials Thaddeus Tomczak, ER-14

11:30 DOE and the Occuparional Safery and Health Act Mike Teresinsti, ER-13

12:15-1:15 Lunch (Mountaineer I and I Rooms)

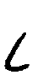

Tuesday Afternoon, May 7

Conduct of Operations - Alber E. Evans, Presiding (Fairview II and III Rooms)

1:30 Requirements of DOE Order 5480.19

Paul L. Ziemer, EH-1

2:30 The Drafi Accelerator Safery Order

Albert E. Evans, ER-13 
IIY as '91 68:33 cooll-EROWF FPX1615-574-0323

F.2

OBES WORKSHOP ON ES\&H

Worting Group 6

Special Problems of User Facilities

Name

D. Arther L. Biespessecte, Chairmen

J. Sueve Bintley

brees. srown

Jim Comon

Nomen Fewell

Jom B. Hyres

Rosedll HI Hoebser, Sr.

Puul Johneos

Frederick A Koommof

Roger ?you

D. Rexs

Frederick A. Schmidt

M. T. Thomes

Willien Thaminson

Kennech Wesinecos

John A. Cerino

locest M. Waters

Mest. Endnarezuk Fesmilab
Organization

Suniod Uhivenity

Sadit Nuinal Lobactacies

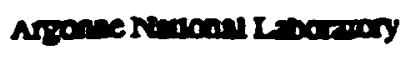

Dos

Broct teven Nhionul Laboriosy

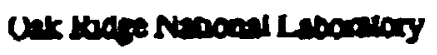

Arpone Nrional Laboray

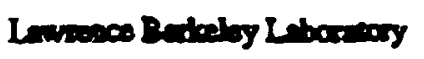

DOE

Los Amonos Nationd Labortay

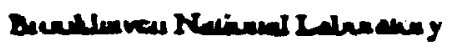

Ames Lebonery

Brnele Pacific Nonthwest Lab

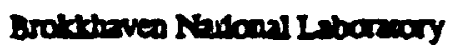

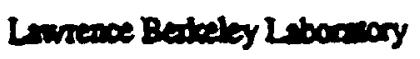

Sunford thiversiny

DOE

washingtor chicago.

Ciry

sinationd

Liverex

Npoune

Wastingeren

Upeos

Oex Riture

Argone

Bateiky

Wectinguen

Loc Alimos

Upeon

Ames

Rirthend

Uproa

Beateley

Sunford 


\section{OBES Workshop on Implementation of Environment, Safety, and Health Requirements}

Gatlimburs, Tennessee

Mas 7-10, 1991

\section{ATTENDEES}

\section{Department of Enerey}

Iohn L. Burnett

Jim Cannon

Albert E. Evans

Louis C. Iannielio

Frederick A. Koomanoff

Joseph R. Maher

Mary Anne Scott

John Stefano

Michael Teresinsto

Iran L. Thomas

Neill Thomasson

Ted Tomezak

$\because$ Robert M Waters

Paul L. Ziemer

DOE/Albuaueraue Operations

Herb C. Bohannon, Jr.

\section{DOE/Chicage Operations}

Joseph P. Drago

David T. Goldman

Angela C. Harvey

Victor J. Potent

John M. Searing

Anibal L. Taboas

DOEAdaho Operations

Isarnu Aokj

\section{DOE/Oak Ridge Operations}

Leonard Blankner

F. Les Girn

Barsy Willis
DOF/Richland Office

Cesar E. Collontes

Ames Laboratory

Lowell Mathison

Frederick A. Schmidt

Rawley Strass

Areonne National Laboratory

Walt Bird

Rudolph Bouie

Bruce S. Brown

Bob D. Dunlap

Russell H. Huebner, ST.

Battelle-Pacific Northrient Lab

Lynn R. Ebertard

Lany Kimmel

Larry R. Pederson

M. T. Thomas

John W. Wald

Pat A. Wright

Brookhaven National Laberntory

M. Bebon

John DiNicola

Norman Fewell

Allen N. Goiand

Gerald C. Kinne

Jack Preses

Dave Rorer

William Thomlinson

Eermi National Accelerator Lab

Mark Bodnarczak 
Iahe National Enginesring Lab

Don W. Keefer

James Seydel

\section{Lavence Berkeley Laboratory}

(6) Paul Johnson James F. "Buck" Koonce

Kenneth Westroacolt

Lawrence livernore NationaL Lab

Al Diba

Lawrence R. Newkirk

Pamela K. Shell

\section{Los Alamos_National Lhoratory}

Michael T. Brandt

Diane D. Norton

Roger Pynn

\section{Qak Ridge National Laboratory}

Bill R. Appleton

Rober L. Clark

Lou B. Dunlap

John B. Hayter

William $H$. Miller

Frank A. Modine

James B. Roberto

Tom Row

James O. Stiegler

Anthony L. Wright

Princeton Plasma Physics Lab

Dave O'Neill

Ned R. Sauthoff

Sandia NationaL Labs-Albuquerque

Chuck Gibbon

Ronald E. Lochman

Sandia National_Labs-Livermore

J. Steve Binkley
Solor Enecer Research Institute

Saryen R Deb

Lawrence M. Murphy

Roben O'Doberty

Stanford_Senchrotron Radiation_Lab

Arthur 1. Bienenstock

John A. Cerino

Teresa Troxel

University of Illinois=Urbana

Boyd W. "Buzz" Bowdish

Pete Masias

William A. Testory 
ATTACHMENT 3 


\section{Research Reactors}

\section{Current status and their major roles}
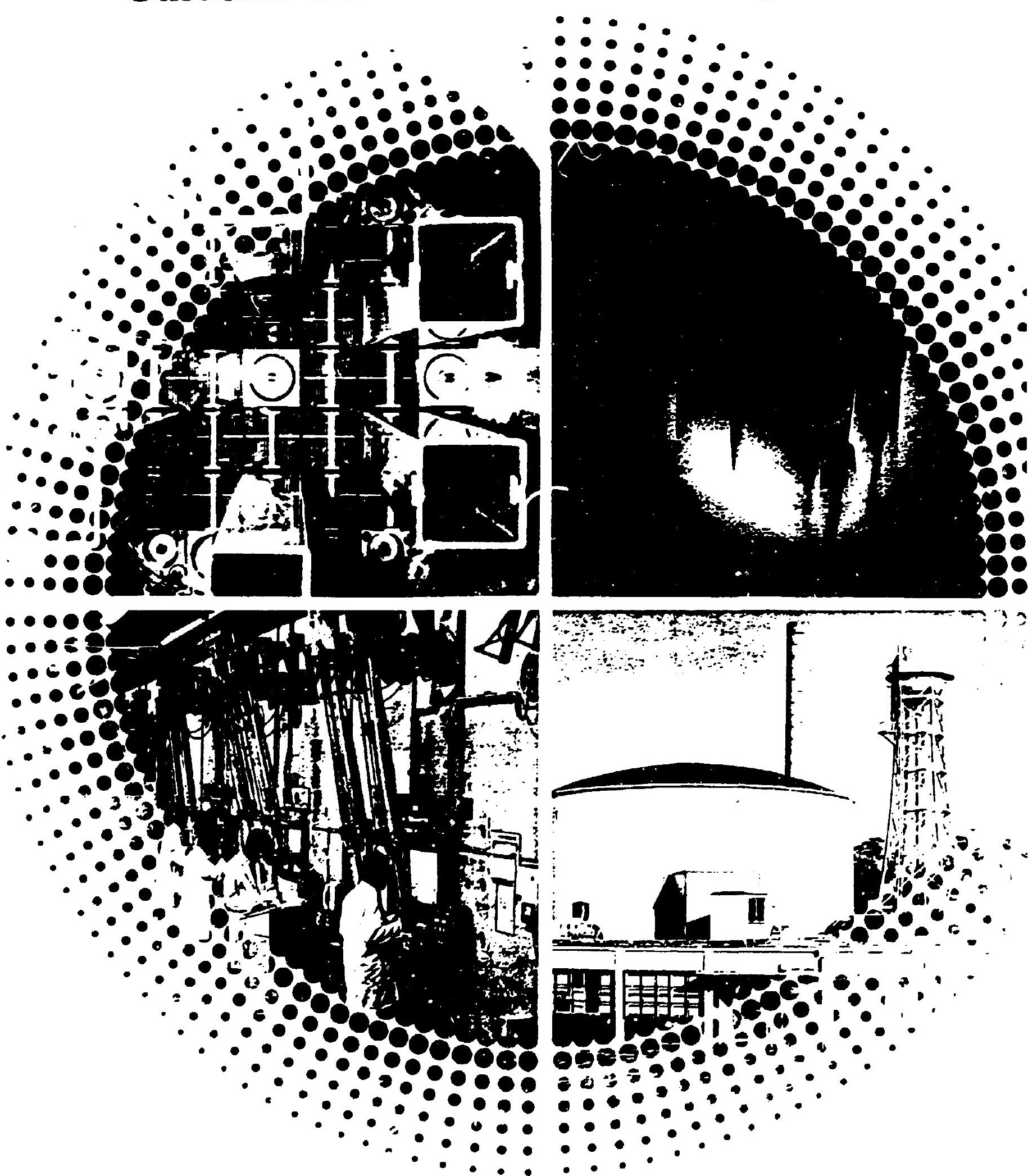

$\therefore \therefore$

-

$\therefore$ action

$\therefore \because 0$ d

$\because \because 01-1$

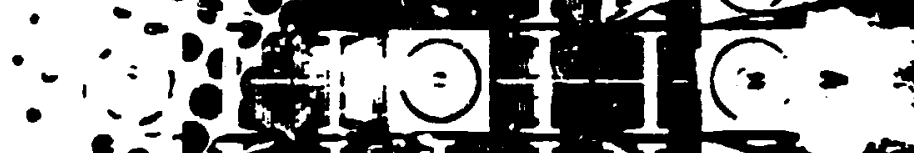

$\therefore \therefore=$

$\because \because$

$\therefore$

$\therefore$

(a)

...8

or

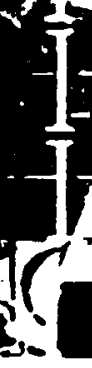

$-4 i+14$

Tokai Research
- 0

09000.0.

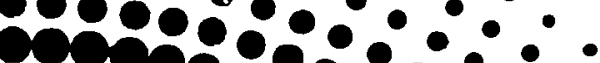

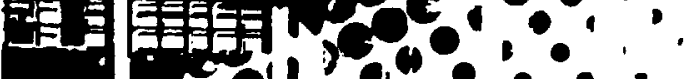

(1)

(

Establishment

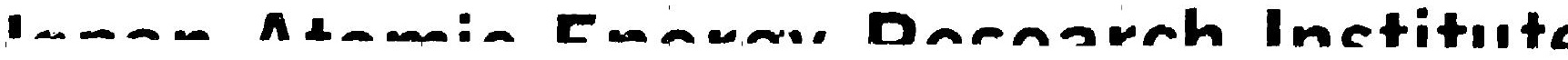




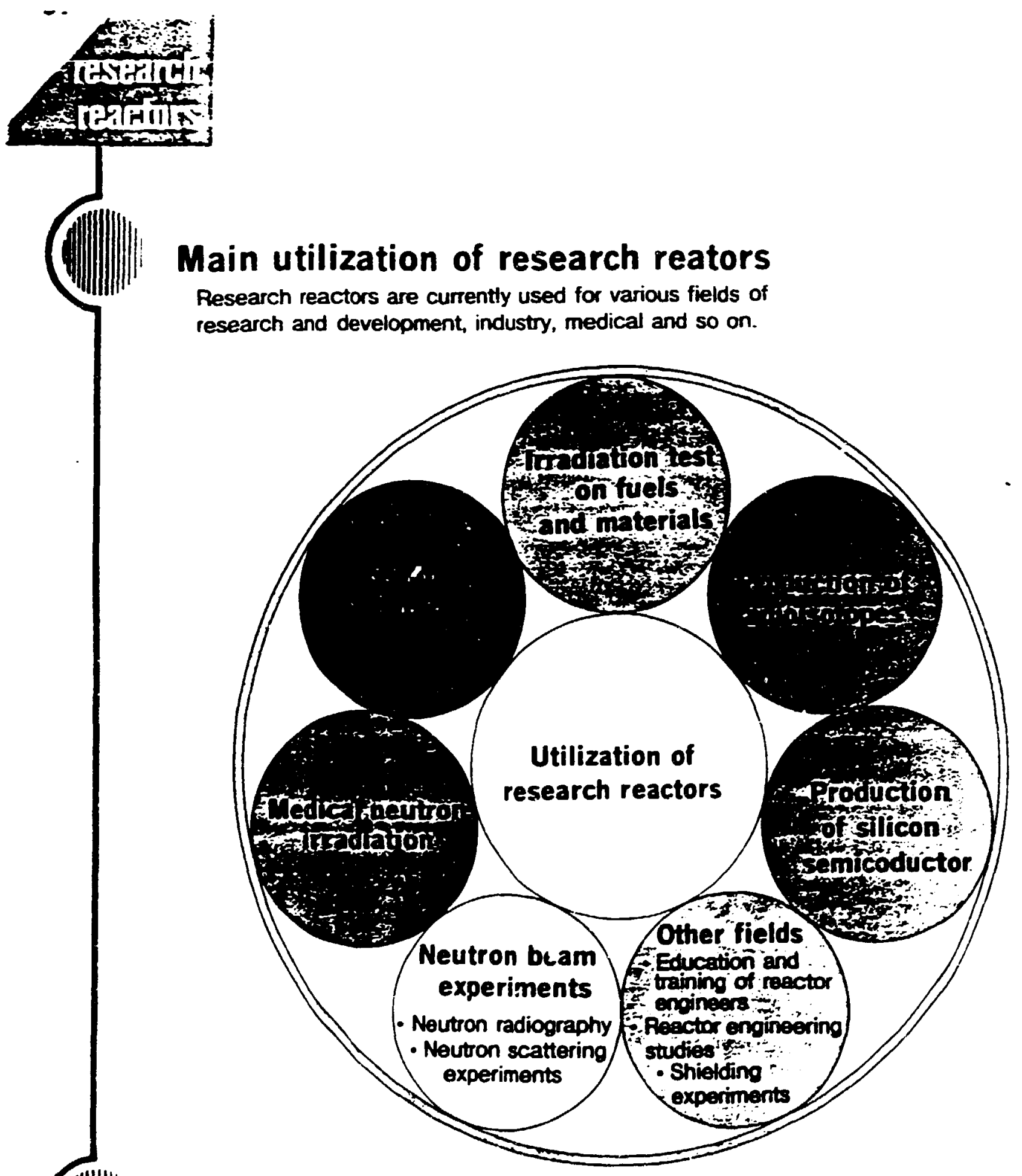

\section{Procedure for joint use of research reactor}

Procedure of utilization in research reactors is shown as follow

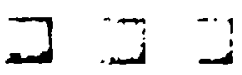

Application for use

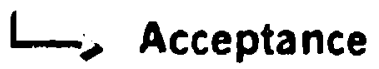

$\longrightarrow$ Preparation of utilization plan

L Irradiation experiments 


\section{Capsules for irradiation tests}

Various capsules are used to irradiate samples in accordance with the irradiation condi neutron exposure, temperature, etc. Typical capsules are presented below.

\section{Polyethylene capsule}

Polyethylene capsule is used mainly for short-term irradiation with pneumatic tube (PN hydraulic rabbit facility (HR) which allow the maximum irradiation time of $20 \mathrm{~min}$ in PN and 40 n HR.

PN capsule in JRR-2

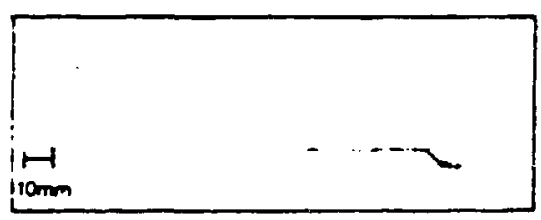

PN capsule in JRR-4

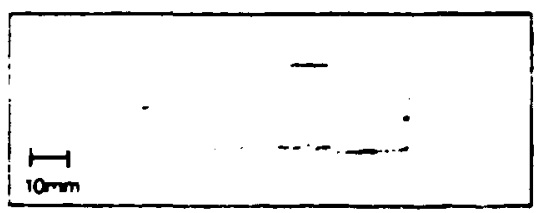

PN capsule in JRR-3M

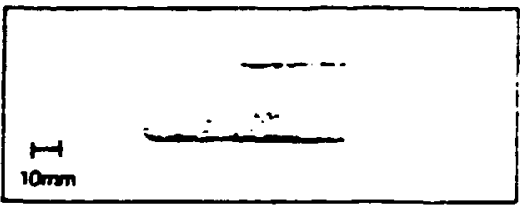

HR capsule in JRR-4

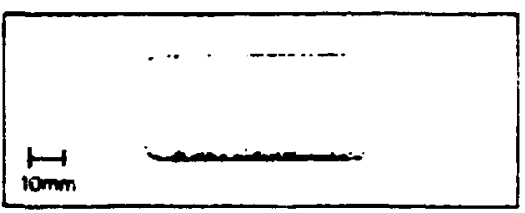

PN capsule in JRR-3M (activation analysis)

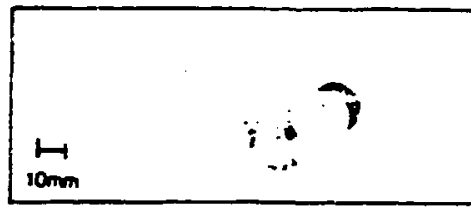

General use in JRR: : JRR

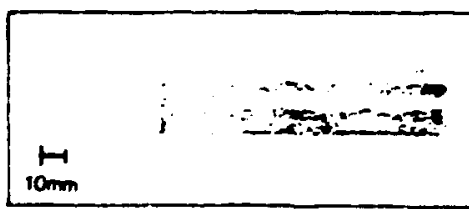

\section{Aluminium capsule}

Aluminium capsule is mainly used for long-term irradiation.

Capsules in vertical holes of JRA-2

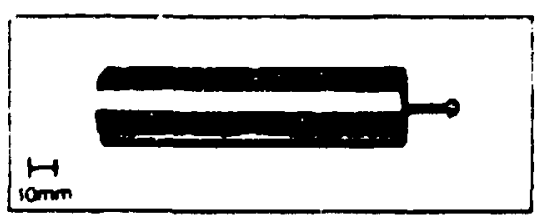

HR capsule in JRR-3M

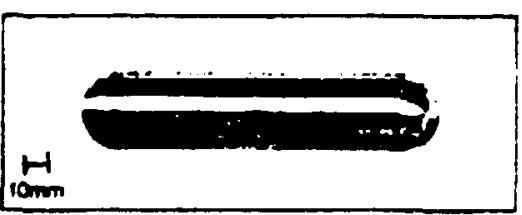

General use in JRR-2, JRR-

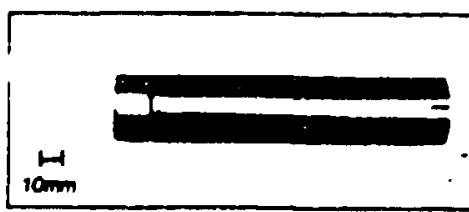

\section{Instrumented capsules}

Instrume .ed capsules are used for long-term irradiation test on fuels and materials. This of capsule can control the temperature of the specimen. Typical instrumented capsules aresh below.

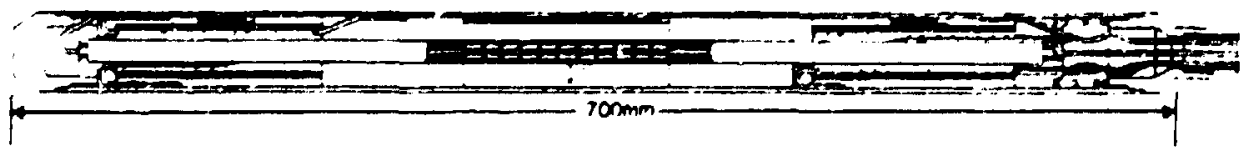




\section{Neutron activation analysis (N.A.A.)}

When materials absorb neutrons, they change to the radioactive and their radioactive rays peculia to the materials are emitted. In activation analysis, the composing elements of the materials as well as extremely small amount of impurities in the materials can be examined by measuring such emitted radiation.

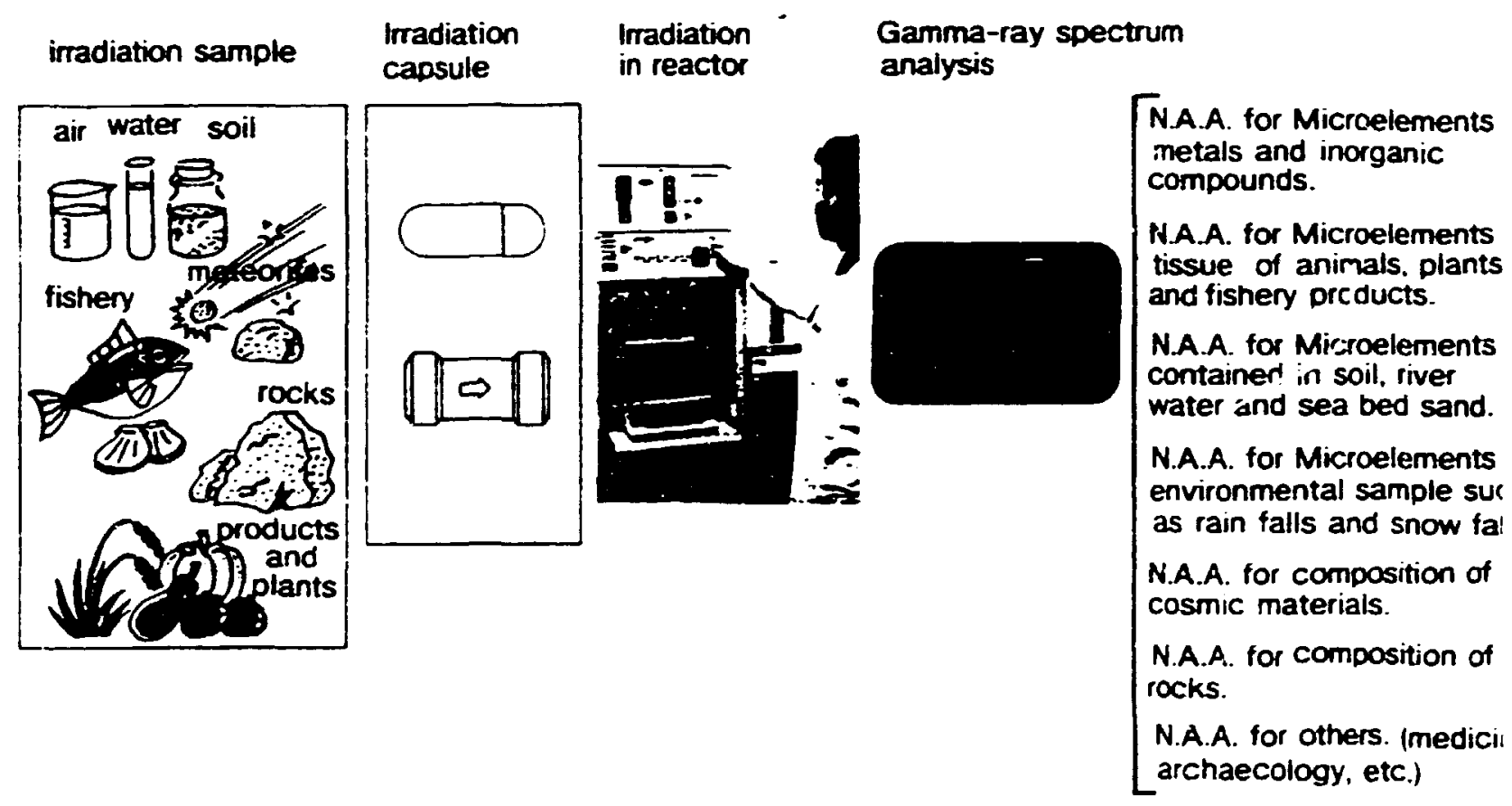

\section{Irradiation test on fuels and materials}

Irradiation tests together with post irradiation examination on fuels and materials contribute to the confirmation of their integrity and the research and development for the present and future nuclear reactors and fusion reactors.

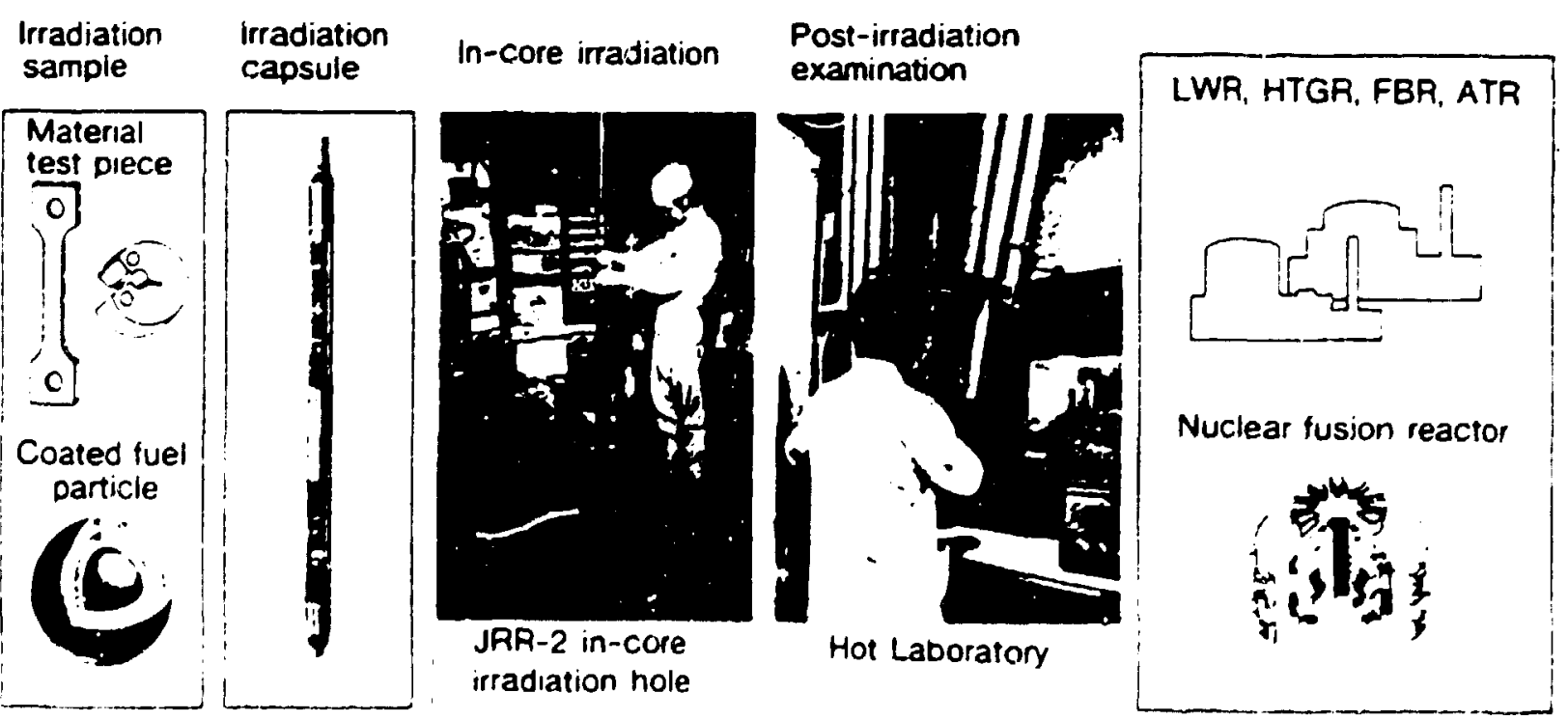




\section{Production of radioisotopes}

Research reactors are used routinely to produce a range of radioisotopes for med pharmacy, science, agriculture and industry, which are classified to radiation source, the pr sed. labelled organic compounds and calibration source for gamma-ray spectrometer.
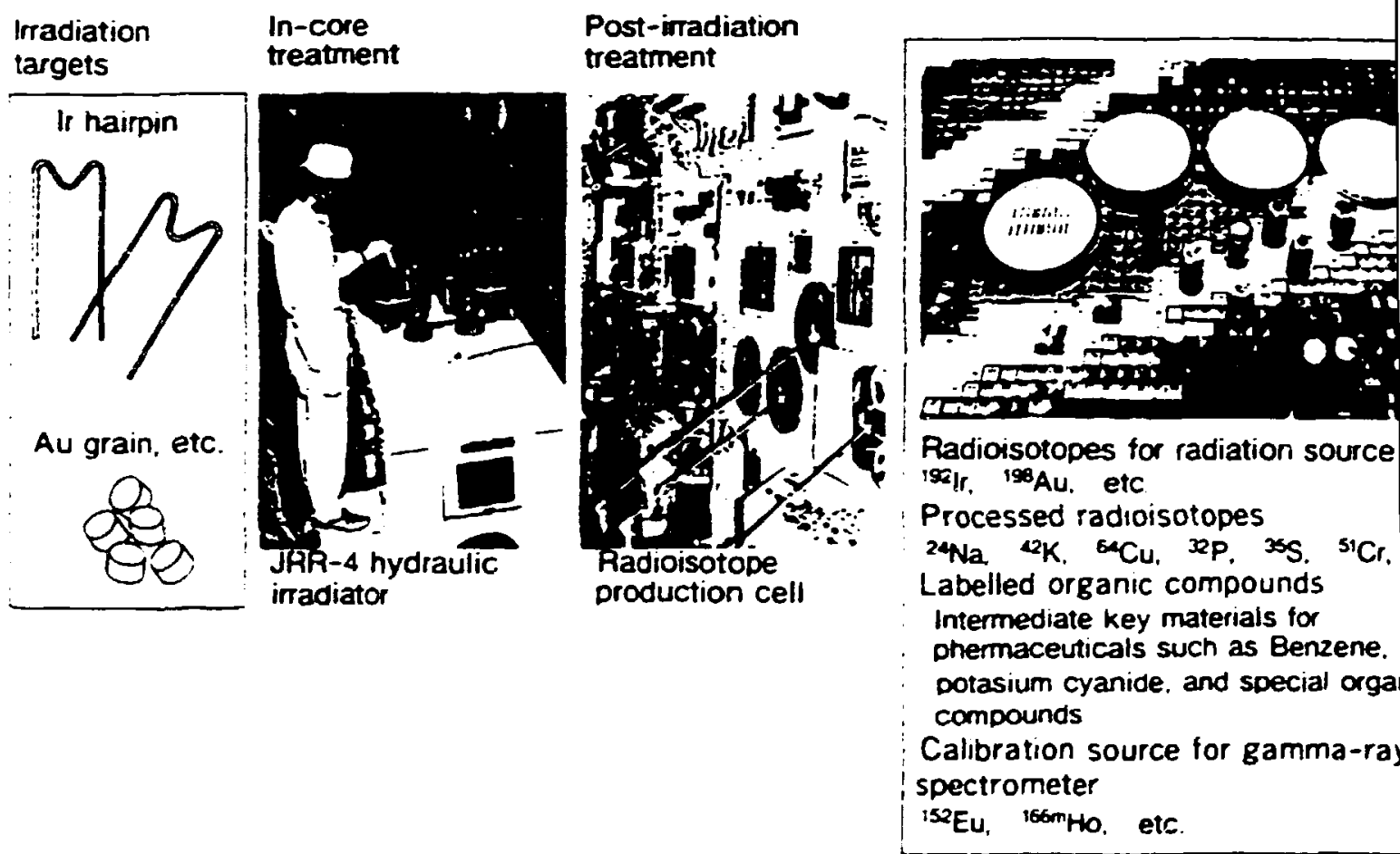

\section{Production of silicon semiconductor}

Silicon semiconductor is made in core irradiating silicon single crystal and homogenec onping phosphor into silicon by nuclear reaction ${ }^{\mathrm{r}}{ }^{\mathrm{S}} \mathrm{Si}(\mathrm{n}, y)^{\mathrm{J}} \mathrm{Si} \rightarrow{ }^{\mathrm{J}} \mathrm{P}$, Silicon semi- conductor produced in such a way is used for power transistor, high-voltage/large-current control thysis and $C C D$ used in video cameras.

Single crystal silicon ingot

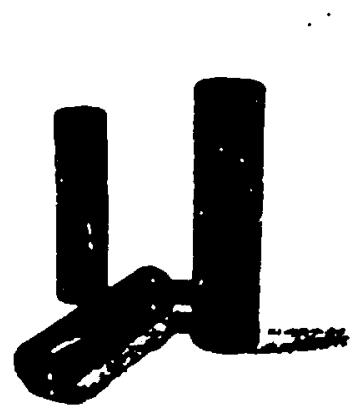

In-core treatment

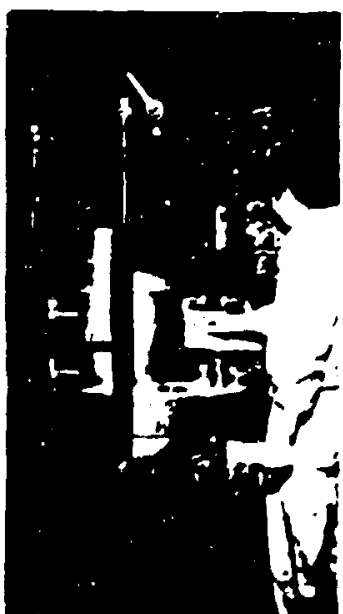

Silicon slice-semiconductor fablication

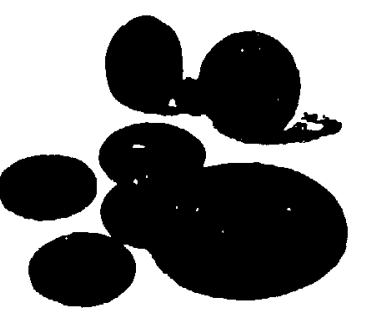

Silicon wafer

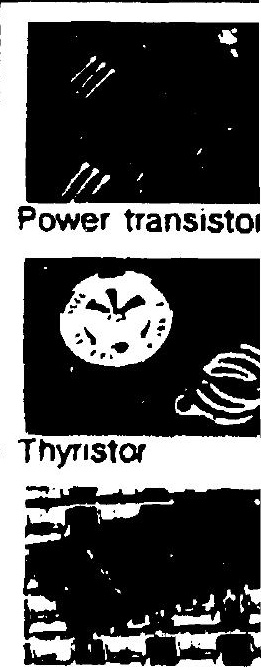




\section{Neutron beam experiments}

Neutron beam experiments include neutron scattering experiments, neutron radiography and so on which use the extracted neutrons from reactor.

Neutron scattering is a technique to find answers to fundamental questions about the structure and composition of materials. Neutron radiography is to take pictures as a method of non-destructive inspection using neuton features.

\section{Neutron scattering experiments}

By examining the status of scattered neutron on a material, a material's atomic/molecular structure and kinetic status can be determined by computer analysis. Cold neutrons make it possible to observe the structure of high polymer materials such as fiber synthesis and plastics.

Neutron diffractometer,

Neutron soectrometer.

Neutron topographey, device, etc.

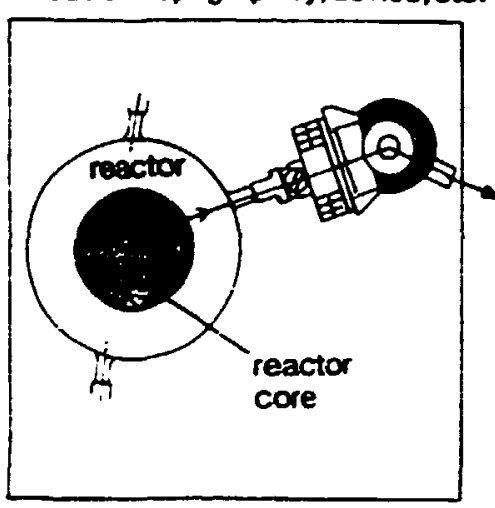

Measurement of angle distribution

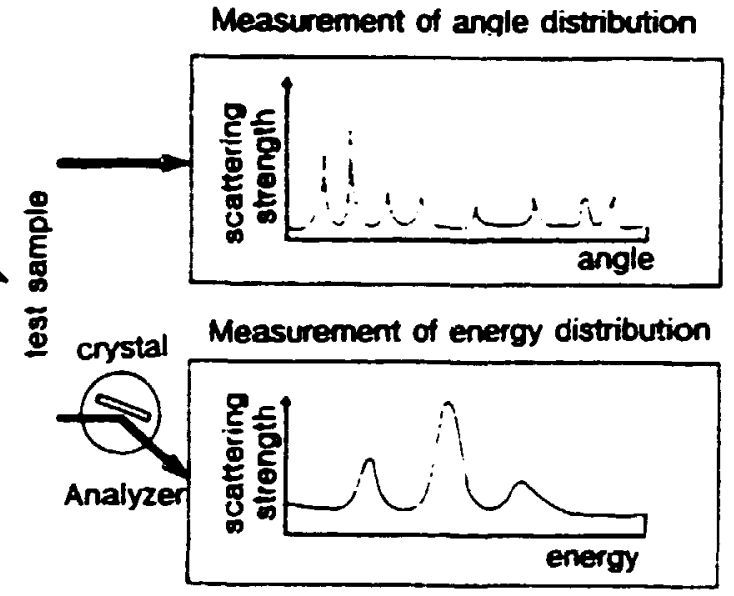

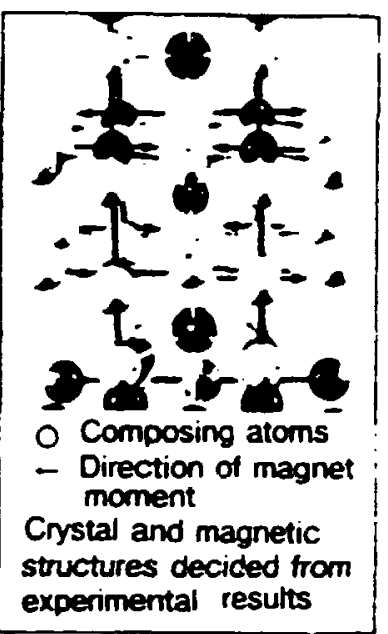

\section{Neutron radiography}

Differing from X-ray, neutson varies in permeation characteristics depended on the neutron absorption peculiar to materials. Neutron permeates heavy metals like lead. while neutron is absorbed in light elements such as hydrogen. Neutron radiography is one of non-destructive examination method effectively using this characteristics. It is possible to take permeation pictures by neutron radiography differing from $X$-ray, and the method is used to inspect space rocket parts and aircraft parts as well as observation on status of oil flow within engines. When cold neutron is used, different pictures can be taken from those by their low enegy and long wave.

Take picture by neutron

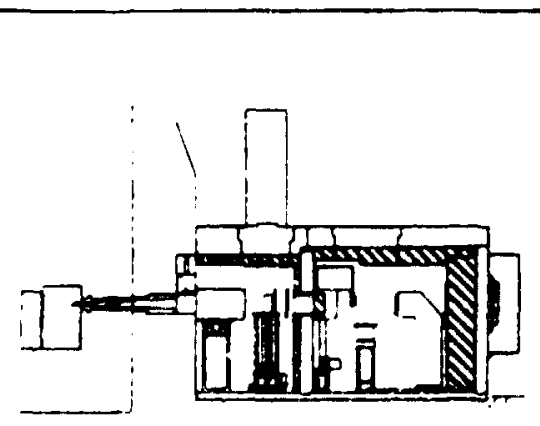

JRR-3M Neutron radiography device
Fuels picture taken by neutron radiography

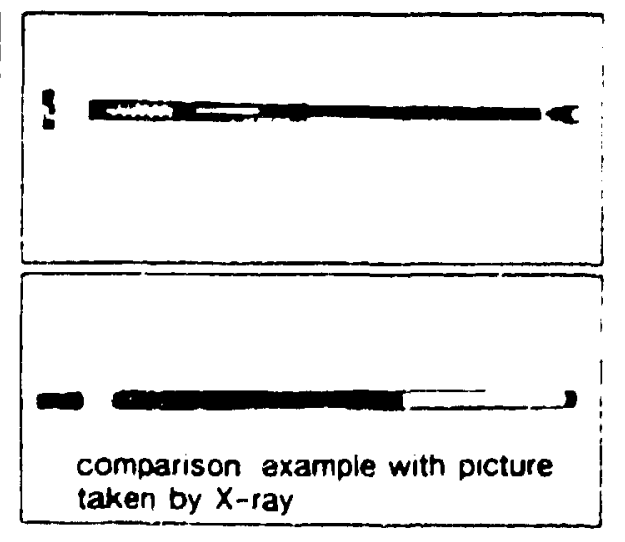

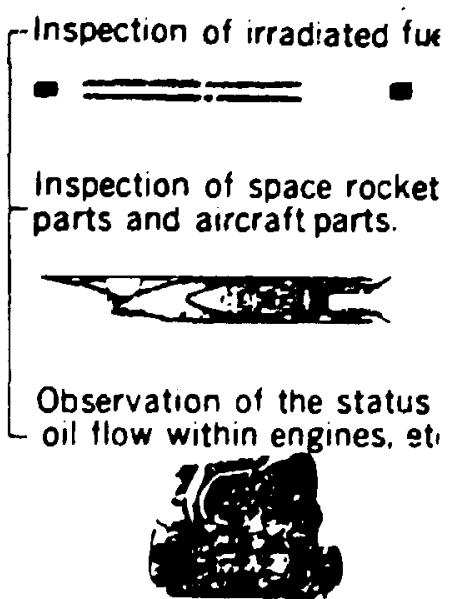




\section{Medical neutron irradiation}

Neutron produced in reactors can be used for neutron capture therapy on malignant tumor and skin cancer. The principle is that boron compounds are injected selectively into cells which are then irradiated by thermal neutron. The cancer cell is destroyed by alpha and litium particle, both of which are produced by nuclear reaction ${ }^{1}{ }^{10} \mathrm{~B}(\mathrm{n}, \alpha){ }^{7} \mathrm{Li}_{\mathrm{J}}$.
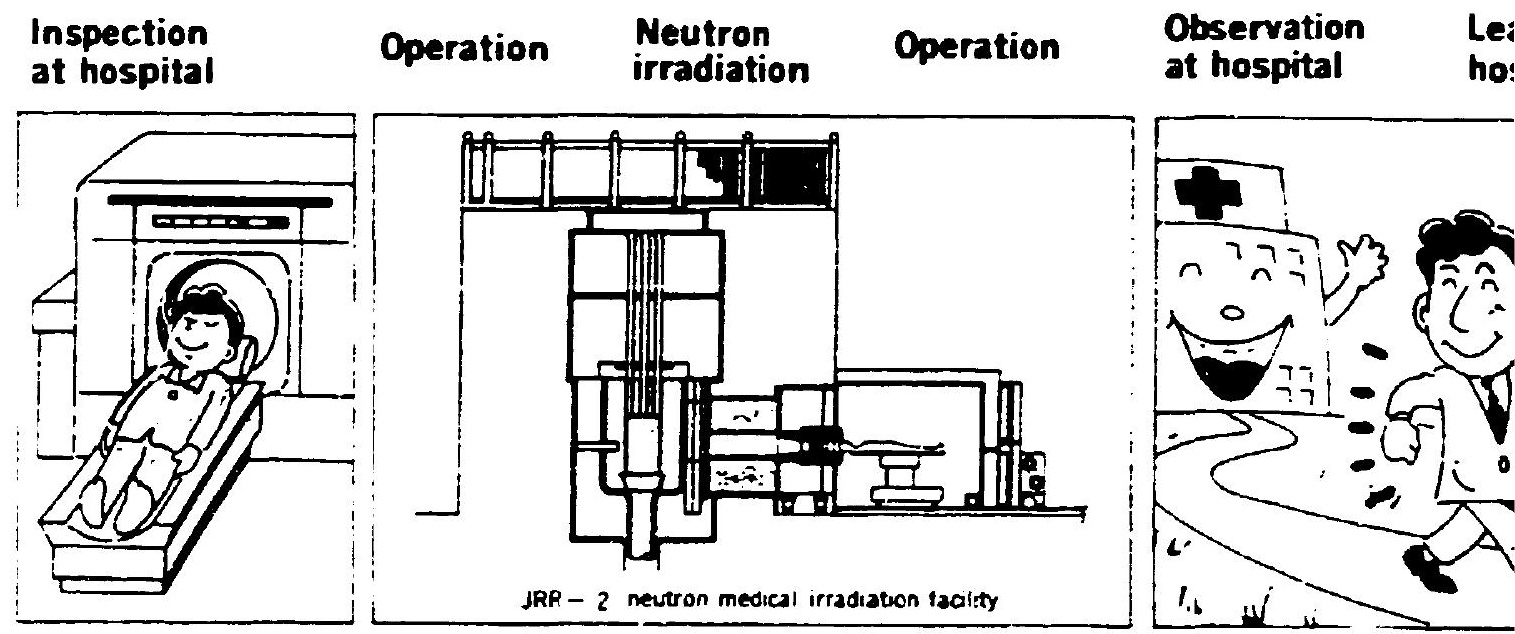

\section{Current status of research reactor utilization}

Utilization status of research reactors during $1988 \sim 1990$ is presented below by uti purposes and by utilizing organizations. In the utilization purpose classification, most occupied by activation analysis and neutron beam experiments. There are many institutes ing universities in addition to JAERI.

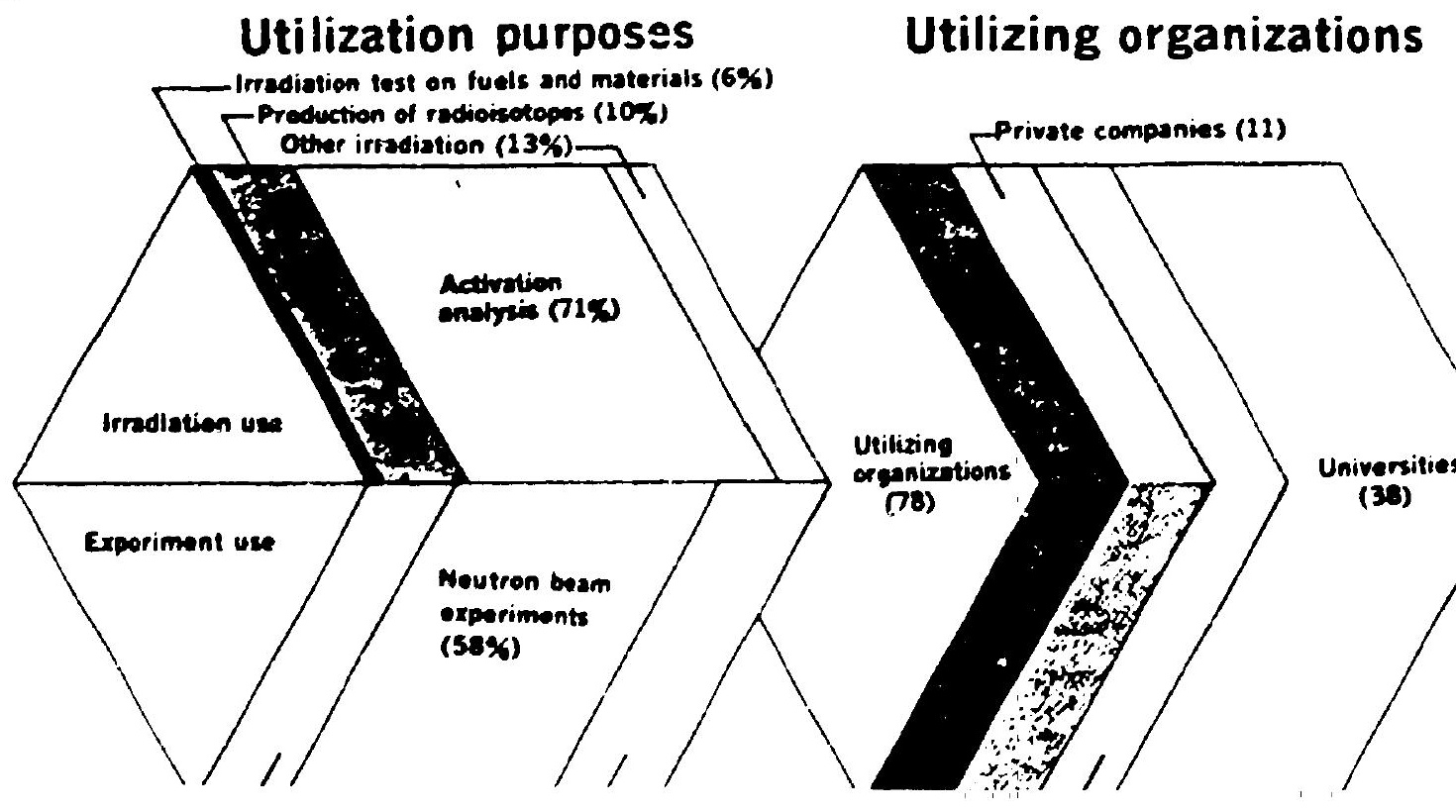




\section{Utilization of research reactors in future}

Research reactors are currently utilized for various sthdies. And it is turtter expected to mell respond to advanced, diversified and upgraded researches in future.

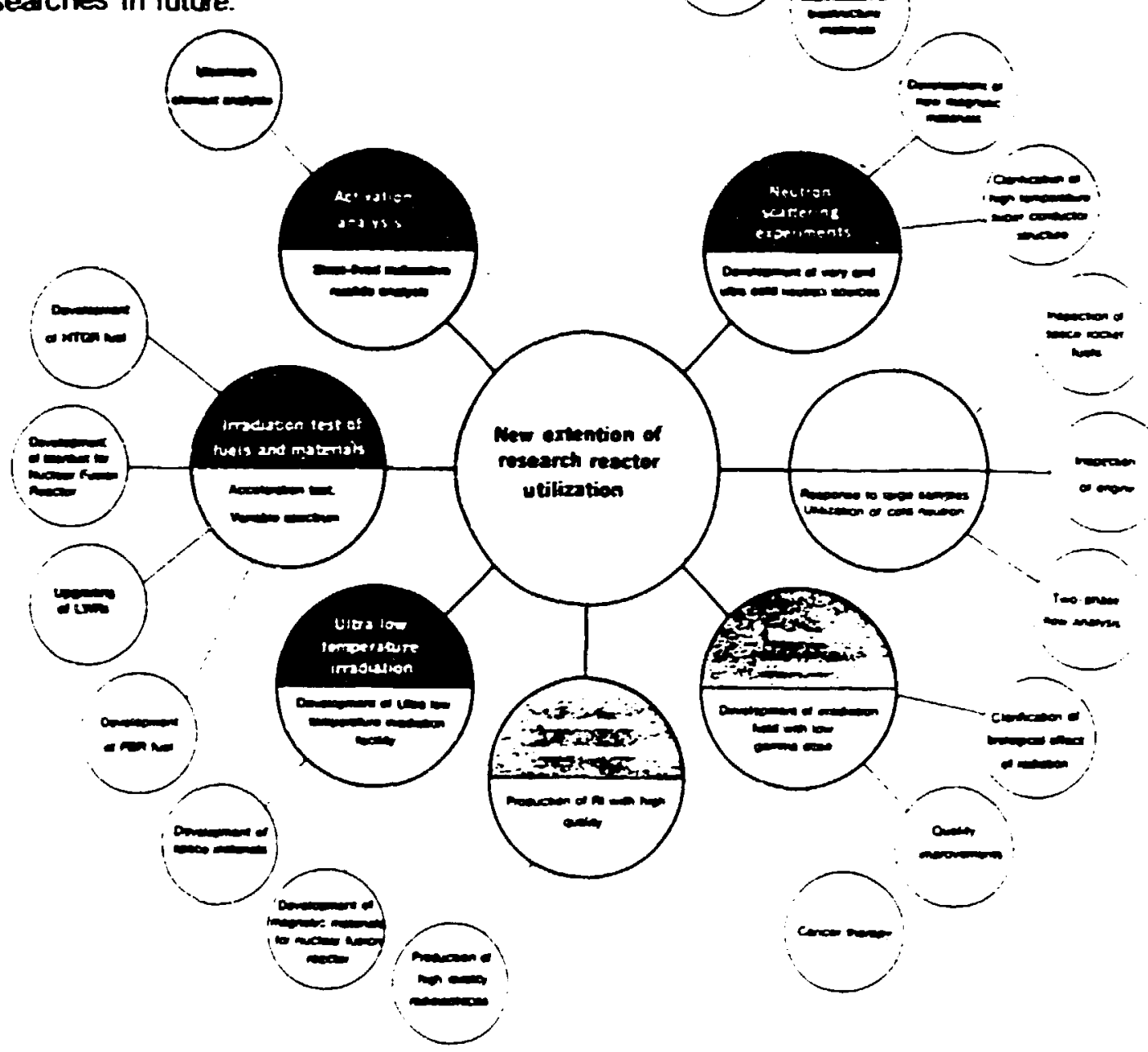

\section{Various neutrons for use}

\begin{tabular}{|c|c|c|c|c|c|c|}
\hline & $\begin{array}{l}\text { Uitra cold } \\
\text { neutron }\end{array}$ & $\begin{array}{l}\text { Very cold } \\
\text { neutron }\end{array}$ & Cold neutron & $\begin{array}{l}\text { Thermal } \\
\text { neutron }\end{array}$ & $\begin{array}{l}\text { Intermediate } \\
\text { neutron }\end{array}$ & Fast neutron \\
\hline 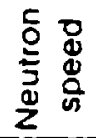 & $1 \mathrm{~m} / \mathrm{s}$ & & $\mathrm{m} / \mathrm{s}$ & & $\mathrm{m} / \mathrm{s}$ & $\mathrm{km} / \mathrm{s}$ \\
\hline
\end{tabular}

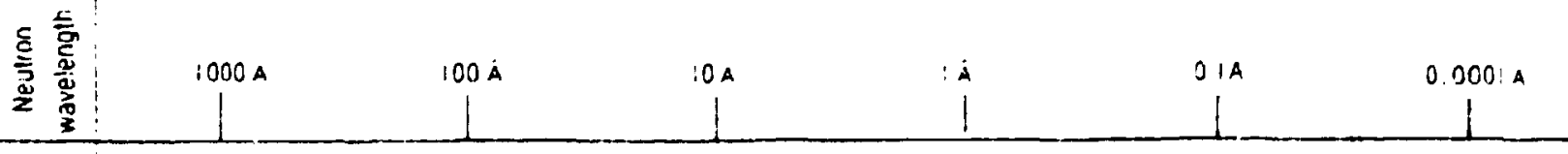

Neutron beam experiments

JRR-2, JRR-4, JMTR 

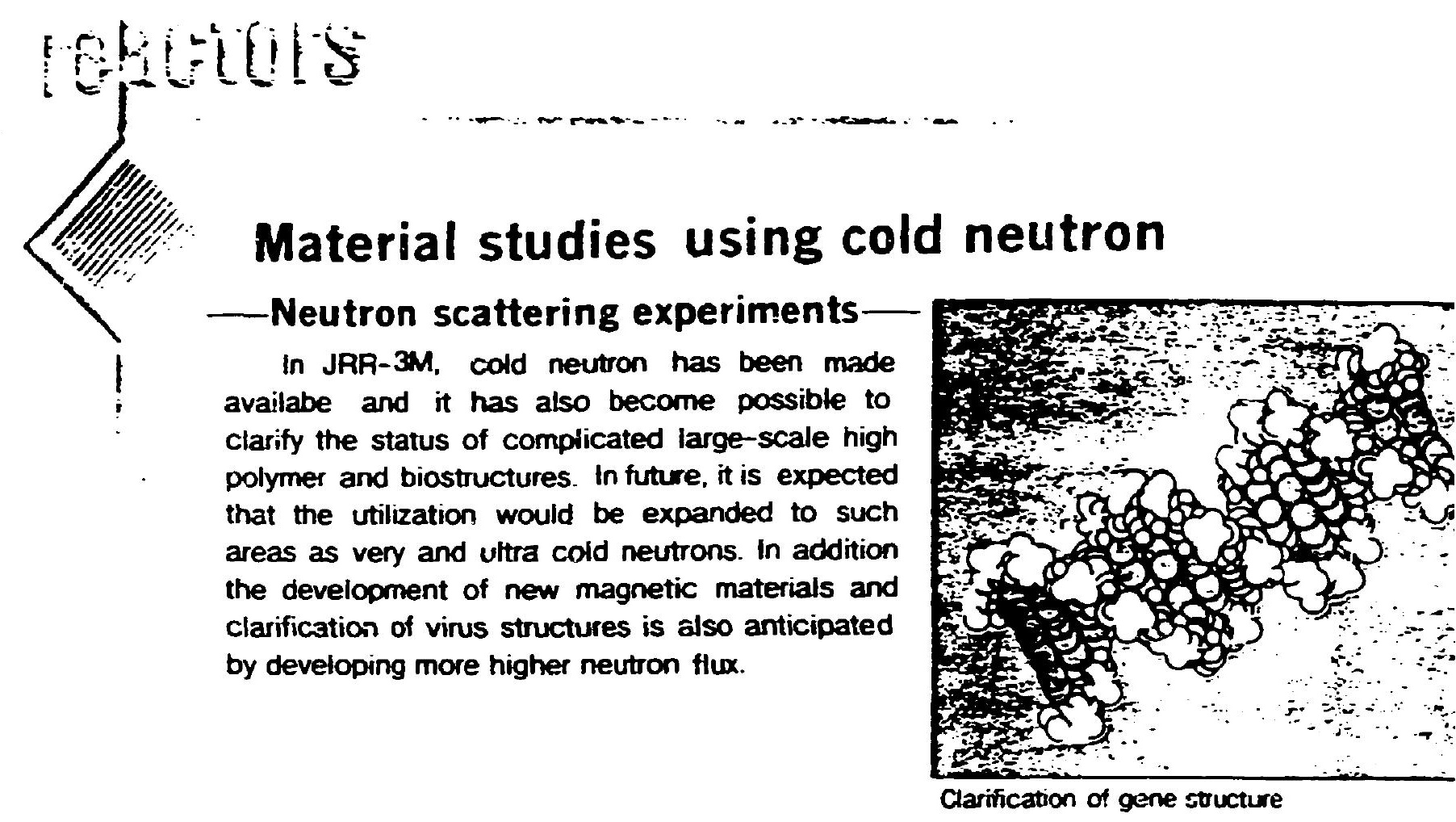

\section{Application to medical science}

\section{-Development of tumor therapy-}

Research on tumor therapy by using neutron irradiation was initiated in Japan as early as about 20 years ago mainly for brain tumor and skin cancer. Practical examples have experienced more than 100 by this time. By conducting various developmental researches relating to medical treatment further application is expected to other cancers in future. Research and development works are aiso in progress for a medical reactor to ur:Jertake the therapy required.

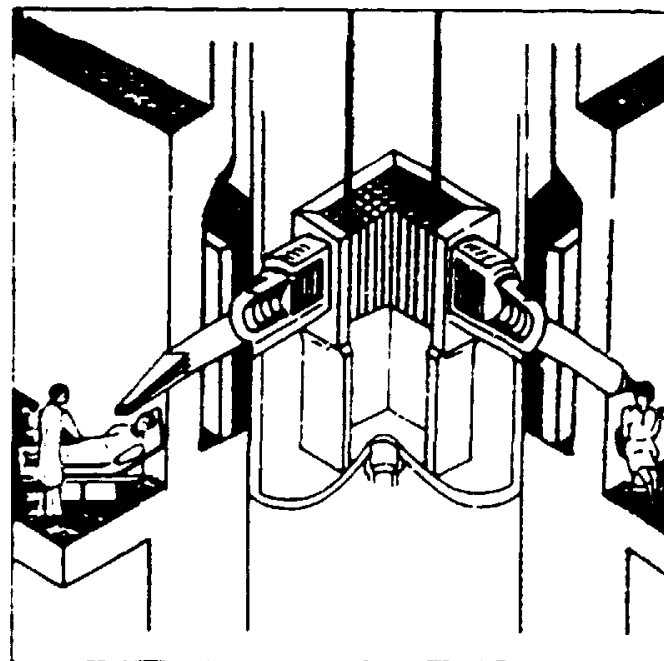

Conceptual figure of a reactor for medical us

\section{Material research in extremely low temperature}

With respect to develcpmental researches on superconductive magnetic materials in nuclear fusion reactor and space materials, it is urgently required to make estımates on their radiation-resistance characteristics in extremely low temperature. Furthermore, it is predicted that the need would affect 10 such fields as chemistry, biology as well as mrdicine. Therefore, it is highly expected that the cryogenic neutron irradiation idcility should

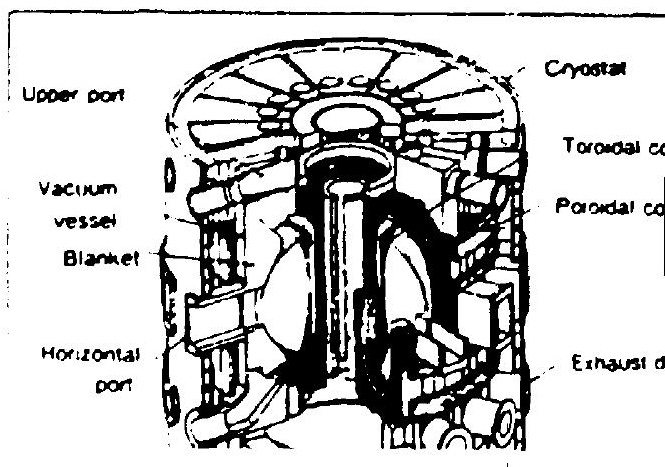




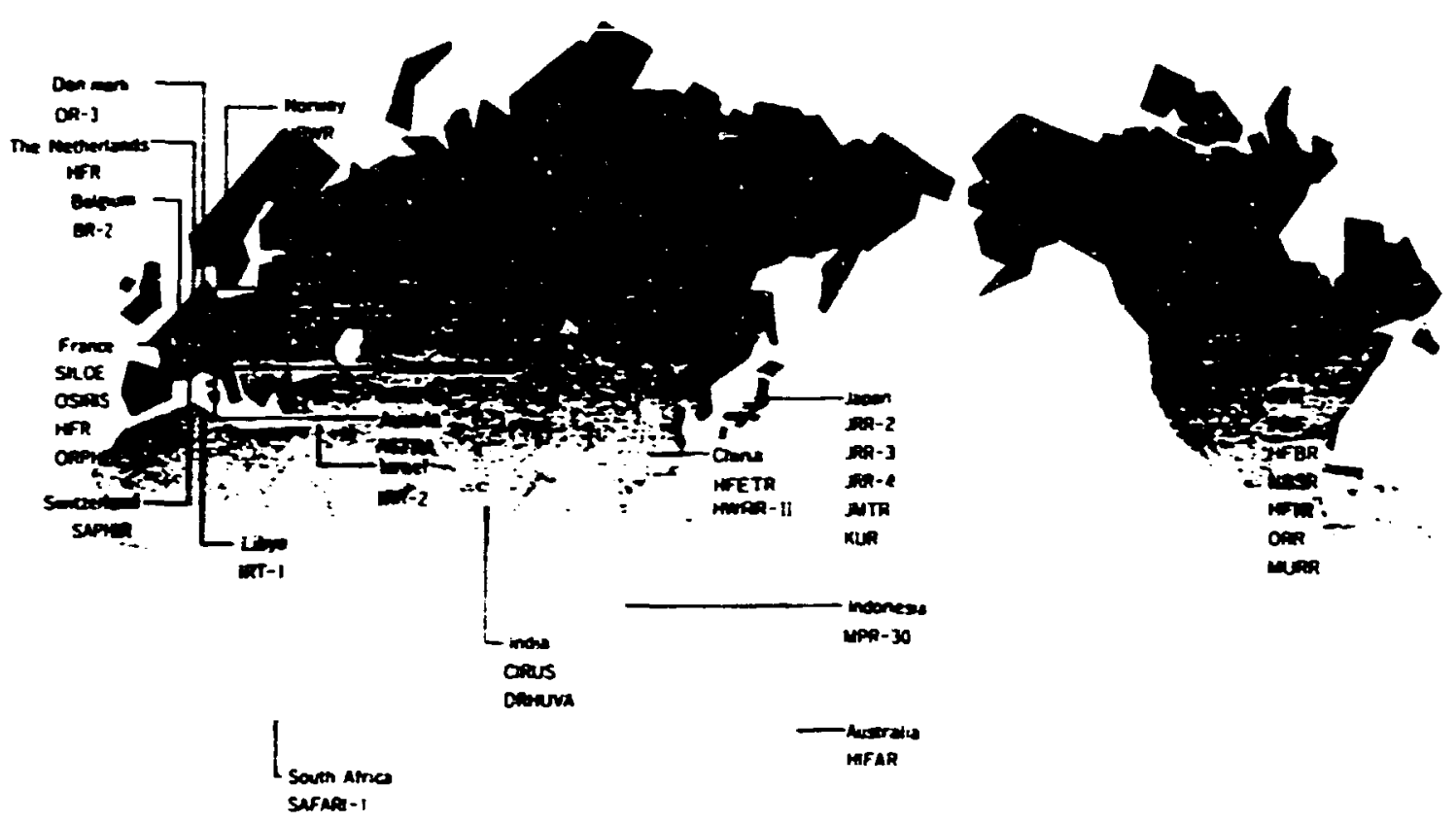

Major research reactors in the world

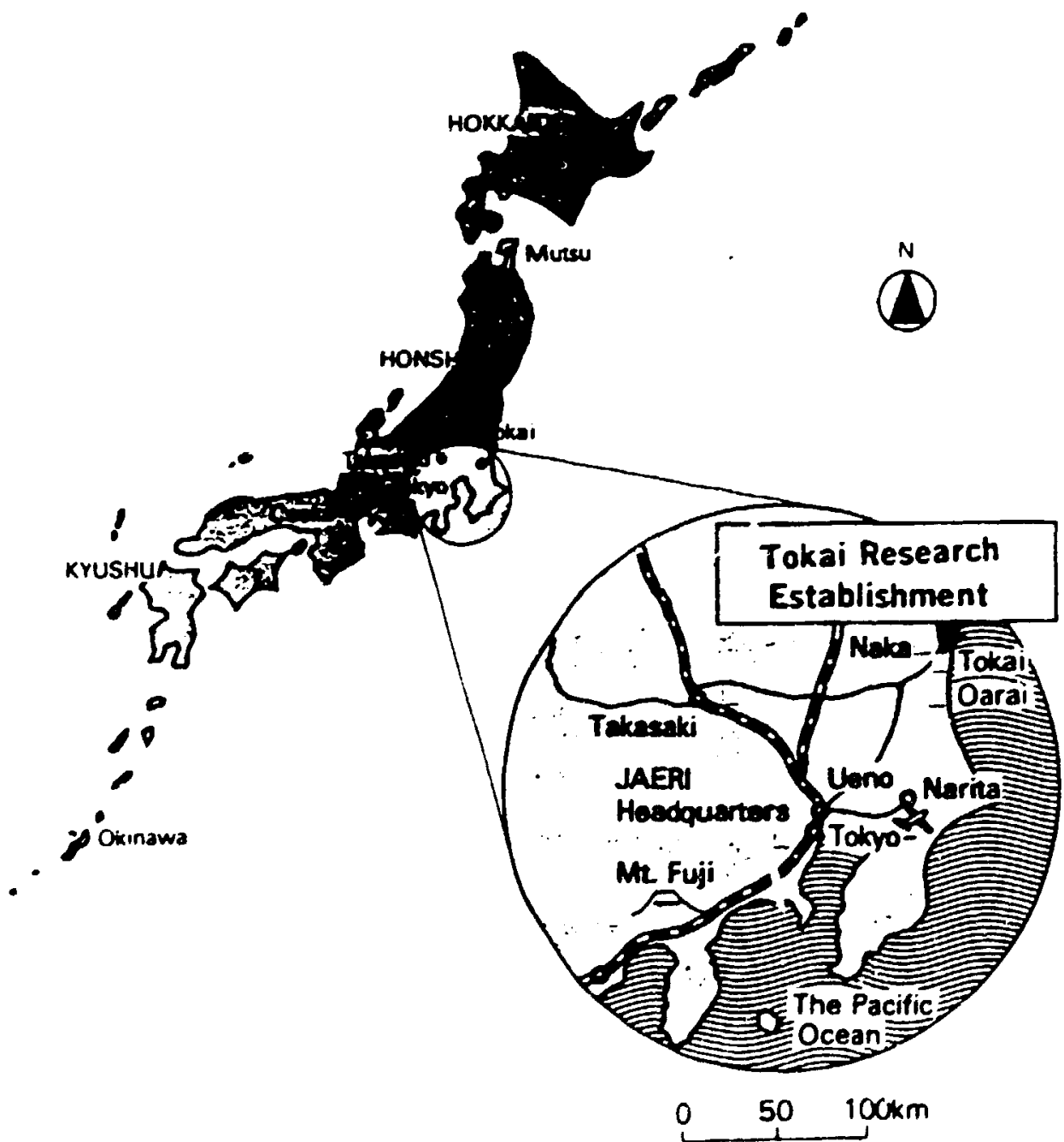

Department of Research Reactor

Tokai Research Establishment 
ATTACHMENT 4 
Date: $\quad$ April 13, 1995

To: $\quad$ HFIR Futures Group

c: Information List

From: $\quad$ C. D. West, FEDC, MS-8218 (4-0370) - RC

Subject: $\quad$ Executive Committee Meeting

Yesterday, April 12, I gave the ORNL Executive Committee a status report on our work. A copy of the handouts I used will be sent to you with the minutes from our Monday, April 10, meeting: I used fewer and simpler viewgraphs but chose to leave a fairly omprehensive hard copy with them. Thank you very much for the guidance and input you gave me about this presentation at our last meeting.

My impression was that all of the members of the Executive $\mathrm{Cr}$ nmittee regarded the basi $\mathrm{c}$ premise of our exercise (i.e., that it is important not only to maintain but to enhance the facility's capabilities) as a gi ven and that they will support sensible and realistic proposals. Also, I didn't sense that anyone had any problems with the way we have chosen to go about our task.

There was a discussion of the most effective way to handle the "administrative changes:" I believe everyone agreed completely that we (ORNL) must lis ttin to the users' inputs on this topic, and that the issue of whether to include the details in any published report or simply to provide them to laboratory management can be considered later.

I have been telling you that our chrres from Van Hook was simply to list the options in some way that would help laboratory manager ent to make choices, but my impression from the meeting yesterday is that recommendations from us would not be unwelcome and might have som $e$ influence.

Van Hook suggested that Dave Reichle be added to the distribution list of information copies, and Reichle agreed that he would find that useful. This was on e of scveral indications that Van Hook wants to make sure that the research opportunities offered by HFIR to the life sciences $b \quad c$ publicized to ORNL staff and other workers in those fields.

CDW:kfr 


\title{
HFIR Futures Group
}

\author{
J. E. Bigelow \\ E. D. Collins \\ G. F. Flanagan \\ R. M. Harrington \\ J. B. Hayter \\ M. M. Houser \\ J. P. Moore \\ L. Robinson \\ K. R. Thoms
}

Information Copies

B. R. Appleton

J. B. Ball

R. E. Battle

H. A. Glovier

H. A. Mook

D. E. Reichle

J. B. Richard 
ATTACHMENT 5 


\section{THE NEUTRON COMMUNITY NEEDS BOTH PULSED SPALLATION AND STEADY-STATE NEUTRON SOURCE CAPABILITIES}

- Some neutron scattering (beam) experiments need a continuous, high neutron flux

- Isotope production, especially transuranic and other neutron-rich isotopes, depends completely upon a high time-averaged neutron flux, which the spallation sources do not provide

- Materials testing and most neutron activation analysis also needs a high average flux

CDW/kfr (4-24-95) 


\section{ORNL HAS TASKED A USER-DRIVEN GROUP TO RECOMMEND ENHANCEMENTS THAT WILL IMPROVE THE RESEARCH PERFORMANCE AND EXTEND THE LIFETIME OF HFIR}

HFIR Futures Group Membership and Areas of Interest

J. E. Bigelow Transuranic isotope production

E. D. Collins Light isotope production

G. F. Flanagan Research Reactors Division

R. M. Harrington

J. B. Hayter Reactor safety

M. M. Houser

Neutron scattering

J. P. Moore Technical Secretary

L. Robinson

$\mathrm{Pu} 238$ production

K. R. Thoms

C. D. West

Neutron activation analysis

Materials irradiation testing

Chairman

THE STUDY GROUP HAS IDENTIFIED A MAJOR, SHORT-TERM OPPORTUNITY THAT WOULD 


\section{GIVE THE U.S. A WORLD CLASS CAPABILITY IN COLD NEUTRON BEAMS}

- Install a small, low inventory, liquid hydrogen cold source in the existing through tube

- the unperturbed thermal flux at this

location is about twice that at the ILL

vertical cold source position

- but, the small hydrogen cold source would have less gain than the big deuterium one at ILL

- The net result would be a cold neutron flux of the same order of magnitude as ILL, although of course with space for many fewer guides

- The work would be planned to maximize construction, assembly and testing away from HFIR, prior to installation, to minimize technical risk and HFIR downtime

- This could be accomplished in one-to-two years, within the budget that might be available from the DOE facilities utilization initiative for such projects 


\section{THE GROUP HAS ALSO BEGUN TO STI IDY A MAJOR HFIR UPGRADE}

- Replace the beryllium reflector block with an annular, low-pressure tank of heavy water

- $\quad$ Raise power by $20 \%-25 \%$, with the same cooling system

- Install a large, optimized $\mathrm{LD}_{2}$ cold source

- $\quad$ Add more beam tubes and guides

- Addition of an over-the-pool hot cell for experiment handling and spent fuel handling

- Replacement of certain I\&C and electrical systems for greater reactor availability 


\section{A NUMBER OF INCREMENTAL IMPROVEMENTS WOULD STEADILY ENHANCE THE HFIR'S SCIENTIFIC UTILITY AND BRING THE U.S. SOME UNIQUE CAPABILITIES}

- Additional rabbit tubes in the target island and reflector to enhance isotope production, materials irradiation and neutron activation analysis capabilities

- Use of modern inspection techniques (using new equipment at B\&W partly funded by ANS) and selection of fuel plates and cores to allow operation, with the same or even higher safety margins, at $10 \%$ higher power

- Rearrangements in the existing HFIR building and addition of another building to increase guide hall space available

- New scattering instruments in a different layout to make more efficient use of existing beams

- Enhanced isotope production (including ${ }^{238} \mathrm{Pu}$ ) facilities in the permanent beryllium 
ATTACHMENT 6 
Ideas for redesion of the reactor top head

The reactor top head should be redsigned so that penetrations through it line up directly with the VXF irradiation positions. Consideration should also be given to reducing the dianeter of tbe quick opening hatch so that refueling can be performed without removing experiments from the RB* positions. By havinc: all the penetrations vertically line up with irraciation facilities, experiments and target kolders can be rotated easily to smooth out fluence gradients. Both of these modifications might even permit the installation of either additional hydraulic rabbit facilities (albiet with lower flux than the present one), or facilities which would permit the installation and removal of targets (larger than rabbits) during reactor operation if that were desirable. 
ATTACHMENT 7 


\section{MINOR COST ( $<1 \%$ to $2 \%$ of HFIR ANNUAL OPERATING BUDGET) CHANGES (2)}

Enhongements Recuiring Some

Chroves to the Reactor

Harded spectrum in targets

- displace some light water from the arget iland the

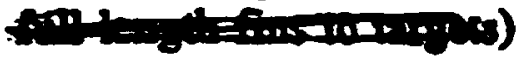

- use stainless steel tuget jackets (spectral tailoring)

New imadiation holes in beryllium (when Bo is changed out)

Increase diameter of some beam mbes More nevitrons on sample (when BC is changed)

Provide more convenient access to capsules in PTP positions (during sboudowns)
Benefits

Reduced thermal flux will reduce heat output from ficaile nuclides. Increased resonance flux will increase production of ${ }^{252} \mathrm{Cf}$ and even more so 254 Es.

As above, plus a stronger target, less likely to be bent or ruptured.

Enhonced isotope production and / or matecials irmatiation capabilities

Enhanced isorope production and matrials irradiation capabitities

If SAR's done in-bouse. 
SIGNIFICANT COST (CDSTS OUTSIDE RRD IN THE RANGE 2\%-10\% OF ANNUAL OPEPATING BUDGET - WOULD REQUIRE SUBSTANIIAL AND DEAERMIID REPRIORIIZATION OF OTHER WORK TO ACCOMPLISH WIIAOUT ADDIIONAI FUNDNG, OR PERHAPS USE OP FACIIIIIES INIIIATIVE FUNDS OR GPP) (3)

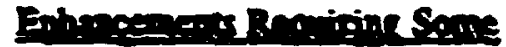
Qrmate the Rerax

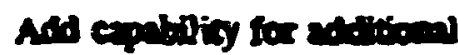

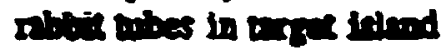

Provide more conventent access to capsules in PTP positions during shutdows.

\section{Modity dewerer up bead for

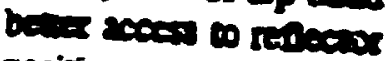 poritions}

Purde epping tor

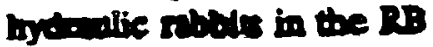
and VXF parions conses

S1 Mobuct

$\$ 0.5 \mathrm{M}$

$\cos M-2 M$

St Mrivit

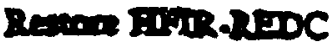
bycrobic tronpars tacingy
$\$ 1 M-\$ 1.5 M$

We would like again to be able to plan some research productions of $2.3-\mathrm{h}{ }^{250} \mathrm{Bk}$ and 39-h ${ }^{2 S A m}$ Es which require transfer on the time scale of a few hours racher than a day or more. Once the facility is put back into service, there would be cost savings on bandling, decanning and processing all discharged rabbits. 


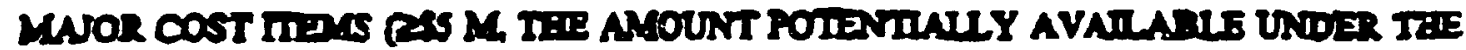

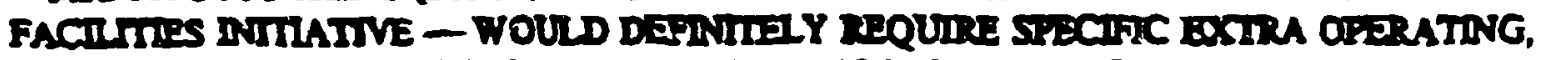
CAPITAL EQULIDN, OR IDNE IIAM PUNDS)

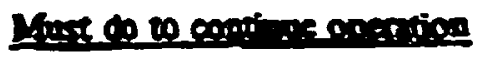

Degilition teplecener

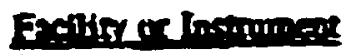

E.poventery

Repises and tipende LeC syations

Install a hot cell acessible from the reactor pool as at the ORR. (Poseibly a moveable one which can be swung over the pool.)

Position souxce

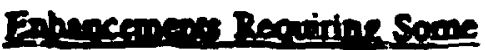

Cinnes on the Reacor

New, lager thoneh-tube and

vetical cold source (at

beryition chasecons)

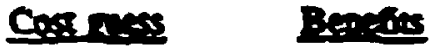

\$.4 M Aroids clocedown!

sS M

$510 M$

$\mathbf{s 1 7} \mathbf{M}$

NoS M

$2579 \mathrm{M}$

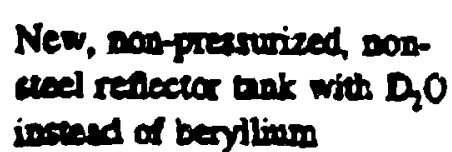

New, nop-preasuized pon-
creel repoctar tink with $D_{2} O$
insend of beytlinm

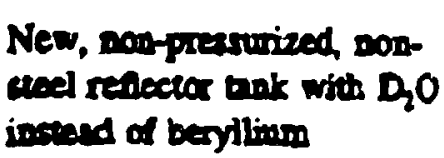

Mroc Peofomine

Enhecemere

Large dectexium cold source

in the vew $D_{2} O$ renlector

\section{E-roned retiablity and avilibity}

By providing for removal of unnecessary ends, shrouds, etc. would facilitate handling and transfer of irradiated targets or materials testing experiments. Possibly colild be used to can fuel elements or ecrap for long-term storage.

A wadd bering trality

A rally major entencemest of anteros scatraing cypallibies would make EIFR a world-beate in come very imparater mens
Wonld require additom guide hill spece more thus, more benm mibes. linge cald source, and otha new inclides. Would maxe FIIIR 2 -3 times beter the DL (althoogh still with fewer instort ment stions). 


\section{IIJMS WIIH NO COST GUESS AVAILABLE YET}

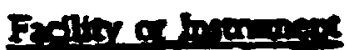

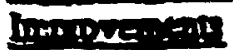

Nem, moderes seanding

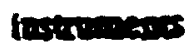

New bournexe legour

Impore traporation

nemods trom Exid to

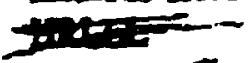

$$
\text { IFEI }
$$

incressed ceppody of

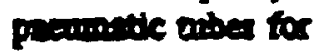
mancoil anstysis
Bepeste

Const toprove pexionsmce on eximing beams

Much exhooed expednevel explinity bor verecen secictatal

$\$ 3 M$

Ideally, a new cask-trailertiedown combination could be safer and also easier to use. We may be required someday to use licensed shipping containers for onsite transportation.

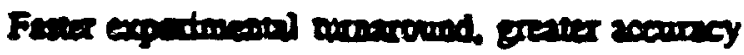

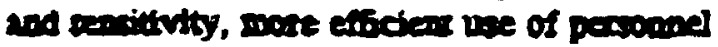
tione, and cont grings 
ATTACHMENT 8 


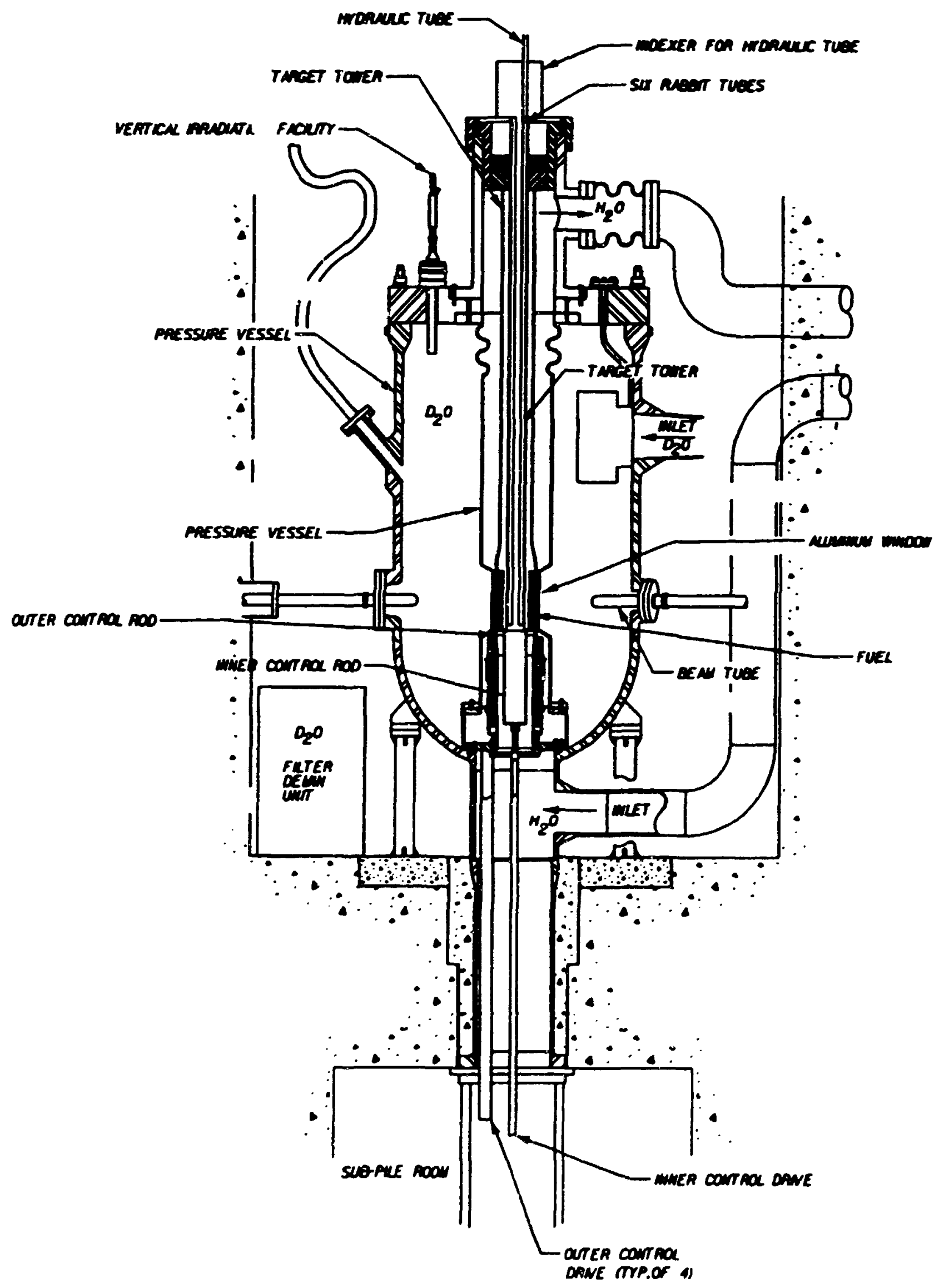


May 16, 1995

\section{HFIR Futures Group Meeting}

\section{Attendance}

The HFIR Futures Group beld its eighth meeting at 8:30 a.m. on Monday, May 8, 1995, in the Blue Room of the FEDC. Those in attendance were:

\section{John Bigelow \\ George Flanagan \\ Mike Harrington \\ John Hayter \\ Michele Houser \\ Larry Robinson \\ Ken Thoms \\ Colin West (clair)}

Ken Farrell (observer).

\section{Opening}

The meeting began with Colin West asking for comments conceming the meeting notes for the last meeting and proceeded according to the agenda shown in Attachment 1. John Hayter had a change in the description of spallation source charged particle beams in the notes. Colin then asked for a report on the Washington meeting from George Flanagan.

\section{Report on Washington meeting}

George said that the higher DOE officials were not in attendance for the whole meeting. Due to recent changes in the DOE, many things are currently in disarray at headquarters. However, according to Ray Hunter, the Office of Nuclear Energy will continue to regulate the research reactors, while the Office of Energy Research will fund them. This extension of the status quo is part of DOE's long-term plan. All three research reactors represented at the meeting (HFIR, HFBR, and ATR; will now report to Matt Hutumaker. George explained that Ray Hunter has been promoted to second in command in the Office of Nuclear Energy. Terry Lash is the manager of that of fice, but Ray Hunter has more direct contact with the reactors being regulated.

\section{Y-12 uranium feedstock}

George said that the problems of getting fuel feedstock from Y-12 were cir,cussed at the meeting; apparently DOE headquarters was not aware that the situation concerning getting the uranium feedstock out of the facility was as critical as it is. ATR's fuel production line will have to be shut down this summer if feedstock is not able to be obtained. The site office in Idaho knew ahout 
the feedstock situation, but evidently the local contractors at ATR did not. George said that the Oak Ridge site office had been working very hard on this for HFIR.

\section{DNFSB}

The Defense Nuclear Facility Safety Board (DNFSB) is involved with the ATR, but not with HFIR or HFBR. There are some processes at the ATR associated with the Office of Defense Programs, especially the production of tritium. This has allowed the DNFSB to become involved with the facility. and the group conducts several visits to the ATR each year.

\section{Control room staffing}

Gejige remarked that control room staffing was different at the ATR and HFBR than at HFIR. Oak Hidge is the only site that has degreed people in the control room. HFIR had to go hire Shift Technical Advisors (STAs) a few years ago to meet an order that came out after the Three Mile Island incident. Thise STAs are degreed engineers who work shifts with the operators in the control room. The two other reactors chose not to hire STAs, and their site offices permitted this. George said that the other two reactors had closer relationships between the contractor and the site office.

\section{Safety documentation approvals}

The people who attended the meeting from Idaho did a presentation on the Safety Assessment approval process. George said that the 3 reactors represented had basically the same process, except that approvals associated with ATR were a bit more liberal than those at the HFIR. Also, ATR has been able to participate in a new method of obtaining funal approval on its SAR and Technical Specifications. A "hit squad" from DOE headquarters actually came and is staying on site with ATR personnel while the SAR and Tech. Specs. are being redone. This "hit squad" is giving guidance and comments to ensure that the requirements are completed in a satisfactory manner. This is the philosophy 10 be applied $t 0$ all sites in the future. Also, design changes will need to be approved by the site office only if they involve an unresolved safety question (USQ). Using this method, ATR should have a DOE Order 5480.23-approved SAR and Tech. Specs. by the end of the summer.

\section{HFBR upgrades}

Also discussed in Washington were the upgrades that HFBR is planning for the reactor (see Autachment 2). As can be seen, replacing the thermal shield and the reactor vessel before the turn of the century is part of the plan. Also included is a cold neutron source beam improvement in which the number of guides is increased from 3 to 5 and the total number of experiment instrument stations expanded to 31 . Both Gilber Commonwealth and PCI Westinghouse have done cost estimates on the vessel replacement and have found the upgrade to he technically feasible. No information about cost was disseminated at the meeting.

\section{Upgrades on existing facilities}

The situation seems to be that the Office of Energy Research is currently concentrating its attention and funding on the spallation source. Any funding allocated for existing facilities would be a bonus above and beyoud that for the spallation source. This is much the same situation as there was when the ANS was in design. Existing facilities may not get any funding appropriated while a large new project is being considered. 
The intent of the Facility Upgrade Initiative was for it to be a continuous process. There are 3 parts to this funding with each reactor getting a certain share of it. There are around two million dollars in HFIR's budget for this coming year from this. The two other parts of this money, the University research agreements and the equipment upgrades were to be competitive. HFBR, having an extensive upgrade proposal already on the books, may be at an advantage in this.

\section{New requirements}

George said that one of the DOE officials, Mr. Marionelli, was quite upset with the way the RADCON manual had been updated. When it goes into effect, essentialiy the whole HFIR reactor building will become a regulated zone. This would mean that users, as well as operations personnel, would have to undergo radiation worker training to enter the facility unescorted. This could be very problematic for visitors. Discussion took place concerning this, and Colin said that the Futures Groul; could make recommendations about this issue, and others, in its final report.

\section{Status of action items}

\section{Comments on updated proposal lists}

Colin then asked for comments on the updated proposal lists that were sent out since the last meeting. John $\mathbf{H}$. advised adding a column to each upgrade suggestion with wording such as "does affect reactor" or "doesn't affect reactor." Colin asked John Bigelow for some phrasing about the "convenient access to capsules in PTP positions" proposal.

\section{Meeting of A. T. Lucas with others}

Colin mentioned that both George and Michele Houser had attended a meeting among Trevor Lucas, Doug Selby, RRD representatives, and others last week concerning the proposed new cold source for the H.TR. Michele passed out the handouts from the meeting (see Auachment 3) and remarked that Doug Selby had said it was the first of a series of seminars on a HFIR cold source. She said that Trevor had talked about several different options for a HFIR cold source and had done a write-up of them. She said that George could address the details in a more complete fashion.

George told about Trevor's "economy model" cold source, which was basically an insenion into the existing HB-4 beam tube. Other options required more and more mudification, albeit with better and better performance. The flux in the region proposed for a cold source is greater than that at the ILL. Questions about funding arose, and Colin asked about HFIR's Accelerator and Reactor Improvement and Modification (ARIM) funds. George said that these funds were dedicated io spent fuel storage for the next few years. The cost of the cold soarce will probably be driven by the refrigerators. Trevor was going to call NIST to get some idea of that facility's spending on its chillers. Michele will check with Trevor about the cost information.

George commented that the representatu ves from RRD at the cold source meeting thought it was quite a feasible thing to do. Most secmed to think that the regulatory issuc cost would be greater than the design cost. George cautioned that the group needed to be realistic about the time frame needed in which to add a cold source; it will probably take longer than onc year.

The group thought that the next step would be to designate a management team to lay out a plan for actually doing thesc upgrades, especially designing and installing a cold source. Logistics, personnel. and critical path activities are all issucs which need to he addressed. Colin said that there was probably 
some funding available for this, but problems could be encountered because of budget codes. The competitive nature of some of the available funds should be communicated to this team so that steps can be taken for the HFIR facility to be in contention for them.

\section{Petten upgrade report}

Since the last meeting, Ken Thoms had shared his copy of the Petten upgrade report with Colin, who had forwarded it on to George. It evidently was a detailed document, except that it contained no cost figures. Ken T. will try to obtain some unofficial cost numbers on Petten's vessel replacement from a contact he has at that facility.

\section{Comments on HFIR alsemative vessel write-up}

Comments were next solicited on the write-up associated with the HFIR alternative to replacing the current reactor vessel of insering a D ${ }_{2} \mathrm{O}$ tank inside of it and removing the beryllium reflector. Ken $\mathrm{T}$. had some questions about the location of the materials irradiation facilities on the drawing associated with the write-up. George said this location could be moved so that materials irradiation experiments could obtain the flux they needed (this was also true for the RB 'positions). John $H$. asked about the gap between the cold source and the beam tube in the drawing and remarked that this gap was not good. George reminded everyone that the drawing was simply a cartoon showing a concept and that it would need more work to show details.

\section{Comments on draft Executive Summary}

Colin then asked if there were any comments on the draft Executive Summary of the Futures Group report which had been sent out to the group members since the last meeting. He said he would like to share it with the information group after receiving comments. The Futures Group gave come comments, and the revised summary is shown in Attachment 4. It was agreed that Colin will send this draft out to the information group after contacting key members about the urgency of looking at the upgrades in a timely fashion.

\section{Other business}

Ken $T$. had some comments on the updated lists of upgrades. He mentioned that there was a gap in the cost categories of "Significant" and "Major" from \$2.8M to \$5M since HFIR's operating budget is around $\$ 28 \mathrm{M}$. This problem will be addressed in the next revision of upgrade suggestions. Ken T. had some ideas about how the hot cell proposal might affect HFIR's interaction with other ORNL facilities and agreed to give some wording on that. The access to the PTP position item was mentioned, and John B. agreed to give more wording for this idea's benefits. Larry Robinson explained his ideas about an informal operatior.al consortium (i.c., a more team-oriented environment) at Ken T.'s request. Also, all references to "material analysis" will be changed to "neutron activation analysis."

George had a draft proposal on neutron radiography research at HFIR which involves three divisions. After ob aining permission for its distribution to the Futures Group from the team leader, the draft proposal is shown in Altachment 5. The group adjoumed until May 15. 


\section{ACTION ITEMS}

Ken T. will write wording for the hot cell upgrade idea.

John B. will provide phrasing concerning access to the PTP positions.

Michele will get cost figures from Trevor Lucas for the proposed cold source refrigerators (on the order of $2 \mathrm{~kW}$ ).

Colin will contact key members and send the revised draft Executive Summary for the Futures Group report to the information group.

Michele will revise the upgrade lists according to comments received.

M. M. Houser, May 9, 1995

Distribution

HFIR Futures Group Attendees (notes for record + Attachments 2, 4, and 5)

J. E. Bigelow, 7930, MS-6385

E. D. Collins, 7930, MS-6385

K. Farrell, 5500, MS-6376

G. F. Flanagan, 7917, MS-6398

R. M. Harrington, FEDC, MS-8218

J. B. Hayter, FEDC, MS-8218

M. M. Houser, FEDC, MS-8218

L. Robinson. 4500S, MS-6128

K. R. Thoms, 9108 , MS -8087

C. D. West, FEDC, MS-8218

For information (notes for record + all attachments)

B. R. Appleton, 4500 N, MS- 6240

J. B. Ball, 4500 N, MS -6182

R. E. Batule, FEDC, MS-8218

H. A. Glovier. 7917, MS-6398

H. A. Mook, 7962, MS-6393

J. P. Moore, 4508, MS-6080

D. E. Reichle, 4500-N, MS-6253

J. B. Richard, 7962, MS-6391 
ATTACHMENT 1 


\title{
AGENDA FOR \\ HFIR FUTURES GROUP MEETING
}

\author{
Monday, May \&, 1995 \\ $8: 30$ a.m. \\ FEDC, Blue room
}

- Discussion: Changes or corrections to 4/24/95 meeting notes for the record

- Report on Washington meetin;

G. F. Flanagan

- Status of action items

- Comments on updated proposal lists

- $\quad$ Meeting of A. T. Lucas, D. H. Cook, S. E.

C. D. West

Burnette, and others

- $\quad$ Petten upgrade repor

K. R. Thoms

Comments on aiternative to HFIR vessel replacement write-up

- Discussion: Comments on draft Executive Summary

C. D. West

- Any other business 
ATTACHMENT 2 


$$
\begin{aligned}
& \text { Limiblitide it visul } \\
& 2015-20:-1 \\
& \text { wm- s; }
\end{aligned}
$$

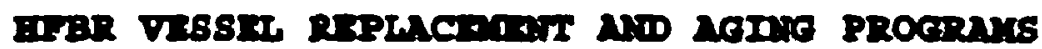

basic $60 \mathrm{~m}$

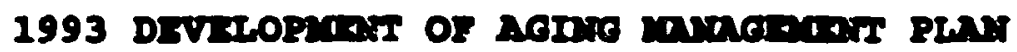

PHASE I

$$
\begin{aligned}
& \text { 4umb- } \\
& 60 m w-9
\end{aligned}
$$

PRELIMINARY COMPONENT SCREENING

PRELIMINARY AGING DBGRADATION EVALUATION

ESTIMATE REMAINING LIFE

DEVELOP IMPLEMENTATION PLAN

PHASE II

DETAILED IMPLEMENTATION PLAN AND PROCEDURES

FINAL IDENTIFICATION OF LIFE-LIMITING COMPONENTS

DETAILED AGING DEGRADATION EVALUATION

FINAL DETERMINATION OF REMAINING LIFETIME

DEVELOP LIFE EXTENSION TECHNIQUES

PHASE III

ONGOING HFBR AGING MANAGEMENT PLAN (HFBR-AMP)

DEVELOP ISI AND IST PROGRAM

ESTABLISH PERIODIC MONITORING PARAMETERS

LIFE EXTENSION TECHNIQUES IMPLEMENTED

TREND ANALYSIS

APPROVED BY DOE - 1994

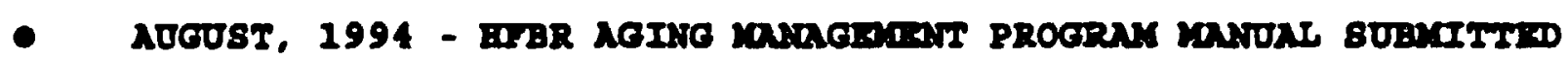

DETAILED PROGRAM DESCRIPTION

SCHEDULE

LEVEL OF EFFORT 
- NIr acrivigiss as scindu

PRELIMINARY SCREBNING FOR LIFE-LIMITING COMPONENTS COYPLETED

REACTOR VESSEL

THBRMAL SHIELD

IDENTIFIED CONDITIONALLY LIFB-LIMITING COMPONENTS

CONFINENIENT STEEL DOME AND LINER

CONFINEMANT BUILDING CONCRETE WALL AND FOOTING

BIOLOGICAL SHIELD

CONTROL ROD DRIVE ASSEMBLY

PRELIMINARY AGING DEGRADATION EVALUATION OF EACH LIFELIMITING COMPONEANT IN PROGRESS - RESULTS DUE MAY 1995

HFBR-AMP STARTED, COMPLETION DUE AUGUST 1995 FOR SUBMITTAL TO DOE

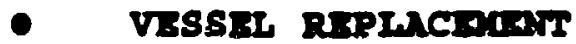

OCTOBER 1994 - RD FEASIBILITY STUDY COMPLETED

IDENTIFIES 2 LIFE-LIMITING COMPONENTS

REACTOR VESSEL

THERMAL SHIELD

REPLACEMENT FOUND TO BE FEASIBLE BY RD, ALARON CORP. , PCI ENERGY SERVICES (WESTINGHOUSE SUBSIDIARY), AND GILBERT COMDONWEALTH, INC. (MOST DETAILED EVALUATION)

OTHER MODIFICATIONS

COID NEUTRON BEAM IMPROVMMENT

INCREASE SUBTHERMAL NEUTRON FLUX $3 \mathrm{X}$

INCREASE NEUTRON GUIDES FROM 3 TO 5

OPFIMIZE GUIDE ANGLES AND POSITIONS 


\section{GUIDE HATL}

INCREASE NUNBER OF EXPERIMENT INSTRUMENT STATIONS $2 \mathrm{x}$

INCREASB TOTAL NOMBER OF STATIUNS TO 31

GILBERT COMONWEALTH PERPORMING DESIGN OVERVIEN ASSESSMENT FOR VESSEL AND THERMAL SHIELD REPLACEMENT

DEMONSTRATE TECHNICAL FEASIBILITY

PROVIDE BASIS AND JUSTIFICATION FOR FUNDING REQUEST FOR CONCEPTUAL DESIGN

PROVIDE PRELIMINARY ESTIMATE OF COST AND SCHEDULE

RD ESTIMATE OF SCHEDULE

3.5 YEARS TO SELECT VENDOR, PLAN DETAILS, FABRICATE REPLACEMIENT VESSEL

REMOVAL OF EXISTING VESSEL IN 3RD YEAR

1 YEAR FOR INSTALLATION AND OPERATIONAL TESTING TOTAL OUT OF SERVICE TIME = 2 YEARS 
ATTACHMENT 3 


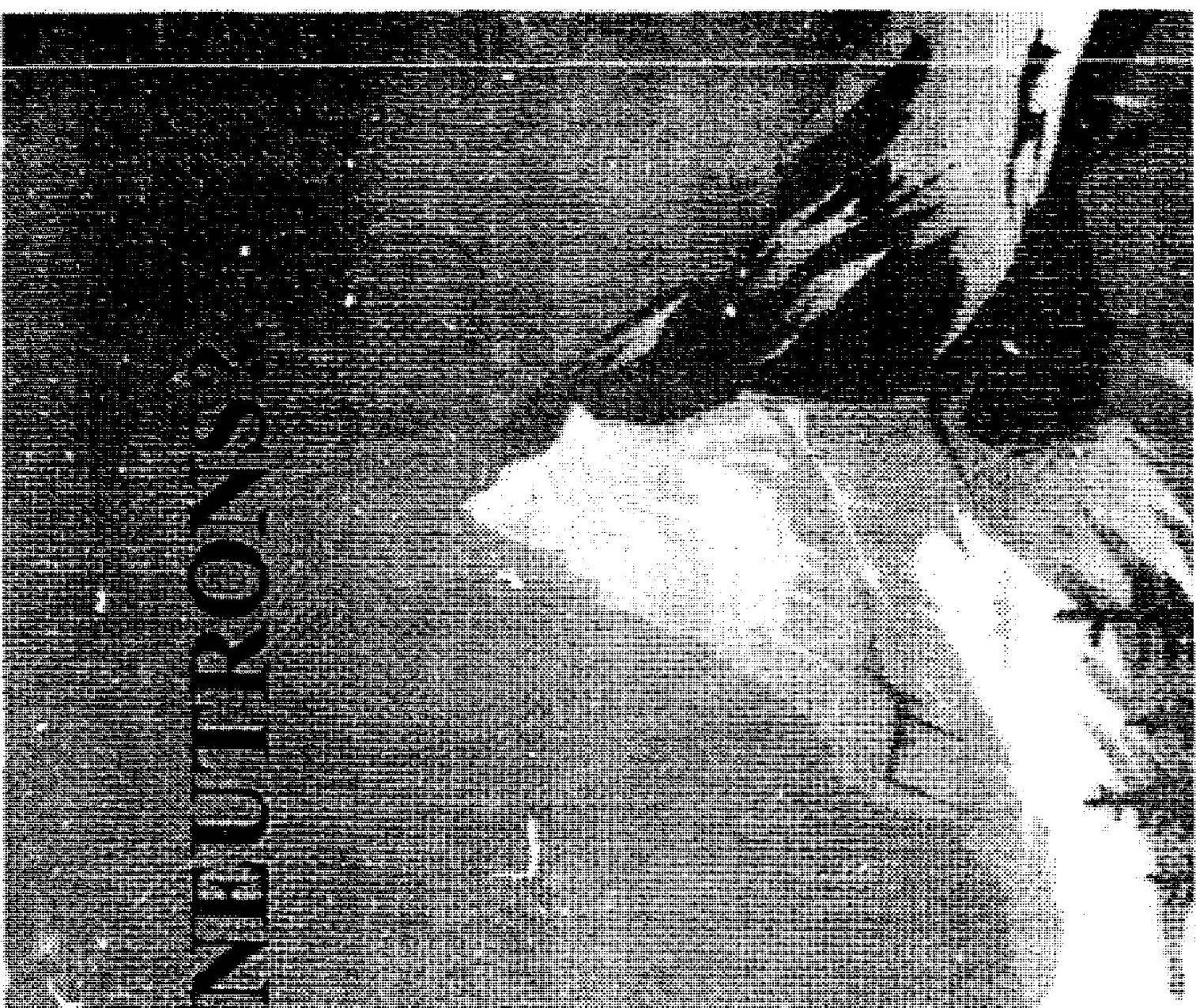

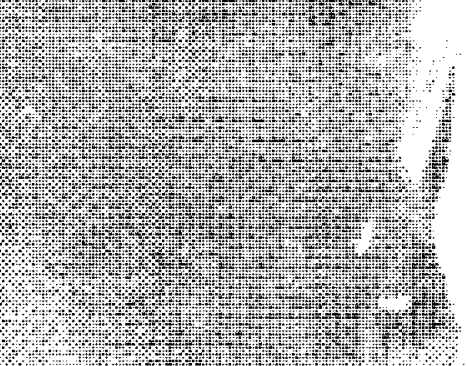
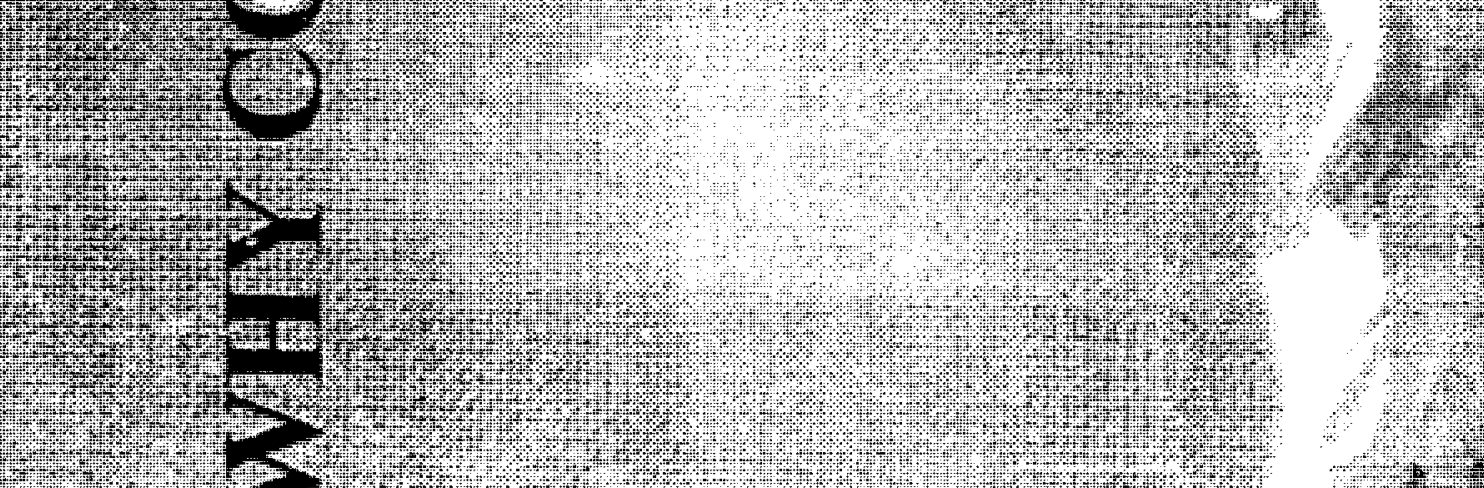

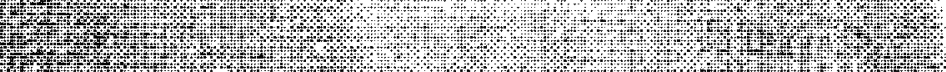

W.

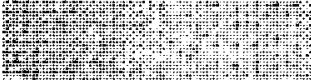

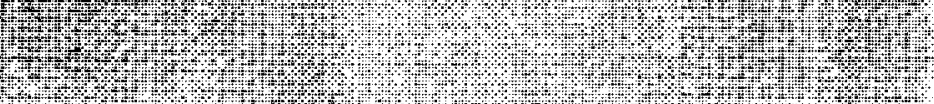

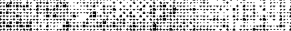

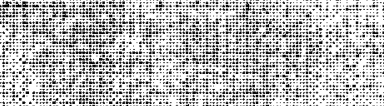

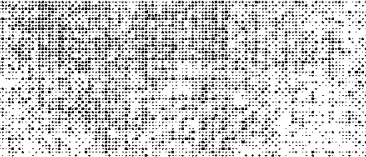

$+4+4+4+4+4)$

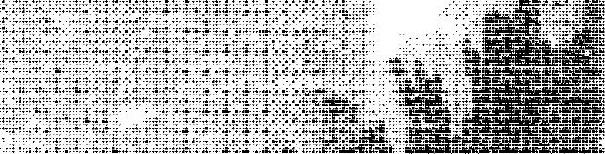
and 47 III

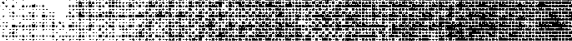

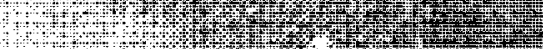
mW 


\section{WHAT SIZED STRUCTURES ARE IMPORTANT FOR NEW MATERIALS?}

- 20 Years Ago Neutron Science Was Studying Atoms, While Industry Was Interested in Structural Detail 100,000x Larger

- Today, Both Have Converged to Study Structures the Size of 100 to 1000 Atoms (the So-Called Colloidal Size Range)

- Materials in this Size Range Take on Interesting New Properties

- For example, aluminum foil and flour are everyday kitchen materials

- Either of these materials becomes a high explosive when ground into colloidal size and mixed with air 


\section{IN THE FIELD OF NEUTRON SCATTERING COLD NEUTRON RESEARCH IS WHERE IT'S HAPPENING}

- Cold Neutrons are the kinder, BNL)

- Many of the new neutron scattering applications are only feasible with cold neutrons

- There is a shortage of cold neutrons in the World

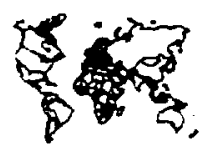

- Europe is presently winning the there, requests for cold neutron

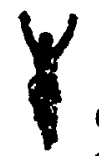
cold neutron race; but even beams are four times the availability

- Cold sources in the United States have been almost nonexistent, but recently NIST and BNL cold sources have helped. However, many researchers must still travel from the US to Europe to perfonm their research.

- The ANS would have given the cold neutron research, but even ANS we could still take the lead

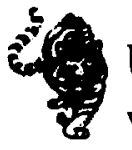
United States the lead in with cancellation of the in this important field with an aggressive cold source upgrade to HFIR 


\section{WHAT ARE WE MISSING?}

- Neutrons Measure Energies and Sizes in the Region Bounded by Heavy Lines

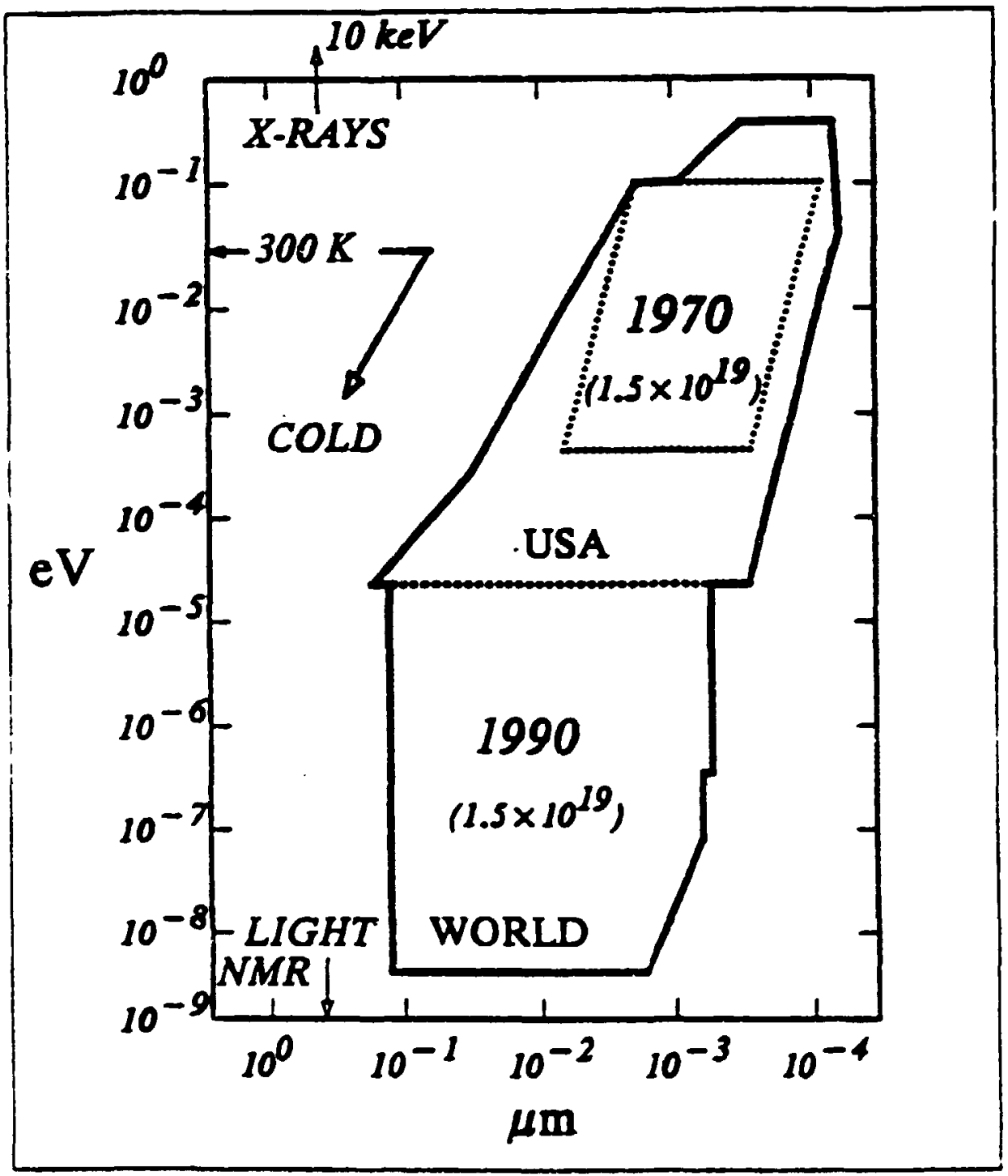

- Studies on most new materials take place towards the bottom left hand corner

- This region is inaccessible in the U.S. 


\section{A SCATTERING EXPERIMENT}

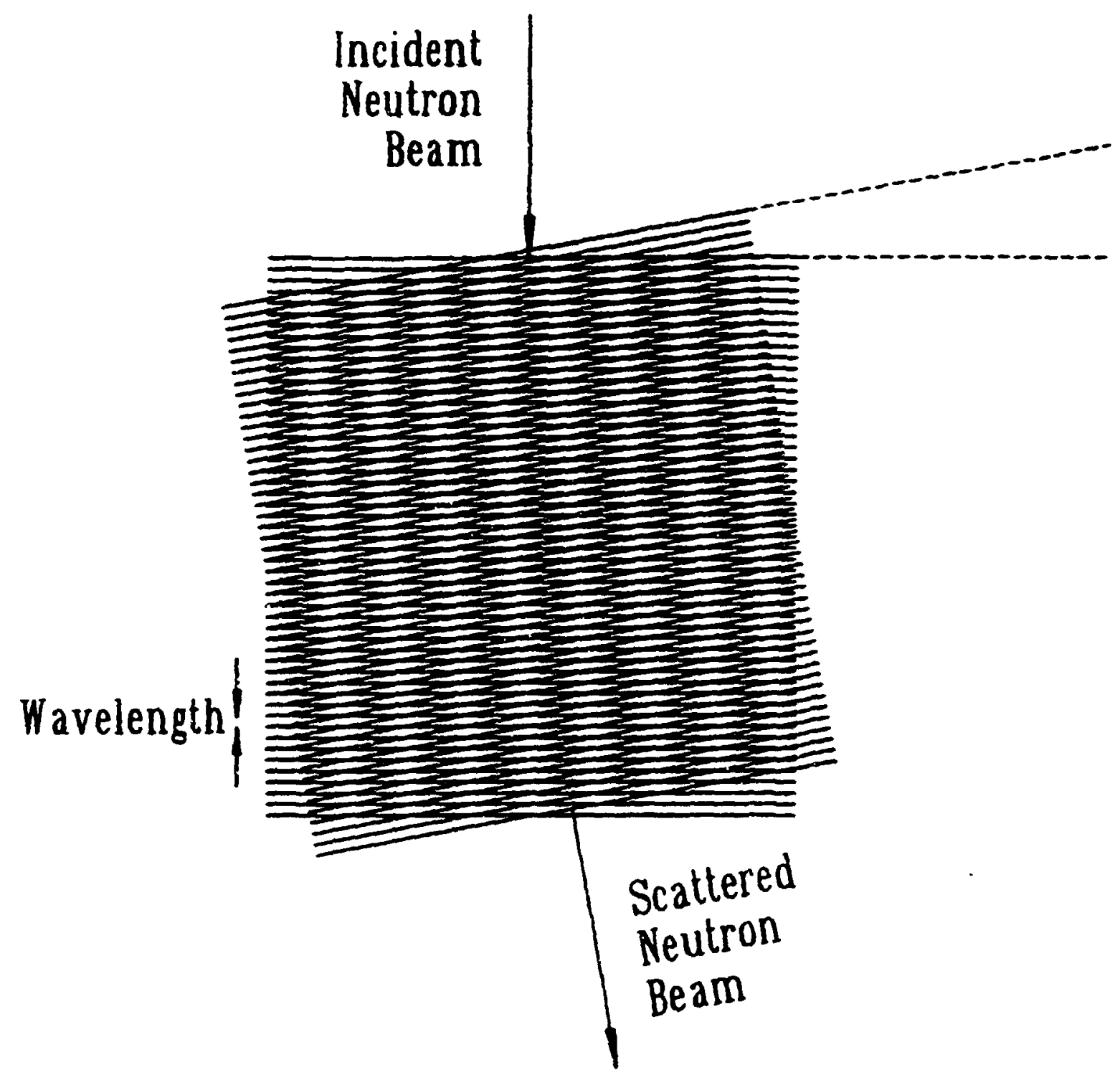

- The Angle Through Which Neutrons Are Scattered Tells Us the Size of Structure Scattering Them

- The smallest angle corresponds to the largest structure - to observe even larger structures, the wavelength must be scaled up, which means colder neutrons 


\section{WHAT ARE WE MISSING?}

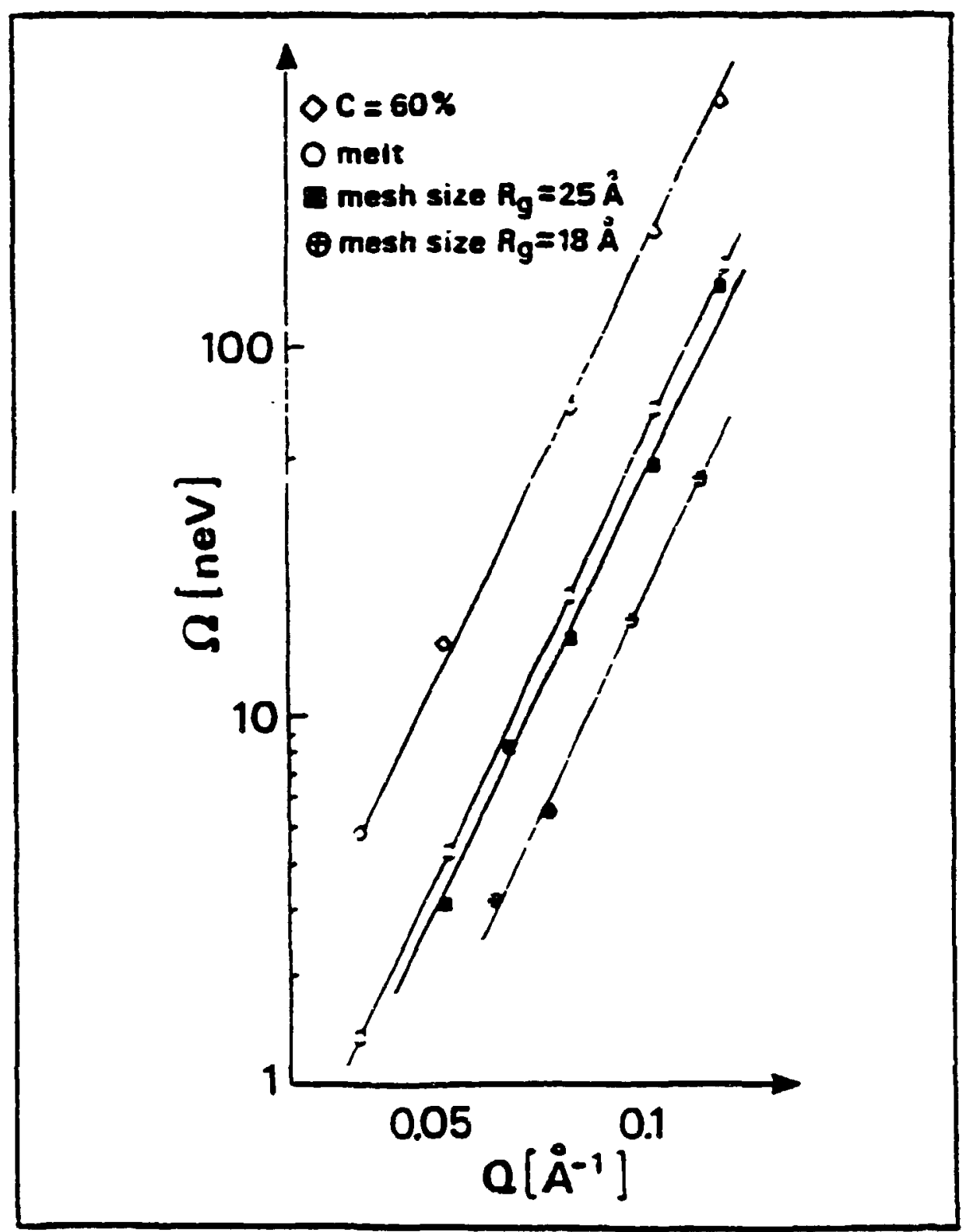

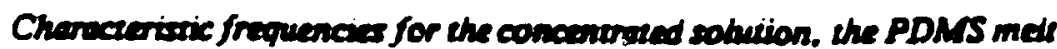
and the trupped chains. The solid lines displesy the $Q-Q^{5}$ sentins low.

- The Best U.S. Spectrometer Would Need 1000x Improvement in Resolution to do This Important Polymer Measurement

- Concorde only beats Lindbergh by $10 x$ 
WHAT ARE WE MISSING?

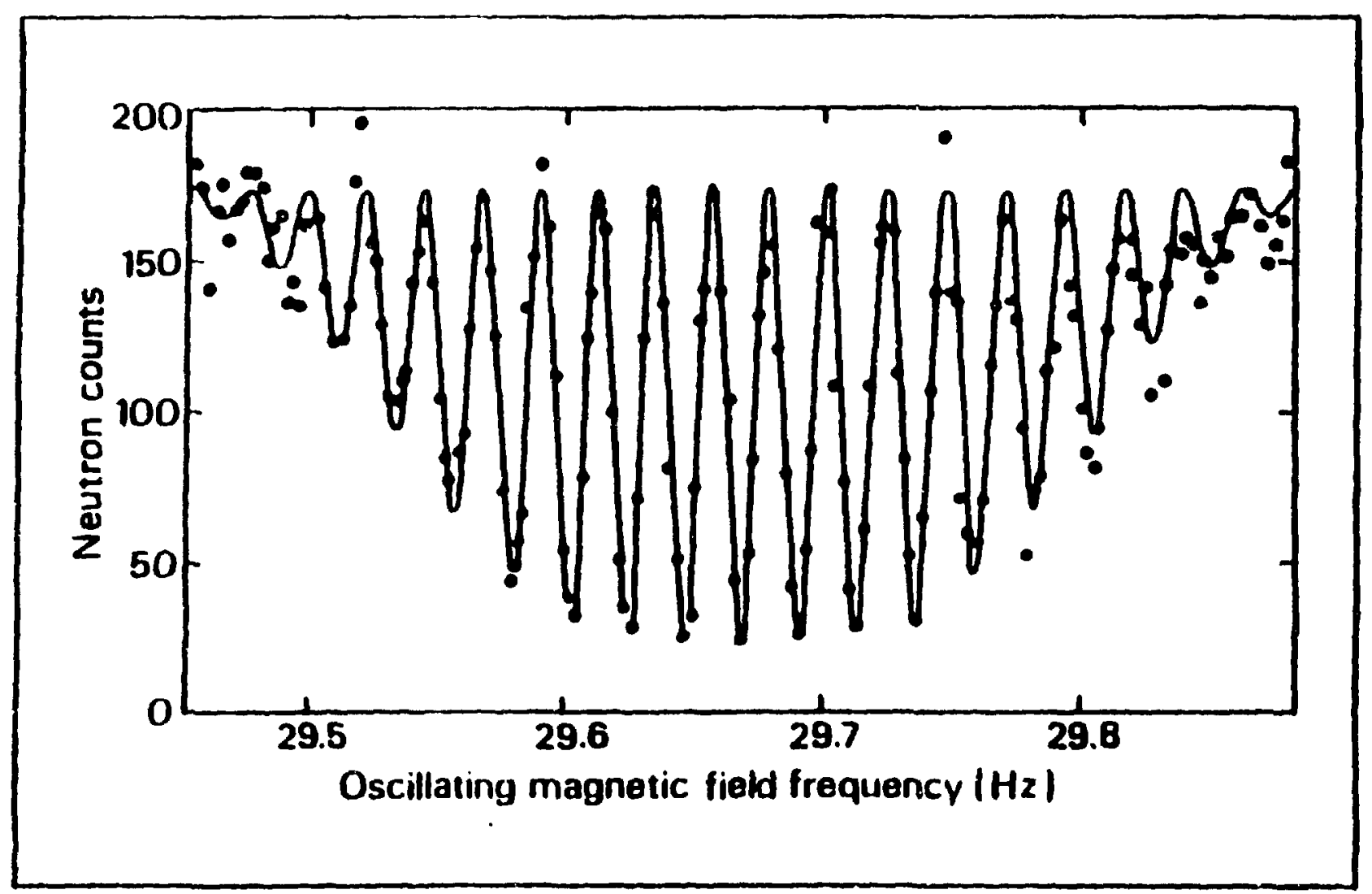

Separate oscillotory field magnetic resonance curve from the neutron electric dipole experimellt (with stored neutrons).

- 1989 Nobel Laureate Norman Ramsey (Harvard) is Searching for the Neutron Dipole Moment

- For the past 15 years, he has had to do it in Europe 


\section{A MEASURE OF CAPABILITY}

- Effective Neutrons Per Second Available To Users( ${ }^{(a)}$

\begin{tabular}{lcccr}
\hline & HFBR $^{(b)}$ & HFIR $^{(c)}$ & ILL $^{(d)}$ & ANS $^{(\theta)}$ \\
\hline Hot & 0 & 0 & 471 & 470 \\
Thermal & 347 & 413 & 1,627 & 11,556 \\
Cold & 27 & 0 & 708 & 16,200 \\
Very Cold & 0 & 0 & 36 & 252 \\
Ultra Cold & 0 & 0 & 464 & 2,780 \\
\hline
\end{tabular}

\footnotetext{
(a) A number of beame $x$ usolul area of each beam $x$ peak llux In relloctor $\left(10^{19} \cdot 1\right)$

(b) 40 MW operation

(c) 85 MW operation

(d) Beams avallable to users are overdemanded by aboul a lactor of 4
}

(e) Minimum iequiremenis assessed by the ecienilic communliy through lour nallonal workahope and by the Nallonal Steorlng Commiltee for the Advanced Neutron Source. 


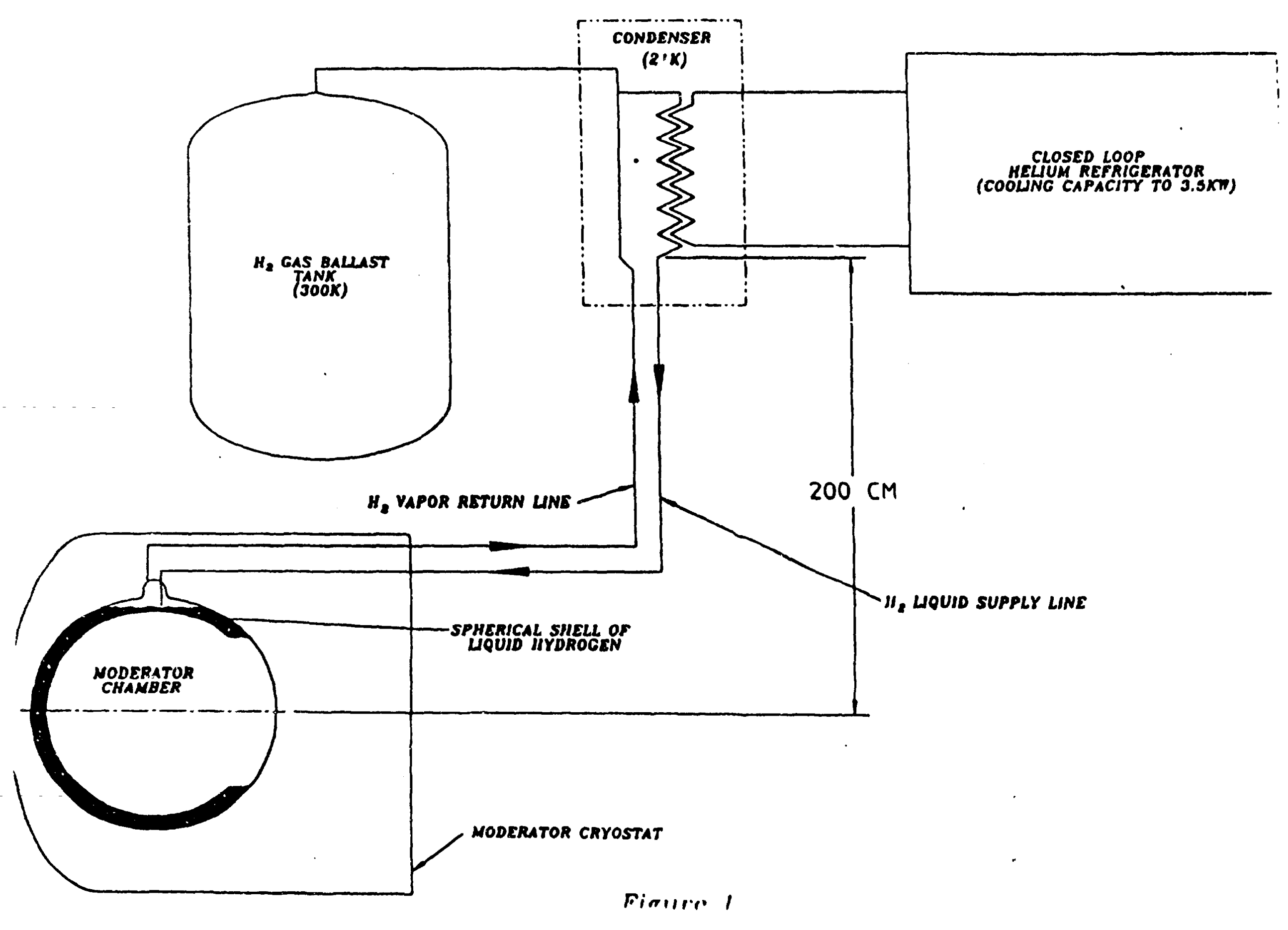




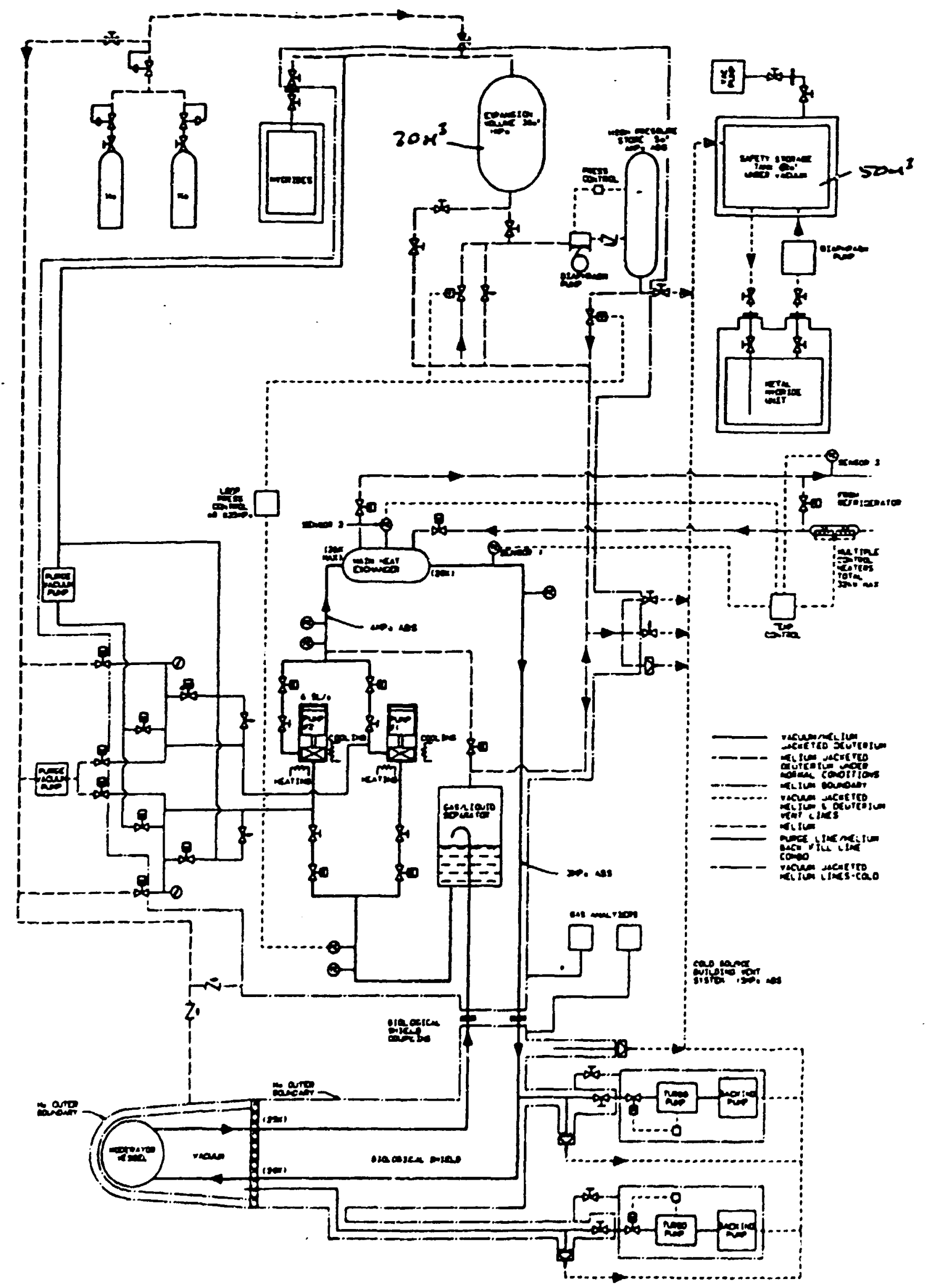




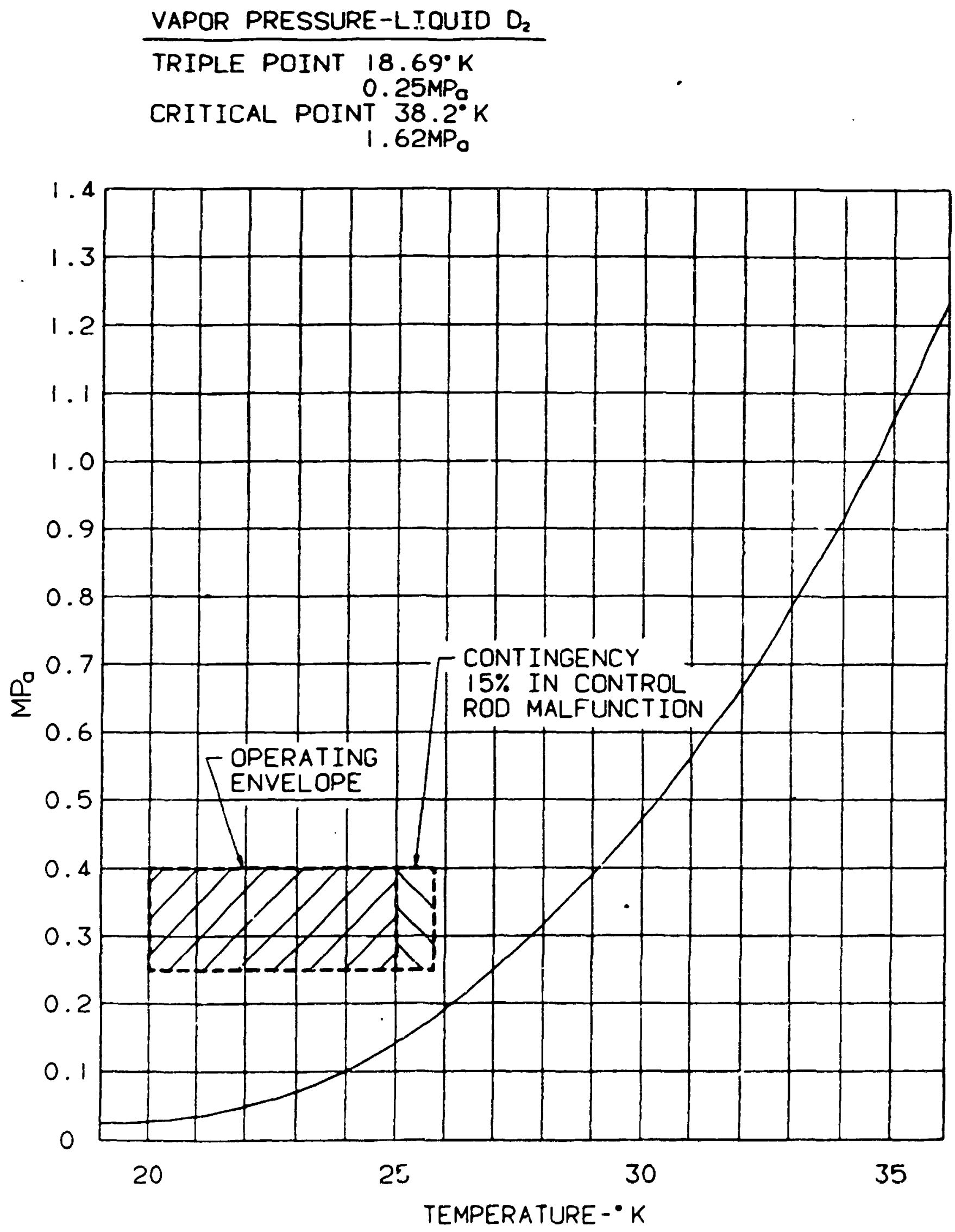




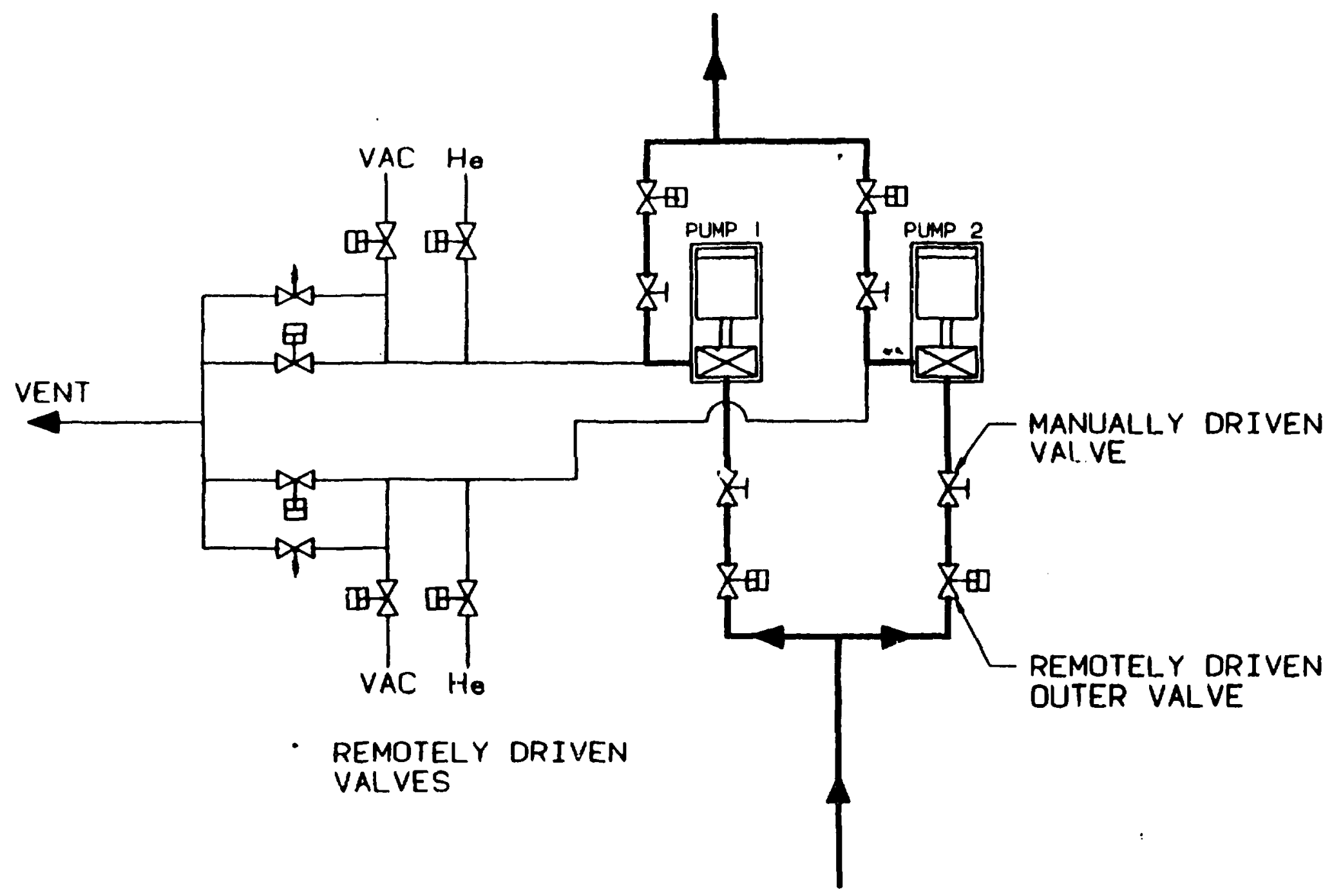

FIG. 13 


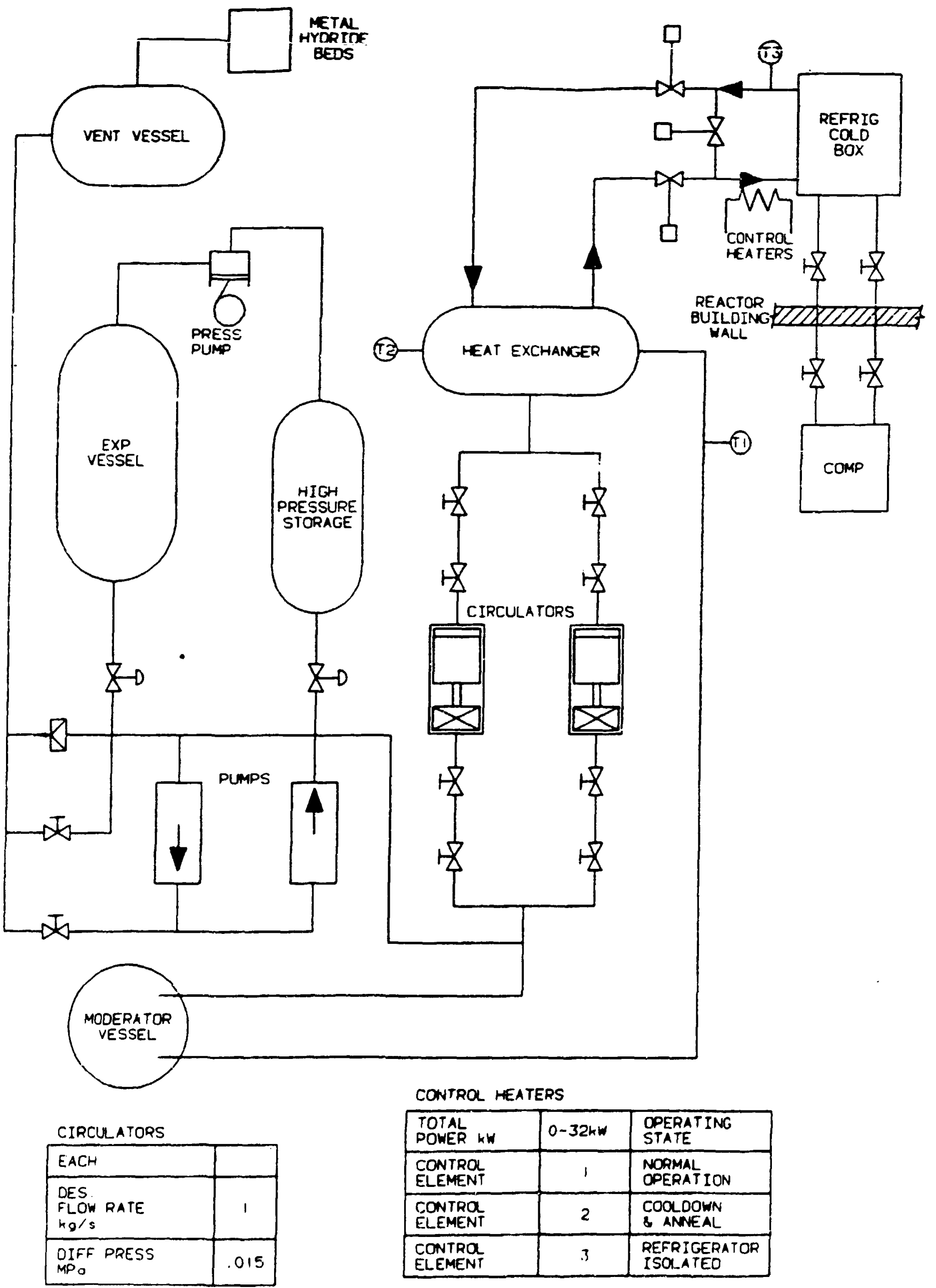




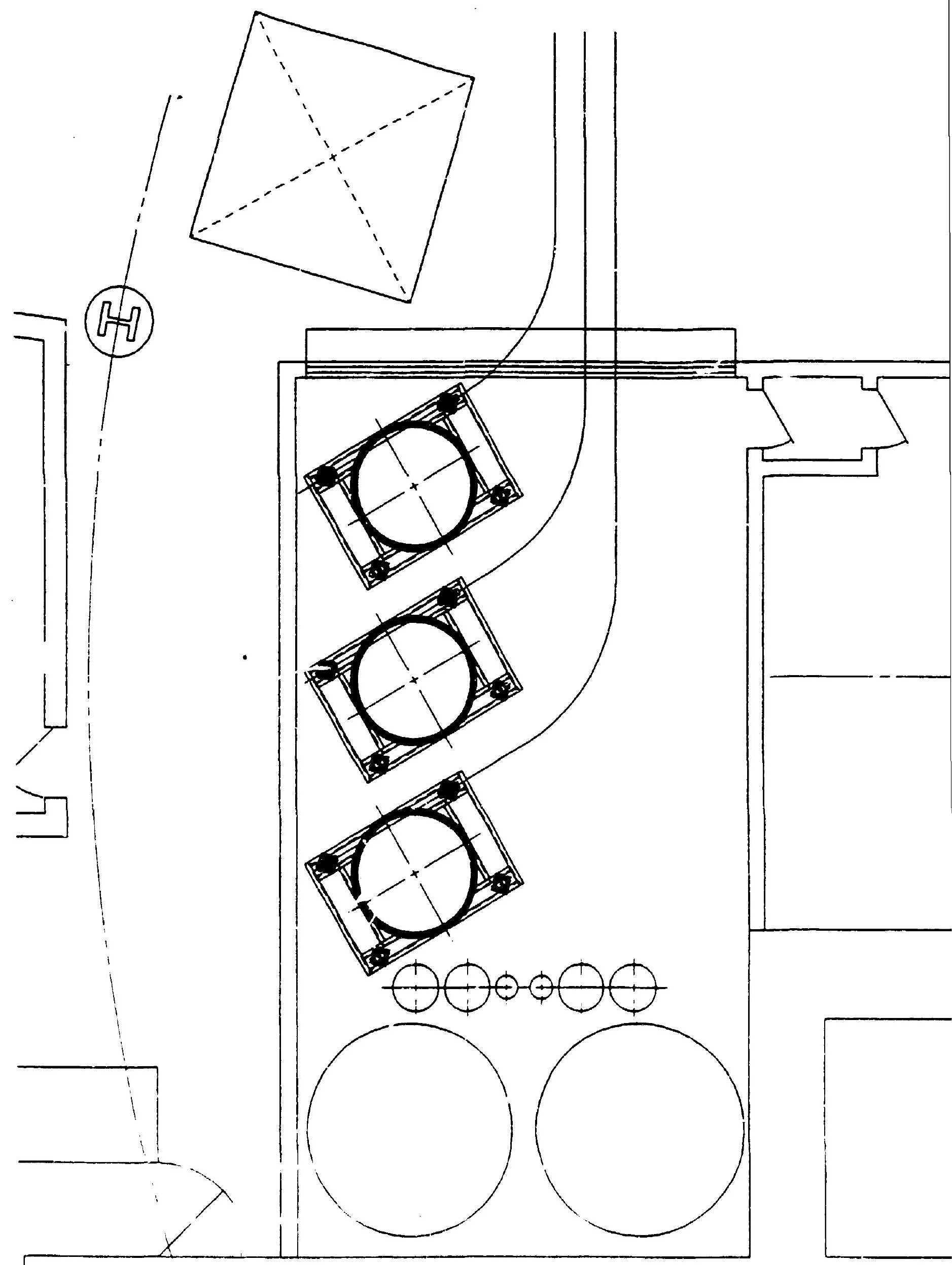




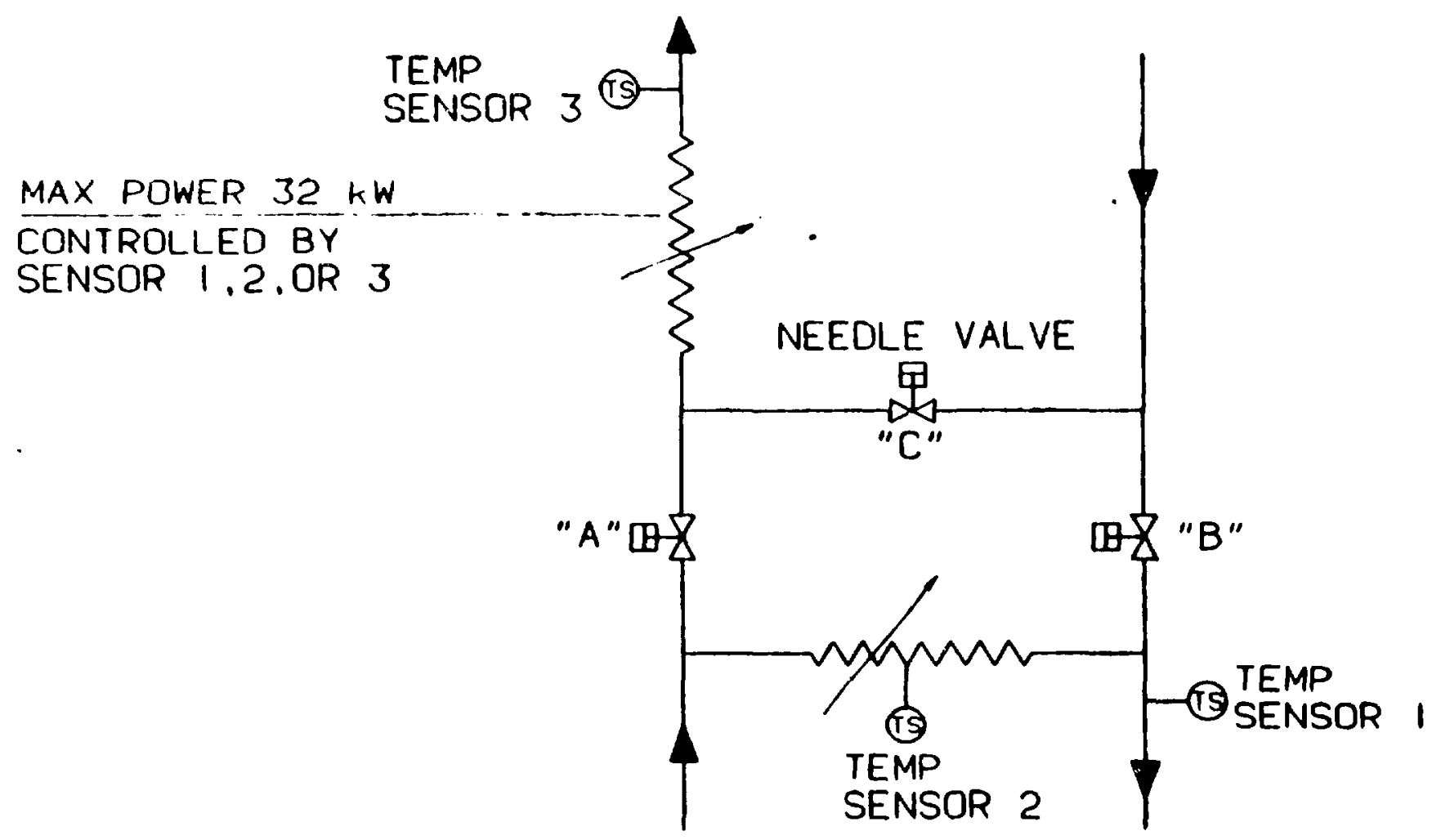

\begin{tabular}{|c|c|c|c|c|}
\hline REOUIREMENT & $\begin{array}{l}\text { REFRIGERATOR ON IN } \\
\text { STANDBY MODE LOOP } \\
\text { AT AMBIENT TEMP. }\end{array}$ & $\begin{array}{l}\text { REFR IGERATOR IN } \\
\text { STANDBY MODE. LOOP } \\
\text { TO BE COOLED TO } \\
\text { OPERATIONAL TEMP. }\end{array}$ & $\begin{array}{l}\text { REFR IGERATOR AND } \\
\text { LOOP TO BE COOLED } \\
\text { FROM AMBIENT TEMP } \\
\text { TOGE THER. }\end{array}$ & $\begin{array}{l}\text { NORMAL } \\
\text { COLD } \\
\text { OPERAT ION. }\end{array}$ \\
\hline VALVE STATE & $\begin{array}{l}\text { A \& B-CLOSED } \\
\text { C-OPEN }\end{array}$ & $\begin{array}{l}A \text { \& } \\
\text { C- "T-OPENED" OPED } \\
\text { CLOSE }\end{array}$ & $\begin{array}{l}\text { A \& B-OPEN } \\
C-\stackrel{C}{C} \text { OSED }\end{array}$ & $\begin{array}{l}A \& \text { B-OPEN } \\
C-C L O S E D\end{array}$ \\
\hline $\begin{array}{l}\text { TEMP SENSOR } \\
\text { CONTROL.LING }\end{array}$ & 3 & 2 & 2 & 1 \\
\hline
\end{tabular}




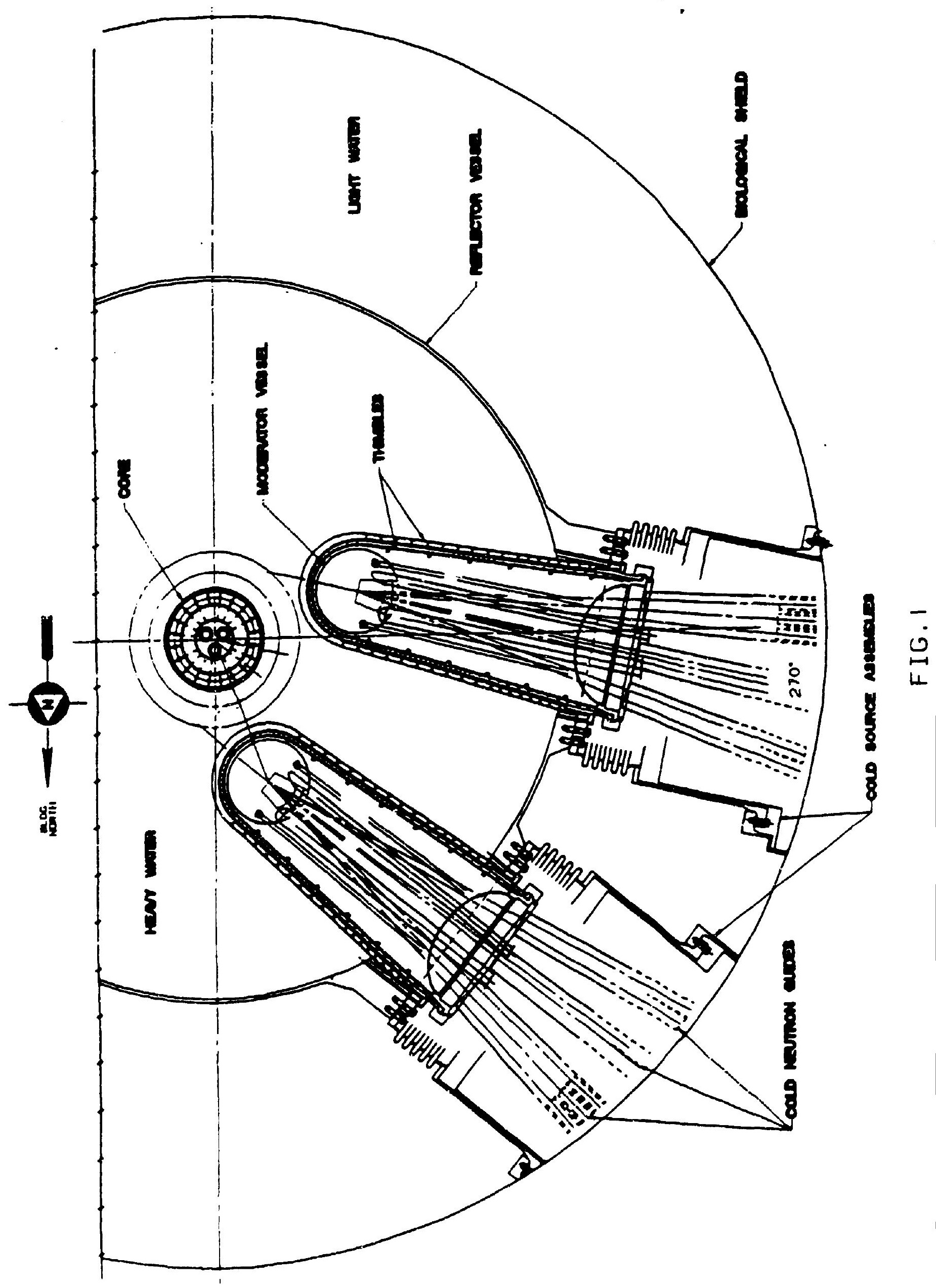




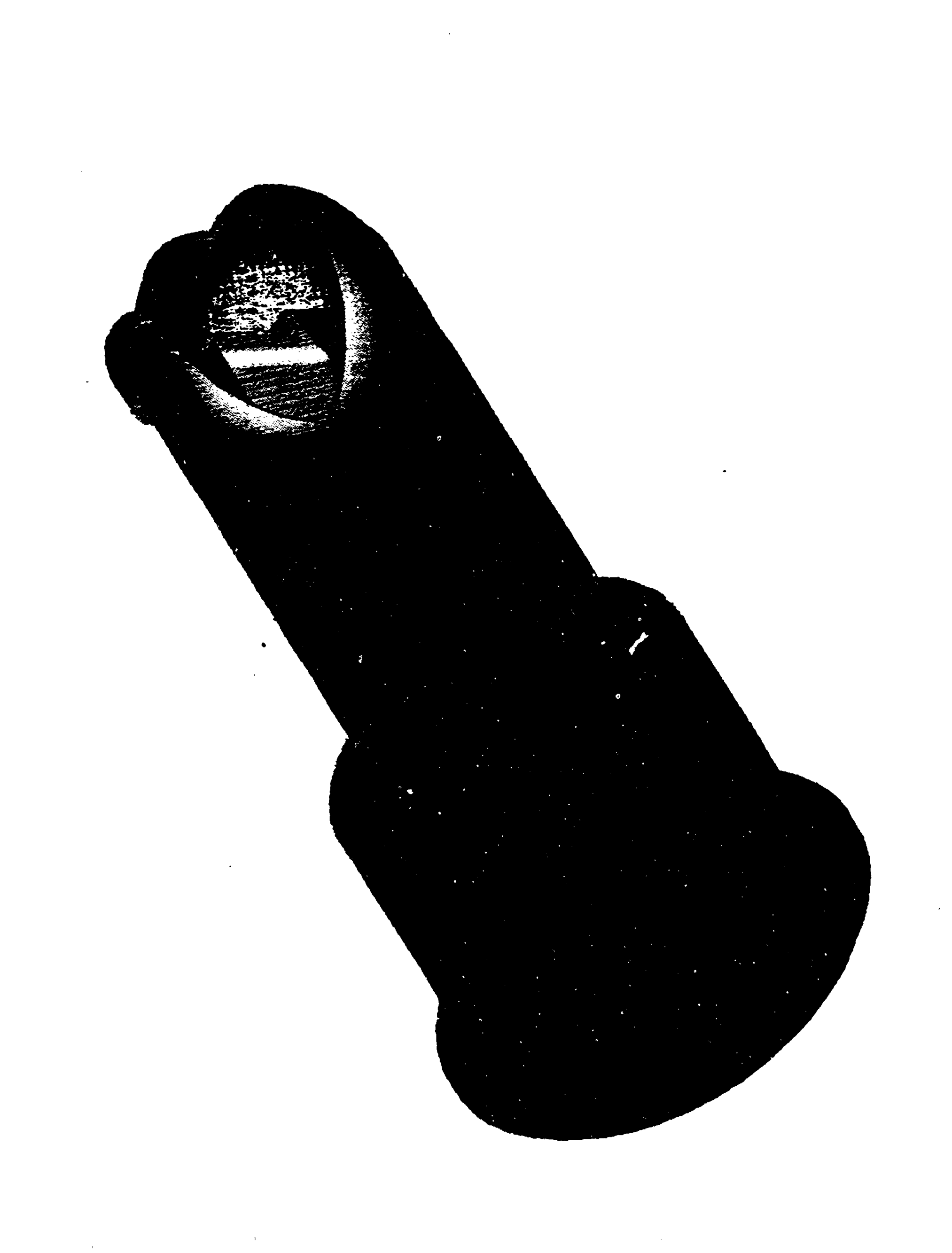




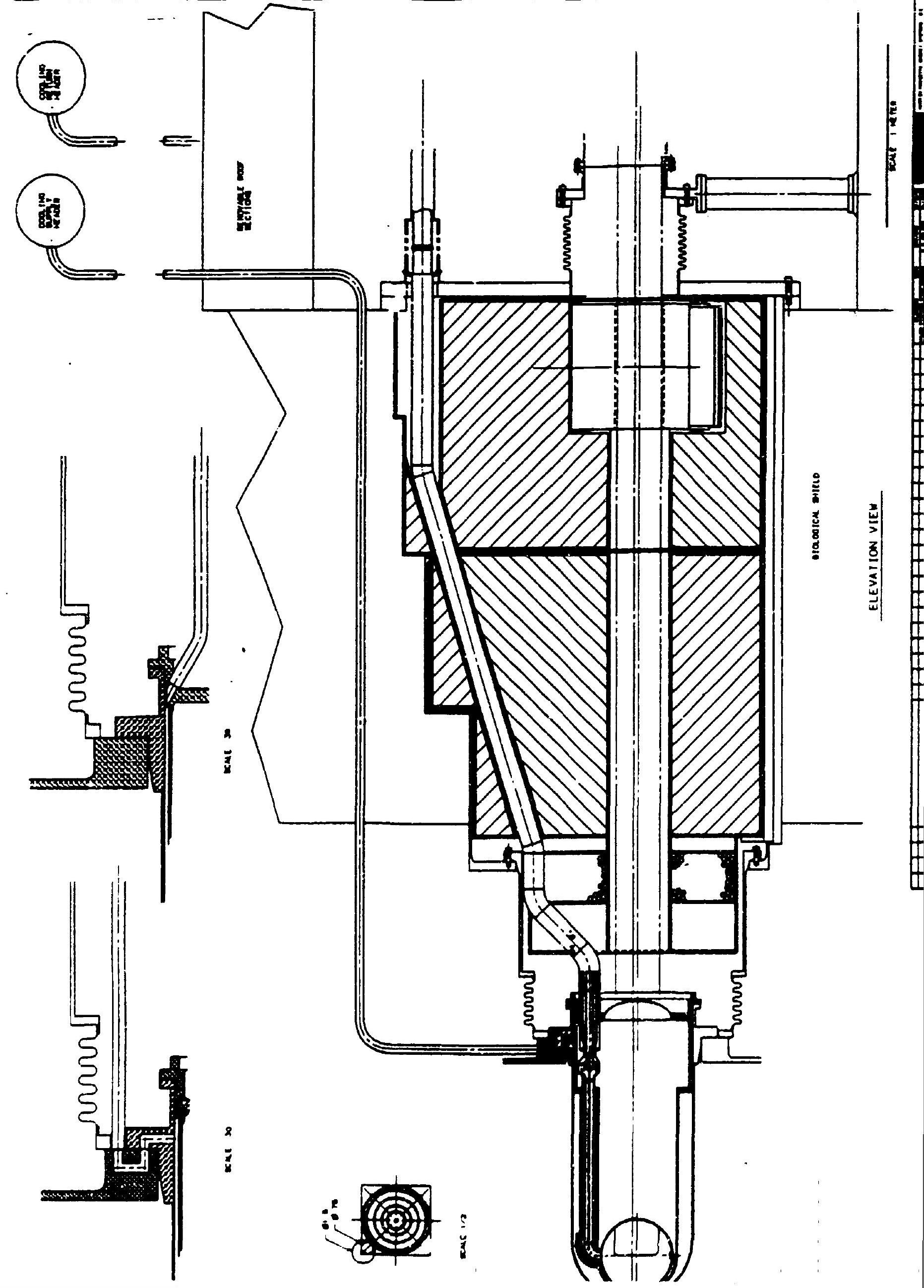



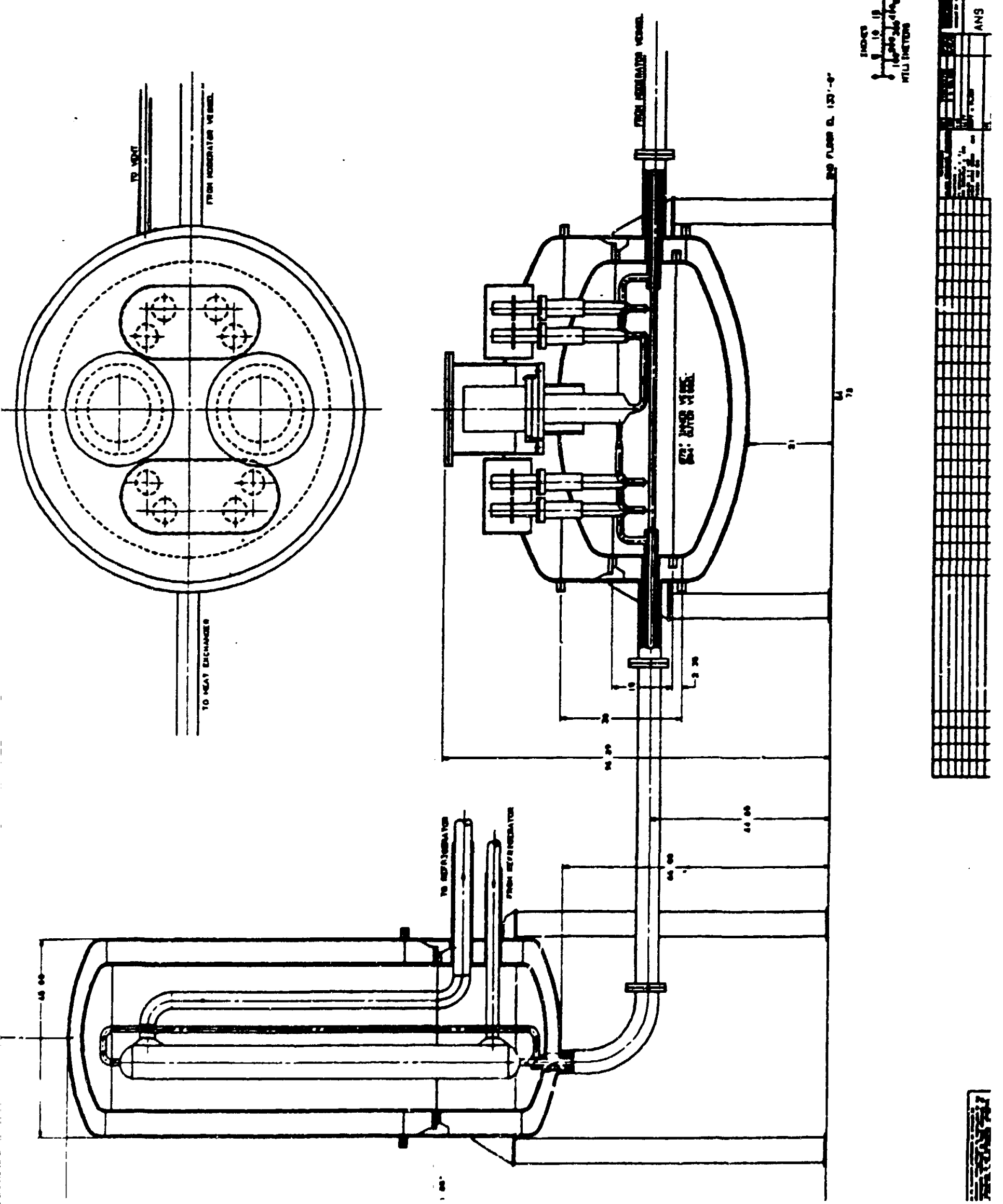


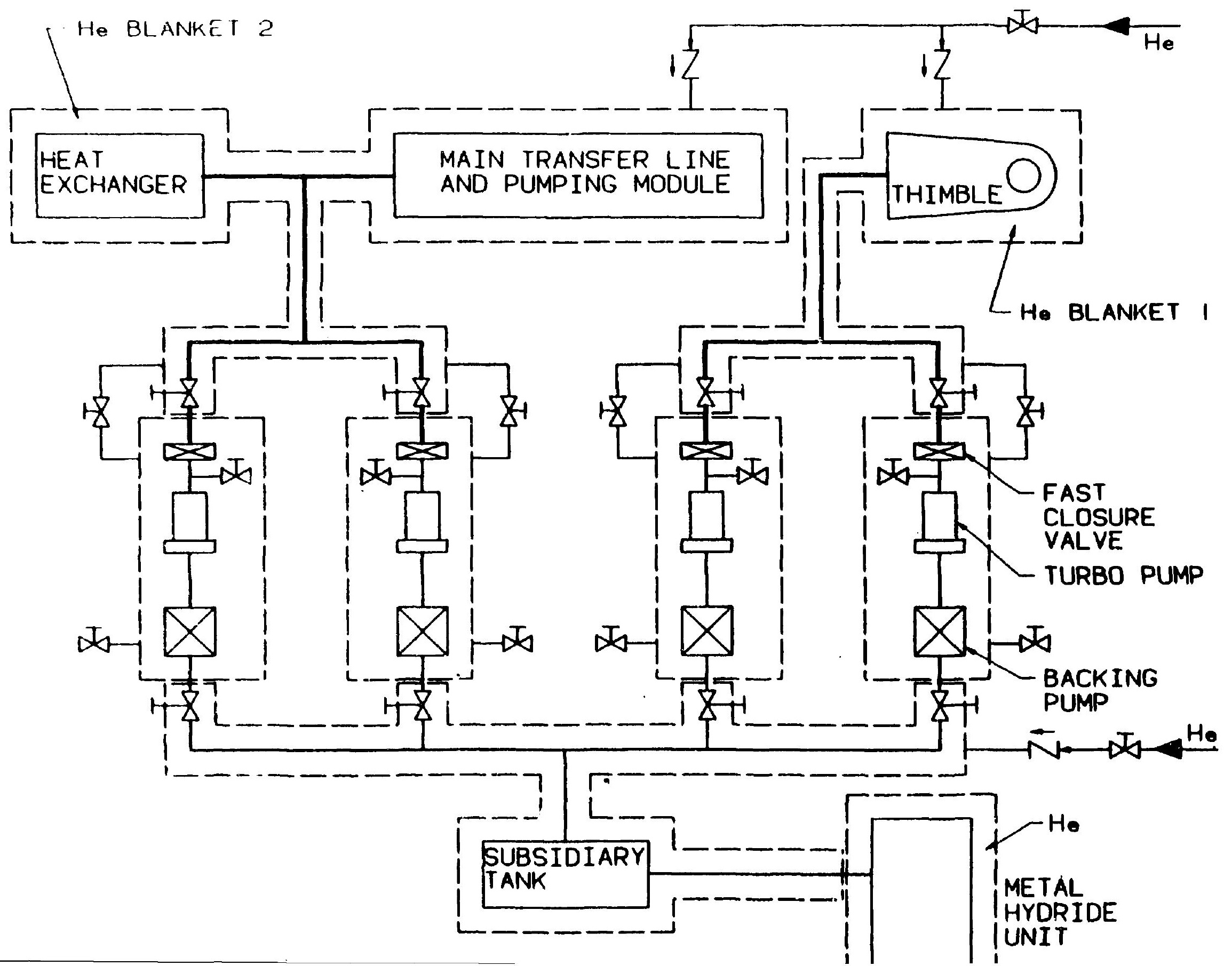




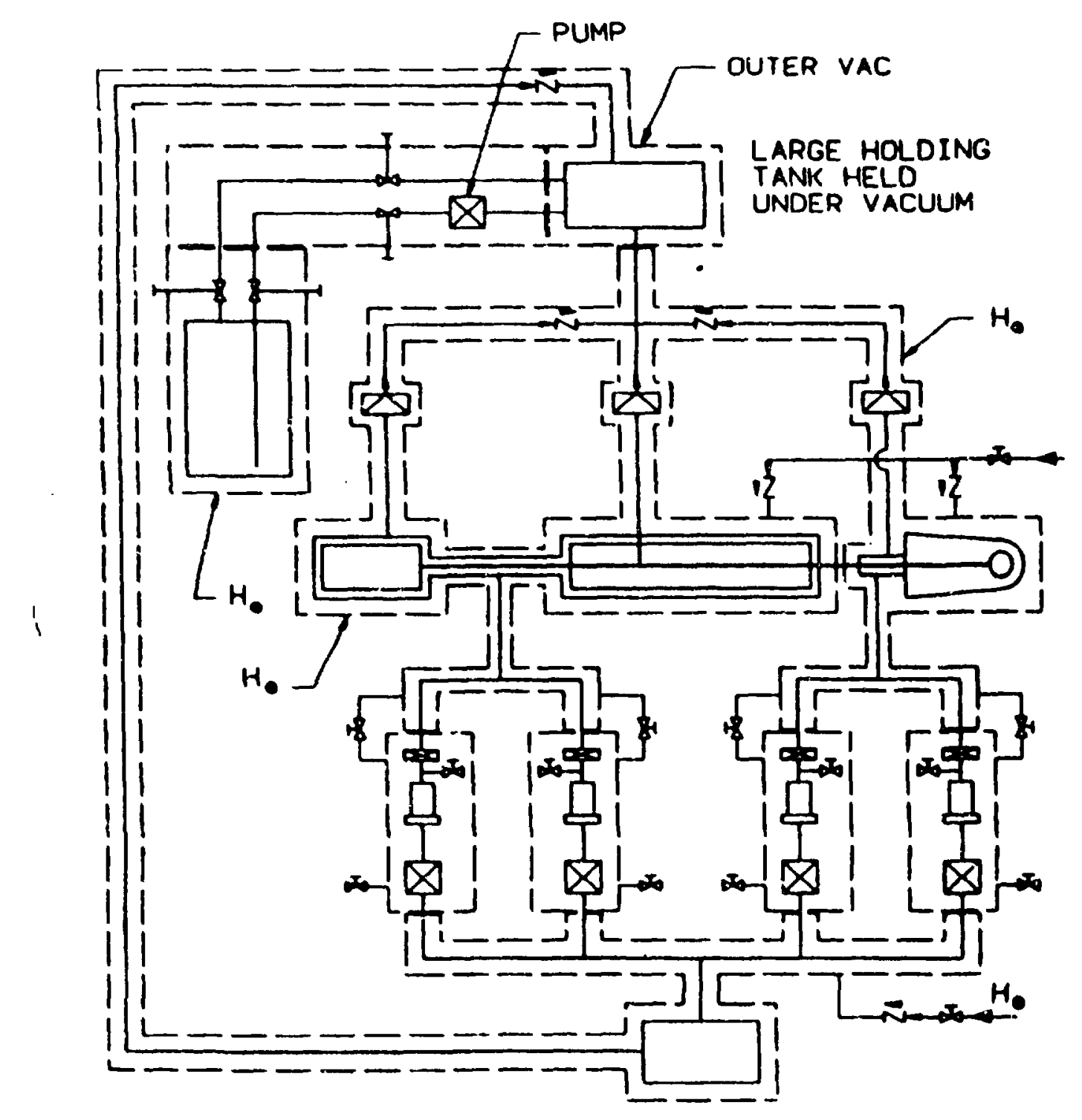

FIG.20 


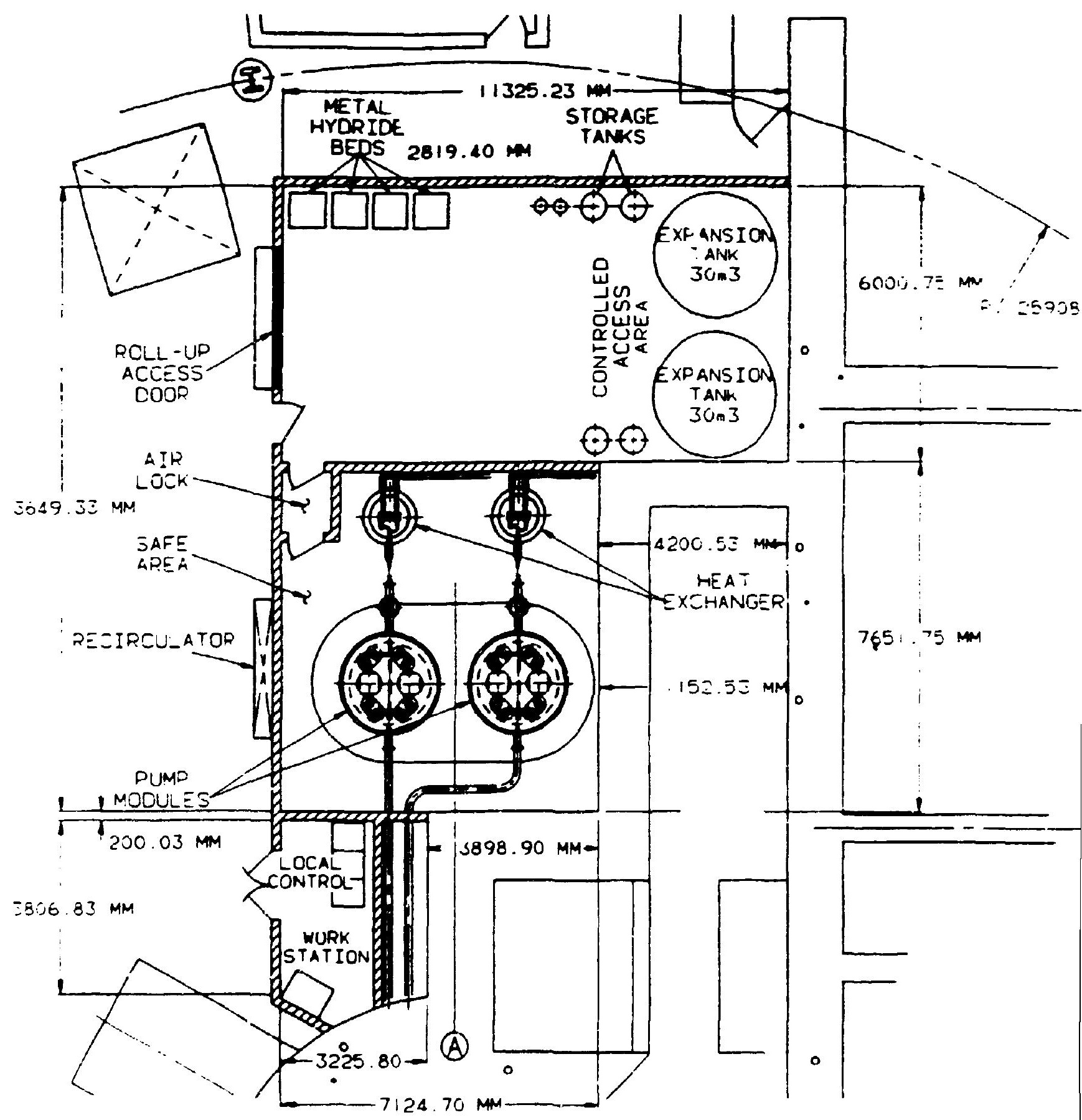



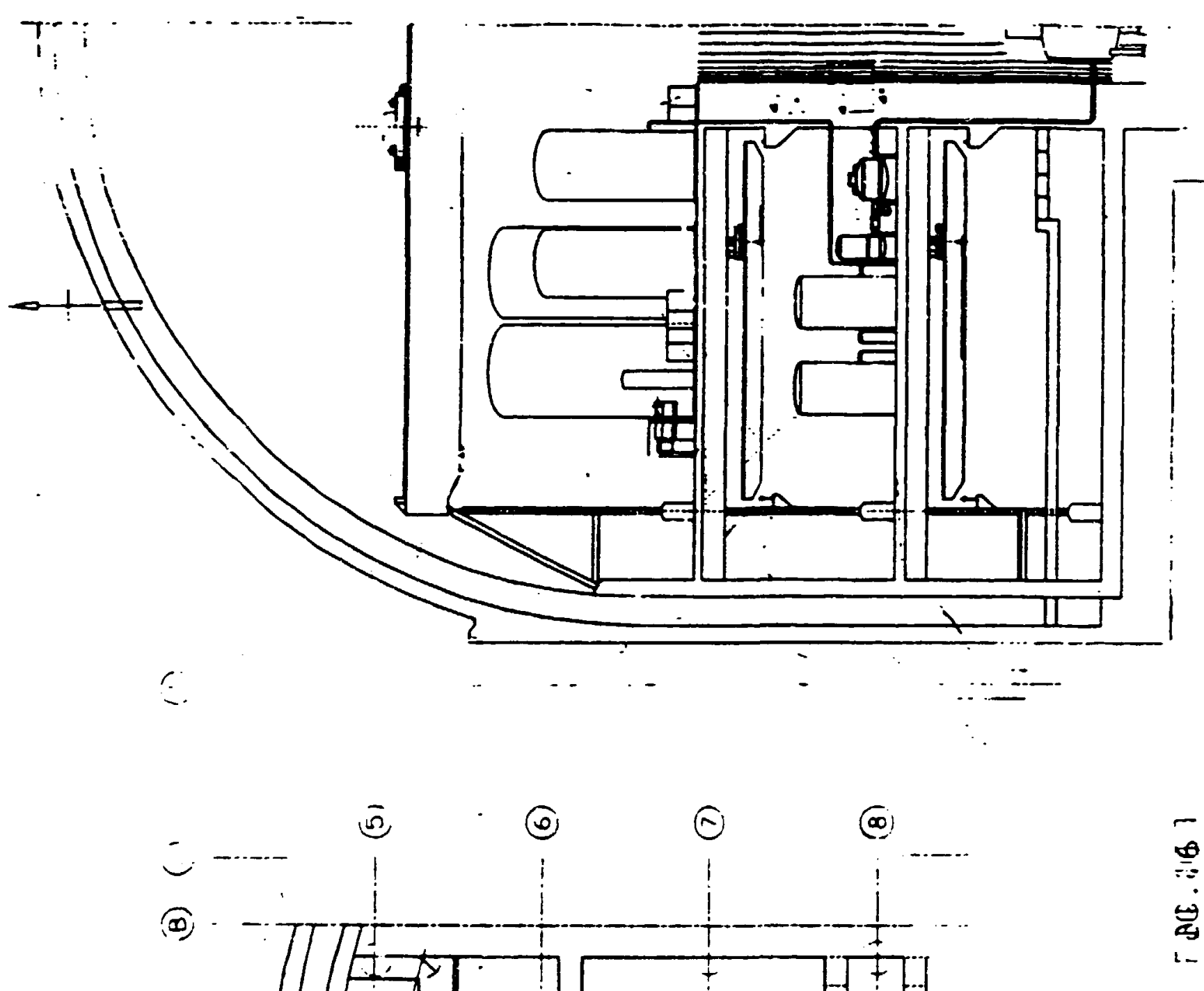


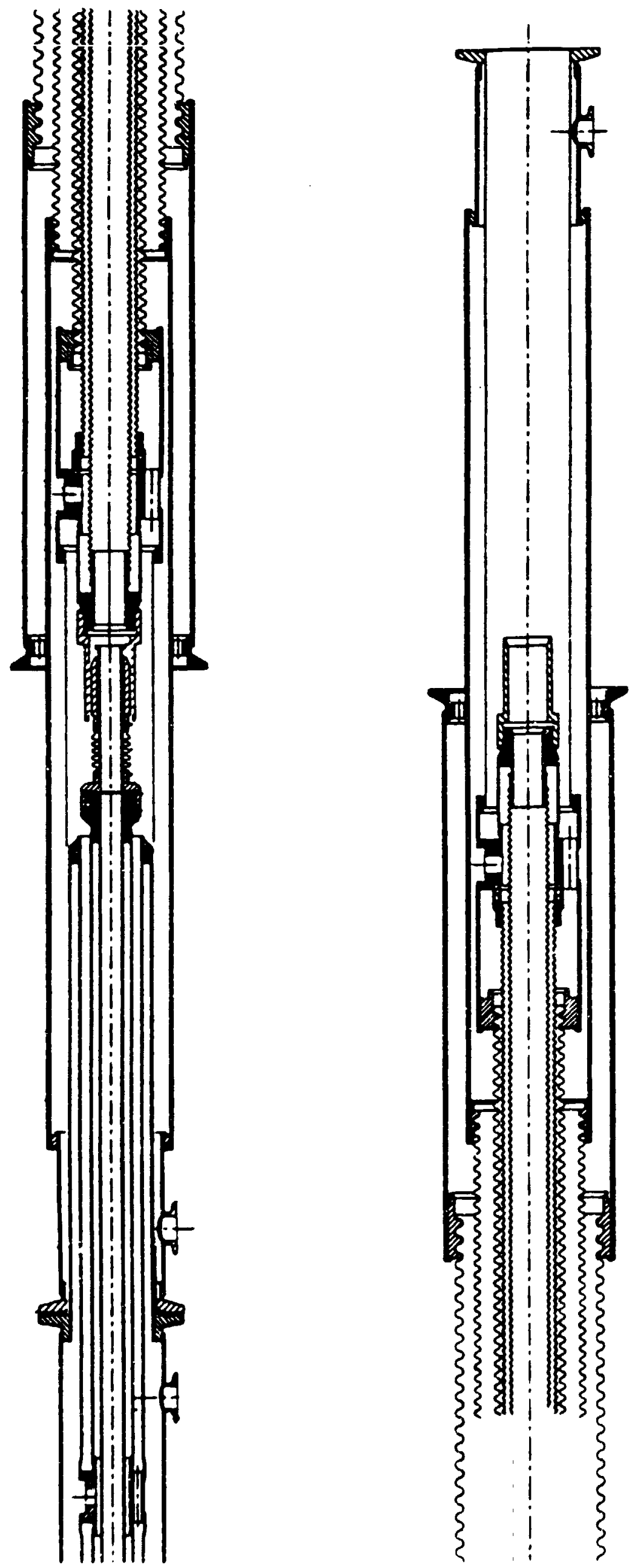




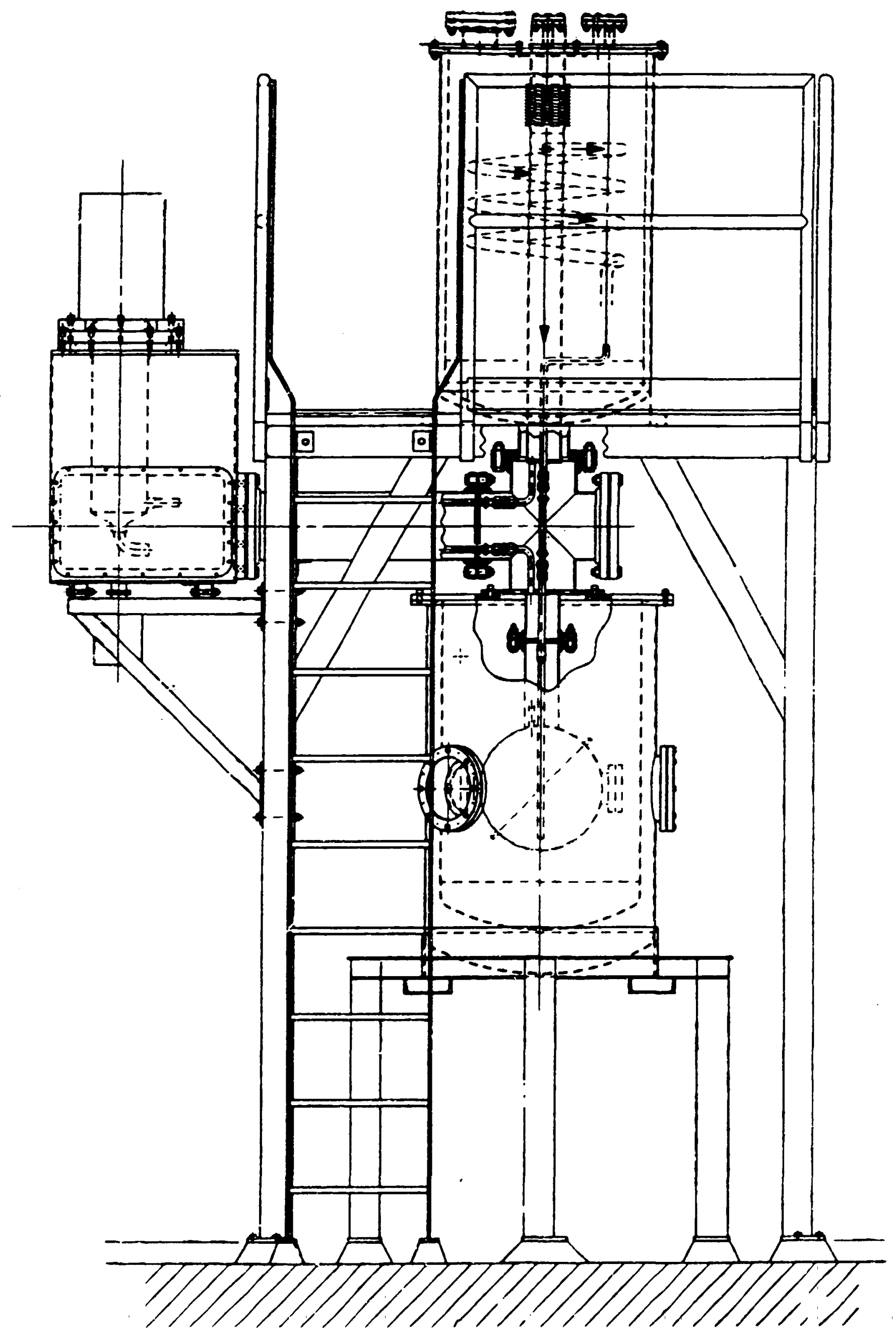




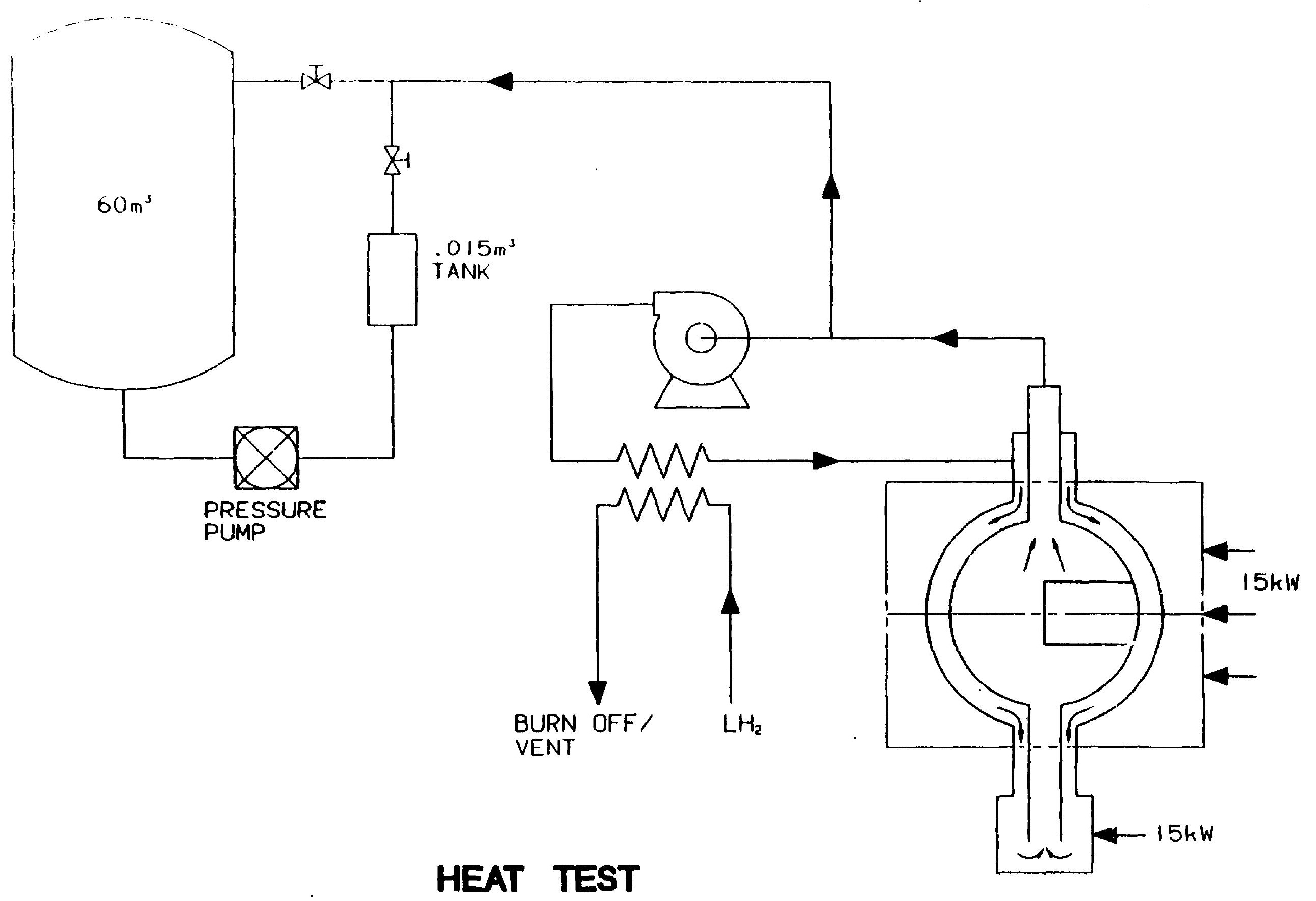




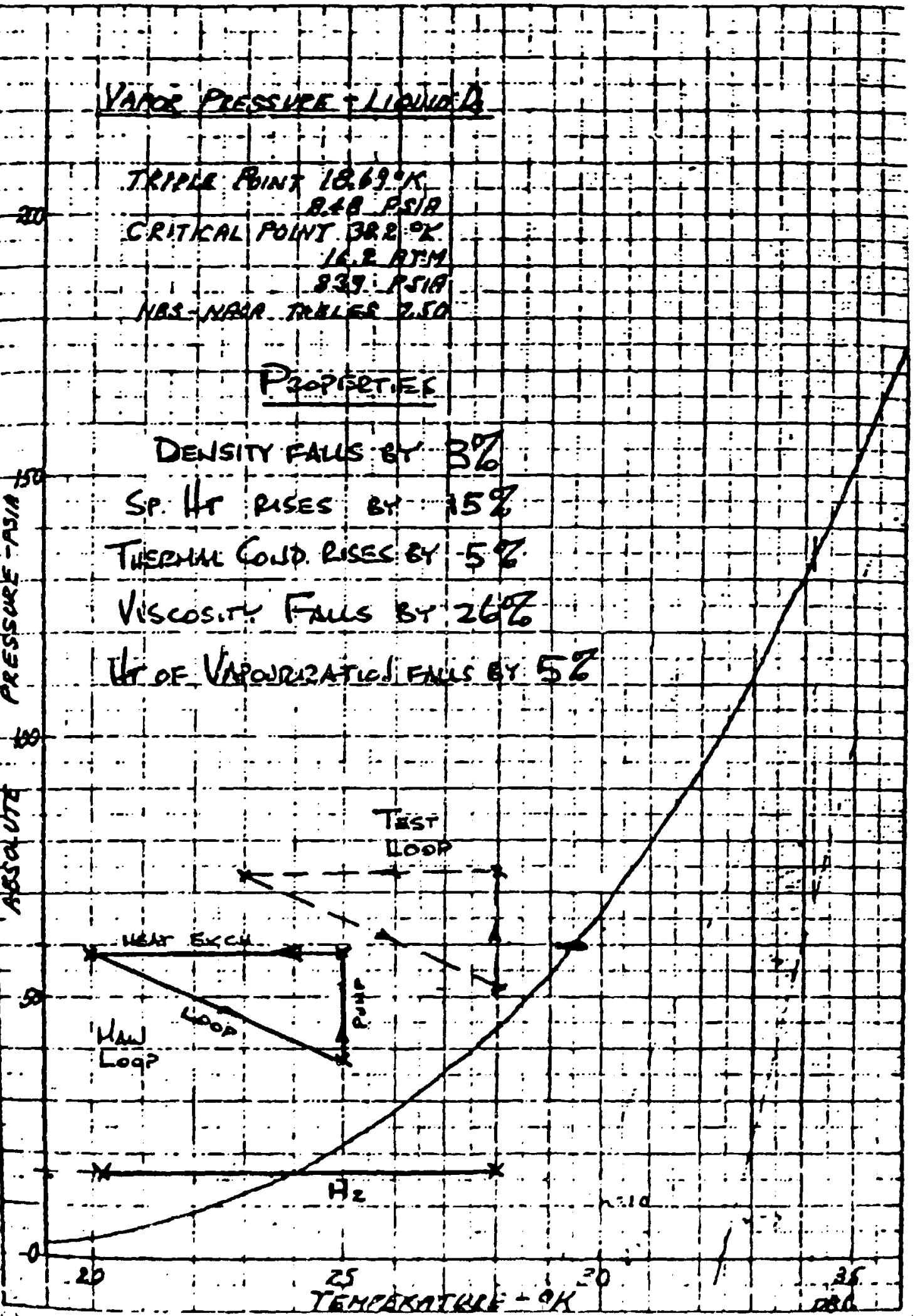




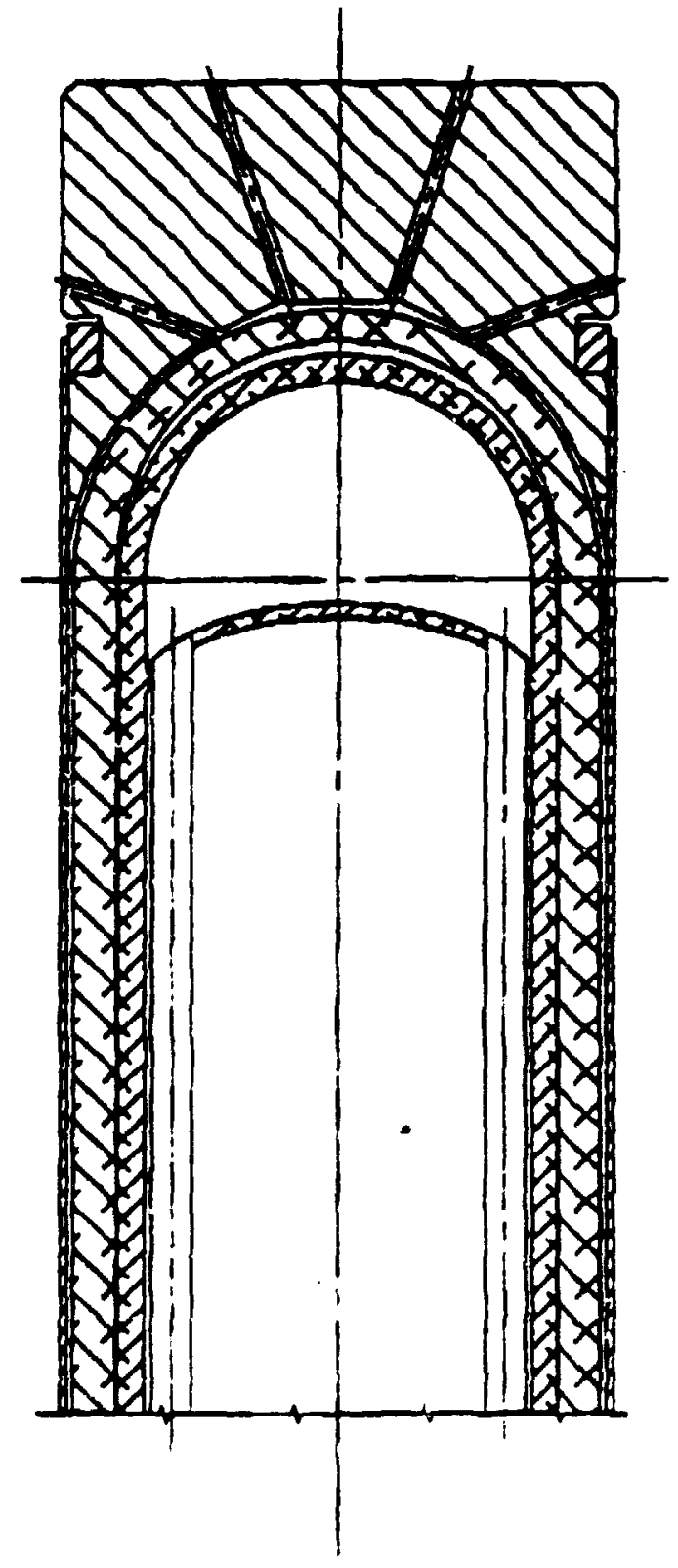

感 

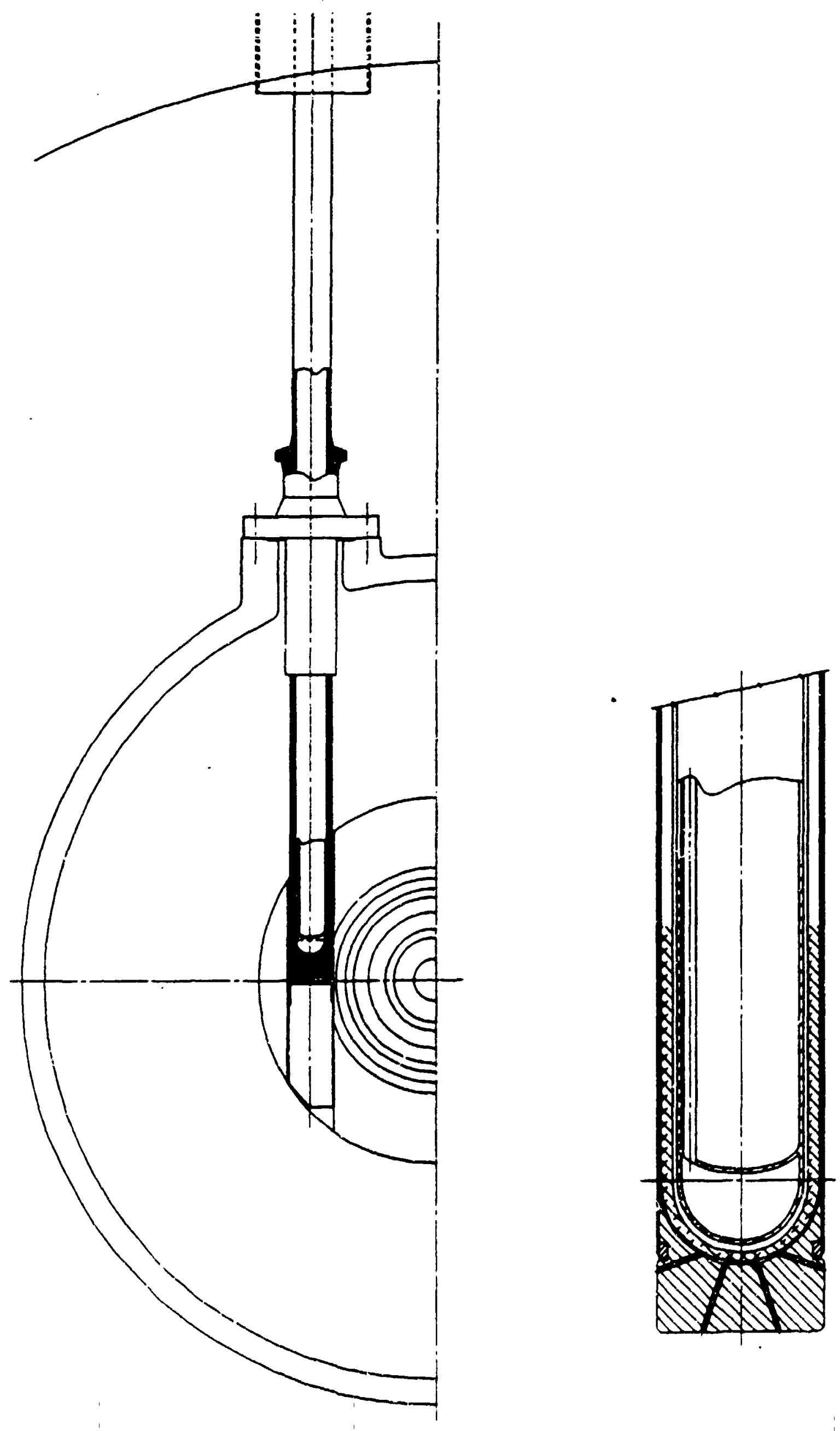

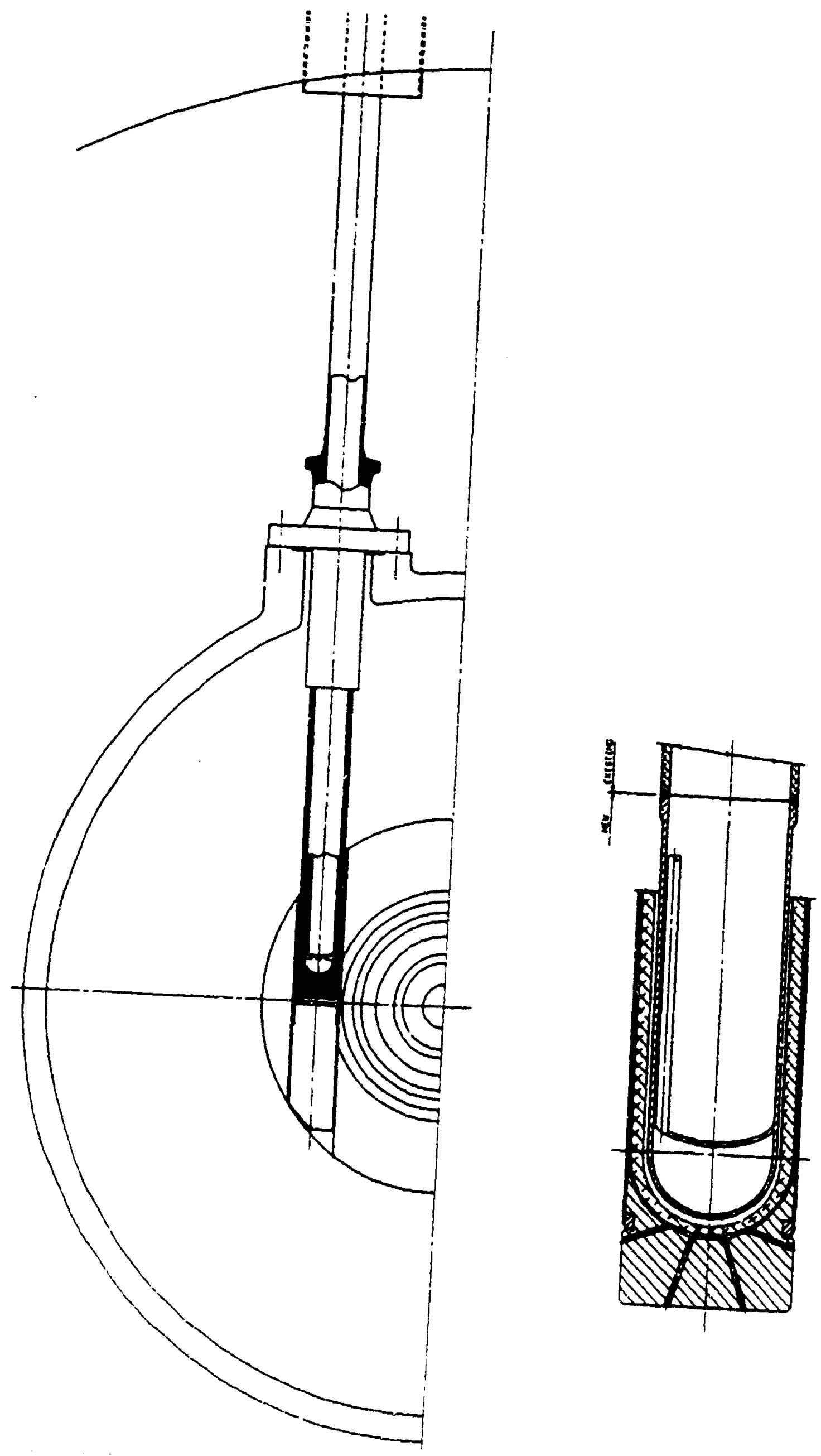


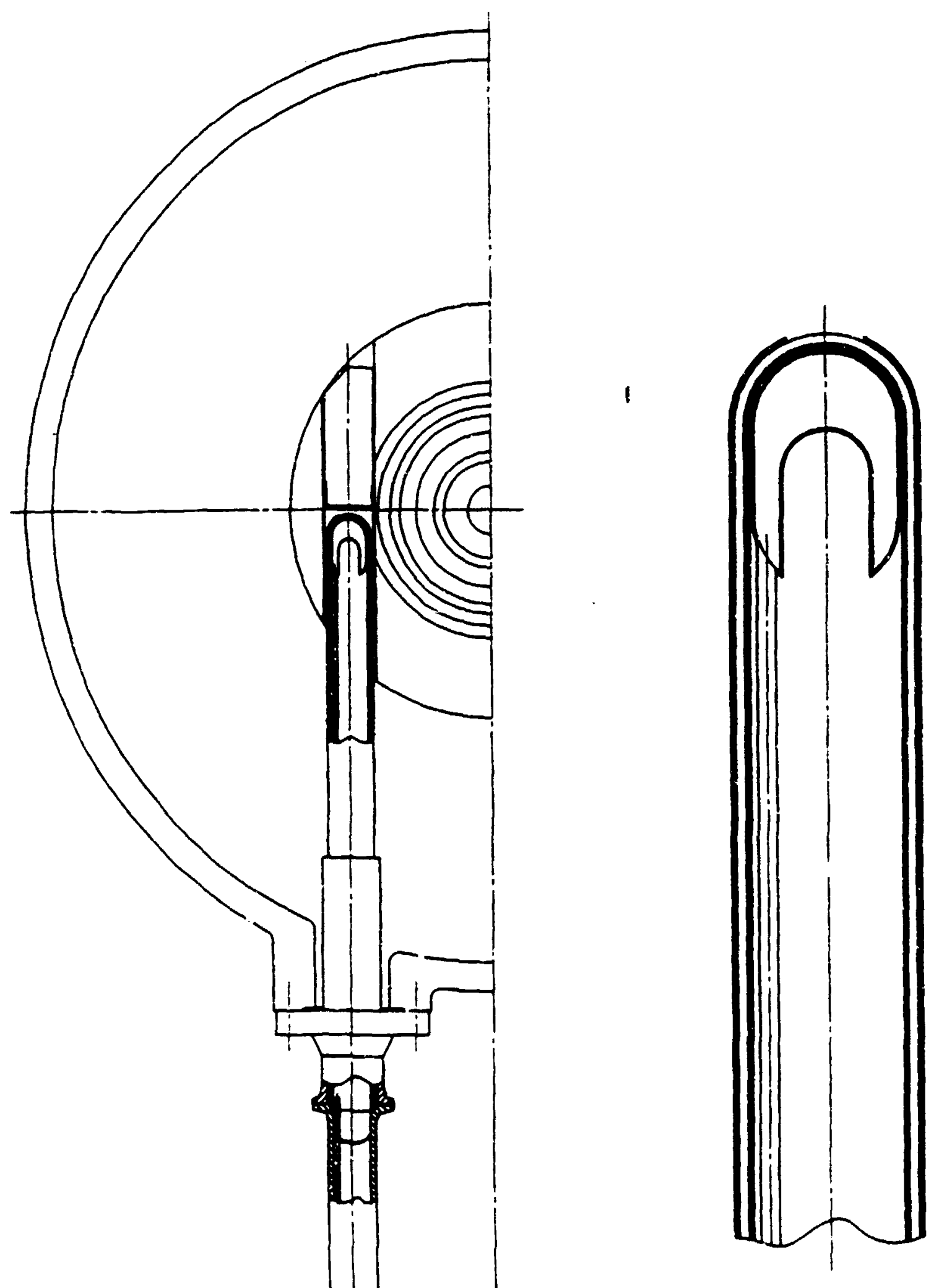




$$
\text { Fin }
$$




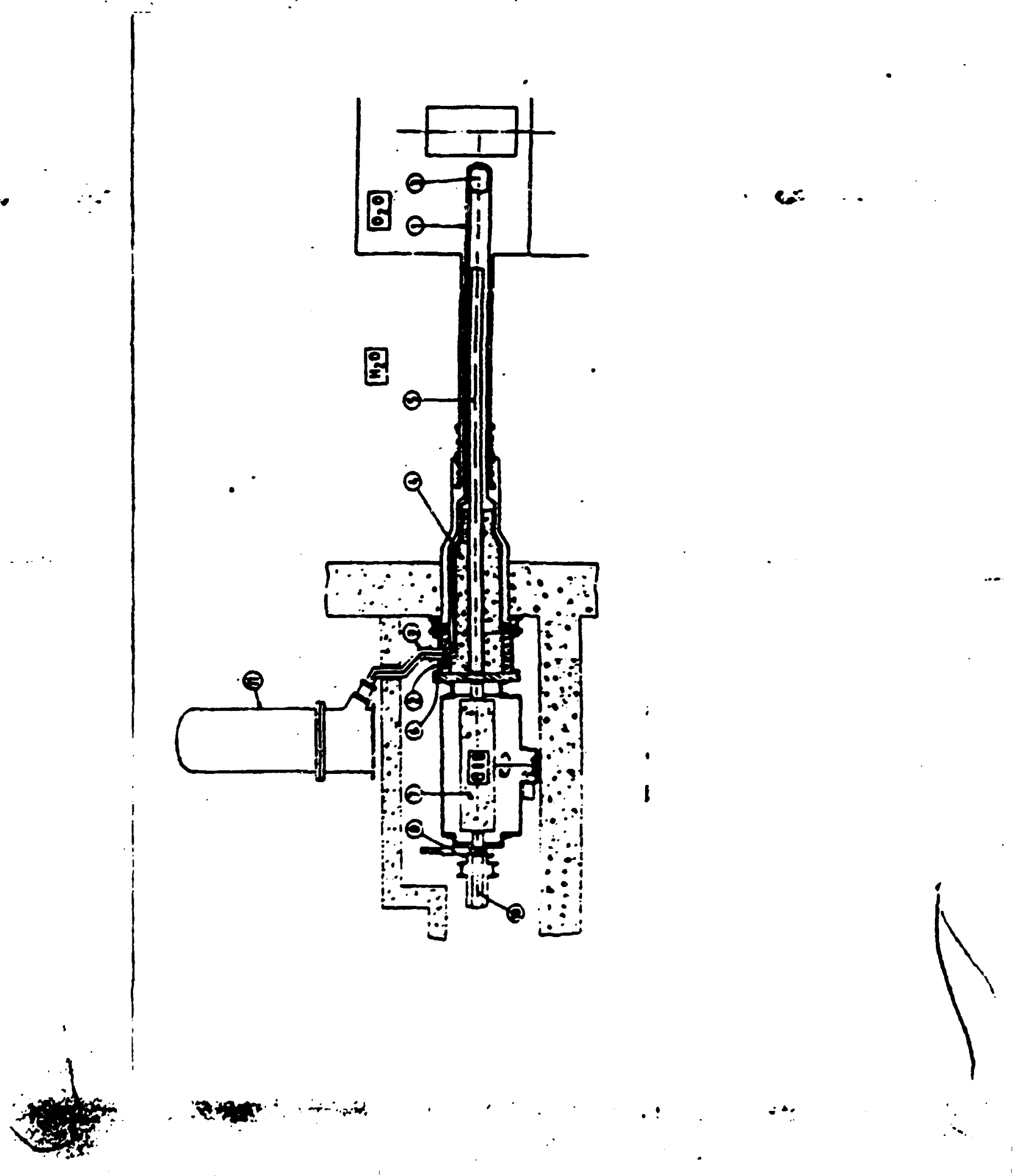




\section{Possibilities for the Addition of a Cold Source to the HFIR Reactor}

\section{General}

It is generally agreed that the scope of the HFIR reactor could be considerably enhanced by the addition of a cold source. If space were available, this would probably be liquid deuterium, but the tight constraints of a possibly retrofitted smaller source makes liquid hydrogen almost mandatory. A design using beam line HB4 could be implemented relatively quickly, but a better long term option might be to consider the cold source in the overall future plans for HFIR. Alternatively, the retrofit design might be considered as a short term option, in which case all cryogenic equipment would be designed and installed to readily accommodate a future change.

\section{Brief System description}

The annular plate fuel reactor core is surrounded by a beryllium reflector. The reflector assembly comprises three inner beryllium steeves are known as the removable reflector, a fourth sleeve known as the semi-permanent reflector and the main berylium ring known as the permanent reflector. Pressurized light water is contained by a stainless steel vessel about $7.25 \mathrm{ft}$ in diameter. This water acts as a reflector and serves to cool the core. It is passed downward between the core plates and is then piped away to the heat exchangers and circulating pumps, before being returned to the vessel. Two experiment beam tubes made from 6061 aluminum alloy and designated $\mathrm{HB} 2$ \& $\mathrm{HB} 3$, pass through the vessel wall and terminate close to the core. Two further 6061 beam tubes, are on a common center line and enter the vessel from opposite sides. They are terminated with flat berylium ends separated from each other by water about $3 / 4^{n}$ thick. The beryllium and water act as a neutron moderator for instruments using beam tubes HB1 \& HB4, but HB4 is designated for the possible inclusion of th:e cold source. The water is constantly circulated to prevent overheating. Since all the beam tubes must withstand external pressure equal to that of the tank, they are correspondingly thick walled. Induced heat is removed by water drawn from the tank and passed through outer cooling jackets, to be eventually discharged to the low pressure side of the core cooling circuit. The high pressure tank is immersed in a light water pool, outside of which is the concrete biological shielding. Beam tube extensions pass through the pool and concrete shielding. Forced cooling is not required for the extensions. An inner 6061 tube, which is a close fit inside the main beam tube, extends from the face of the concrete shielding to a point corresponding to the wall of the reflector vessel where it is closed by a hemispherical end. The high pressure region stops at the vessel wall where the high pressure tube is sealed and bolted. However, in the event of a tube failure, the entire beam line could be internally pressurized which would externall; pressurize the inner tube. Consequently this has a wall thickness of $1 / 8^{\prime \prime}$. A window, some way into the tube, allows it to be filled with water to serve as a shield if the beam line is nct in use. Drain lines and a sloping bore allow the water to be adequately drained when required. 
The HFIR notes on experiment facilities require that failure of a beam tube, which allows the inside to rise to tank pressure, must not result in a water leakage greater than 100 gals/min assuming a driving pressure of 1000 psi. Also, such an insert is required to meet this criterion at all tines the reactor is operating.

In addition to this, it would be necessary to meet hydrogen safety requirements considered applicable to the HFIR reactor. This would certainly include enclosing the system in an inert gas blanket. Also, any leakages occurring during on line servicing must be monitored and vented safely. Electrical equipment adjacent to all hydrogen bearing components must meet intrinsic safety standards, or be inert gas blanketed.

\section{A Short Route to Installing a Cold Source}

There are four general ways in which a useful cold source might be placed close to the reactor core, each progressively demanding more modifications to the system:

1) An extension of the inner tube to the inner end of the beam tube would allow a liquid hydrogen vessel to be formed at its end. Since the actual water pressure is significantly below that for which the system was designed, the tube extension could be reduced in outside diameter to provide vacuum space around it. A machined internal window isolates a chamber about $5 \mathrm{cms}$ wide in the axial direction which contains liquid hydrogen as shown in fig 1 . This maintains the required strength of the tube but presents a much thinner wall to the cold neutrons entering the beam line. Part of the heat induced in the new length of vacuum isolated pipe is dumped into the cryogen, and the remainder is conducted to the original tube section to be removed by the water cooled beam tube. It is desirable to provide a helium interface between the liquid hydrogen vessel and a vacuum space to prevent possible cyopumping. However in this case, the wall thickness of the tube described might be regarded as sufficient to limit leakage risks to an acceptable level. This configuration probably represents the minimum changes realistically possible and very importantly represents a device that can be fully tested or tside of the reactor and then be installed very quickly. There are problems that would have be addressed. If for instance the vacuum were to fail, the beam tube temperature could fall low enough to freeze the cooling water outside of the beam tube. However, the thickness of the beam tube could be regarded as sufficient to make the risk of leakage, and therefore cryopumping, acceptably low. Also an insert 13' long would require great care in handling and possibly special handling equipment. The length of small diameter tube, right through to the outside of the shielding, would limit the experimental flexibility of the source. The outer window of the inner tube would have to be removed losing the ability to fill the pipe with shielding water.

2) Better access could be obtained by replacing the outer beam tube section as in fig 2 . The forward tube remains unchanged but a new inner tube is inserted which looks similar to that of the option 1. The new outer beam tube can now be optimized, possible using mirrored guide lines. The cryogenic service lines now exit through the 
light water pool and a window closes the inner beam tube section. A second window closes the forward end of the new guides and the two windows fit as close as possible to each other. A helium filled cavity bridges the space between and the cavity has pressure relief to allow high pressure water to escape to the pool in the event of a failure. This configuration eases some of the shortcomings of scheme 1 , but control of high pressure water loss for long enough to allow safe shutdown of the reactor would have to be considered very carefully.

3) This configuration is similar to option 2 , with the further replacement of the forward tube, ref fig 3. The new tube would be designed to maximize the opening through the vessel flange. Reduced operational water pressure would allow this new tube to be reduced in wall thickness relative to the existing tube and permit a helium blanket to be incorporated. The cryogenic moderator now represents an independent vessel suspended within its vacuum space. An increase in moderator also becomes possible. The most obvious potential problem identified is simply the removal of the vessel flange bolts: if any were to break, which is possible since they have been irradiated and immersed in water for a long time, the consequences could be serious.

4) The final configuration assumes replacement of the beryllium reflector with one providing a larger cavity for the cold source as in fig 4 . The moderator diameter is now limited only by the diameter of the vessel flange. This is the largest moderator that can be installed without replacement of the vessel or enlargement of its entry port.

\section{The Longer Route}

Replacement of the vessel coupled with the use of heavy water rather than beryllium would allow the moderator to be fully optimized. The higher flux densities made possible would justify a completely new guide hall and experiment facility.

Once more there are three possibilities:

1) Retaining the existing vessel would obviously save the cost of replacement and removal and disposal of the original. This is a possibility since the vessel need not be pressurized if the core cooling arrangement were to be changed. However, modifying the vessel ports in situ might prove extremely difficult. In addition, the size of the vessel might not be optimum for a heavy water reflector. Subsequent activation of the stainless steel vessel would be higher to the point at which any future removal might become a more serious problem.

3) Building a new vessel inside or outside of the original would overcome the immediate problem of removal and disposal, but as above, the higher activation might cause future problems and large apertures would still have to be made to facilitate the new ports.

4) Complete removal and replacement of the vessel is the most expensive option but is the best choice for optimization. Vessel size could be decided indejendently and it 
could be made from pure aluminum to minimize activation. Ports and apertures could be positioned as required and it might, if necessary, be made to ASME standards as a secondary containment for the reactor cooling water.

\section{Cold Loop}

The loop would use many of the principles developed for the ANS. It would be a closed circuit with buffer space to contain the hydrogen inventory at ambient temperature. A similar pressure control system would be applied to reduce the total inventory by reducing the pressure of the storage tank to 0.1MPa during cold operation. Two circulators would be incorporated together with cryovalves to allow changeover during operation. Replacement of an off line circulator would also be possible during operation. The circulators and valves together with temperature and pressure sensors would bo in a single unit called the pumping module. Pressure relief systems would be installed to allow for fault situations and gas would be either vented through a dedicated stack, or held for a monitoring period prior to venting.

\section{Refrigerator}

The refrigerator would require a cooling capacity in the region of $2 \mathrm{~kW}$ at $20 \mathrm{~K}$. The compressor section would be housed within the building, if necessary away from the cold box. The helium/hydrogen heat exchanger would be housed together with the pumping module, in a safe room adjacent to the shielding face.

\section{Final Comments}

Both the rebuild and insert configurations appear to be feasible. It might be considered worthwhile to consider the simple installation as a temporary expedient until the opportune time to carry out a rebuild program. In this event the refrigerator would be designed and installed to suit either installation with easy rerouting of the transfer lines.

\section{A.T.Lucas}

4:27:95 

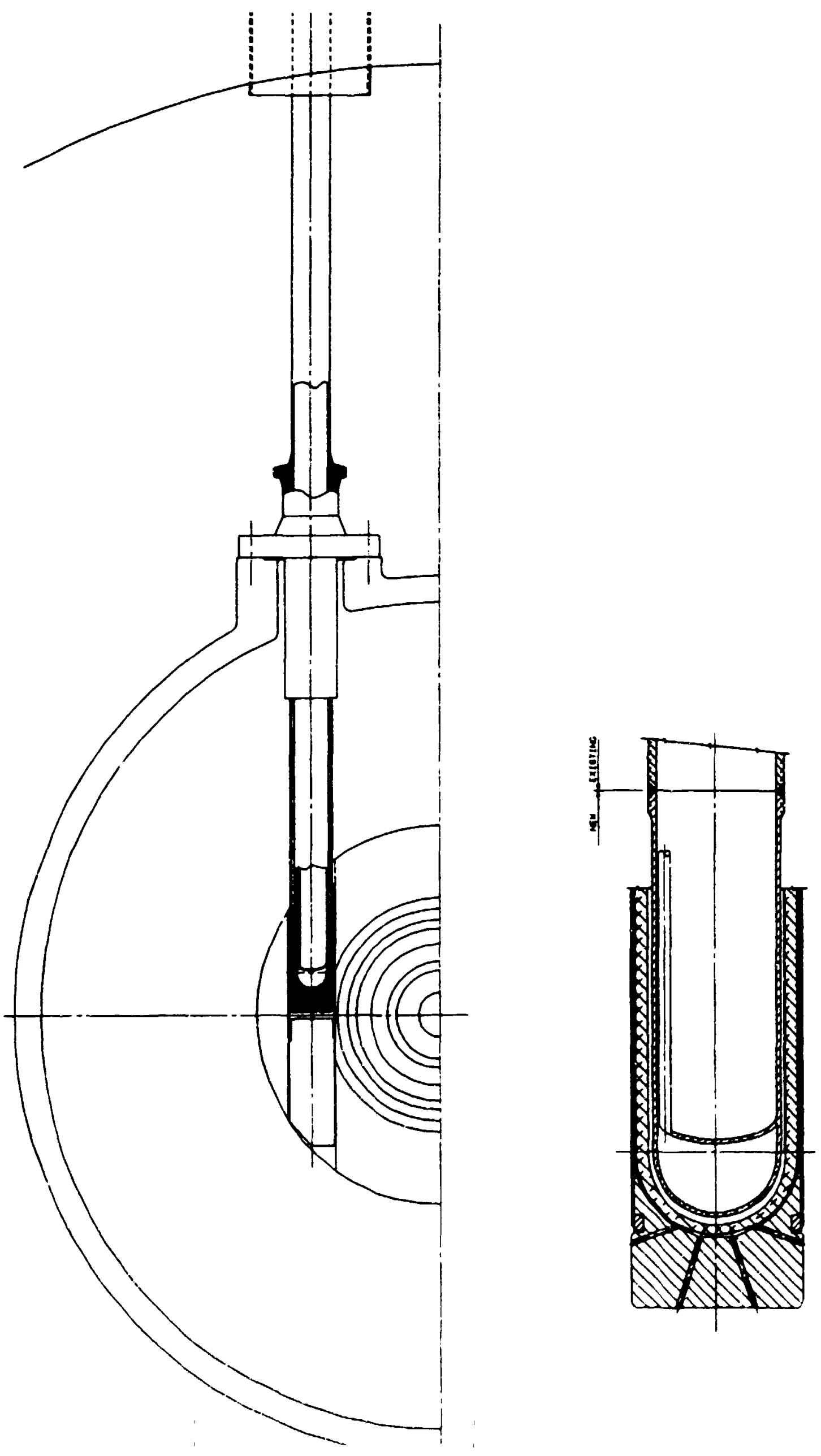

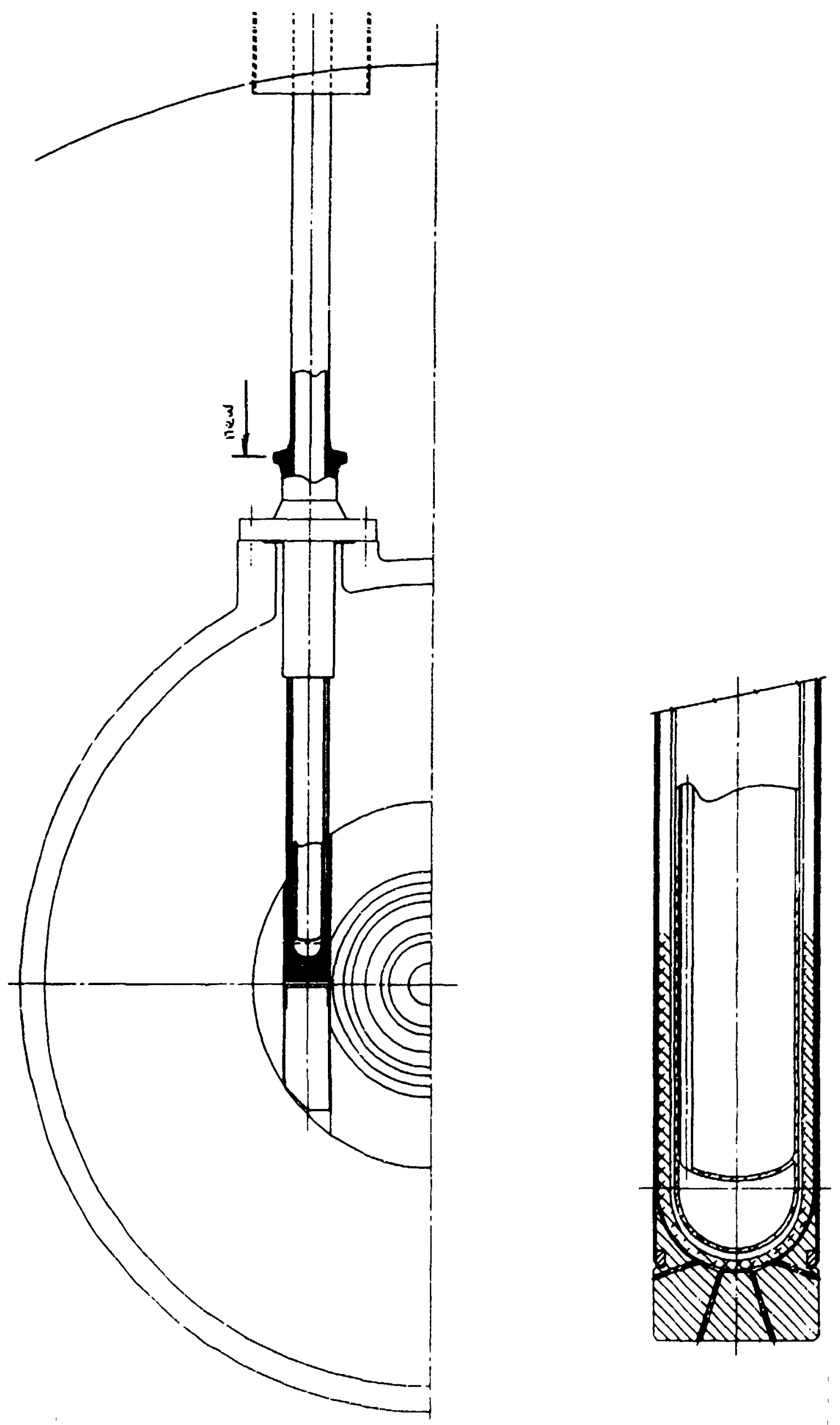

6 

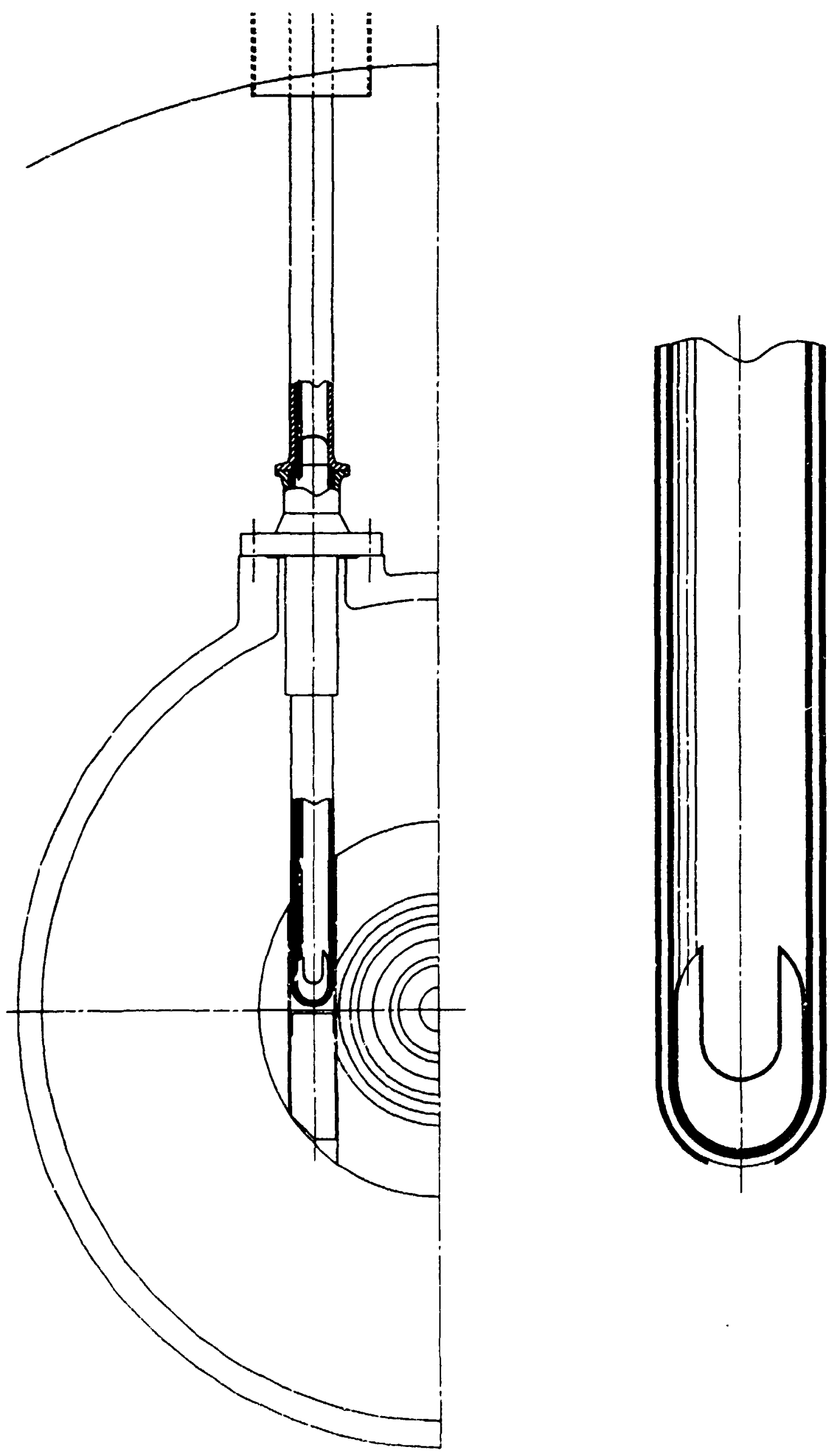

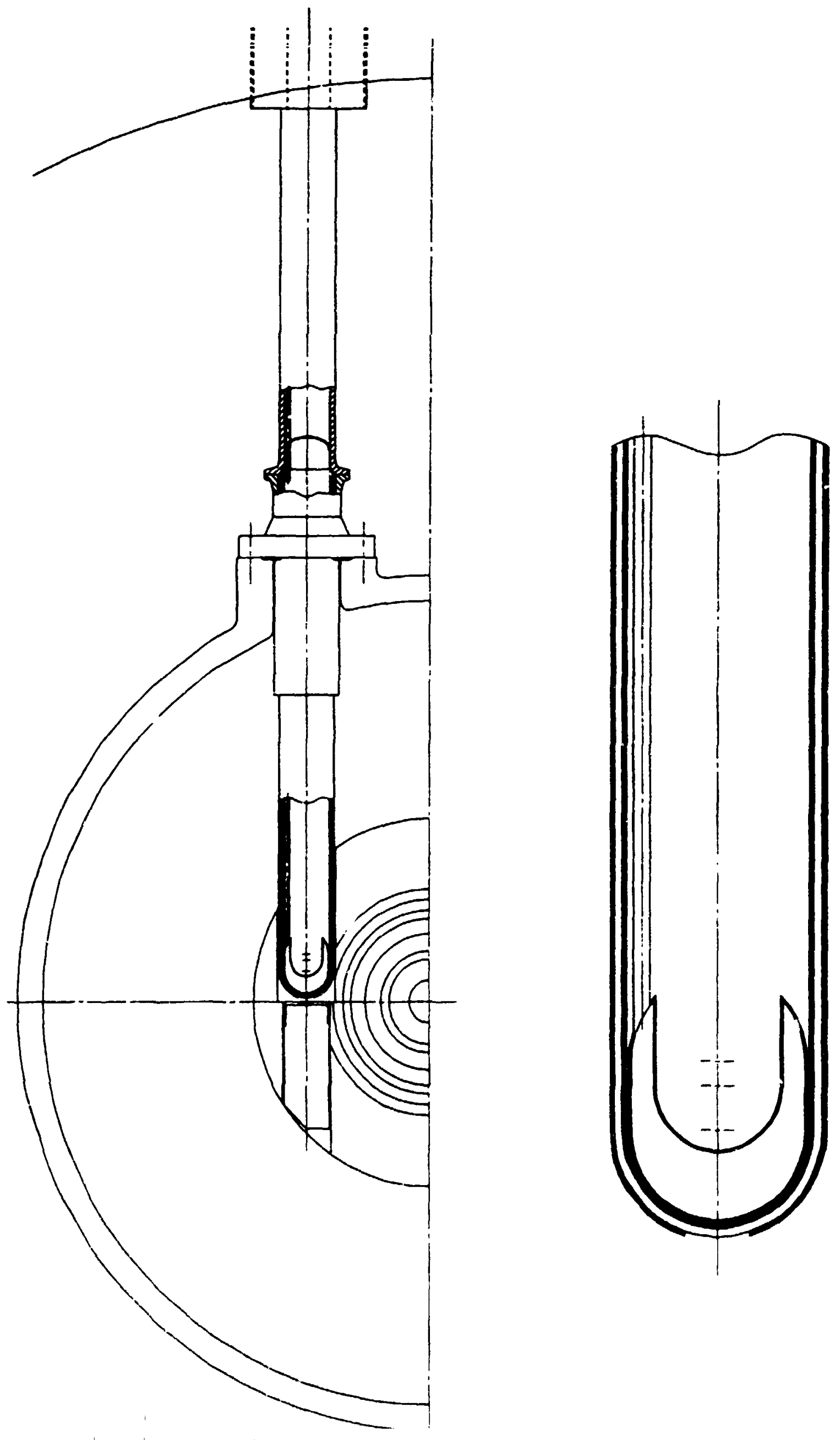
ATTACHMENT 4 


\section{REPORT OF THE HIGH FLUX ISOTOPE REACTOR (HFIR) FUTURES GROUP-DRAFT EXECUTIVE SUMMARY}

The HFIR Futures Group proposed, studied, and evaluated changes that would either enhance the scientific capabilities of HFIR, or extend its operating life, or enhance its accessibility and effectiveness as a user facility. The group also leamed of several things that must be done to avoid inevitable shutdown of operations by certain dates (i.e., obtaining supplies of $\mathrm{U}_{3} \mathrm{O}_{8}$ from $\mathrm{Y}-12$ for Babcock \& Wilcox to fabricate fuel elements, inservice inspection of accessible reactor components, and replacement of the "permanent" beryllium reflector).

The most significant short-term enhancement is to install a small, liquid hydrogen cold source in an existing beam tube. With this, Oak Ridge National Laboratory (ORNL) would provide the United States (U.S.) with cold neutron beams of an intensity comparabie to those available to European researchers at the Institut Laue-Langevin (ILL) and at ORPHEE, while retaining a superior thermal neutron flux. The group believes that this could be accomplished in one to two years at a cost on the order of $\$ 5$ million, which could be available through the U.S. Department of Energy's (DOE) Facilities Utilization Initiative. Careful design and planning wiil allow the cold source system to be constructed and tested away from HFIR and then be transported there for installation and commissioning with minimal reactor downtime. In parallel with this, there are importan! instrument, beam hall, and irradiation facility enhancements that would improve the research and production capabilities significantly and that could be carried out with existing sources of money, including HFIR operating funds and GPP funds.

In addition, and with little or no resources beyond those already available to ORNL, improved analyses and new fuel inspection techniques would permit us to demonstrate that HFIR can be operated safely at $100 \mathrm{MW}$, thus regaining the performance (neutron flux) that was lost when the operating pressure and po'ver were reduced on discovery of the pressure vessel's embrittlement.

The group also identified changes in the user program and its procedures that would increase the effectiveness and accessibility of the facility, especially for non-ORNL scientists. 
Beyond this ongoing program of continial, cost-effective upgrades that we recommend, there will be a tremendous opportunity for a major upgrade to HFIR at the time the beryllium is repi_ad. As a minimum, the new permanent beryllium should be designed with larger holes for beam tubes, larger verical holes for irradiation positions, and a large vertical hole for a new (possioly liquid deuterium) cold neutron source. A more exciting possibility, to which we hope the laboratory will make a commitment, is that the beryllium reflector could be replaced by an annular tank of heavy water, a big liquid deuterium cold source installed, extra beam tubes and neutron guides added, and additional guide hall space, beyond the near-term guide hall expansions we propose, could be built. This would give ORNL, and the nation, a facility with two to three times the neutron beam intensity of the world's best -- the ILL. HFIR would retain capabilir:as for isotope production that are unique in the Westem world. There would still be fewer beams and instrument stations than at ILL because of space and topographical limitatiors, but the available teams would be world beaters.

The rewards of these actions are very great, but to attain them will require both an immediate and a long-term, strong commitment from the laboratory's Executive Committee to promote, encourage, support and, in some cases, fund this endeaver. The need $f \mathrm{c}$ action is immediate because the window of opportunity is rather narrow, constrained by the funding cycle of the Facilities Utilization Initiative and by the need for DOE to focus its plans for improvement and life extension projects across all the department's reactor sites. 
ATTACHMENT 5 
April 30, 1995 draft

\section{Center for Neutron Characterization of Engines and Energy Conversion Components}

Vision To establish unique, neutron based measurement capabilities at ORNL for characterization of engines and energy conversion components. Together with the existing Neutron Residual Stress Facility the new instruments would become the core of a unique center for neutron characterization of engine and energy conversion components.

Targeted Competency The ability to achieve efficiency in engines and energy conversion components typivally requires extensive knowledge of the temperature. intemal structure/clearances/fit, and materials characteristics such as texture. Coupled with the knowlerge of the residual stress state such instrumental capabilities can provide industrial engineers critical design and life prediction data. Utilizing unique neutron sources at ORNL, capabilities for neutron tomography and radiography, for neutron absorption spectroscopy (as a sensitive temperature sensor), and for non destructive texture analysis will be developed and demonstrated. The appendix provides a summary of each of the three deveiopment areas and the science and industrial significance.

Research Team A multi disciplinary team is required to successfully develop and demonstrate the instruments of this center, including:

Camden Hubbard, M\&C, team leader

Michael Wright, 18C, Neutron detector development, instrumentation

Duane Larson (?), ORELA resonance spectroscopy RRD, Tomography and slant tube development

Steve Spooner, SSD, Monochromator development, metallurgy

Stan David \& Daniel McGuire, M\&C, Tomography, radiography, metallurgy

Kris Kozaczek, M\&C, Texture analysis, metaliurgy

Tad Dodson, M\&C, Advanced instrument control and automation

Significance \& Relevance Neutron based materials characterization for engine and energy conversion components is a growing competence for ORNL due to the Neutron Residual Stress User Facility (NRSF) developed under LDRD support and now funded jointly by EE and ER. During the interaction with users at the NRSF, the realization of the neutron's unique capacity as a non destructive, intemal probe has lead to requests for capabilities to measure temperature, structure, and texture within the volume of a specimen, just as is done for residual stress mapping. The development of these capabilities builds on ORNL's core competencies in Advanced Materials Characterization and Neutron-Based Science and Technology while complementing Energy Production and Eno-Use Technologies.

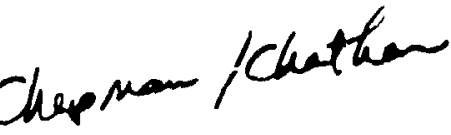


Besearciz Qutline Each of the three measurement developments and demonstrations will be conducted by teams composed of research team members and supported by post doctoral staff. Demonstration projects will be selected with industry input and with potential sponsors' needs in mind.

Future Sponsors Demonstration of the capabilities should lead to DOE, other agency, and direct industrial support, potentially including operation as a User Center. Within DOE the targeted potential sponsor is Energy Efficiency and Renewable Energy Office of Transportation Technology and Office of Industrial Technology, which together sponsor numerous projects to improve engine efficiencies and energy conversion technologies. Among other agencies, NASA could be a prime sponsor due to their emphasis on jet turbine engines. Within DOD, for example, the Army would benefit from improved diesel engines. In the industrial segment, companies such as GE Aircraft, Detroit Diesel Corporation, Cummins Engine, Caterpiliar, Westinghouse, Pratt Whitney, Boeing, Ford, ... who have already begun to develop working relationships with the HTML's NRSF will likely expand their involvement with ORNL through use of these measurement capabilities.

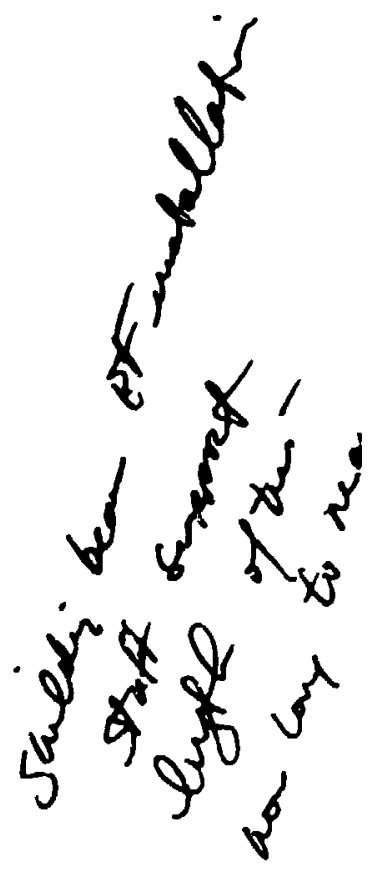




\section{Appendix}

The tomography/radiography measurement development will utilize the unequalled flux of HFIR to achieve a unique U.S. capability in depth of penetration, resolution, and speed of measurement. The long term concept is to develop one of the "slant tubes" (basically unused capability at HFIR) by design of shiolding and use of a pyrollitic graphite monochromator to deliver a highly intense mono energetic neutron bearn with near parallel beam optics. Initially, short duration experiments with lower resolution and complexity could be performed with borrowing time on one oi more existing beam lines such as HB-1B or HB-2. Development of a 2-D fast, high resolution detector will be pursued to further enhance the measurement capability. This same detector will augment the texture instrument. The demonstration experiments will be selected to show the unique measurement attributes of neutron radiography and will utilize the analysis capabilities built up as part of the NDT Group of M\&C.

Neutron resonance spectroscopy has been a significant component of ORELA activities for years. The application of this capability as a temperature probe for components within operating engines in a non invasive manner holds great potential for improving engine design in the U.S. and for providing a capability currently in use in Europe by companies such as Rolls Royce. Exact knowledge of an engine material's temperature is one of industry's most frequent requests due to its impact on efficiency and material's performance. Coupling with ORNL's efforts in Engine materials and operational characterization requires developmer.. of facilities to permit measurements on real engines in operation. Demonstration projects should involve measurement on test systems and then on operating diesel. internal combustion, and possibly turbine engines. Affiliation with the Neutron Residual Stress Facility - HTML and the other proposed neutron characterization proposed resources would greatly expand visibility ind potential for future DOE, other agency, an.d industria! sponsorship.

Texture within a component can only be determined by destructive means today. Use of neutron diffraction similar to that used for residual stress mapping methods will enable internal mapping. This measurement capability will be deveioped as an attachment to the neutron residual stress mapping facility. To achieve adequate speed of measurement, one must sample a large fraction of reciprocal space. To do this a 2[D detector will be developed based on concepts recently tested by I\&C at HFIR for other instruments. The complimentary nature of neutrons and $\mathrm{x}$-rays will be coupled by involvement of $\mathrm{Dr}$. Kris Kozaczek, lead scientist for $\mathrm{x}$-ray measurement of texture and residual stresses in metals. Users of the $x$-ray facility typically couple the measured texture with understanding of the anisotropic materials behavior due to non random grain orientations. The surface mappings by $x$-rays and through thickness mappings by neutron are essential to proper modeling of metals processes and performance. 
May 16, 1995

HFIR Futures Group Meeting

Altendance

The HFIR Futures Group held its ninth meeting at 9:00 a.m. on Monday, May 15, 1995, in the Blue Room of the FEDC. Those in attendance were:

Jim Ball (observer)

John Bigelow

Emory Collins

George Flanagan

Mike Harrington

John Hayter

Michele Houser

Peyton Moose

Larry Robinson

Ken Thoms

Colin West (chair).

\section{Opening}

The meeting began with Colin West asking for any changes to the notes from the May 8 meeting. George Flanagan commented that the section conceraing the DOE officials' stay at ATR needed to be amended to reflect the fact that the officials are still there. This change will be made to the notes from that week. The meeting proceeded according to the agenda shown in Attachment 1.

\section{Possible Executive Committee presentation}

Colin then told the group that he had been able to get on the Executive Committee agenda for this week's Wednesday meeting to talk about the progress of the HFIR Futuies Group. He said he could tell the Executive Committee that there were three blocks of suggestions--in-house initiatives, significant cost items, and major cost items. The leading itern would probably be the installation of a cold source at the HFIR under the Scientific Facilities Initialive. A major upgrade of the HFIR would also be desirable and would not necessarily be detrimental for the spallation source project. Colin then went through a compiled list of in-house initiatives which could be presented to the committee (see Attachment 2).

John Hayter remarked that it was important w get user agreement by doing the Monte Carlo MOCUP model promptly. He also had some questions about the increase in power to $100 \mathrm{MW}$. John $\mathrm{H}$. remarked that it would not be good to have a long downtime for a mere $10 \%$ increase in power. George told him that this would not be the case. 
Colin mentioned that RRD has an alternative proposal to make for Larry Robinson's suggestion of taking some existing storage space in the HFIR reactor building for use as laboratory facilities for neutron activation analysis. George said that RRD thought a block building could be added to the building to expand the facilities for neutron activation analysis. This block building would be outside containment, thus allowing the alterations to be done under less-stringent rules.

John $\mathrm{H}$. mentioned that the new instrument layout proposed was constrained by the current building configuration at the HFIR. He auggested some wording such as "more effective use of existing beams in the space available." The name of the program involving funding for the upgrade of national labs, the Scientific Facilities Initiative, was clarified in the discussion. Jim Ball remarked that there was still a lot of support for this program in political circles, even though it is in the Congressional committee process right now.

John Bigelow commented that Chuck Alexander had suggested adding burnable poison to the transuranic targets in order to harden the spectrum. John B. currently has some experiments underway to ascertain methods of hardening the spectrum and should be able to analyze the results soon. He is using solid aluminum targets as dummies to displace a substantial amount of water.

Questions arose about the redesign of the so-called permanent beryllium. George said that he believes that its redesign included all elements associated with redesign. The funding associated with the refurbishment is currently from Peyton Moore's program, but George nought that other items could be included since a change was in place anyway.

The item having to do with the increased capacity of the pneumatic tubes was discussed. Larry said that he was mainly interested in accommodating larger pneumatic rabbits. The one $\mathrm{cm}{ }^{3}$ pneumatic tube located in EF-3 could probably be replaced with a tube that could accommodate a $40 \mathrm{~cm}{ }^{3}$ rabbit. The total number of pneumatic tubes vould still be two: Lany thought the cost would be in the range of $\$ 200 \mathrm{~K}-\$ 300 \mathrm{~K}$.

Mike Harrington had some questions about the items that appeared to be low or no cost He questioned the drain on significant resources, especially with regards to the beryllium replacement and the change to $100 \mathrm{MW}$ operation. Mike asked if the update of the SAR would require significant re-prioritization of other work. George remarked that design changes are a continuous loop of two parts-an analysis process and a design process. When a design is changed, the SAR has to be re-done before the design can be implemented. After the change is made, the analysis is then verified. For example, arnund $\$ 1$ $M$ is estimated for the update of HFIR's SAR to upgrade to $100 \mathrm{MW}$ operation. Most of this cost is for RRD staff time. George said that RRD tries to do most of the work in-house, but when it comes to the question of available staff, some work is allocated to sub-contractors. If the SAR is being updated anyway, one more item added to a list of changes to be included in the update is no additional drain on resources. John $\mathrm{H}$. asked if the change to $100 \mathrm{MW}$ power would change the fission product loading, and George said it would not.

Colin then showed slides of items which were of significant or major cost (see Attachment 3). Colin will combine the two items having to do with changes in the reactor top head. George reiterated the need for 6 pneumatic rabbit posiisons in the target area. Colin suggested that the "install new reflector vessel" item be supplanted by RRD's proposal to put a D ${ }_{2} \mathrm{O}$ tank inside the existing vessel and replace the beryllium with deuterium. Colin had estimated this improvement to cost around $\$ 79 \mathrm{M}$, whereas George thought it would require around $\$ 100 \mathrm{M}$ : Colin conceded the point. 
Colin then went on to mention the fact that the Executive Committee was most excited about placing a small cold source in an existing beam tube. Members of the Executive Committee think this would work and seem to be interested in seeing this installation ac:ilaliy happen. Colin said that he was comfortable with the estimate of \$S M beyond RRD's usual budget for this small cold source installation.

There may be another possibility for an even better design for a cold source than the one for $\mathrm{HB}-4$. John $\mathbf{H}$. has done some work with super mirrors, which offer greater reflectivity of neutrons (see Attachment 4), and has invented a configuration that can act as a fast neutron and gamma filter. NIST has been a tryiug ground for some of the concepts associaied with super mirrors, although all of them have not yet teen tested as proof-of-principle. By using super mirror technology, a cold source could perhaps be instai'ed in HB-2, which has a larger diameter flange and bole, as well as a higher flux (if filtered properly). This technology only works on cold neutrons, so benefits from these concepts could only be realized if a cold source were installed. However, John $\mathrm{H}$. says it is always better to avoid looking at a noisy source than to than to filter it! This possibility needs more exploration in the funure.

There was some discussion about the I \& C upgrade item. Mike mentioned that Ron Battle had said that these upgrades could be done incrementally, tst requining \$5 $\mathrm{M}$ all at one time. George teplied that at some point, all control systems have to be upgraded at once. The question was asked if the NRC had ever ruled on digital control systems. It was remarked that Idaho had recently updated to an al!digital system. but Idaho is not regulated by NRC. Colin concluded his remarks about the Executive Committee presentation by saying that he planned to leave a copy of the draft Executive Sumnary (see Attachment 5) with the committee.

\section{Status of action items}

There were no major comments on the updated proposal lists, and Ken Thoms did not yet have wording concerning the hot cell upgade idea. John B. had faxed comments to Michele Houser conceming the PTP positions, and his input had been included in the latest revision of the proposal lists. Michele had gotuen some input from Trevor Lucas on the cost of the proposed cold source refrigerators. According 10 Trevor, the cost of the "economy model" cold source refrigerators at the HFIR would be from $\$ 2.5$ $\mathbf{M}-\$ 3 \mathrm{M}$, but in some information received after the meeting, it was noted that this cost could perhaps be lowered. If a liquid nitrogen pre-cooler is used, the cost would drop 10 around $\$ 1.5 \mathrm{M}$. However, this system would be more complex than the configuration of the original "economy model." Colin remarked that he had gotten some comments on the draft Executive Simmiary from Jim and others, and said that he would entertain other comments on the summary or the tables before his presentation to the Executive Committee. 
Any other business

Ken had some information concerning the vessel replacement at the Petten facility. He passed the unofficial cost figures on to George after the Futures Group discussed some particulars about the Dutch facility. The group then adjourned unil March 22.

M. M. Houser, May 16, 1995

\section{ACTION ITEMS}

Colin will report back to the group on his meeting with the Executive Committee.

Ken will complete some wording concerning the hot cell upgrade idea.

Distribution

HFIR Futures Group Attendees (notes for record + Altachment 4)

J. E. Bigelow, 7930, MS-6385

E. D. Collins, $7>30$, MS-6385

G. F. Flanagan, 7917, MS-6398

R. M. Harrington, FEDC, MS-8218

J. B. Hayter, FEDC, MS-8218

M. M. Houser, FEDC, MS-8218

J. P. Moore, 4508 , MS- 6080

L. Robinson, 4500S, MS-6128

K. R. Thoms, 9108 , MS-8087

C. D. West, FEDC, MS-8218

For information (notes for record + all atiachments)

B. R. Appleton, $4500 \mathrm{~N}, \mathrm{MS}-6240$

J. B. Ball, $4500 \mathrm{~N}$, MS -6182

R. E. Battle, FEDC, MS- 8218

H. A. Glovier. 7917 , MS-6398

H. A. Mook, 7962, MS-6393

D. E. Reichle: $4500-\mathrm{N}$, MS-6253

J. B. Richard, 7962, MS-6391 
ATTACHMENT 1 


\title{
AGENDA FOR \\ HFIR FUTURES GROUP MEETING
}

\author{
Monday, May 15, 1995 \\ 9:00 a.m. \\ FEDC, Blue Room
}

- Discussion: Changes or corrections to 5/8/95 meeting

notes for the record

- Status of action items

- Comments on updated proposal lists

- Wording for hot cell upgrade

K. R. Thoms

- $\quad$ Phrasing cencerning access to PTP positions

J. E. Bigelow

- Cost of cnld source refrigerators

M. M. Ho'user

- $\quad$ Reponse from draft Executive Summary

C. D. West

- Any other business 
ATTACHMENT 2 


\title{
PROC. SPIE $1738,2(1992)$
}

Newron optics at the Adveced Neatroe Sounce

\author{
John B. Hayter \\ Solid State Division, Oak Ridge National Leboratory \\ FEDCNAS-8218, P. O. Bax 2009, Oak Ridge, IN $37331-8218$
}

\begin{abstract}
ARstuCT
The Advanced Nentron Sowree (ANS), aurenth in conceptonl desigen at Oal Ridge National Laboratory, will be a multipurpose neutron research hborntory senving the seeds of scadesic and industrial wers throughout the nation id

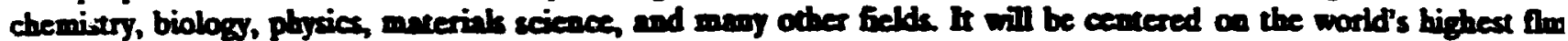
neutron beam reactor, but that is only the anties point for ensuring high produciving, which will be entwaced further

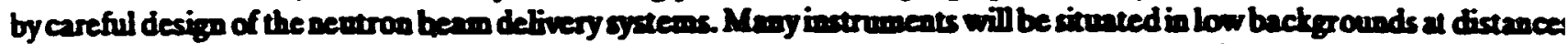

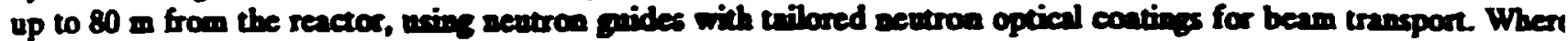
appropriate, multilayer optical coatings will also be med in bean focnesing (and sometimes defocussing) devices. Certain

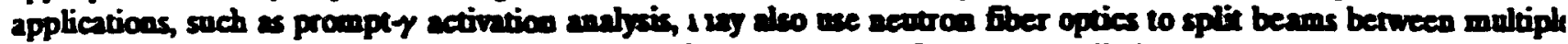
samples. Neutros optical techniques weh a interferometry and reflectoneary will form a basic part of the rescarch

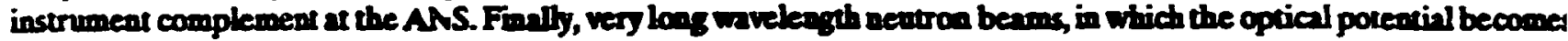
very large, will be provided for specinlized research.
\end{abstract}

\section{INTRODUCTION}

The Advanced Neutron Source (ANS) is a new research facility plansed to be operational at Oal Ridge at the atar of the nex decade. The primary gal of the facitity is 10 provide the world's best semton scatteriog apabitities for research in condensed-matter physics, fundameatal and melear physich, polymer and colloia science, metak, alloys and cer amics, chemistry, biology and medecine, materials engineering and other areas. To this ead, the L-ant of the facilit is a steady-state research reactor providing a thermal fhe of a leant $5 \times 10^{19} \mathrm{~m}^{-2} \mathrm{~s}^{-1}$ with hot and cold sources for spectral tailoring and a suite of state-of-the-ant instrumentation. The reactor will also provide materials imadiation and isorope production facilities, especially for transuranic isotopes anch as ${ }^{252} \mathrm{CC}$

Neutron beams are exuracted from the heavy water reflector by beam tubes which either penetrate into the peal thermal flux region (about $400 \mathrm{~mm}$ from the center of the $500 \mathrm{~mm}$ diameter reactor core) or view the bot source. Hot beams terminate in the beam room on the ground foor of the reator coatsiment boilding . Thermal beams ma terminate either in the ground floor beas room (horizoatsl besms) or in a second foor benm room (slant beams). Cold neutrons are transported from one or other of the two liquid deuterium cold sources by borizontal neutron guides into a neutron guide ball adjacent to the containment building, of by slant guides to the secoad floor. Very cold nentron (VCN) are transported by two $S$-bent guides to a research area on top of the shielding structure which contains the horizontal cold guides as they pass through the ground foor beam room. One of the VCN beams will feed a turbine convertor to produce ultracold neutrons (UCN) for fundamental pluysies and other research. The other VCN beam wit be dedicated to a neutron optical station. Apart from this and other stations dedicated directly to neuron optica studies, ${ }^{1}$ extensive nse will be made of devices such as focousing monochromatons and the beam and guide geometrie have beeo optimized with this in mind.

\section{THE BEAM ROOMS}

The ground floor beam room (fig 1) will be the primary area for seatrering research with hot and thermal neutrons. The curreat layout assumes that, apart from a single through tube for auclear physice, all thermal teams will lie in the same plane. The representative mix of instrumests shown is wh at would be built if the facility were available today. Since the desired instrument complement is likely to e volve before the facility is operational, the beams are all equivalent and optimized for the "worst-case" instrument in terms of minimum desired horizontel and vertical divergence requirements Alehough we cannot predict the detailed experiments likely to be done a decade from now, the general evolution of 
Which repions are of interest in $\left(Q_{0}\right)$ spece parnits an andyis $\alpha$ inetrument oppes and focussing requirements. This he led to a choice of thermel and bot bean ine $100 \mathrm{~mm}$ vide by $200 \mathrm{~mm}$ high

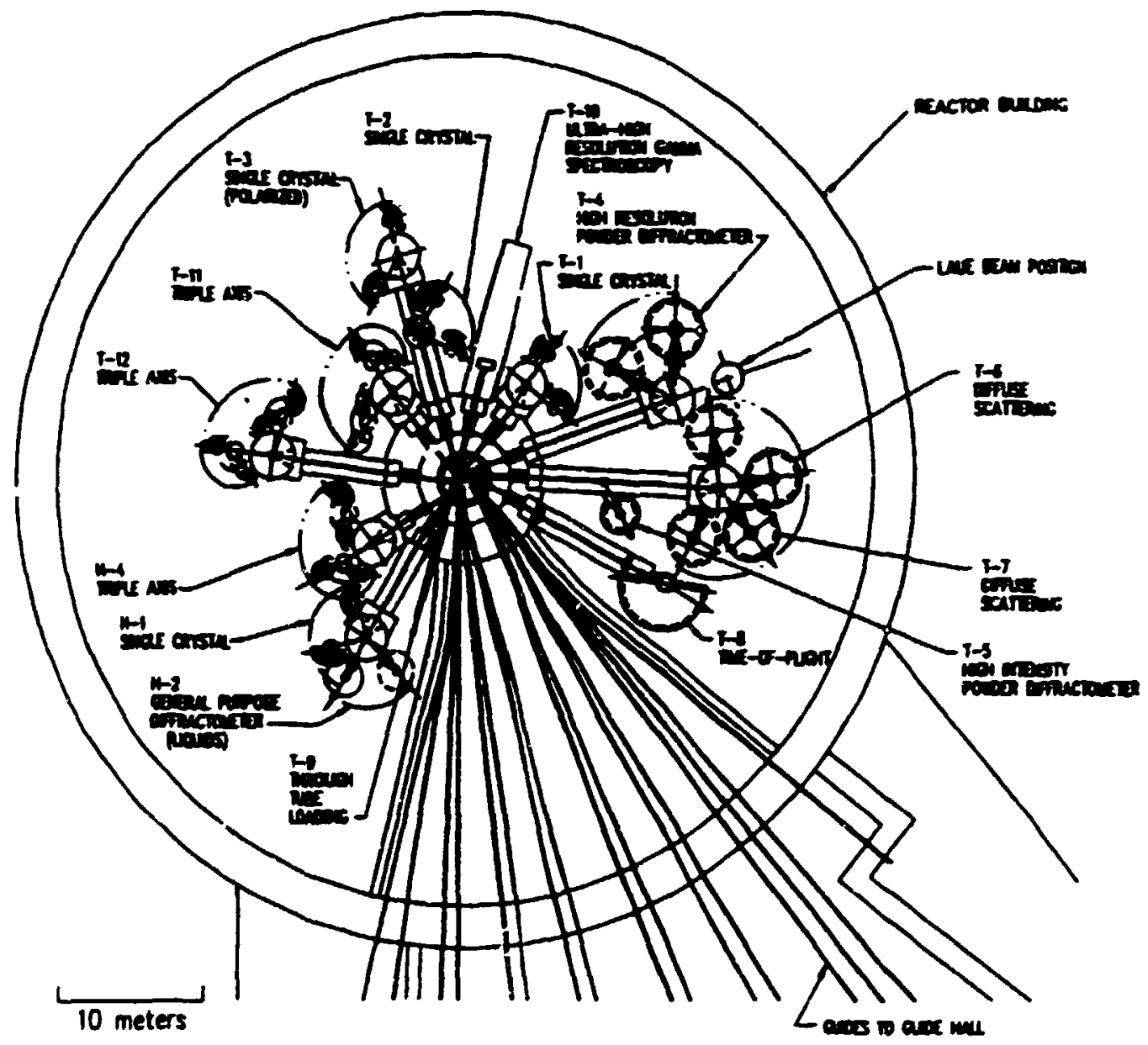

Fig 1. The growad floor beam room.

Many instruments, for example high resolution difractometers, require a high-angle monochrosator takeof. Others, such as triple-aris spectrometers, require wide sweeps to aceomodate high-angle anslyzer pocitizens. In most reactor installations to date, these angular ranges have been compromised by the geometrieal coastraints imposed by trying to masimize the number of insuruments while keeping each instrument as close to the reactor as possible. The layour shown in fig 1 is predicated os the use of supermino thermal guides 10 allow some imatruments to be stood awny from the biological shielding in such a way that each instrumeat an be configured optionally for high resolutios work.

Thermal-beam scatrering instnuments for diffraction include 4-circle diffuratometers on a thermal tube (TI) or supermir or guide (T2). A polarized beam is eariarked for single-crystal diffraction (T3) bou, in geseral, is is expected that polarized neutoss (and polarization analyais) will be routinely available whenever warnanted ca any iestrument on the ANS. This poses a challeage for enpermirror polarizes desiga to produce neutron optical polarizers (and analyzern) which can be used as insertion devices (probsbly in the form of supermirror-on-silicos atacks) at thermal wavelengthe, so that monochromator optics can be optimized for any given experiment independently of any polarization function.

High resolution (T4) and hipb-intensity (TS) powder differactometen and two diffuse scattering spectrometers (T6/7) complement the single cryual instruments. Tume-of-Right (T8) and triple axis spectrometers (T11/12) are also provided. 


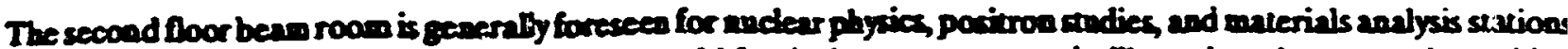
Neutron depeth profiling ill be provided on a slans cold for the buter porpose and will require mirrors or microguides to split the beam into several five, shallow beans for surfice stodies.

\section{TiE CUDS Ball}

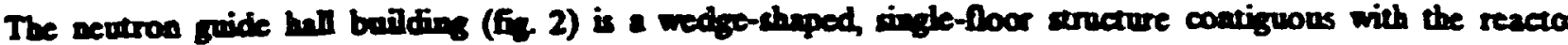
containment building and oficoshaboratory complex

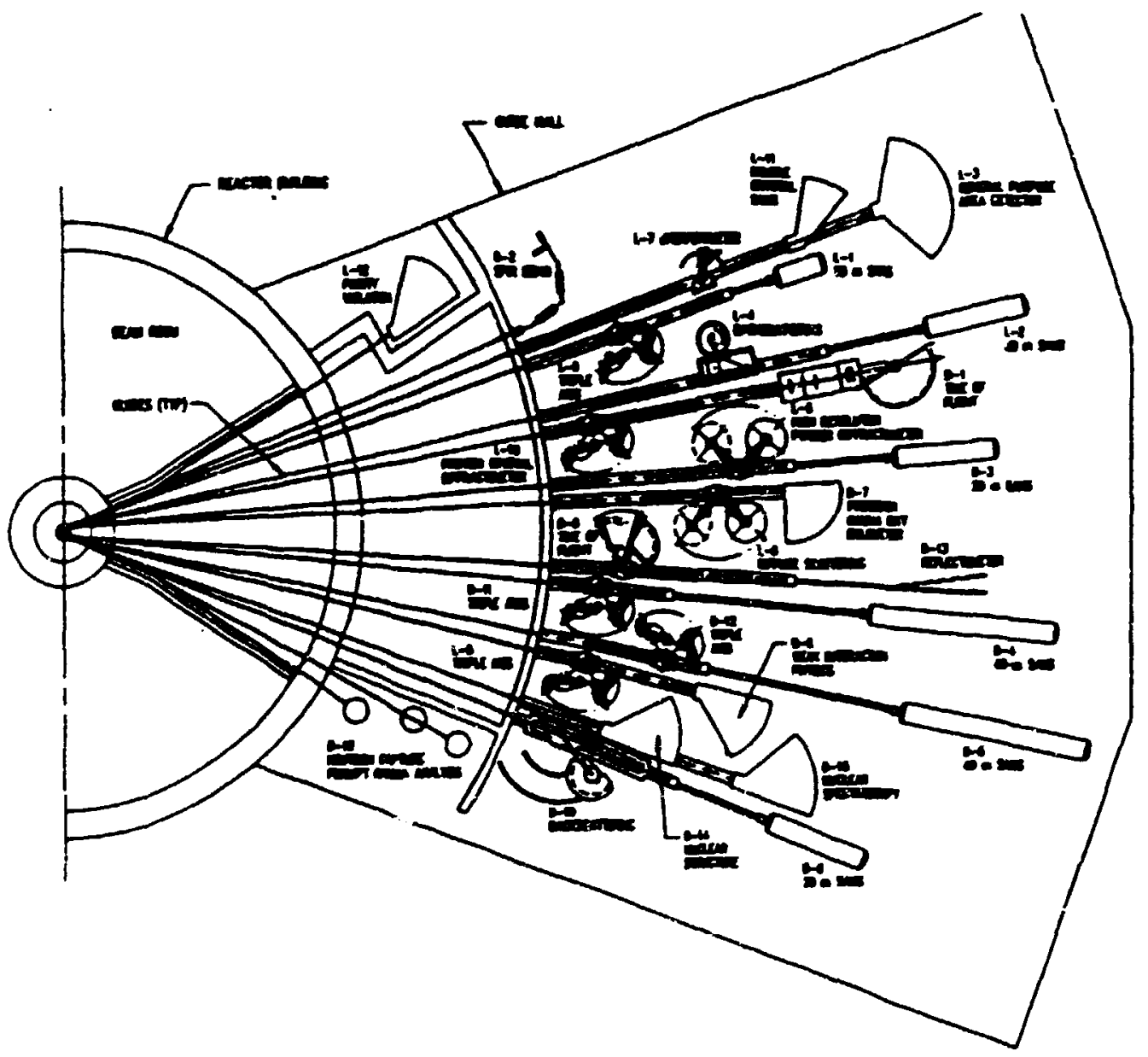

Fig. 2 The cold seutroo guide hall.

Seven borizontal guides emano:e from eacb cold source (see fig 1), pass through containment, and enter the gaid ball, remaining inside a common shiclling area until they have diverged sufficiently to allow cuficient space for instrument placement. For the sam. ansons as the thermal beams, all guides are equivaleat to allow a find choice 0 instruments to be made much closer to start-up. Consideration of instrumeat configurations with focursing devices ha led to a choice of guides $50 \mathrm{~mm}$ wide hy $150 \mathrm{~mm}$ high for the concepnul design. However, unlike the beam tubes (whic affect the reactor), this choice can be modified to some extent during detailed design, provided it does notchange esoup to impact the cold source design. The six innermost guides in each balf of the guide hall are all straight; possible fiter for fast neutrons and gammas will be considered in the next section. Unlike curved guides, straight guides allow th width to be chosen independen ty of the length, do noe distort the intensity profile, transport cool as well as cold neutron and transmit the source divergence unchanged. The latter is imporant at wavelengths such that the critical angle of th 
gride conting exceeds the divergerece limitation imposed by the gride/cold cource froen-ead geometry, a curved guide would increase the divergence to rvice the critical asgle at these waveagths regardless of the initial illumination

The straight guides will have sapermirror contiogs top and botto to provide adequate vertial divergeace for instruments, such as triple ares, which nse focussing monochrommors. The choice of supermirror contrings for the sides

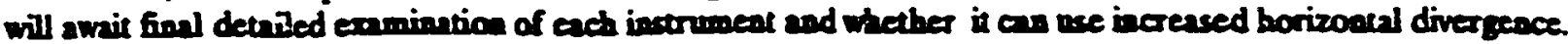

About one-third of the cold severon stations provided are for anclear or fundnmental physics applications The moat prevalent scattering instruments are the mall-angle canterins cameras (D3-6, L1/2 and L11), which will ofier varying degrees of resolution and at leat one of which wit have reflecteneter copabitivia for surface studies. Diffuse scatrering and high-resolution ponder diffraction will be avilable (LS/O), together with a geseral purpose area detector for

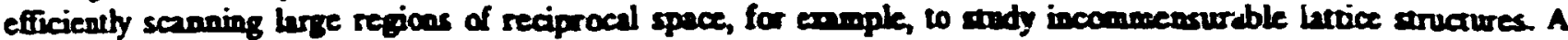

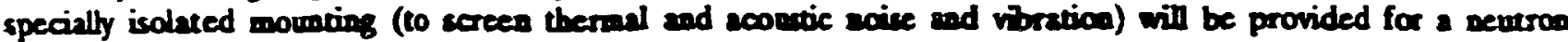
interferometer station (L7). Conventional, focussing mosoctromice cool and cold veutron triple-axis spectrometers will be the basis for inelastic scattering sndies in the goide hall (D11/2, L89/10), Logether with mukichopper (D1) and time-focussing (D9) time-of-flight spectrometers. High-resalmion bxckestering spectrometers (LA, D10) will use crystal focussing in two dimensions; cerrain triple-asis experiments my abso use this form of focussing.

The outermost guide ca cach cold source is for a dedicated porpoee. Each of these gaides is composed of imo staright segmeals separated by a neutron bem beader. The station D-16 uees the defiection to provide a very clean beam in a low gamma-background area for prompt-pamms activation andysis studies for snatytical cbemistry. This beam will be split into several smaller beams sufficienty separied to permi muhiple samples to be anvilyzed simultaneously. A final decision on how to split the teams hes not been taken, bat the use of microgmides' may provide an attrative future opiion to conver a large beam into many amalt-sample stations. On the cther side of the gride ball, the ourermost guide is caken into a polarizing beam splitter and a polarized beam is transported to a special area for studies, soch as parity violation, which use liquid bydrogen or other potencilly dangerons enmplex. The other spim-atate will be transported to feed a seuron spin-echo spectroneter.

Many of these instruments provide challeages for aeutroe optical desigen, for ex-mple to focus small-angle seattering or spiv-echo beams using toroidal or other mirror geometries, or anti-trompene focussing devices for beam compression, either to allow smaller samples when the increased dirergence is acceptable, or to minimize the vindow size in fase choppers for time-of-light spectrometers.

\section{OPMCAL FILTERS}

One of the main advantuges of struight grides is that cool nevtrons (wavelengths of order 0.2-0.4 am) are transported as well as cold neutrons. This has a corresponding disadvatage, aamely that fast aeutron and gamma noise is alos transported to the instrument since it looks directly at the cold source in the reflector. Instrments on sinight guides at the ANS start at least $50 \mathrm{~m}$ fom the reactor, so that distance improves signat-to-boise substantially, simce the sigad is transported within the guide while the noise diverges as $2 \mathrm{r}^{2}$ Experience at the National lnstirute for Standards and Technology, which has installed straight guides, indicates that this is generally adequate. However, it will abmost certsinty be desirable to provide even lower noise for cenain difficult experiments in the guide ball and we are atudying fikers (such as cooled single-crystal silicon and other crystals) which may be used as insertion devices in the froant eads of the guides. An atrernative possibility being studied is to use a neutron opticil deflector as a filter. This deflector should have the characteristics of a bandpass filher which only transports neutrons above a minimum wavelength, but which preserves the beam diver gence while bendiag the transported beam sufficiently away from the initiv direction that the fast neutron and gamma noise may be stopped well upstream of the instruments.

Fig. 3 shows one possible concept for this type of optial filter. Conceptually, it is equivaleat to one sectico of a polygonal app=oximation to a curved guide. The initial Ni guide of width $d$ is followed at as angle $\gamma$ by a leagth os supermirr or guide (SM), afier which the Ni guide contiuses at a further angle $\gamma$. This geometry has the property that a parallel beam is transported unctanged, unlike the case of a curved guide. If $\gamma$ is taken to be the critical angle for $N_{i}$ at the shorest wavelength of interest, the supermirror critical angle must be twice that of $\mathrm{Ni}$ 


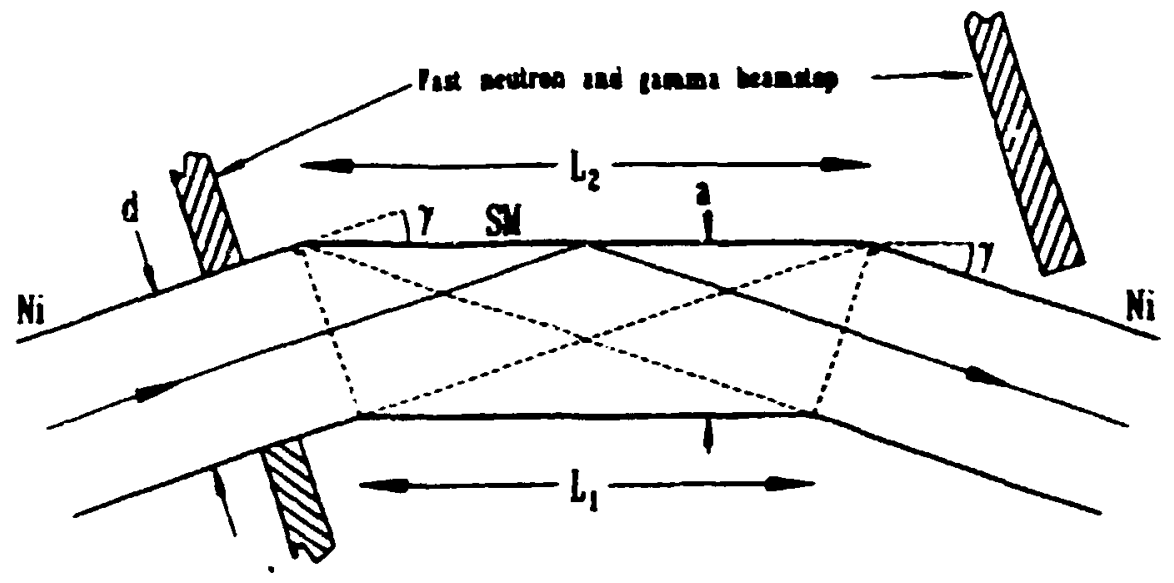

Fiz 3. Fin view of optical fither geometry.

For this geometry,

$L_{2}=d / \sin$

$L_{1}=L_{2}-2 d$ sing

$a=d \cos y$

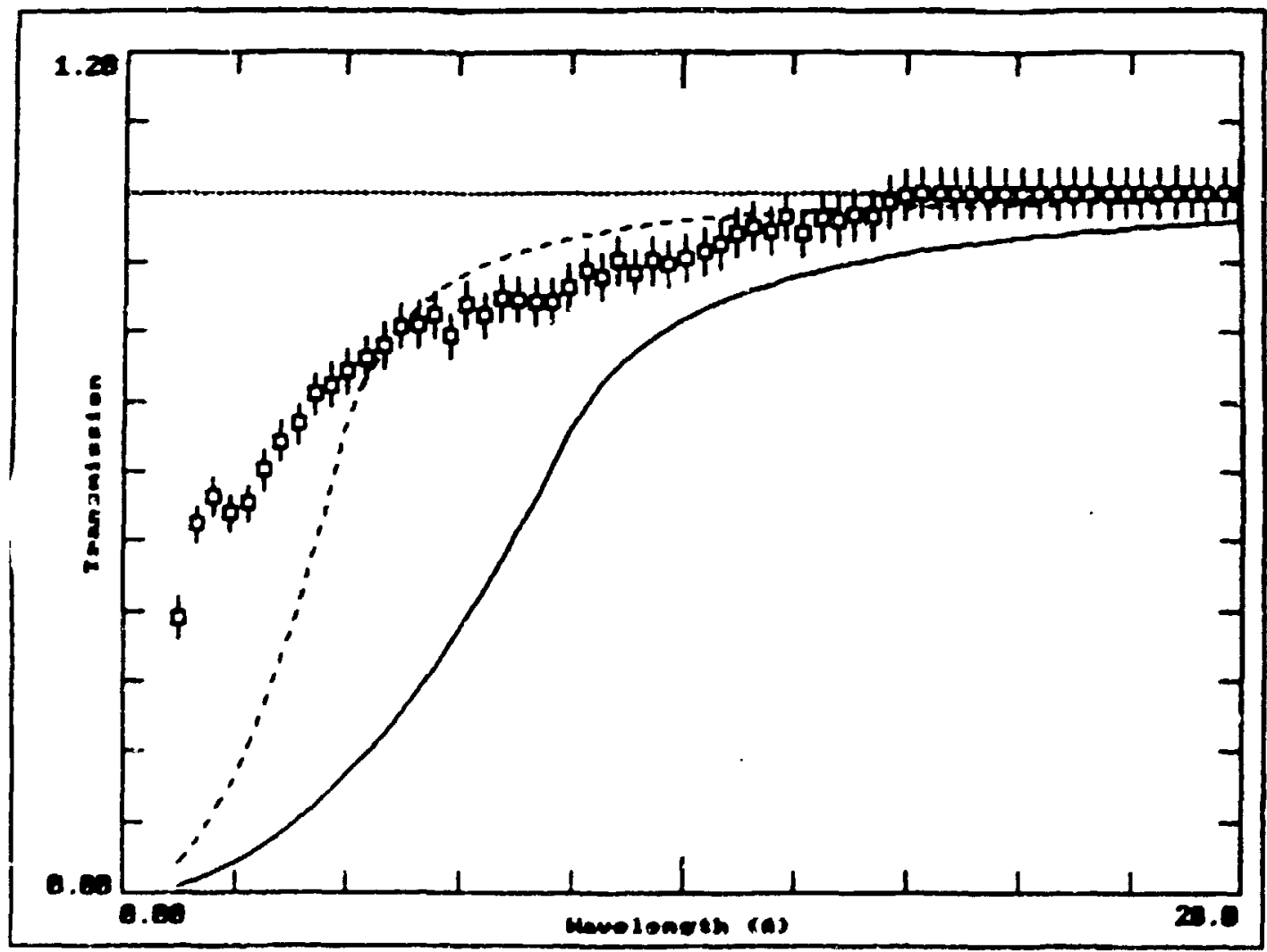

Fig. 4. Transmission as a function of waveleagab for seraight and curved optical filers (see tead). 
If $\mathrm{d}=50 \mathrm{~mm}$ and $\gamma$ is choces as the crition ande for $\mathrm{Ni}$ a $02 \mathrm{am}$ charcteriatic waveleagth, a $=50 \mathrm{~mm}, L_{1}=14.323$

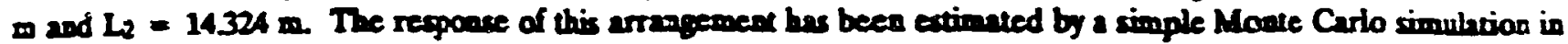
which the divergence in the Ni gride was tatea as uniform within the anglar range correspondiag to each wavelength

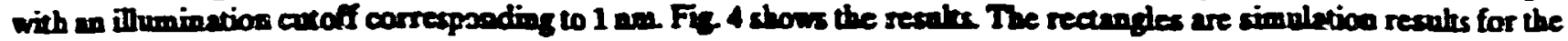
device of fig. 3. The solid tine is for a curved $\mathrm{Ni}$ gride of the same leaph as the fiter and the dashed line is for an

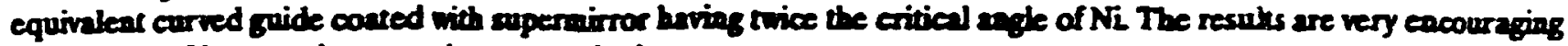
and studies of inproved geometries are continning.

\section{Actarow DocEMENT}

I have benefitted fros discuscions with W. A. Hamiltos asd I. J. Mekennmy about acutros optical fiker geometries. Oak Ridge National Laboratory is managed by Mertin Marieta Energy Syterm, Inc, for the US. Departwent of Energy under Contract No. DEACOS-810R21400.

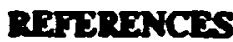

1. A. G. Klein and S. A. Werex, Reger. Prog. Fhye, 46, 299 (1983).

2. R. Currat, Nuch inere and Methodr, 19, 21 (1973).

3. M. A. Kunakbov, Nucl Instr. and Methods, B46, 283 (1990). 
ATTACHMENT 3 
In-house Initiatives can be Accommodated Within Existing Resources

licm Notes Niming

Complete preparation and benchmarking of the deiailed Monte Carlo model of the HFIR and couple it to the Idaho MOCUP depletion cince

New gamma-irradiation facility (inside spent control plates)

Prepare SARs anil seck approval for lox) MIt pewer uperation based on selection of existing fuel elements and improved fuel plate inspection/selection.

Use a beam tube or an EF tacility (EF-l or EF-2) fir neutron radiography and

tomography:

Expanded laborattory tacilities for neutron activation anadisis.
Availability of this model will be crucial to the detailed evaluation of proposed reaclor enhancements. A suitable workstation that can be dedicated to this model can be made available as the result of the ANS project

closeoul.

A research application for this new facility has been identified by Environmental

Seiences and Biology Divisions.

Mure sensitive, digital inspectun cquipment is now available at $\mathrm{B} \& \mathrm{~W}$.

A new LDRD propusal by M\&C/SS/RRD.
Work already underway on model. Coupling 16) MOCUP not yet begun. CDW needs to provide workstation.

Work on a proof-of-principle test has begun.

Some work has begun in RRD,

Necds further planning to evaluate timing.

RRD has an altemative proposal to make. 
New mstrument layout to make more cllecilice use of existing heams.

Niw. medesn scattering instruments.

Raisi the epithermal-(1)-thermal thux ratio in the transtranic largets to enhance progluction rille.

Radesign permalsent beryllium fur enhanced imadiation h. ke capacity. a sertical decess ald sururce. and larger be all lubes or thimbles.

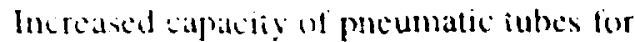
neteron atuation analysis.
Solid State Division already has some funding for this.

Solic! Seate Division already has some funding for this.

Add structural matcrial (c.g., fins) to displace water in the neighborhood of the largels. Use stainless steel target jackets as a form of spectral tailuring.

To be ready for one of the possibilities for a major ungrade when the reflector must bo: changed.

[Larty Robinson: does this mean latger rabbits, or more lubes, or both? Do you have a cost guess"?
Necds Solid Stalc Division planning and coordination with RRI).

Needs Solid State Division plann!ng and coordination with RRD.

John Bigelow can start experiments anytime.

Irradiation hole redesign initiated. Cold source and beam tube hole redesign needed by end C'Y 1996.

Some of this work is part of the bery!lium redesign. The irradiation capabilities need prioritization by the user community (c.g.. materials testing vs isotope production). 
ATTACHMENT 4 
SIGNIFICANT COST (COSTS OUTSIDE RRD IN THE RANGE 2\% OF ANNUAL OPERATING BUDGET TO \$5 M - WOULD REQUIRE SUBSTANTIAL AND DETERMINED REPRIORITIZATION OF OTHER WORK TO ACCOMPLISH WITHOUT ADDITIONAL FUNDING, OR PERHAPS USE OF FACILITIES INITIATIVE FUNDS OR GPP) (4)

Enhancements

Requiring Some

Changes to the

Reactor

Modify reactor top head for better access to reflector positions
Cost Benefits

guess

$\$ 0.5 \mathrm{M}$ Impioved access to

- \$2 M reflector positions

will benefit any

radioisotope being produced there.

Would provide direct (straight line) access to VXF positions. Experiments and target holders can be rotated easily to smooth out fluence gradients. 


\section{SIGNIFICANT COST (COSTS OUTSIDE RRD}

IN THE RANGE 2\% OF ANNUAL OPERATING BUDGET TO $\$ 5 \mathrm{M}$ - WOULD REQUIRE SUBSTANTIAL AND DETERMINED REPRIORITIZATION OF OTHER WORK TO ACCOMPLISH WITHOUT ADDITIONAL FUNDING, OR PERHAPS USE OF FACILITIES INITIATIVE FUNDS OR GPP) (5)

Enhancements

Requiring Some

Changes to the

\section{Reactor}

Reduce diameter of quick-opening hatch on the reactor top head

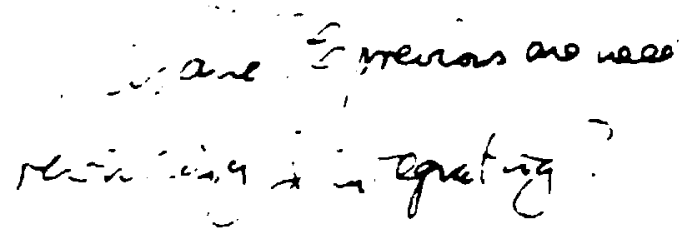

Cost Benefits

guess
Refueling can be performed $v$ ithout removing experiments from the $\mathrm{RB}^{*}$ positions.

Note: Both of the reactor top head modifications might perrit the installation of either additional hydraulic rabbit facilities (albeit with lower flux than the present one), or facilities which would permit the installation and removal of targets (larger than rabbits) during reactor operation if that were desirable. 
MAJOR COST ITEMS (Z\$S M, THE AMOUNT POTENTIALLY AVAILABLE UNDER THE FACILITIES INITIATIVE WOULD DEFINITELY REQUIRE SPECIFIC EXTRA OPERATING, CAPITAL EQUIPMENT, OR LINE ITEM FUNDS)

Enhancements Requiring Cost guess Benefits

Some Changes to the

Reactor

New, larger through-tube and $\$ 25 \mathrm{M}$ vertical cold source (at beryllium changeout)
A really major enhancement of neutron scatterin capabilities wouk make HFIR a world-beater in some very important areas

Major Performance

Enhancements

New, non-pressurized, non- $\quad 2 \$ 79 \mathrm{M}^{*}$ steel reflector tank with $\mathrm{D}_{2} \mathrm{O}$ instead of beryllium

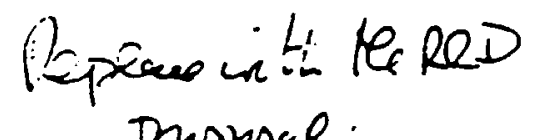

Further work on this estimate is underway.

Would require additional guide hall space, more flux, more beam tubes, large cold source, and othel new facilities.

Would make HFIR 2-3 times better than ILL (although still wi fewer instrument stations). 


\section{ITEMS WTTH NO COST GUUESS ÂVÁILABLE Y'ET}

Facility or

\section{Instrument}

Improvements

New, modern

scattering

instruments

New instrument layout

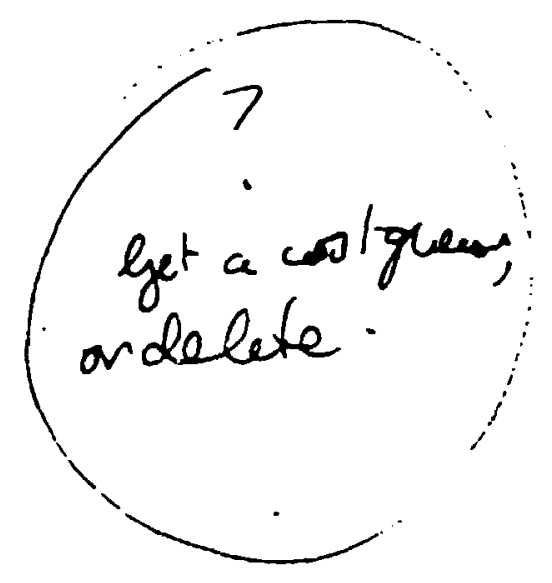

$\$ 3 \mathrm{M}$

Improve

Cost quess

transportation methods from HFIR to IFEL

Benefits

Could improve performance on existing beams

Much enhanced experimental capability for neutron scattering

Ideally, a new cask-trailertiedown combination could be safer and also easier to use. We may be required someday to use licensed shipping containers for on-site transportation. 
ATTACHMENT 5 


\section{REPORT OF HIGH FLUX ISOTOPE REACTOR (HFIR) FUTURES GROUP}

\section{(DRAFT EXECUTIVE SUMMARY FOR DISCUSSION AT FUTURES GROUP, 5-15-95)}

The HFIR Futures Group proposed, studied, and evaluated changes that would either enhance the scientific capabilities of HFIR, or extend its operating life, or enhance it: accessibility and effectiveness as a user facility. The group also leamed of several things that must be done to avoid inevitable shutdown of operations by certain dates (i.e., obtaining supplies of $\mathrm{U}_{3} \mathrm{O}_{8}$ from $\mathrm{Y}-12$ for Babcock \& Wilcox to fabricate fuel elements, inservice inspection of accessible reactor components, and replacement of the "permanent" beryllium reflector).

The most significant short-term enhancement is to install a small, liquid hydrogen cold source in an existing beam tube. With this, Oak Ridge National Laboratory (ORNL) would provide the United States (U.S.) with cold neutron beams of an intensity comparable to those available to European researchers at the Insitut I-aue-Langevin (ILL) and at ORPHEE, while retaining a superior thermal neutron flux. The group believes that this could be accomplished in one to two years at a cost (beyond the normal HFIR operating budget) on the order of $\$ 5$ million, which could be available through the U.S. Department of Energy's (DOE) Scientific Facilities Initiative. Careful design and planning will allow the cold source system to be constructed and tested away from HFIR and then be transported there for installation and commissioning with minimal reactor downtime. In parallel with this, there are important instrument, beam hall, and irradiation facility enhancements that would improve the research and production capabilities significantly and that could be carried out with existing sources of money, including HFIR operating funds and GPP funds.

In addition, and with little or no resources beyond those already available to ORNL, improved analyses and new fuel inspection techniques would permit us to demonstrate that HFIR can be operated safely at $100 \mathrm{MW}$, thus regaining the performance (neutron flux) that was lost when the operating pressure and power were reduced on discovery of the pressure vessel's embrittlement. This activity would also have to include revisions to the Safety Analysis Report and the Technical Safety Requirements. 
The group also identified changes in the user program and its procedures that would increase the effectiveness and accessibility of the facility, especially for non-ORNL scientists.

Beyond this ongoing program of continual, cost-effective upgrades that we recommend, there will be a tremendous opportunity for a major upgrade to HFIR at the time the beryllium is replaced. As a minimum, the new permanent beryllium should be designed with larger holes for beam tubes, larger vertical holes for irradiation positions, and a large vertical hole for a new (possibly liquid deuterium) cold neutron source. A more exciting possibility is that the beryllium reflector could be replaced by an annular tank of heavy water, a big liquid deuterium cold source installed, extra beam tubes and neutron guides added, and additional guide hall space, beyond the near-term guide hall expansions proposed above, could be built. This would give ORNL, and the nation, a facility with two to three times the neutron beam intensity of the world's best - the $\mathbf{L L}$. HFIR would retain capabilities for isotope production that are unique in the Western world. There would still be fewer beams and instrument stations than at ILL because of space and topographical limitations, but the available beams would be world beaters.

The rewards of these action; are very great, but to attain them will require both an immediate and a long-term, strong commitment from the laboratory's Executive Committee to promote, encourage, support and, in some cases, fund this endeavor. The need for action is immediate because the window of opportunity is rather narrow, constrained by the funding cycle of the Scientific Facilities Initiative and by the need for DOE to focus its plans for improvement and life extension projects across all the department's reactor sites. 
May 23, 1995

\section{HFIR Futures Group Meeting}

Attendance

The HFIR Funres Group held its tenth meeting at 8:30 a.m on Monday, May 22, 1995, in the Blue Room of the FEDC. Those in al.wdance were:

Emory Collins

George Flanagan

Mike Harrington

Michele Houser

Herb Mook

Larry Robinson

Ken Thoms

Colin West (chair)

Ken Farrell (observer).

\section{Opening}

Colin West began the meeting by showing the group a viewgraph of the major upgrades that the various DOE national laboratories have done in the past few years (see Attachment 1). ORNL has never had a major line item for new or upgraded scientific user facilities--the combined line item funding for such upgrades in the past few years for Oak Ridge was only around $\$ 2 \mathrm{M}$. This could make ORNL vulnerable when Congress or the Administration looks at the future of national laboratories-all the more reason to look favorabiy at the proposed HFIR upgrades!!

Colin then presented the agenda for the day's meeting, as seen in Attachment 2. There were no responses to the request for any changes to the notes about the previous meeting.

\section{Executive Committee meeting.}

Colin toid the group about his meeting with ORNL's Executive Committee last week. He had already sent out a memo describing the meeting and including the viewgraphs that he had presented. Colin believed that we really have the attention of the Executive Committee members.

The recommendations were cffered in a 3-pronged approach: the first category includes items that can be done with existing funding in a Minor Cost Initiative p.ogram. Work has already begun on some of these activities.

The second category includes things that could be donc for the order of $\$ 5 \mathrm{M}$, perhaps using Scientific Facilities Initiative funds, if available. The most important of these upgrades is a HFIR 
cold source. Colin said that Bob Van Hook was enthusiastic about this and reminded everyone that there was some unspent capital equipment money available at ORNL, on the order of tens of millions of dollars. He asked Colin if the cold source upgrade could be done with capital equipment funds, and Colin replied in the affirmative. Bill Appleton was assigned the task of investigating the amount and availability of the capital equipment funds.

Colin told the Executive Committee that he had some funding that could be used to start work on a cold source. He recommended that the cold source team be physically housed with $\mathrm{RRD}$; that appropriate outsile expertise be employed (i.e., Trevor Lucas); and that a suitable team leader be appointed (Colin proposed Doug Selby). The committee accepted all of these proposals, merely asking when Doug could begin work on this project. Both Colin and Bill Appleton said be would be available immediately to start work on this endeavor, even though the ANS closeout effor would be hampered somewhat by Doug's other duties.

The third prong of the Futures Group recommendations consists of the Significant Cost Initiatives. These upgrades need prioritization and better cost and schedule estimates. The point was made to the Executive Committee that the Funures Group thought that it is appropriate to ask for major funds, even with the possible location of a spallation source in Oak Ridge pending, but the Executive Committee decided not to highlight this or make a request for a major HFIR upgrade just yet.

George Flanagan asked about the possibility of mentioning the $\mathrm{D}{ }_{2} \mathrm{O}$ tank idea at the upcoming IGORR meeting. Colin said that it was all right to talk about the idea, but we are not ready to discuss cost or schedule yet. George mentioned that DOE officials had already heard of this proposal at a meeting in Washington; Colin has also kept his ORO colleagues informed. The timing of the spallation source/accelerator decision was discussed, as well as what its cost could mean to other projects.

Herb Mook mentioned that Iran Thomas has asked that all national laboratories develop metrics on their research reactors. These metrics would include things such as the number of users and the facility's capabilities. Herb said that he did not think that a deadline had been given for this, and he did not know how the effort was being organized for the HFIR. This can be seen as a comparison of the various merits of each site's research reactor(s).

Colin said that he had one-half hour to speak in the Executive Committee meeting and that the response he got from committee members was very encouraging. He thought that overall the Executive Committee meeting was a very good one.

The timing for informing the DOE site office of the proposed upgrades was discussed, and Colin said they were already aware of what had been happening with the HFIR Futures Group. Colin maintains regular communication with the DOE contacts in the FEDC and said they had been encouraging of the group's efforts. Bill Appleton was going to DOE headquarters on May 22, and it was mentioned that prior interactions with top DOE officials had indicated that many were supportive of the cold source and $\mathrm{D}_{2} \mathrm{O}$ tank ideas.

Colin explained to Herb the idea of John Hayter's super-mirror invention being used in conjunction with the configuration of HB-2 to produce a better cold source than the one proposed for HB-4. Herb had some reservations about doing this, mainly due to the lack of space for a guide hall associated with that beam. Colin said if this propisal was decided upon, he thought people could work with the guide hall space problem. 
Wording to do with hot cell upgrade

Ken Thoms had sent wording having to do with the hot cell upgrade to Michele Houser (see Attachment 3). After some discussion, $\operatorname{Ken} T$. thought there could be more wording given to describe the benefits of implementing this upgrade; he will do this and send the information to Michele and Colin.

\section{Neutron activation analysis}

Colin mentioned to Larry Robinson that the Executive Committee had asked him if neutron activ ation analysis was growing as a field or not. Larry said that the field is steady or growing--one problem is that when the group moved from the ORR to the HFIR, it simply mai itained its capabilities, rather than increasing them. The pneumatic rabbits used allow irradiation of only one sample at a time, which greatly increases the cost of irradiation. Upgrades might offer more efficient throughput and better use of experimenter time.

Larry said that modification of the holes in the permanent beryllium reflector would offer the opportunity to install larger rabbits for the VXF-7 position, which has a better flux than the EF-3 position. The only limitation of the EF-3 position is the EF capacity itself. A rabbit of up to $40 \mathrm{~cm}$ could perhaps be accommodated in EF-3 (a $10 \mathrm{~cm}{ }^{3}$ rabbit in EF-3 matches the flux in VXF-7). George said if the modification of the rabbits for the EF-3 position was not a large cost item, that some of his personnel could begin on sketches for Larry. He suggested that they meet sometime in the near future. Larry wanted to make sure that the modification of both of the PT positions was mentioned in the HFIR Futures Group report.

\section{HFIR Futures Group Repont}

Colin suggested that the HFIR Futures Group had essentially done the work it had been assigned. The group has gotten approval to go ahead with several of the upgrades it has proposed; what is left is the documentation of the group's actions in a report. Colin said he would be glad for someone to volunteer to write the report. If no one volunteers, Colin stated he would work on it and send draft copies to everyone. He suggested that the group write up its work formally as an "M" or "TM" report. The group has gathered a lot of information that could be good reference for future endeavors.

Colin said there were no particular time pressures, as far as he knew. He will be attending the IGORR meeting in Gatlinburg for the rest of the week of May 22, so there may be a bit of delay in starting it. Colin remarked that the group could communicate by e-mail and fax, or it could meet again. He said he would poll the group in a week or two to see if the members wanted to meet or not. The suggestion was made to simply entitle the write-up the "HFIR Futures Group Report."

Colin asked George about the cost of the $\mathrm{D}{ }_{2} \mathrm{O}$ tank item. George confirmed that the cost was from $\$ 100 \mathrm{M}-\$ 150 \mathrm{M}$. The cost of the big D ${ }_{2} \mathrm{O}$ cold source was on the order of $\$ 45 \mathrm{M}$, with the cost of a guide hall or equipment being minor in comparison to these items. 


\section{Closing}

Co.in thanked the group members for their time and cooperation. He expressed his appreciaiion for the teamwork that all in the group had exhibited, and the group then adjourned.

M. M. Houser, May 22, 1995

\section{ACTION ITEMS}

Ken T. will write up the advantages associated with having a hot cell at the HFIR facility and give the write-up to Colin or Michele.

Colin will begin the drafi of the HFIR Futures Group Report and send it to group members for review.

Distribution

\section{HFIR Futures Group Attendees (notes for record + Attachments 1 and 3)}

E. D. Collins, 7930, MS-6385

K. Farrell, 5500, MS-6376

G. F. Flanagan, 7917, MS-6398

R. M. Harrington, FEDC, MS-8218

M. M. Houser, FEDC, MS-8218

H. A. Mook, 7962, MS-6393

L. Robinson, 4500S, MS-6128

K. R. Thoms, 9108, MS-8087

C. D. West, FEDC, MS-8218

For information (notes for record + all attachments)

B. R. Appleion, $4500 \mathrm{~N}, \mathrm{MS}-6240$

J. B. Ball, $4500 \mathrm{~N}, \mathrm{MS}-6182$

R. E. Battle, FEDC, MS- 8218

J E. Bigelow, 7930, MS-6385

H. A. Glovier, 7917, MS-6398

J. B. Hayter, FEDC, MS-8218

J. P. Moore, 4508, MS-6080

D. E. Keichle, $4500-\mathrm{N}, \mathrm{MS}-6253$

J. B. Richard, 7962, MS-6391 
ATTACHMENT 1 


\section{AMONG THE ENERGY RESEARCH LABORATORIES, ORNL IS POTENTIALLY VULNERABLE BECAUSE OF A LACK OF MAJOR INVESTMENT IN SCIENTIFIC USER FACILITIES}

$\begin{array}{llr}\text { ANL } & \text { Advanced Photon Source } & \$ 812 \mathrm{M} \\ \text { BNL } & \begin{array}{l}\text { Relativistic Heavy Ion } \\ \text { Collider }\end{array} & 595 \mathrm{M} \\ & \text { Advanced Light Source } & 146 \mathrm{M}\end{array}$

The biggest scientific line item at ORNL in recent years is Accelerator or Reactor Improvement money of $\$ 1.2 \mathrm{M}$ ! The top three line items at ORNL are all relatively small and all waste related:

Bethel Valley Low Level Waste Project Melton Valley Storage Tank Capacity

$65 \mathrm{M}$ Increase

Melton Valley LLW System Upgrade

$41 \mathrm{M}$

HFIR (ARIM)

$1.2 \mathrm{M}$

Tandem Tube Upgrade

$0.5 \mathrm{M}$ 
ATTACHMENT 2 


\title{
AGENDA FOR \\ HFIR FUTURES GROUP MEETING
}

\author{
Monday, May 22, 1995 \\ $8: 30 \mathrm{am}$. \\ FEDC, Blue Room
}

- Discussion: Changes or corrections to 5/15/95 meeting notes for the record

- Status of action items

- $\quad$ Executive Committee meeting

C. D. West

- Wording for hot cell upgrade

K. R. Thoms

- Final report preparation

C. D. West

Any other business 
ATTACHMENT 3 


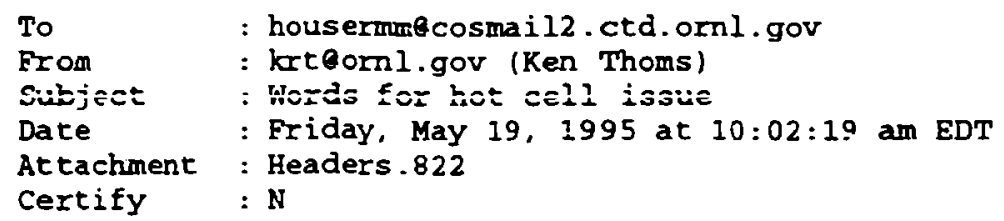

Michele.

I've come up with some words, but I'm not real happy with them. Perhaps we should go with them and Iun them by the committee. Here goes:

-By providing for removal of unnecessary hardware, would facilitate handlinç and transfer of irradiated targets or materials testing experiments. Would permit smaller cask for companion initiative (Improve transportation methods from HFIR to IFEL), reduce person-dose levels, provide means to can fuel elements or scrap for long term storage, and reduce need for building 3525 (IFEL)."

Ken 


\section{Internal Distribution}

1. B. R. Appletion

2. J. B. Ball

3. R. E. Batle

4. J. E. Bigelow

5. E. D. Collins

6. G. F. Flanagan

7. H. A. Glovier

8. R. M. Hlarrington

9. J. B. Hayter

10. M. M. Huwer

11. H. A. Mook
12. J. B. Richard

13. L. Robinson

14. K. R. Thoms

15. C. D. West

16. ORNL Patent Office

17-18. Central Reserach Library Document Reference Sect.

19-20. Laboratory Records Dept.

21. Laboratory Records, RC

22. Y-12 Technical Library

\section{External Distribution}

23. Office of Scientific and Technical Information, P.O. Box 62, Oak Ridge, Tennessee 37831 

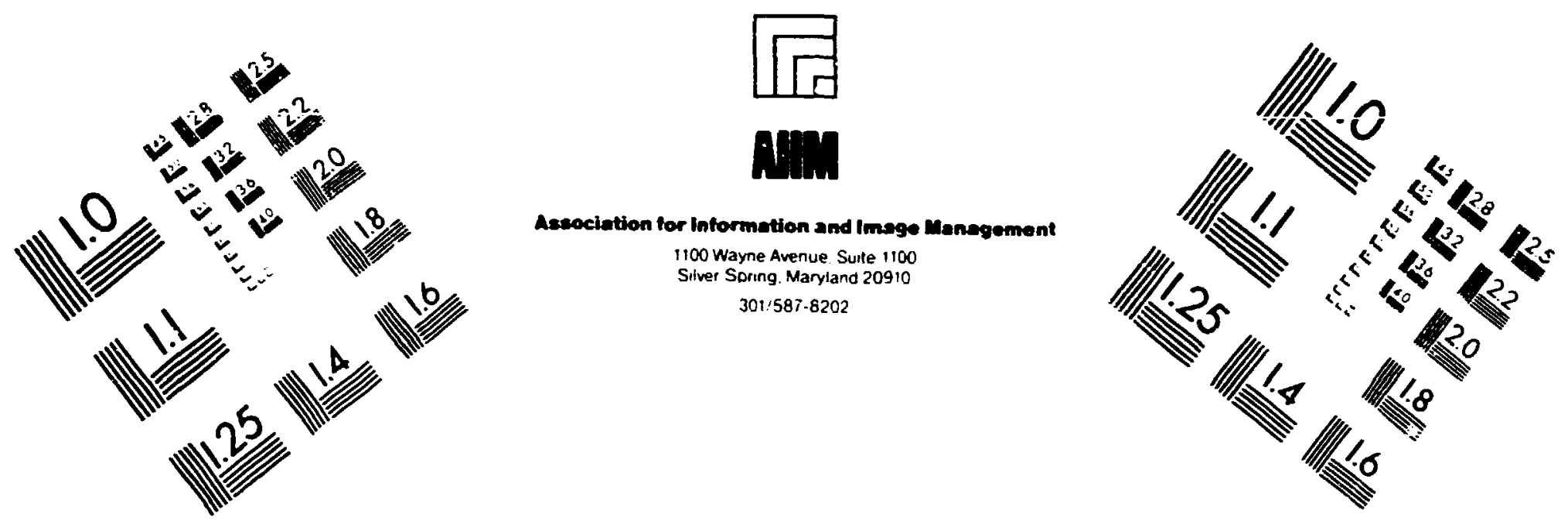

\section{Centimeter}

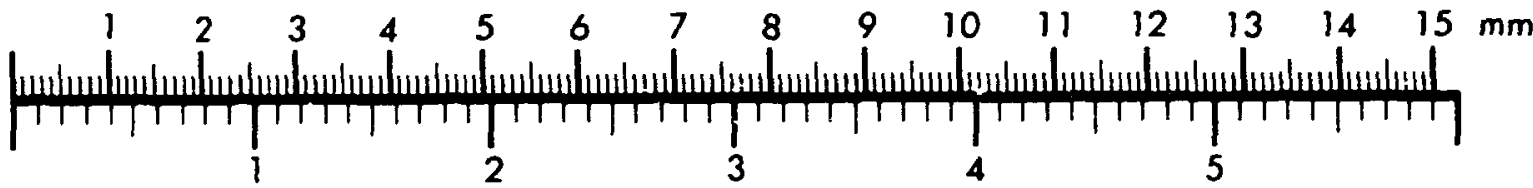

Inches
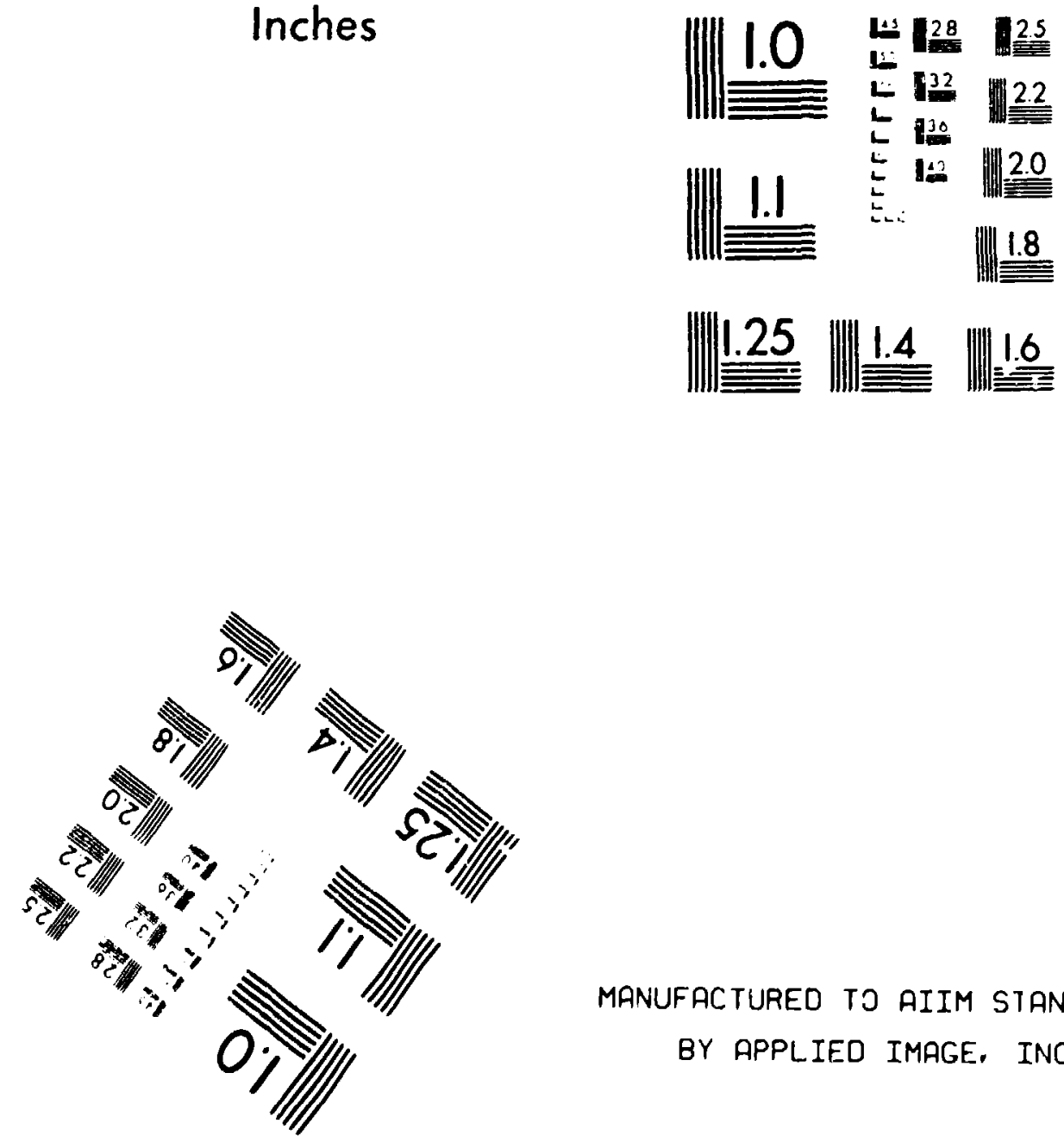

MANUFACTURED TO AIIM STANDARDS

BY APPLIED IMAGE, INC.

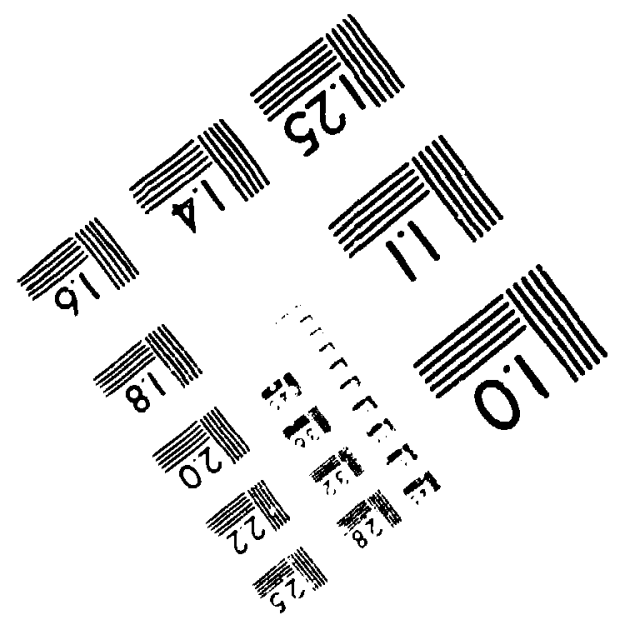


